US Army Corps of Engineers $s_{\circledast}$

Engineer Research and

Development Center

Simulation Based Reliability and Safety (SimBRS) ERS WD 67: "Modeling and Simulation of Multi-Physics Material Response in Geo-Environments"

\title{
Development of CORPS-STIF 1.0 with Application to Ultra-High Performance Concrete (UHPC)
}

Isaac L. Howard, Thomas Allard, Ashley Carey,

April 2021

Matthew Priddy, Alta Knizley, and Jameson D. Shannon
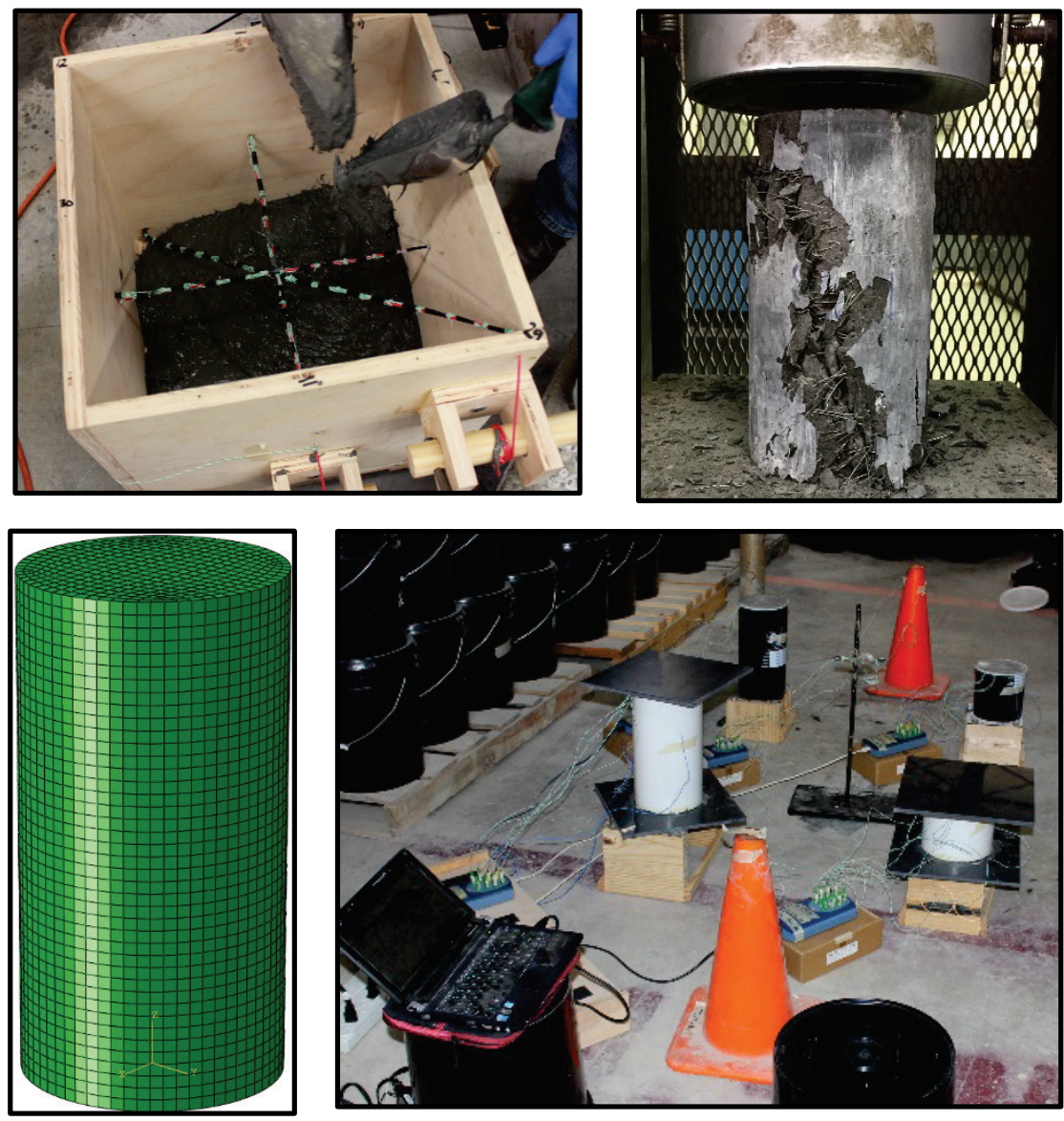

Approved for public release; distribution is unlimited. 
The U.S. Army Engineer Research and Development Center (ERDC) solves the nation's toughest engineering and environmental challenges. ERDC develops innovative solutions in civil and military engineering, geospatial sciences, water resources, and environmental sciences for the Army, the Department of Defense, civilian agencies, and our nation's public good. Find out more at www.erdc.usace.army.mil.

To search for other technical reports published by ERDC, visit the ERDC online library at https://erdclibrary.on.worldcat.org/discovery. 


\section{Development of CORPS-STIF 1.0 with Application to Ultra High Performance Concrete (UHPC)}

Jameson D. Shannon

Geotechnical and Structures Laboratory

Concrete Materials Branch

U.S. Army Engineer Research and Development Center

3909 Halls Ferry Road

Vicksburg, MS, 39180

Isaac L. Howard and Thomas Allard

Mississippi State University

Center for Advanced Vehicular Systems (CAVS) and

Civil and Environmental Engineering (CEE) Department

200 Research Boulevard

Starkville, MS, 39759

Ashley Carey, Matthew Priddy, and Alta Knizley

Mississippi State University

Center for Advanced Vehicular Systems (CAVS) and

Mechanical Engineering (ME) Department

200 Research Boulevard

Starkville, MS, 39759

Final report

Approved for public release; distribution is unlimited.

Prepared for U.S. Army Corps of Engineers

Washington, DC 20314-1000

Under Project W56HZV-08-C-0236, "Modeling and Simulation of Multi-Physics Material Response in Geo-environments" 


\section{Abstract}

This report introduces the first release of CORPS-STIF (Concrete Observations Repository and Predictive Software - Structural and Thermodynamical Integrated Framework). CORPS-STIF is envisioned to be used as a tool to optimize material constituents and geometries of mass concrete placements specifically for ultra-high performance concretes (UHPCs). An observations repository (OR) containing results of 649 mechanical property tests and 10 thermodynamical tests were recorded to be used as inputs for current and future releases. A thermodynamical integrated framework (TIF) was developed where the heat transfer coefficient was a function of temperature and determined at each time step. A structural integrated framework (SIF) modeled strength development in cylinders that underwent isothermal curing. CORPS-STIF represents a step toward understanding and predicting strength gain of UHPC for full-scale structures and specifically in mass concrete.

DISCLAIMER: The contents of this report are not to be used for advertising, publication, or promotional purposes. Citation of trade names does not constitute an official endorsement or approval of the use of such commercial products. All product names and trademarks cited are the property of their respective owners. The findings of this report are not to be construed as an official Department of the Army position unless so designated by other authorized documents. 


\section{Contents}

Abstract............................................................................................................................. if

Figures and Tables.................................................................................................................v

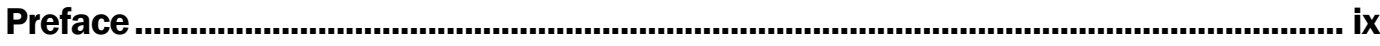

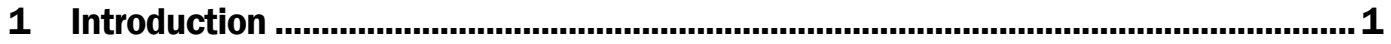

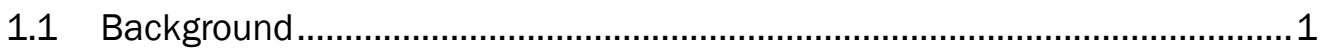

1.2 Objectives..................................................................................... 1

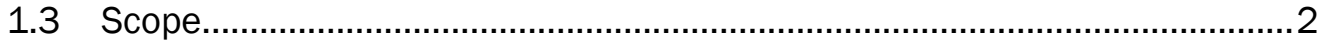

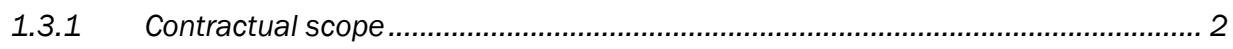

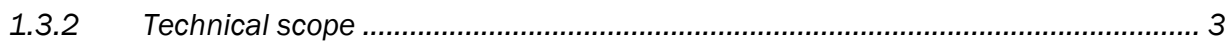

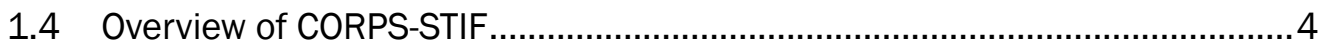

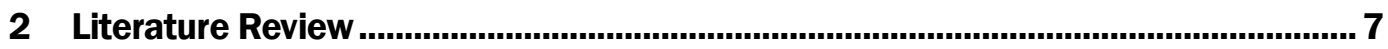

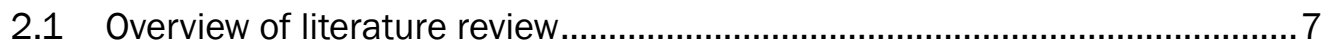

2.2 UHPC mechanical properties..................................................................... 7

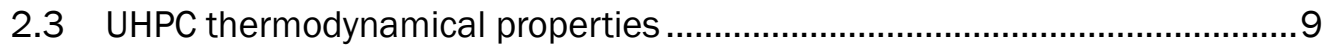

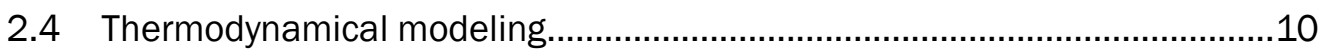

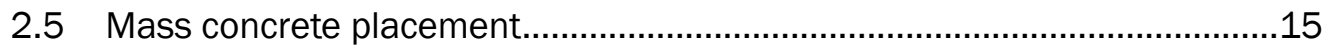

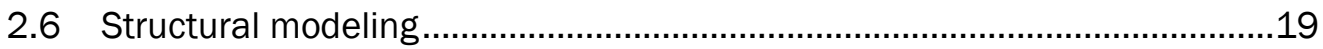

$2.7 \quad$ High strength concrete proportions..........................................................21

2.8 Numerical framework studies...................................................................... 22

2.9 UHPC types.................................................................................... 24

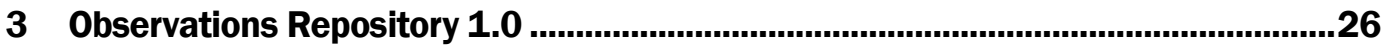

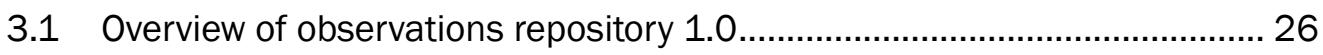

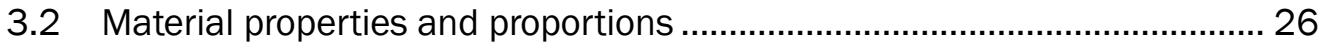

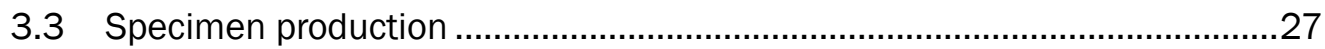

3.3.1 Physical property specimen production................................................................ 27

3.3.2 Casting thermodynamical property specimens....................................................29

3.4 Curing methods and maturity calculations for mechanical property

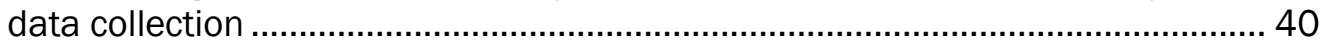

3.4.1 Curing environments and temperature measurement .........................................40

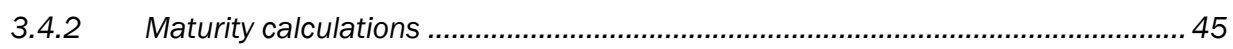

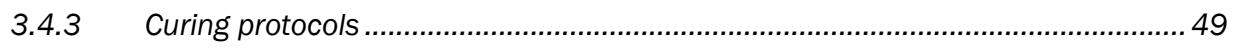

3.5 Physical property data collection ...................................................... 52

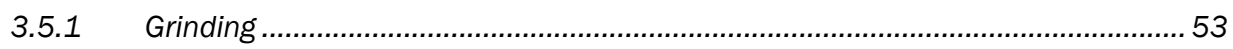

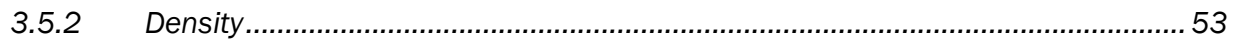

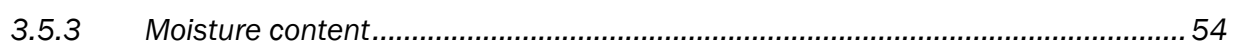

3.5.4 Compressive strength measurement.............................................................. 54

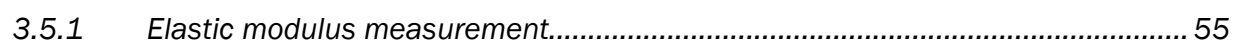

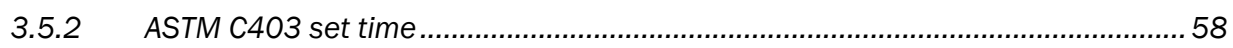

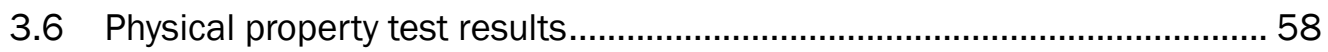




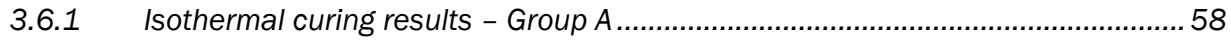

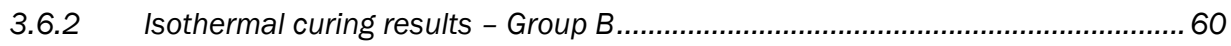

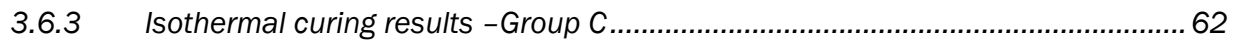

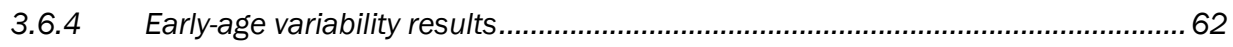

3.6.5 Isothermal curing results - Moisture Effects ...................................................63

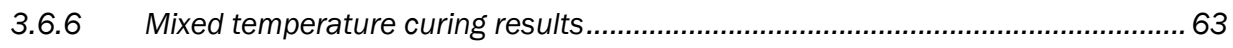

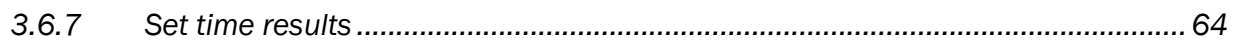

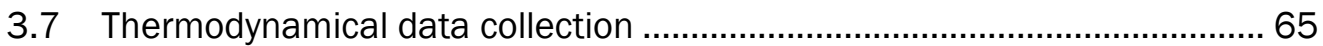

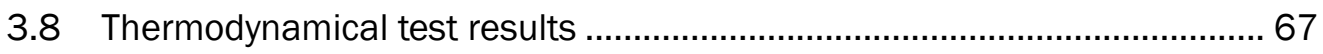

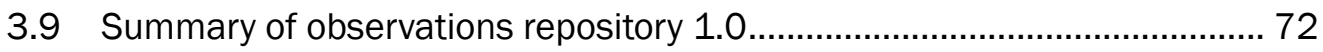

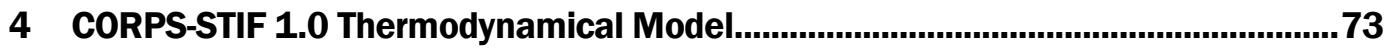

4.1 Overview of thermodynamically modeling efforts .................................. 73

4.2 Thermodynamical experiments analysis ............................................ 73

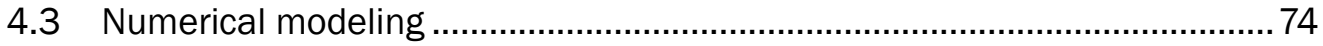

4.4 Numerical modeling results .............................................................. 78

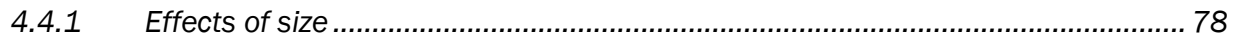

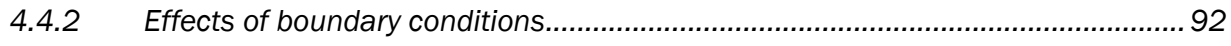

4.5 Summary of thermodynamcial modeling and TIF ................................... 98

5 CORPS-STIF 1.0 Isothermal Curing Model ...................................................... 100

5.1 Overview of structural modeling efforts .............................................. 100

5.2 Numerical model development......................................................... 100

5.2.1 Numerical model development ........................................................................ 100

5.2.2 Discretization of numerical model ..................................................................... 107

5.3 Finite element implementation.................................................. 108

5.3.1 Finite element model description........................................................................ 108

5.3.2 Mesh convergence and selection ..................................................................110

5.3.3 Finite element model results............................................................................ 112

5.4 Summary of isothermal curing modeling and SIF ............................... 115

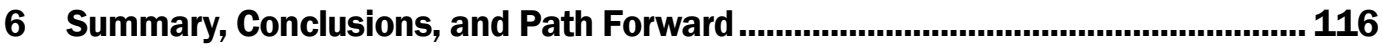

6.1 Summary ..................................................................................... 116

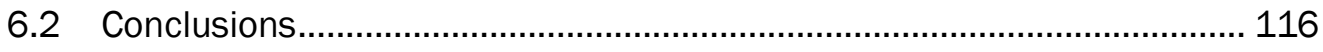

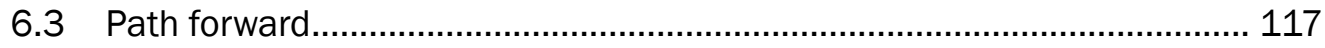

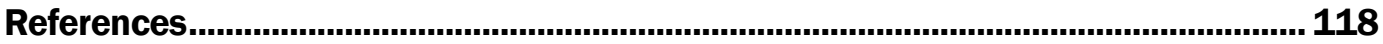

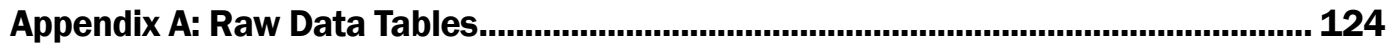

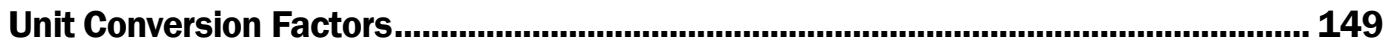

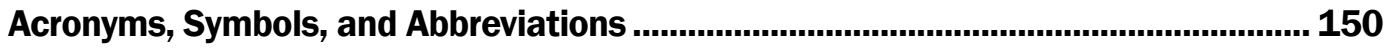

Report Documentation Page 


\section{Figures and Tables}

\section{Figures}

Figure 1. CORPS-STIF 1.0 flowchart.

Figure 2. (a) conditioned raw materials, (b) batched materials, (c) hand mixed dry materials, (d) adding $80 \%$ of total water, (e) adding admixture, (f) adding fibers, (g) completed mixture, (h) vibrating table, and (i) finished specimen.

Figure 3. Mold preparation for thermodynamical property specimens-cubes; (a) cut panels of 19-mm-thick birch hardwood, (b) constructing the cube, (c) built cube, (d) sanding edges, (e) running thermocouples, (f) finished $10 \mathrm{~cm}-\mathrm{Cu}$, (g) finished $20 \mathrm{~cm}-\mathrm{Cu}$, and $(\mathrm{h})$ finished $40 \mathrm{~cm}-\mathrm{Cu}$.

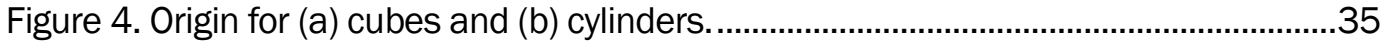

Figure 5. Mold preparation for thermodynamical property specimens - cylinders; ..........36

Figure 6: Ambient thermocouple layouts; (a) $10 \mathrm{~cm}-\mathrm{Cu}$ and $20 \mathrm{~cm}-\mathrm{Cu}$, (b) $7.6 \mathrm{~cm}$ Cy, 10.2cm-Cy, and 15.2cm-Cy, (c) 40cm-Cu, and (d) 15.2x15.2-PP, 15.2x30.5PP, 15.2x15.2-PVC, and 15.2x30.5-PVC.

Figure 7. Thermodynamical testing setup; (a) $10 \mathrm{~cm}-\mathrm{Cu}$ and $20 \mathrm{~cm}-\mathrm{Cu}$, (b) $7.6 \mathrm{~cm}$ Cy, 10.2cm-Cy, and 15.2cm-Cy, (c) 40cm-Cu, and (d) 15.2x15.2-PP, 15.2x30.5PP, 15.2x15.2-PVC, and 15.2x30.5-PVC.

Figure 8. Curing environments; (a) $\mathrm{CE}_{1}$, (b) $\mathrm{CE}_{2}$, (c) $\mathrm{CE}_{3}$, (d) $\mathrm{CE}_{4}$, (e) $\mathrm{CE}_{5}$, (f) $\mathrm{CE}_{6}$, (g) $\mathrm{CE}_{7}$ (1 of 2), (h) $\mathrm{CE}_{7}$ (2 of 2).

Figure 9. Specimen preparation and testing; (a) end grinder, (b) compression test, (c) elastic modulus - analog dial, and (d) elastic modulus - LVDT. 53

Figure 10. Compressive strength results of FT specimens...............................................55

Figure 11. Elastic modulus versus temperature of ET specimens. ....................................57

Figure 12. Elastic modulus results for isothermal curing. ..................................................59

Figure 13. Compressive strength results for isothermal curing. .........................................59

Figure 14. Compressive strength - isothermal Group A and B comparison......................61

Figure 15. Moisture effects for (a) compressive strength (b) and elastic modulus............63

Figure 16. Data logger board configuration. ..................................................................6

Figure 17. 10cm-Cu recorded thermal profile.................................................................67

Figure 18. 20cm-Cu recorded thermal profile................................................................68

Figure 19. 40cm-Cu recorded thermal profile. ..................................................................68

Figure 20. 7.6cm-Cy average thermal profile......................................................................69

Figure 21. 10.2cm-Cy average thermal profile...............................................................69

Figure 22. 15.2cm-Cy average thermal profile................................................................ 70

Figure 23. 15.2x15.2-PP average thermal profile............................................................

Figure 24. 15.2x30.5-PP average thermal profile.................................................................. 71

Figure 25. 15.2x15.2-PVC average thermal profile......................................................... 71

Figure 26. 15.2x30.5-PVC average thermal profile. ……………...................................... 72 
Figure 27. (a) Experimental and (b) simulation temperature versus time results for three temperature locations at a center cross section of $7.6 \mathrm{~cm}-$ Cy. ...............................79

Figure 28. Convection coefficient calculated for $7.6 \mathrm{~cm}-\mathrm{Cy}$.

Figure 29. Simulation temperature results for $7.6 \mathrm{~cm}-\mathrm{Cy}$, assuming constant convection coefficient of (a) $10 \mathrm{~W} / \mathrm{m}^{2} \cdot \mathrm{K}$ and (b) $7.5 \mathrm{~W} / \mathrm{m}^{2} \cdot \mathrm{K}$.

Figure 30. Simulation temperature results for $7.6 \mathrm{~cm}-\mathrm{Cy}$, assuming constant convection coefficient of (a) $4.5 \mathrm{~W} / \mathrm{m}^{2} \cdot \mathrm{K}$ and (b) $2.2 \mathrm{~W} / \mathrm{m}^{2} \cdot \mathrm{K}$.

Figure 31 (a) experimental and (b) simulation temperature versus time results for three locations at a center cross section of $10.2 \mathrm{~cm}-C y$ and (c) convection coefficient calculated for $10.2 \mathrm{~cm}-$ Cy.

Figure 32. Simulation temperature results for $10.2 \mathrm{~cm}$-Cy assuming constant convection coefficient of (a) $10 \mathrm{~W} / \mathrm{m}^{2} \cdot \mathrm{K}$ and (b) $7.5 \mathrm{~W} / \mathrm{m}^{2} \cdot \mathrm{K}$.

Figure 33. Simulation temperature results for $10.2 \mathrm{~cm}-\mathrm{Cy}$, assuming constant convection coefficient of (a) $4.5 \mathrm{~W} / \mathrm{m}^{2} \cdot \mathrm{K}$ and (b) $2.2 \mathrm{~W} / \mathrm{m}^{2} \cdot \mathrm{K}$.

Figure 34. (a) experimental and (b) simulation temperature versus time results for three temperature locations at a center cross section of $15.2 \mathrm{~cm}-\mathrm{Cy}$ and (c) convection coefficient calculated for $15.2 \mathrm{~cm}-\mathrm{Cy}$

Figure 35. Simulation temperature results for $15.2 \mathrm{~cm}-\mathrm{Cy}$ assuming constant convection coefficient of (a) $10 \mathrm{~W} / \mathrm{m}^{2} \cdot \mathrm{K}$ and (b) $7.5 \mathrm{~W} / \mathrm{m}^{2} \cdot \mathrm{K}$.

Figure 36. Simulation temperature results for $15.2 \mathrm{~cm}-C y$ assuming constant convection coefficient of (a) $4.5 \mathrm{~W} / \mathrm{m}^{2} \cdot \mathrm{K}$ and (b) $2.2 \mathrm{~W} / \mathrm{m}^{2} \cdot \mathrm{K}$.

Figure 37. Comparative temperature data for 15.2×30.5-PP (a) experimental results and (b) simulation results.

Figure 38. Comparative temperature data for 15.2x30.5-PVC (a) experimental results and (b) simulation results.

Figure 39. Comparative temperature data for 15.2x15.2-PP (a) experimental results and (b) simulation results.

Figure 40. Comparative temperature data for 15.2x15.2-PVC (a) experimental and (b) simulation results 98

Figure 41. Compressive strength measurements and numerical predictions. 104

Figure 42. Elastic modulus measurements and numerical predictions. 105

Figure 43. Parametric functions and output of numerical models................................ 106

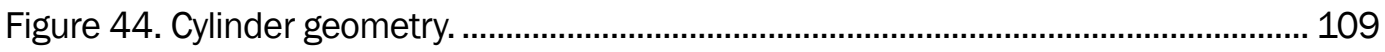

Figure 45. Mesh convergence. ................................................................................... 111

Figure 46. Final meshed geometry of $10.2 \mathrm{~cm}$ by $20.3 \mathrm{~cm}$ tall cylinder. ......................... 112

Figure 47. Finite element simulation results. 114

\section{Tables}

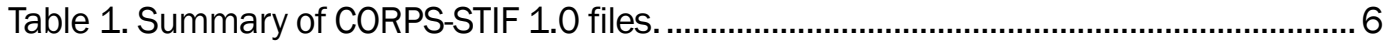

Table 2. Ingredient properties and proportions of UHPC mixture tested. ...........................27

Table 3. Thermodynamical testing overview. ....................................................................30

Table 4. Cartesian coordinates of thermocouples 1 to 34 in $40 \mathrm{~cm}-\mathrm{Cu}$..............................32

Table 5. Cartesian coordinates of thermocouples 35 to $40 \mathrm{in} 40 \mathrm{~cm}-\mathrm{Cu}$...........................33 
Table 6: Cartesian coordinates of thermocouples in $20 \mathrm{~cm}-\mathrm{Cu}$.............................................33

Table 7. Cartesian coordinates of thermocouples in 10cm-Cu. .......................................34

Table 8. Radial coordinates of thermocouples in 15.2cm-Cy............................................36

Table 9. Radial coordinates of thermocouples in 10.2cm-Cy............................................37

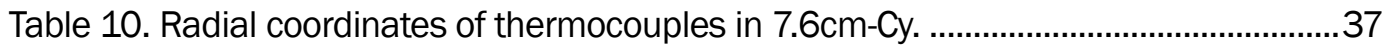

Table 11. Radial coordinates of thermocouples in 15.2x15.2-PP and 15.2x15.2-

PVC.

Table 12. Radial coordinates of thermocouples in 15.2×30.5-PP and 15.2×30.5-

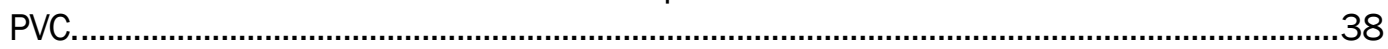

Table 13. Curing environment (CE) description and temperature setting. ..........................41

Table 14. $\mathrm{CE}_{3}$ temperature history for duration of study...................................................4

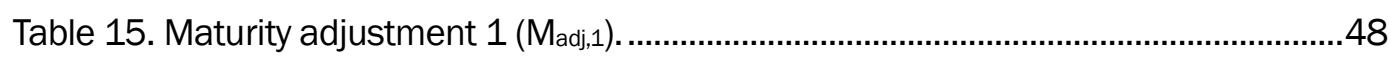

Table 16. Maturity adjustment 2 (Madj,2) ........................................................................49

Table 17. Description of isothermal curing specimens.....................................................50

Table 18. Mixed temperature curing specimens.............................................................52

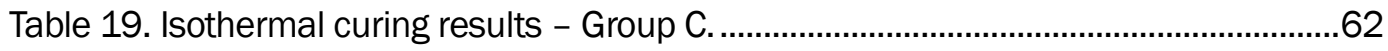

Table 20. Mixed temperature curing compressive strength results. .................................64

Table 21. Mixed temperature curing elastic modulus results. ...........................................64

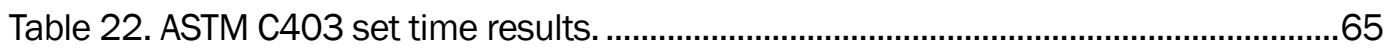

Table 23. Cylinder experimental program details............................................................ 74

Table 24. Calibrated heat generation constants. .................................................................... 76

Table 25. Constant concrete properties. ....................................................................... 77

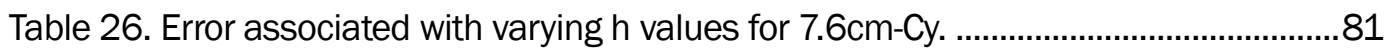

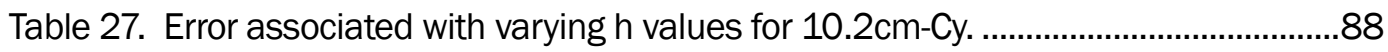

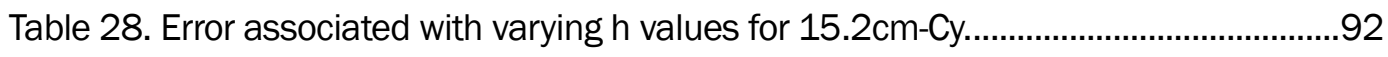

Table 29. Relevant thermal properties of insulation for boundary condition

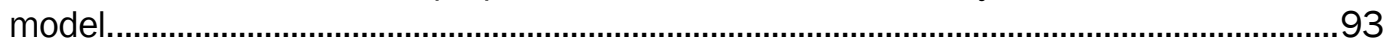

Table 30. Temperature predication and error for 15.2x30.5-PP and 15.2x30.5-

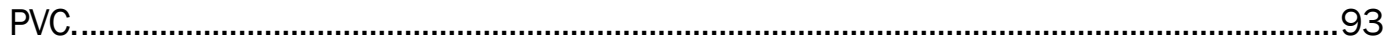

Table 31. Temperature prediction and error for 15.2x15.2-PP and 15.2x15.2-PVC..........96

Table 32. Error associated with each Nu correlation for 15.2x15.2-PP. ................................6

Table 33. Numerical models and parametric functions................................................. 102

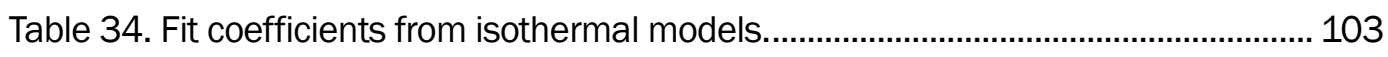

Table 35. Incrementation details for each step..................................................................... 110

Table 36. Mesh convergence summary........................................................................ 111

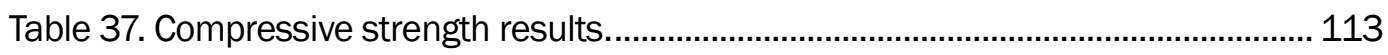

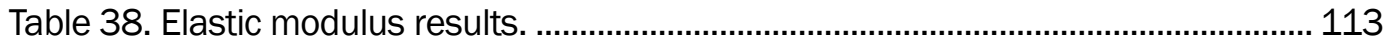

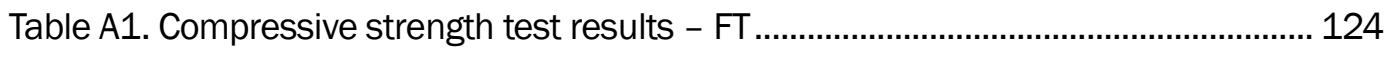

Table A2. Compressive strength test results - ET ............................................................ 124

Table A3. Elastic modulus test results - ET .................................................................. 124 


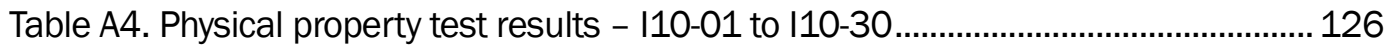

Table A5. Physical property test results - I10-31 to I62 ................................................. 127

Table A6. Physical property test results - I10-63 to I10-86................................................ 128

Table A7. Physical property test results - I23-01 to I23-32 ................................................ 129

Table A8. Physical property test results - 123-33 to I23-64 ............................................. 130

Table A9. Physical property test results - I23-65 to I23-91 ............................................. 131

Table A10. Physical property test results - I30-01 to I30-32 …......................................... 132

Table A11. Physical property test results - I30-33 to I30-59 ............................................ 133

Table A12. Physical property test results - 150-01 to 150-32 .......................................... 134

Table A13. Physical property test results - 150-33 to 150-64............................................ 135

Table A14. Physical property test results - 150-64 to I50-76 ............................................... 136

Table A15. Physical property test results - 170-01 to I70-32 …....................................... 137

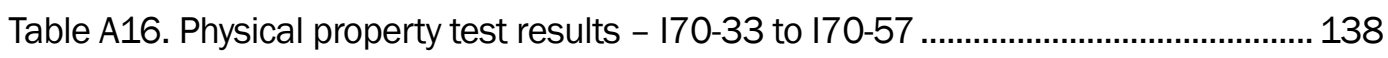

Table A17. Physical property test results - 190-01 to 190-32 …........................................... 139

Table A18. Physical property test results - 190-33 to 190-64............................................ 140

Table A19. Physical property test results - 190-65 to 190-90.............................................141

Table A20. Physical property test results - EAV .............................................................. 142

Table A21. Physical property test results - I23CR-01 to I23CR-32 …................................ 143

Table A22. Physical property test results - I23CR-33 to I23CR-64 ..................................... 144

Table A23. Physical property test results - I23CR-65 to I23CR-76 .................................... 145

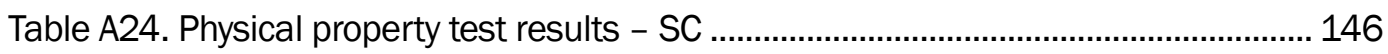

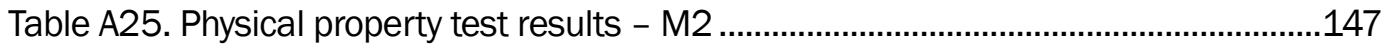

Table A26 Physical property test results - M13 …........................................................147

Table A27. Physical property test results - M20 …....................................................147

Table A28. Physical property test results - M27 ……...................................................... 148 


\section{Preface}

This study was conducted through a collaboration between the U.S. Army Engineer Research and Development Center (ERDC) and the Mississippi State University (MSU) Center for Advanced Vehicular Systems (CAVS). This material is based on work supported by the U.S. Army TACOM Life Cycle Command under Project No. W56HZV-08-C-0236. This project was designated Engineering Work Directive (EWD) 0067 (WD67) - Modeling and Simulation of Multi-Physics Material Response in Geo-environments. This report is related to WD67 Topic 1: Advanced Materials and Modeling for Force Projection and Protection.

The Contracting Officers Representative from the U.S. Army Tank Automotive Research, Development, and Engineering Center (TARDEC) was Mr. Donald J. Dusett. Dr. Roger L. King was the CAVS Director and Principal Investigator for WD67 at the beginning of the project. Dr. Isaac L. Howard was the lead investigator for the WD67 Topic 1 content presented in this report. Dr. Clay Walden assumed the role of CAVS Director during the timeframe of this project. Dr. Robert Moser was the WD67 technical point of contact (TPOC) for the overall work program, and Dr. Jameson Shannon was the TPOC for the work presented in this report. Dr. Michael I. Hammons and Ms. Pamela G. Kinnebrew provided valuable assistance. MSU students Michael Walsleben, Tanner Rhodes, Jim Steele, Nicki Haines, Brittni Cooper, and Brad Hansen provided assistance with a variety of activities, including laboratory testing.

At the time of publication, Dr. Jameson D. Shannon was Chief, GMC, and Mr. Justin S. Strickler was Chief, ESMD. The Deputy Director of ERDCGSL was Mr. Charles W. Ertle II, and the Director was Mr. Bartley P. Durst.

COL Teresa A. Schlosser was the Commander of ERDC, and Dr. David W. Pittman was the Director.

The views and conclusions contained herein are those of the authors and should not be interpreted as necessarily representing the official policies or endorsements, either expressed or implied, of the ERDC or the U.S. Government. Any opinions, findings, conclusions, or recommendations 
expressed in this material are those of the authors and do not necessarily reflect the views of the U.S. Army TACOM Life Cycle Command. 


\section{Introduction}

\subsection{Background}

Ultra-High Performance Concrete (UHPC) with strengths exceeding 150 $\mathrm{MPa}(21.7 \mathrm{ksi}$ ) is a relatively recent development. Optimization of ingredients for UHPC is a complicated process that differs from application to application. Even the definition of "optimal" is not straightforward, as cost, material availability, project needs, and so forth can all have different relative merits from one situation to the next. This report focuses on improved understanding of UHPC for mass concrete applications.

One of the main challenges to characterizing mass concrete is to have an integrated framework that can consider key variables. Experiments are needed to measure the exothermic signature of the selected UHPC proportions, and this signature needs to be understood in the context of the structure's geometry and boundary conditions by way of a thermodynamical model. Once a time-dependent, three-dimensional temperature profile is known, physical testing can be used to assess strength and dimensional stability properties for inputs into finite element analysis (FEA).

A key purpose of this report is to establish a framework through which optimization of UHPC can be enhanced for a given project by measuring fundamental properties in the laboratory and coupling or pairing those properties with thermodynamical and structural models. This framework has been established so that it is adaptable over time as improvements in any area are made. Eventually, this framework should have several uses, including selecting ingredients and proportions for UHPC that optimize performance for a given application, while also considering steel or composite reinforcing systems.

\subsection{Objectives}

The primary objective of this report is to present initial development of a framework for optimizing constituent materials used in UHPC for mass concrete applications, i.e., optimized materials for a given structure in a given environment. This framework includes thermodynamical modeling, finite element analysis, and physical testing. The framework has been named CORPS-STIF (Concrete Observations Repository and Predictive 
Software - Structural and Thermodynamical Integrated Framework). CORPS-STIF was developed so that it can be improved over time. This report is envisioned to be the first in a series of documents where CORPSSTIF is progressively improved in one or more areas.

\subsection{Scope}

\subsubsection{Contractual scope}

This report is part of Work Directive 67 (WD67), where the overall effort was focused on development of enhanced modeling and simulation (M\&S) techniques and computational analysis tools to support military engineering missions of force projection and maneuver support, force protection, and environmental impacts on sensor performance. All activities within this report fall under Topic 1: Advanced Materials and Modeling for Force Projection and Protection. This report is only one component of Topic 1. WD67-Topic 1 was divided into four focus areas, i.e., (i) improving the performance of pavement materials, (ii) understanding geomaterial interactions with structural materials, (iii) novel methods and materials for in-situ soil stabilization or strengthening of infrastructure materials, and (iv) high performance materials for facility protection. The overarching goal of WD67-Topic 1 was to better understand complex problems in force projection and protection. A key goal of this topic was to develop detailed models of materials, system-level prototypes, and models related to materials and material systems to evaluate and optimize the performance of such models. Each WD67 topic had four associated tasks.

- Task 1: Evaluate currently available Products of Interest (POIs).

- Task 2: Reach a decision point (DP) that determines if a new POI is needed, if an existing POI needs modifying, or to combine existing POIs to reach a product.

- Task 3: Proceed with the DP POI decision from Task 2, so long as any computational tools can run on High Performance Computing (HPC) systems and are optimized for large memory systems and multi-core or multi-processor systems.

- Task 4: Evaluate the performance of the POIs developed relative to any comparable tools previously in existence. 
This report was fully funded from WD67-Topic 1, but all the work from WD67-Topic 1 is not included in this report. Future reports are envisioned to contain the remaining WD67-Topic 1 findings that are pertinent to UHPC, possibly in conjunction with UHPC work from companion funded efforts. The POI of this report is CORPS-STIF, as the DP determined a new POI was needed, and directly comparable POIs were not identified.

\subsubsection{Technical scope}

WD67-Topic 1 was divided into four areas (A to D) as described below in addition to writing this technical report (TR).

A: Literature and Practice Review: Review applicable materials (cement, concrete, and composites), experimental techniques, thermodynamical techniques, and structural analysis techniques applicable to mass concrete. Chapter 2 is a literature review that contains a portion of the content reviewed. Remaining literature applicable to Area A is envisioned to be provided in future TRs or in peer reviewed manuscripts.

B: Experimental Program: Conduct experiments that can further understanding of mass concrete and fit into the aforementioned framework and where applicable can serve as inputs for thermodynamical and structural models. Chapter 3 describes all experimental procedures and provides all measurements that were included into the first release of the Observations Repository (OR) for the first release of CORPS-STIF. Chapter 3 also contains some discussion near the end of ongoing experiments that were not included in OR 1.0 but are part of WD 67-Topic 1.

C: Thermodynamical Modeling: Develop a model(s) to attempt to predict temperature within a mass concrete structure. Chapter 4 describes numerical modeling efforts and use of OR 1.0 measurements to produce the first release of the Thermodynamical Integrated Framework (TIF). Chapter 4 also contains some discussion near the end of ongoing work to improve TIF 1.0 that is part of WD 67-Topic 1.

D: Structural Modeling: Develop a model(s) to attempt to predict stresses, strains, and deflections within a mass concrete structure that uses applicable data from items $A$ to $C$ as inputs. Chapter 5 describes numerical modeling efforts and use of OR 1.0 measurements to produce the first release of the Structural Integrated Framework (SIF). Chapter 5 also contains some discussion near the end of ongoing work to improve SIF 1.0 that is part of WD 67-Topic 1. 
The overall focus of this report is mass concrete using UHPC. A multifaceted approach consisting of testing and modeling was employed. One type of UHPC (Cor-TUF Baseline) was utilized throughout. Some items originally envisioned to be assessed in earlier periods of this work, e.g., use of composite strips for crack control, alternative constituent ingredients, and dimensional stability as a function of temperature, extension of CORPS-STIF to small concrete projects in cold weather, i.e., the opposite problem of mass concrete, were not directly considered in this report and have been left for possible future work. After consideration of the content presented in Chapter 2 and the desire for the mass concrete materials themselves (or the structural steel reinforcement) to be able to mitigate cracking, integrating composite strips was not pursued further for purposes of this report. The DP was that CORPS-STIF as described in the next section was more pertinent in terms of focusing efforts than the aforementioned items, which can still be assessed in more detail in the future, if desired.

\subsection{Overview of CORPS-STIF}

CORPS-STIF 1.0, described in Figure 1, includes the ability to assess circular shapes for thermal characteristics (i.e. by way of a polar coordinate system). Additionally, CORPS-STIF can estimate strength and modulus of cylindrical shapes that undergo an isothermal curing regime. Future releases of CORPS-STIF are envisioned to include the ability to address other shapes in three dimensions by way of Cartesian coordinates and the ability to predict mechanical properties of specimens that underwent variable temperature curing.

CORPS-STIF 1.o consists of 8 files as summarized in Table 1. The observations repository (OR), made up of 2 Excel files, contains all data for thermal and mechanical experiments. The CORPS-STIF 1.0 software package is made up of 6 files. A README file is included to inform users of software requirements and provide a general overview of the software. The structural integrated framework (SIF) contains an example Abaqus input file that simulates 3 days of curing at $90^{\circ} \mathrm{C}$ and a User Defined Field Variable (USDFLD) subroutine that develops elastic modulus and compressive strength as functions of time and curing temperature. The thermodynamical integrated framework (TIF) contains two python files that numerically calculate temperature profiles for cylinders with different batch-day constants and one comma-separated value file that contains a 
reference array length and an initial time array for the python scripts.

Figure 1 shows a visualization of the iterative logic behind CORPS-STIF 1.o.

Figure 1. CORPS-STIF 1.0 flowchart.

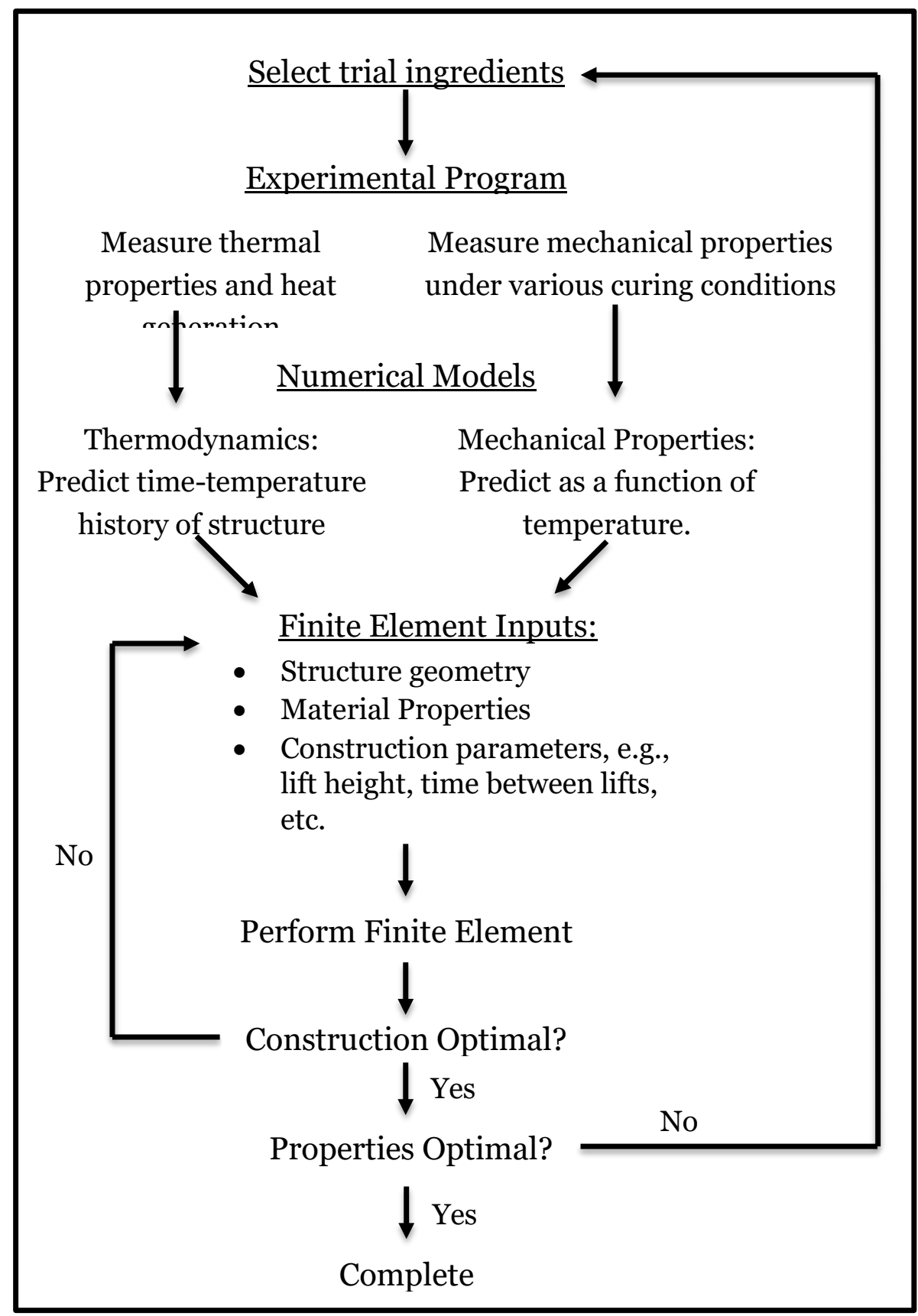


Table 1. Summary of CORPS-STIF 1.0 files.

\begin{tabular}{|l|l|l|}
\hline \multicolumn{1}{|c|}{ File Name } & File Type & Designation \\
\hline README & .txt & -- \\
\hline Observations Repository (1 of 2) - Thermal Experiments & .xlsx & OR \\
\hline $\begin{array}{l}\text { Observations Repository (2 of 2) - Preparation and } \\
\text { Mechanical Testing of Specimens }\end{array}$ & .xlsx & OR \\
\hline Cyl_90_3d.inp &. inp & SIF \\
\hline SIF_subroutine.f &.$f$ & SIF \\
\hline CYLINDERS-TempProfile-Batch1calibration.py & .py & TIF \\
\hline CYLINDERS-TempProfile-Batch2calibration.py & .py & TIF \\
\hline Qgen UHPC_Literature & .csv & TIF \\
\hline
\end{tabular}




\section{Literature Review}

\subsection{Overview of literature review}

A review of literature was performed where the work of others in any area that might benefit the current or possible future versions of CORPS-STIF framework was considered. Some of the information obtained during this review has been omitted from this report and is expected to appear in future reports related to CORPS-STIF. Generally speaking, findings from the review presented in this report are divided into eight categories, and each of these categories is presented in this chapter as stand-alone sections. This literature review was conducted from the perspective that this report would be the basis for continual work on UHPC and/or the CORPS-STIF framework. As such, this review was used as one of the factors leading to what went into CORPS-STIF 1.o, i.e., release 1 of this framework, and also as a repository of information for consideration in future efforts. This literature review is intended to provide some understanding of mass concrete, but it should be noted that the CORPS-STIF framework is eventually intended for use with other types of concrete applications as well.

\subsection{UHPC mechanical properties}

Isaacs et al. (2009) evaluated ultra-high performance, fiber-reinforced concrete via Hopkin's bar, unconfined compressive strength, and indirect tensile testing (unconfined compression and indirect tension testing were comparable to that performed later in this report). Compressive strength testing found that, as load rates increased, strength increased. A complete fracture plane was never found in tension; specimens could have withstood more force. Individual components were not described.

Ferrier et al. (2015) completed both an experimental program and an analytical model of fiber-reinforced polymer rebars in short fiberreinforced ultra-high performance concrete. Beams that were 2 or 4 meters were tested with two different types of rebar, i.e., carbon fiber and glass fibers, at two different stiffness, i.e., a total of four rebar options. For all beams, fiber-reinforced polymer rebar increased tensile capacity while glass fibers provided the highest tensile strengths. However, carbon fiber reduced span displacement due to its high elastic modulus values compared to glass. The elastic, multilinear stress-strain relationship proposed by Habel et al. (2006), was used in modeling efforts. A finite- 
difference method was used to calculate beam deflections. A parametric study determined that the most influential property was the ultimate strength of the FRP rebar, which allows for higher ultimate capacity of the beam up to the compressive strength of the concrete; however, the ductile design criteria required for most beams is lost, and the high stiffness of the beam results in brittle, sudden failure.

Graybeal (2006) provides background on UHPC and its use by the Federal Highway Administration (FHWA). UHPC has improved mechanical properties, e.g., compressive strengths of $193 \mathrm{MPa}$, elastic modulus of 52.4 $\mathrm{GPa}$, and tensile strengths of $9 \mathrm{MPa}$, that allow for conventional structural components to be redesigned and optimized. Claddings and overlays are promising applications of UHPC where an existing structural element can be retrofitted with a strong, protective layer to increase lifespan and impact protection. UHPC has also been used as an effective grouting material between precast concrete members. A complete experimental program was undertaken in an attempt to characterize mechanical properties of UHPC through strength-based behaviors, long-term stability behaviors, and durability behaviors after four different curing regimes. Testing and specifications for UHPC are still under development, but those applicable to conventional concrete were used to determine compressive strength, modulus of elasticity, tensile strength, chloride penetration resistance, freeze-thaw durability, and other properties.

A number of studies on UHPC have shown the dependence of mechanical property development on curing conditions with high temperatures tending to show a positive impact. On the contrary, Lee et al. (2016) highlights the cross-over effect observed in conventional and typical high-strength concretes exposed to high temperatures at early ages. This cross-over effect is characterized by rapid strength gain at early ages but lower ultimate strength for high-temperature curing when compared to low-temperature curing, which results in slower but higher ultimate strength gain.

Ahmad and Hakeem (2015) investigated the effects of air and water curing at $22^{\circ} \mathrm{C}$ on compressive strength and elastic modulus of UHPC at a variety of fiber contents after 28 days. For a fiber content of $6.2 \%$ by weight, curing in air and water resulted in compressive strengths of 149 and 163 $\mathrm{MPa}$ and elastic moduli of 49 and $57 \mathrm{GPa}$, respectively, indicating improved mechanical properties after water curing. Following water 
curing, exposure to heating and cooling cycles for 6 months increased compressive strength to $194 \mathrm{MPa}$ and elastic modulus to $62 \mathrm{GPa}$.

Howard et al. (2018) exposed UHPC to a variety of curing conditions, including (1) 120 days in a room temperature curing room, (2) 6 days in a room temperature curing room followed by 7 days in a $90^{\circ} \mathrm{C}$ water bath, and (3) 6 days in a room temperature curing room followed by 8 days in a $80^{\circ} \mathrm{C}$ water bath. For these three curing conditions, compressive strengths were 149,175 , and $190 \mathrm{MPa}$ and elastic moduli were 49,50 , and $53 \mathrm{GPa}$, respectively.

Wan et al. (2016) exposed UHPC to two curing conditions, including (1) 14 days in a room temperature curing and (2) 7 days in a room temperature curing room followed by 7 days in an $85^{\circ} \mathrm{C}$ water bath. For these two curing conditions, compressive strengths were 99 and $127 \mathrm{MPa}$, respectively.

Prem et al. (2015) exposed cube specimens of UHPC at a variety of fiber contents to three curing conditions, i.e., (1) 28 days of $20^{\circ} \mathrm{C}$ water, (2) $100^{\circ} \mathrm{C}$ steam for $18 \mathrm{hr}$ followed by $20^{\circ} \mathrm{C}$ water curing until 28 days, and (3) $200^{\circ} \mathrm{C}$ steam for $48 \mathrm{hr}$ followed by $20^{\circ} \mathrm{C}$ water curing until 28 days. For a fiber content of $2 \%$ by volume, these three curing conditions resulted in compressive strengths of 144,142 , and $196 \mathrm{MPa}$, respectively.

Wille et al. (2012) achieved high strength and ductility in UHPC without high temperature or pressure curing. UHPC was mixed in a conventional drum mixer with no coarse aggregates, various fine aggregate, and powder proportions and four varying types of fibers. Cube compressive strengths as high as $292 \mathrm{MPa}$ (42 ksi) were achieved using $8 \%$ fiber volume at 28 days of age. Values reported in this study are particularly high compared to typical literature.

\subsection{UHPC thermodynamical properties}

Kodur et al. (2016) describe temperature distribution numerical modeling on a micro-scale to a macro-scale in a blend of UHPC. These models were described as able to be incorporated into a FEA package such as ABAQUS to develop 3-D representations of thermal gradients in mass concrete. A set of governing differential equations were used to define heat transfer between the concrete and its surroundings. These equations utilized four constant concrete material property inputs, i.e., density, specific heat, thermal conductivity, and coefficient of heat 
transfer. Parametric studies were conducted within the model to predict the effects of mix proportion, size, insulation, and reinforcement on the development of heat, strength, and stress. It was found that a batch with higher proportions of silica fume developed higher internal temperatures and compared to a fly-ash blend. Good agreement was found between the predicted temperatures from the thermal model and experimental data. To study the effect of block size, blocks of $1 \mathrm{~m}, 2 \mathrm{~m}$, and $3 \mathrm{~m}$ were modeled by Kodur et al. (2016).

It was evident that the largest concrete block developed the highest peak temperature and temperature gradient. For the 3-m block, thermal tensile stresses developed on the block surface at any given time always exceeded the developed tensile strength. Large masses of these types of concrete are very likely to experience cracking. It was shown that a thermal blanket can slow the rate that heat dissipates and led to a lower thermal gradient. Consequently, differential thermal stresses are less likely to develop, and cracking is less likely.

\subsection{Thermodynamical modeling}

Temperatures within a mass concrete structure are a function of factors including concrete ingredients/proportions, initial material temperatures, structure geometry, and boundary conditions. Mass concrete structures develop thermal gradients since concrete has low thermal conductivity, the interior is at higher temperatures than the exterior, and the interior is expanded relative to the exterior due to these temperature gradients. Heat can usually dissipate more readily from exterior concrete than interior concrete, and the extent of this dissipation is a function of the boundary conditions, e.g., formwork, air conditions, soil conditions, or similar. Relative volume change leads to cracking of mass concrete structures, which reduces overall structural integrity. Modeling mass concrete's temperature distribution has been performed by others in various manners as described in this section.

Ballim (2004) utilized a 2-D numerical model based on the Fourier equation that takes maturity rate and heat evolution versus maturity scale to predict the rate of heat evolution at various times and locations in concrete. Maturity was found with the Arrhenius maturity function, and the equations were reported to be accurate to $\pm 2^{\circ} \mathrm{C}$. 
Kuriakose et al. (2016) modeled concrete hydration as a function of degree of hydration and heat generation as a function of chemical affinity. Conduction through concrete was modeled using Fourier's Law, and boundary conditions used Newton's Law of Cooling (convection) and a sinusoidal equation to account for daily fluctuations in ambient air temperature. All equations were used in a finite element program to discretely solve for temperature distribution that was validated using data from Faria et al. (2006).

Azenha et al. (2009) produced a thermo-mechanical model to predict thermal stresses produced by mass high-performance concrete placements. Heat of hydration and energetic flows from convection and radiation account for thermal analysis while creep and evolution of mechanical properties with respect to time account for mechanical analysis. The thermal numerical model used isothermal calorimetry for inputs to solve Arrhenius and Fourier's laws for conduction. The numerical solution was conducted in the finite element software DIANA and was compared to experimental data collected using strain gauges and thermocouples. A concrete block was poured and insulated with polystyrene while being kept in a constant temperature and humidity environment. The numerical model produced similar temperature distributions compared to recorded data found through experimental testing.

Cervera et al. (2002) produced a numerical model that accounted for the effects of hydration and aging during early-age curing of concrete structures. This model was based off a model from Ulm and Coussy (1995) and verified using data collected by Kim et al. (1998). Once verified using data from literature, experimental data collected from the Öresund Link (a bridge connecting Denmark and Sweden) was compared to the model. Reasonable trends were predicated, but complete accuracy predicting peak temperature was not achieved at multiple points throughout the structure.

Ulm and Coussy (1995) developed a thermo-chemo-mechanical model that accounted for the effects of porosity on heat transfer and chemical reactions in concrete at early ages. Additionally, it was found that differences in thermodynamics were not found to be caused by applied stress, i.e., creep was decoupled from the numerical model.

Chini and Parham (2005) developed adiabatic temperature rise curves for common concretes used by contractors in mass concrete placements. Compressive strength, thermal diffusivity, and heat of hydration were 
found for each concrete mixture studied. These curves conformed to AASHTO cement specifications rather than the ACI curves that have been used for decades. It was found that slag and fly ash could serve as replacements to cement mixtures and reduce the peak temperature. The thermal diffusivity of the concrete was also reduced as pozzolanic materials, i.e., slag and fly ash, were used as a cement replacement.

Ge et al. (2009) performed mortar calorimetry to predict set time. This new method to predict set time required taking the first derivative of the heat evolution curve. Initial setwas the highest peak of the first derivative curve and set time was when the curve hit zero after the initial set time, i.e., the first peak. These results were then compared to ASTM C4O3, and isothermal calorimetry was found to be a good predictor of set time. It was also found that, as cement fineness increases, heat generation also increases while, as the water to cementitious material $(\mathrm{w} / \mathrm{cm})$ ratio decreased, the peak of heat generation was delayed.

Bentz et al. (1998) tested several concrete types, i.e., including and excluding silica fume, to observe temperature rise due to hydration under adiabatic conditions. Both numerical and experimental testing occurred to compare the effects of various materials on early-age temperature histories. Mixing occurred at a constant temperature and then specimens were immediately placed in an adiabatic calorimeter. A microstructural model, based on stoichiometry, was made to account for when pores changed from holding water to being empty as the hydration process continued. The temperature difference can then be found by the cumulative heat generated through each round of the hydration process.

Tia et al. (2010) performed several thermal tests, including isothermal calorimetry, semi-adiabatic calorimetry, adiabatic calorimetry, heat of solution calorimetry, thermal diffusivity, and specific heat capacity, in addition to mechanical testing, including compressive strength, elastic modulus, splitting tensile, flexural strength, tensile modulus of elasticity, and coefficient of thermal expansion. A numerical solution was developed using Fourier's Law and Newton's Law of Cooling. Variables such as thermal diffusivity and specific heat were solved for experimentality and then used as input to the numerical model. Blocks of mass concrete were produced to experimentally verify the numerical solution given above. Thermocouples were used throughout the blocks to measure temperature generation from heat of hydration. Semi-adiabatic and isothermal 
calorimetry testing was performed on concrete samples identical to the blocks to find the relationship between energy rise and temperature rise for input to the finite element model. As block size increased, temperature gradients between the center of the cube and ambient edges also increased, e.g., a $0.5-\mathrm{m}^{3}$ block had a peak temperature of around $58^{\circ} \mathrm{C}$, and a $4-\mathrm{m}^{3}$ block had a peak temperature of around $95^{\circ} \mathrm{C}$. The increased use of insulation during the curing process led to smaller temperature gradients once the concrete had finished setting.

D'Aloia and Chanvillard (2002) proposed that, by finding activation energy of cement, the overall compressive strength of concrete can be predicted. Arrhenius' law was used to find activation energy, and calorimetry testing was used to solve for heat of hydration. The model was based on the mineral composition of cement, i.e., silicates and aluminates, and excluded microstructural size distribution, cement fineness, particle size distribution, and the water-to-cementitious materials $(\mathrm{w} / \mathrm{cm})$ ratio. The different hydration reactions were measured individually to find apparent activation energy and then were summed to give total apparent activation energy. One of the main assumptions made for this model was that there are independent fractional rates rather than equal fractional rates. As a result, the degree of hydration and released heat of each phase were found independently of the other phases. Data from literature did not provide accurate results in the model, so a slightly different version of the Avrami-Erofeev model was used. Experiments were conducted on different types of concrete to check the accuracy of the model. The model was then fitted to the experimental data using seven different constraints.

Ali and Urgessa (2012) developed a numerical model to predict thermal gradients in mass concrete structures that accounts for cement composition, supplementary cementitious materials (SCMs), cement fineness, $\mathrm{w} / \mathrm{cm}$ ratio, placing temperature, admixtures, ambient air temperature, wind speed, solar radiation, solar irradiation, concrete geometry, and concrete size. Equations for conduction, radiation, irradiation, and adiabatic temperature rise were all input to a Matlab script where a Taylor-Galerkin finite element method and finite different method was implemented. This model was then validated using experimental data from Ballim (2004). The model was accurate and produced very similar temperature versus time curves. 
Lawrence et al. (2012) created a numerical model that accounted for the nonhomogeneity of mass concrete when predicting temperature distributions, thermal gradients, and thermal stresses and strains. A range of mixes (with and without SCMs) were used to test a range of temperature distributions. The finite element analysis program DIANA was used to conduct the thermal and structural analysis. For thermal analysis, boundary conditions of internal temperature at pouring and the ambient external temperature were recorded. The slopes of the numerical and experimental solutions were almost identical, but the peak temperatures were slightly different.

Faria et al. (2006) created a numerical model that accounted for cracking due to thermal stresses. Conduction, convection, and radiation were modeled using Fourier's Law, Newton's Law of Cooling, and the StefanBoltzmann equations, respectively. Thermal analysis was implemented using the finite element method and was compared to experimental data. A large slab, i.e., $143 \mathrm{~m}$ by $41 \mathrm{~m}$ by $0.35 \mathrm{~m}$, was poured at a storage building, and sensors were used to monitor strain and temperature immediately after pouring until completely hardened. 1-D and 2-D ideal models were used to make a refined 3-D model that could be checked with the numerical simulation. For the 1-D model, it was assumed that heat transfer could occur only across the slab thickness, i.e., only the slab interacting with the environment was considered. There were deviations between the numerical model and what was actually observed. The main reasons reported were not accurately modeling the inactive period at the beginning of hydration and oversimplified assumptions defining the upper and lower boundary convection coefficients for the slab. The 2-D model used the middle plane of the slab and neglected heat transfer in the plane of the slab. The numerical prediction for the 2-D model was more accurate than the 1-D model. The 3-D model was a combination of the 1-D and 2-D models. At a distance of 1 meter from the different concrete domains, the 3 -D model was almost identical, i.e., within $2 \%$ deviation, to the results of the 1-D model. The stresses in the slab's plane also proved to be less than $5 \%$ different from the 2-D model to the 3-D model.

Coefficient of thermal expansion (CTE) is a thermal property that quantifies volume change concrete experiences while subjected to different temperature environments. Zhou et al. (2014) found a numerical solution to predict the coefficient of thermal expansion of concrete. AASHTO T336 was used to gather experimental data on cement paste, mortar, and 
concrete specimens. It was found that aggregate type and gradation affected CTE values for concrete specimens. The difference between the model and the lab tests were no more than $5 \%$.

Di Luzio and Cusatis (2009a) modeled cement hydration using a complex formulation of time-dependent quantities and concentration of important chemical parameters affecting the temperature and strength development in concrete. This study focused on the constituents of UHPC and the inclusion of the pozzolanic reaction of silica fume. The hydration reaction was modeled using asymptotic hydration degree based on a mass balance of moisture. This model had not been fully calibrated at the time of publication, and it holds many similarities to other models.

\subsection{Mass concrete placement}

Thermal gradients and tensile stresses should be expected to increase as structure dimensions increase. Thermal gradients can be lowered by use of insulated formwork, e.g., thermal blankets, and/or tensile stresses can be mitigated by use of internal reinforcement, e.g., rebar or steel mesh.

The Portland Cement Association (1997) recommends that large-scale construction projects follow design considerations to monitor the heat of hydration in mass concrete structures. For most concrete construction, heat due to hydration dissipates into the air, soil, and environment on a scale comparable to its generation; however, large-scale projects with thick members can have a considerable amount of heat build in them. Temperature rises of $55^{\circ} \mathrm{C}$ have been recorded for certain concrete mixes. Nonlinear expansion can cause cracking as differential temperature gradients develop. Insulation has been used to trap heat but maintain a smaller thermal gradient. A maximum allowable temperature rise of $20^{\circ} \mathrm{C}$ is standard for construction specifications per ACI committee 301 (2016) for conventional concrete structures. Most hydration heat is released within the first one to three days but can go on indefinitely as concrete matures.

Schindler et al. (2017) developed an equation and method to determine temperature difference limits for mass concrete structures based on prior knowledge of material properties. As temperatures develop through the hydration reaction of concrete, thermal stresses develop and cause expansion and contraction at different locations in a mass concrete element. Materials with a higher CTE expand more under elevated temperatures. Aggregate testing in the 1980 s determined that a 
conservative temperature difference limit of $20^{\circ} \mathrm{C}\left(35^{\circ} \mathrm{F}\right)$ should be used based on the properties of gravel. Two main problems face mass concrete structures. First, high early-age temperatures can lead to delayed ettringite formation (DEF). Second, excessive temperature differences can lead to thermal cracking. DEF is an internal sulfate attack where the expansion of the concrete paste weakens the aggregate-paste bond and fills with ettringite crystals. For conventional concrete, temperatures exceeding $70^{\circ} \mathrm{C}\left(160^{\circ} \mathrm{F}\right)$ are likely to allow for DEF to occur. For mixtures with fly ash or slag cement replacing some cement, this temperature limit is $85^{\circ} \mathrm{C}$ $\left(185^{\circ} \mathrm{F}\right)$. Instrumented mass concrete elements were monitored in Alabama to determine if the DEF control limit was exceeded at early ages, and 3 of the 7 elements exceeded DEF control limits.

Garner and Hammons (1991) developed a thermo-mechanical model for modeling the pouring of mass concrete in lifts using the finite element program ABAQUS and subroutines in FORTRAN. Since properties of mass concrete are heavily dependent on amount and type of cementitious materials, aggregate, w/cm ratio, and use of chemical admixtures, and a model that could accurately predict thermal and mechanical properties of mass concrete placements was critical. Properties such as thermal conductivity and specific heat were modeled as functions of temperature for thermal analysis, while ambient and placement temperatures and adiabatic temperature curves were supplied via user input, and wind speed, insulation, and forms were modeled using film coefficients. The produced time temperature history was then used to perform a stress analysis of the structure.

Potgieter and Gamble (1983) evaluated the effects of temperature distribution on structural integrity of bridge decks in the United States. A numerical analysis using Fourier's Law and net surface flow equations was developed as a way to predict temperature distributions throughout bridge decks. The numerical solution was verified using field measurements from the Kishwaukee River Bridge. Using data from several weather stations across the United States, bridges were evaluated for stresses caused by temperature distributions due to ambient temperature fluctuations. This analysis can be used to identify bridges with high probabilities of cracking due to temperature differentials developed through placement and changing ambient temperatures. 
Tia et al. (2013) used a finite element model to predict temperature development within mass concrete infrastructure commonly used in Florida. Isothermal calorimetry was found to be the most appropriate method to quantify heat generation in concrete at early ages. The software TNO DIANA was used to model thermal behavior of concrete. Within the software package, some material properties are both time and temperature dependent. Conduction through the concrete, convection at the boundary, and temperature rise due to heat of hydration are all accounted for in the thermal model. The model was able to reasonably predict temperature gradients throughout mass concrete structures.

Radovanović (1998) developed a model in the interest of retrofitting older mass concrete structures that have cracked. When mass concrete structures are poured, temperature gradients develop due to the low thermal conductivity of concrete. These temperature gradients lead to stresses that cause volume changes and can lead to early-age cracking. In the case of dams in Canada, early-age cracking can cause losses in structural integrity especially in winter months when ice buildup causes additional stresses. Finite element analysis was completed to determine how influential early-age thermal stresses affect overall longevity of mass concrete structures.

Tia et al. (2016) reported on mass concrete usage in infrastructure throughout Florida. A database was created that supplied rate of heat production for several concrete blends commonly used on FDOT projects to better conduct thermal analysis. Soil type and moisture content were also found to have varying insulating effects on mass concrete placements such as bridge footings. Additionally, it was recommended that the maximum volume-to-area (V/A) ratio for high-strength concretes be reduced relative to traditional ready-mixed concrete to account for the increased cement content. Finite element models were completed for bridge elements with varying V/A ratios, material compositions, and soil conditions to quantify the effects of each variable on the thermal profile of a mass concrete structure. Field experiments were also conducted and used to verify the finite element model. Four different soil types were tested at different moisture contents to find the $\mathrm{R}$-value of different soil conditions. Research showed that, for all four soils types, a lower water content led to a higher R-value. Additionally, drilled shafts containing thermocouples at known locations were filled with concrete to measure temperature gradients throughout the structure. The model provided reasonable accuracy. 
Riding et al. (2007) addressed the lack of knowledge available for modeling boundary conditions of mass concrete structures through convection and radiation. By addressing various forms of radiation and convection, numerical approximations of boundary conditions were established. These formulas were acquired from the National Climatic Data Center, the Meteorological Surface Observational Network, and properties found in literature or experimentally. The model was verified using data collected from 12 different concrete bridge structures poured in Texas. The absolute average error of the numerical model when compared to the 12 bridge members ranged from 0.5 to $4.6^{\circ} \mathrm{C}$.

Yunchuan et al. (2012) compared finite element analysis to laboratory experiments to see how accurately thermal stresses in high rise buildings in China can be predicted. A building was modeled in MIDAS using identical boundary conditions as what specimens experienced in the laboratory. FEA was performed on the building with and without internal cooling pipes to establish the effectiveness of internal cooling systems. It was found that, if temperature gradients and subsequent stresses can be controlled, then thermal cracking can be avoided.

Yang et al. (2012) modeled cooling pipes within a mass concrete structure in a finite element program. Assumptions for the model included isotropic and homogenous concrete, thermal properties independent of temperature, and the cooling pipes were modeled as heat sinks. Four different numerical boundary conditions were modeled in addition to a cooling function to account for the pipes. The adiabatic temperature rise curve was modeled using experimental values and then refined using an Arrhenius-type equation. It was found that the model produced similar results when compared to experimental data.

Maruyama et al. (2012) discussed cracking potential in full-scale concrete columns that were made of UHPC. Four different concrete batches were used to make columns that were poured during winter and summer months to capture different environmental effects. The stress distribution in the finite element model was compared with those measured in the poured columns in their axial and lateral directions. The reinforcement ratios were also varied to see the effect reinforcement had on stress distribution and cracking. Equations were developed to describe compressive strength, splitting tensile strength, and elastic modulus as functions of time and have been referenced extensively in literature. It was 
seen that columns placed in the winter had the greatest degree of cracking as the thermal gradients between core and surface were the highest.

\subsection{Structural modeling}

Adley et al. (2010) simulated concrete properties under dynamic and destructive events such as ballistic impacts or explosions. This model includes a "three-invariant failure surface" where the stress and volumetric strain relationship is based on hydrostatic compression. Hydrostatic compression is a theoretical loading condition in which a material is constrained only by stress in the principal directions, and shear stress is excluded. Although this material model is highly specialized for dynamic loading conditions, there are damage parameters built into the model that account for decrease in stress-strain rate as the material undergoes hydrostatic crushing and subsequent increase in stress-strain rate as lockup of the crushed material into uncrushed material.

Alsalman et al. (2017) attempted to model trends of elastic modulus in ultra-high performance concrete. Elastic modulus versus compressive strength trends for conventional concrete are not valid in UHPC as strength develops much faster than elastic modulus. Elastic modulus data were collected from several blends of UHPC to propose a function correlating elastic modulus to compressive strength similar to ACI 318 (2013). Data used to develop this trend resulted in an $\mathrm{R}^{2}=0.37$. This relationship is still not completely understood, and more experimental data are needed to refine the correlation between compressive strength and elastic modulus.

Chandler et al. (2012) used the Discrete Element Method (DEM) and virtual nanoindentation to model Calcium-Silicate-Hydrate (C-S-H) on a nanomechanical level for the purpose of increasing the modeling accuracy of concrete. A larger packing density was more important to particle strength than elastic properties.

Isgor and Razaqpur (2004) numerically modeled the effects of carbonation on reinforcements within concrete. A numerical analysis using the 2-D program CONDUR was used to model time-, moisture-, and temperaturedependent diffusion of carbon dioxide within concrete. Carbonation had a greater chance of occurring when concrete $\mathrm{pH}$ dropped below nine, porosity increased due to poor particle distribution of the concrete, and ambient relative humidity was between $50 \%$ and $70 \%$. It was found that heat generated from carbonation reactions can be neglected when calculating the 
overall temperature distribution. Additionally, two-dimensional models were shown to be much more accurate when crack propagation and orientation were considered and compared to one-dimensional models.

The Department of the Army (1994) used finite element analysis to account for complex geometry, loading, thermal stresses, nonlinear material behavior, and sequential construction. As of the publication of this article in 1994, these techniques were applied to lock monoliths, arch dams, and other mass concrete structures. This study provided a finite element model of thermal and mechanical stresses of a mass concrete structure in ABAQUS to determine cracking potential. Developed by the Army Corps of Engineers, this model was intended to be used in the construction planning and design phase of mass concrete projects, especially hydraulic structures such as dams. Feasibility of a project can be evaluated as well as cracking potential.

Ardiaca (2009) used the finite element modeling program PLAXIS v8 to determine stresses on pre-existing concrete structures. The plasticity parameters corresponding to the Mohr-Coulomb failure envelope are cohesion and friction angle. After conducting one compressive strength test and one tensile strength test, a tangent line can be fit to the Mohr circles drawn from loadings. The angle of this line to the horizontal plane is the friction angle. Cohesion is the intercept of this line with the vertical axis. Analysis was conducted for multiple material models to determine stress and displacement on a tunnel to see how it will be affected by the additional load. This model was not verified for accuracy with field measurements.

Habel et al. (2006) developed a numerical model to study the time dependent mechanical properties of UHPC and evaluate the potential of cracking at early ages. The numerical model was constructed using hydration evolution indexes that were correlated to development of material properties. It has been shown that the development of concrete's mechanical properties is not a function of reaction rate but degree of hydration indices (DRI). Commonly used DRI include maturity, equivalent time, or degree of hydration. Compressive strength, elastic modulus, tensile strength, tensile modulus, linear-free and restrained autogenous shrinkage, and hardening of the test material were determined as a function of DRI using power function curve fitting and input into a finite element model. The correlation coefficients for all of these data fits were between 0.72 and 0.94 indicating decent to good 
agreement. Semi-adiabatic tests were conducted on the test material. Similar to the Waller model and Powers model, the final degree of hydration of the UHPC was only 0.31. The self-desiccating nature of UHPC is why the hydration reaction reaches equilibrium as capillary water is completely consumed. It is expected that other UHPCs will reach similar final degrees of hydration for the same reason.

Yu et al. (2010) created a plastic-damage model that simulated the nonuniform confinement of concrete. A finite element model was developed that accounts for nonlinear behavior caused by plasticity and damage under non-uniform confinement and was applied to a number of scenarios. Complex member sections and concrete cast in a steel pipe may exhibit unusual confinement that is not considered by other plasticity models. Concrete columns and piles are cast into a steel pipe, fiberreinforced polymer pipe, or an annular configuration of either steel or concrete for a number of applications. Depending on the shape of the cross section and material, non-uniform confinement can result in a stressstrain relationship that has not been entirely understood in the past. It has been shown that the use of both Drucker-Prager and Concrete Damaged Plasticity models (DCPMs) should include a strain-hardening/softening rule and a flow rule that are dependent on confinement. Yield criterion was also dependent on the third deviatoric stress invariant. This paper verified the efficacy and accuracy of the modified CDPM that was implemented for a number of concrete cross sections.

Wan et al. (2016) utilized a hygro-thermo-chemo strength development model developed by Ulm and Coussy (1995) to describe the time- and temperature-dependent properties of UHPC. An aging parameter was introduced that related degree of reaction to the ratio of elastic modulus at any time to the ultimate elastic modulus, which is similar to the method described in Habel et al. (2006). Solution variables of the hygro-thermo-chemo strength development model are passed on to a Lattice Discrete Particle Model (LDPM) and verified against observed laboratory data. Laboratory tests included compressive strength, splitting tensile strength, and 3-point bending. Numerical results varied, but some tests were well-described by numerical results.

\subsection{High strength concrete proportions}

Roth (2008) developed a new, very high-strength, discontinuous fiberreinforced concrete material (VHSC) with fiberglass and a w/cm ratio of o.2. 
Tensile testing was conducted on dog-bone-shaped specimens, and flexural testing was conducted on panels. The material was reported to have potential for use as a panel after three-point bending and direct tension mechanical testing was performed in conjunction with numerical analysis where modulus, fiber/matrix bond strength, and initial crack strength was assessed. A cracking model was developed to characterize the stress and strains that occur on the global level. Analytical modeling was combined with sophisticated fiber-pullout models and experimental data to develop a "bridging function" that relates crack opening to stress at the crack. This function had three distinct regions that correspond to the strength reduction as a crack grows. Bridging functions developed from both tensile and flexural tests closely agree. These bridging functions and stress-strain models were implemented in FEA software and produced modest results.

Wu et al. (2016) investigated three different types of steel fibers and different fiber contents that are typically included in UHPC mixtures. An experimental program was conducted that evaluated flowability, compressive strength, and flexural strength of specimens with 1, 2, and $3 \%$ fiber contents at 3, 7, 28, and 90 days. Hooked-end fibers had the greatest decrease in flowability as fiber content increased; straight fibers had the least. Both compressive and flexural strengths increased significantly with fiber content. Hooked-end fibers showed the highest strengths, and straight fibers showed the lowest. Steel fiber content had very little effect on the deflection before first cracking occurred. Once first crack had occurred, fibers were mechanically engaged to bridge the cracks. Flexural toughness was determined according to ASTM C1018 (2006) for each specimen. Hooked fibers had the highest toughness, and straight fibers had the lowest.

Wille et al. (2014) studied properties of strain hardening in UHPC under direct tension loading. Nine different mixes with varying fiber types and volume fractions were tested in direct tension. It was found that fiber volume fraction had more of an effect on tensile strength than fiber type.

\subsection{Numerical framework studies}

CORPS-STIF is intended to be an improved framework for optimizing UHPC ingredient selection for mass concrete placements. As such, due consideration should be given to how all the components fit into an overall framework as many options exist. This section describes guiding efforts by other researchers for the work presented later in this report. 
$\mathrm{Wu}$ and Luna (2001) provided information regarding assembling thermodynamical, structural, and boundary properties together in a time- and space-dependent manner. Their goal was understanding time-temperature-space dependencies of elastic modulus and creep within concrete. Improvements in the accuracy of FE modeling of mass concrete by way of assigning properties to different elements as a function of time-temperature-space were investigated. Conduction, convection, and radiation governing equations were used to model exothermic hydration reactions in a computer program such as Fortran. An FEA program then took each element and assigned stiffness and load values that were then assembled to form a mass concrete structure. Once the structure was compiled, boundary conditions were applied, and governing equations were solved for the structure.

According to Riding et al. (2006), there were three main methods used to predict temperature rise in mass concrete just over a decade ago when this publication was released. The first was the Portland Cement Association (PCA) method described in Design and Control of Concrete Mixtures, which is referred to as the PCA Method. The second method was graphical and is described in section 2 of ACI 207.2R (2007). The Schmidt Method (ACI 207.1R 2005) was the third method, which is essentially a numerical solution to the Fourier Law. These three methods were used to predict temperature rise in eight different structures found in bridges and compared to temperature data collected via thermocouples from eight structures. The Schmidt Method was the most accurate, but refinement was still needed to provide more clarity. There are two parts to the Schmidt Method, i.e., heat transfer and heat generation. The heat transfer part can be refined by measuring thermal conductivity and specific heat as functions of temperature instead of strictly constants. The heat generation part needs more refinement. The heat generation can be found with an adiabatic temperature distribution curve that can be calculated by hand (less accurate) and by isothermal calorimetry tests (more accurate). The measured isothermal calorimetry curves can account for chemical admixtures, but the equations provided in ACI 207.1R do not account for admixtures.

Fairbairn et al. (2004) optimized the construction stage of mass concrete projects. The authors utilized a coupled thermo-chemo-mechanical model (Ulm and Coussy 1995) employing a considerable amount of coding into on FEA framework that also included a generic algorithm to optimize cost. 
The models employed relationships to account for hydration, thermalchemical coupling, chemo-mechanical coupling, and chemo-plastic coupling that relied upon laboratory measured compressive strength and semi-adiabatic temperature evolution.

Bombich et al. (1991) created a user-made FORTRAN subroutine (DFLUX) that incorporated user inputs to determine thermal stresses and temperature gradients in a mass concrete structure via Fourier's Law. A user-defined material model, UMAT, for aging creep was included to account for change in concrete material strength, modulus of elasticity, creep, shrinkage, etc., and contained a cracking model to evolve the onset and effects of cracking. The model included the capability to simulate placement of incremental stages of concrete in a structure and provided other user-defined subroutines to model heat evolution of cement in the concrete mixture. Structures were then modeled in ABAQUS followed by a finite element analysis of each concrete structure using DFLUX. Accuracy was checked using laboratory experiments where temperature in mass concrete structures was measured via thermocouples. Temperature predications were similar to experimental data, but more detailed analysis could be performed by using more complex and comprehensive equations that account for mix variability and curing treatments.

\subsection{UHPC types}

Generic Ultra-High Performance Concrete (GUHPC) is a family of concretes that uses locally available materials, usually resulting in lower strength but also in more favorable supply and economics.

Cor-Tuf is a UHPC mix design developed by the Engineer Research and Development Center (ERDC) that can produce $207 \mathrm{MPa}$ (30 ksi) compressive strengths. Cor-Tuf can be sensitive to materials changes (silica fume in particular). Green et al. (2014) reported on the history and usage of UHPC by the U.S. Army Corps of Engineers (USACE) and the ERDC. Over $30 \mathrm{yr}$ of research has occurred with a variety of applications to both civilian and military projects. Various mixtures of ingredients have been tried and selected over the years to produce a concrete mixture with a very low water-to-cement ratio, compressive strengths of nearly $207 \mathrm{MPa}$ (30 ksi), low porosity, and dispersed steel fibers. Various materials have been included such as varying proportions of portland cement, silica fume, silica flour, chemical admixtures, silica-ceramic microspheres, and steel fibers. Optimization 
of material constituents led to the Cor-Tuf and Cor-Tuf Baseline mixtures. Currently, these products are being studied for infrastructure applications including repair and retrofit of armoring systems and marine structures. Case studies have been conducted on UHPC's application in long-term exposure to harsh environments and use in marine navigation structures. Ongoing experiments at the Treat Island Natural Weathering Station near Eastport, ME, subject UHPC beams to drastic freeze-thaw and drying cycles caused by the harsh weather and drastic tides. The Newt Graham Lock and Dam near Tulsa, OK, was retrofitted with UHPC armor plates that were able to achieve compressive strengths of $159 \mathrm{MPa}$ (23 ksi) with in field curing. 


\section{Observations Repository 1.0}

\subsection{Overview of observations repository 1.0}

This chapter contains material properties, describes all experimental activities, and provides test results with minimal explanation or analysis. The main purpose of this chapter is to document all experimental activities, define experimental terminology, and present all measured results that are analyzed and utilized within numerical modeling efforts in subsequent chapters or in a few cases, are available solely for future CORPS-STIF efforts. Experiments were divided into two categories. The first category was physical property experiments where density, compressive strength, and elastic modulus were measured after exposing specimens to seven different curing environments for varying durations, as well as set-time tests at three different temperatures. A total of 649 specimens were tested for physical properties. The second experimental category was measuring thermodynamical properties at several locations within UHPC masses of different shapes and sizes. Ten thermodynamical experiments -- three cubes and seven cylinders -- were performed where temperature measurements were taken during early-age hydration. These experiments are included in the first release of the observations repository (OR) of CORPS-STIF 1.o.

The experiments documented in this OR 1.0 are a portion of the total CORPS-STIF research effort as WD67. Related experiments conducted over the past $5 \mathrm{yr}$ are included in Howard et al. (2018) and Carey et al. $(2019)^{*}$, in which a total of 578 additional experiments are contained. Remaining WD 67 experiments are expected to be housed in the second release of the observations repository (OR 2.0).

\subsection{Material properties and proportions}

Table 2 summarizes the eight constituents that form Cor-Tuf UHPC for this project, alongside proportioning information to produce $2.83 \times 10^{-2} \mathrm{~m}^{3}(1$ $\mathrm{ft} 3$ ) of concrete. Brief material descriptions are also provided in Table 2 in addition to batching quantities and specific gravities. Howard et al. (2018)

\footnotetext{
* Carey, A. S., I. L. Howard, D. A. Scott, R. D. Moser, J. Shannon, and A. Knizley. 2019. Understanding ingredients and proportioning of ultra-high performance concrete via mechanical tests. In review with a peer-reviewed journal.
} 
provides more information about these ingredients. The same relative proportions were used throughout this report, with the only variable being batch size. Actual batch sizes range from $3.96 \times 10^{-3}$ to $7.08 \times 10^{-2} \mathrm{~m}^{3}(0.14$ to $2.5 \mathrm{ft} 3$ ) as described in the following section.

Table 2. Ingredient properties and proportions of UHPC mixture tested.

\begin{tabular}{|c|c|c|c|}
\hline Constituent & $\mathrm{Y}$ & Description & $\begin{array}{c}\text { Batching Quantities for } \\
2.83 \times 10^{-2} \mathrm{~m}^{3} \\
\left(1 \mathrm{ft}^{3}\right)\end{array}$ \\
\hline Air & 0.00 & Air filling voids in UHPC & - \\
\hline Water & 1.00 & Taken from laboratory tap & $4.67 \mathrm{~kg}$ \\
\hline Fibers & 7.85 & Dramix ${ }^{\circledR}$ 3D 55/30 BG & $6.99 \mathrm{~kg}$ \\
\hline Admixture & 1.08 & ADVA® 190 & $0.353 \mathrm{~L}$ \\
\hline Cement & 3.15 & API Class H (HSR) Cement & $22.32 \mathrm{~kg}$ \\
\hline Silica Fume & 2.25 & Elkem Microsilica ES 900-W & $8.71 \mathrm{~kg}$ \\
\hline Silica Flour & 2.65 & SIL-CO-SIL $® 75$ Ground Silica & $6.17 \mathrm{~kg}$ \\
\hline Sand & 2.65 & F-50 Whole Grain Silica & $21.64 \mathrm{~kg}$ \\
\hline
\end{tabular}

$\mathrm{Y}=$ apparent specific gravity.

\subsection{Specimen production}

\subsubsection{Physical property specimen production}

Ingredients were obtained from ERDC in super sacks and lined paper bags. Upon arrival at MSU, all ingredients were transferred into 5-gal plastic buckets stored on pallets in a warehouse that was not temperaturecontrolled. Ingredients were supplied and restocked in April 2017, July 2017, October 2017, and May 2018. At least $12 \mathrm{hr}$ before use in specimen production, ingredients were taken from the warehouse to an airconditioned laboratory (Figure 2a) and batched into 2-gal plastic buckets (Figure 2b). Batches were proportioned for $3.96 \times 10^{-3} \mathrm{~m}^{3}(0.14 \mathrm{ft} 3)$, yielding two $10.2-\mathrm{cm}$ by $20.3-\mathrm{cm}$ (4-in. by 8 -in.) cylindrical specimens. 
Figure 2. (a) conditioned raw materials, (b) batched materials, (c) hand mixed dry materials, (d) adding $80 \%$ of total water, (e) adding admixture, (f) adding fibers, (g) completed mixture, $(\mathrm{h})$ vibrating table, and (i) finished specimen.
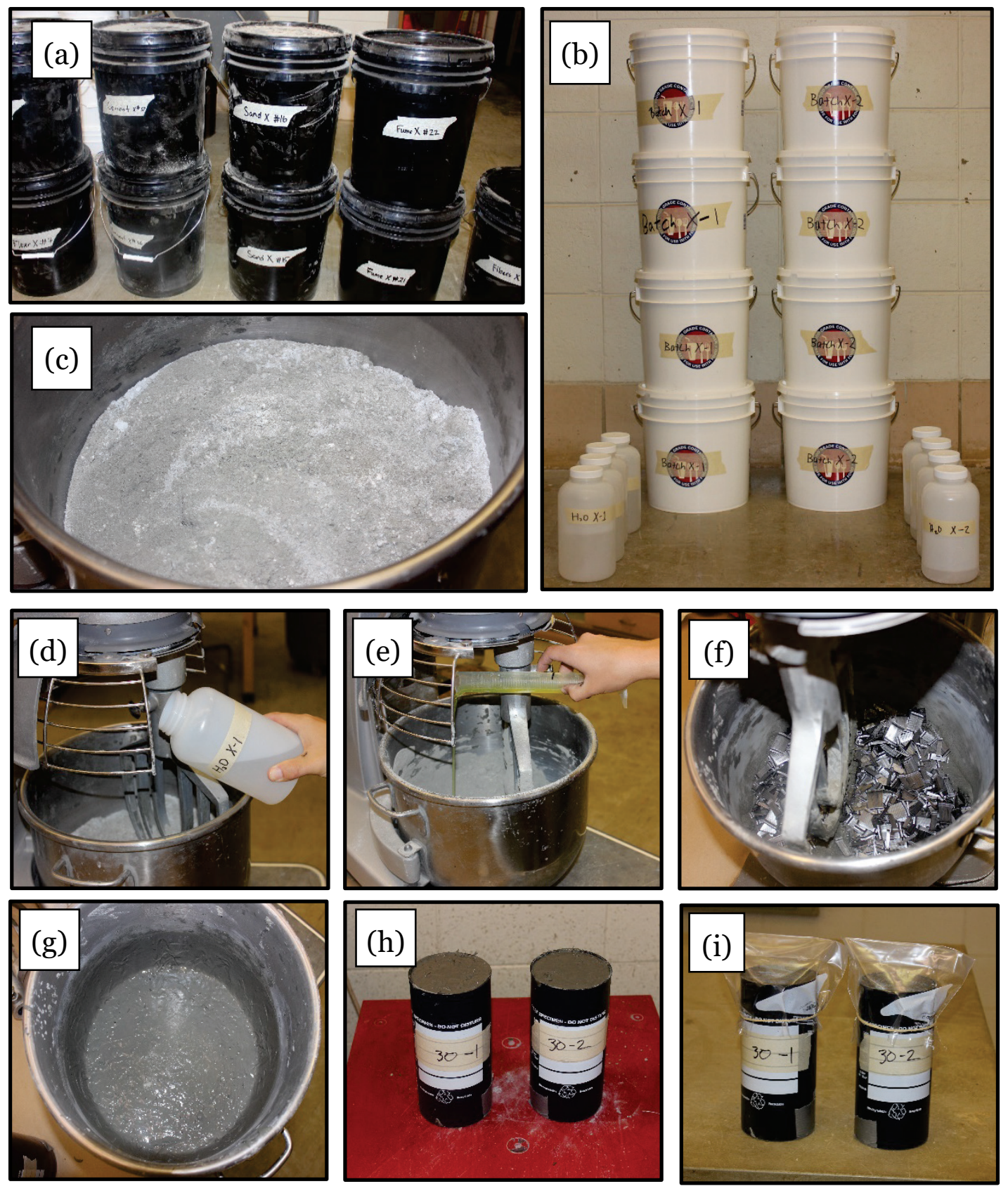

Specimens were mixed in a Hobart HL 200 tabletop mixer with a paddle attachment. After materials were batched, dry ingredients were added to the 19-L (20-quart) mixing bowl (Figure 2c). These ingredients included cement, silica fume, silica flour, and sand. Dry ingredients were blended on the lowest mixer setting for approximately $90 \mathrm{sec}$. Then, $80 \%$ of the total amount of water was added to the dry materials (Figure 2d) and 
mixed at the same low speed for an additional $90 \mathrm{sec}$. Next, admixture was introduced to the mix (Figure 2e), and the remaining $20 \%$ of water was used to rinse the graduated cylinder and added to the mixture. Mixing then continued at a slightly faster speed and was stopped every 5 min to scrape dry materials off the edges of the bowl and paddle attachment. Mixing continued until the mixture was "broken over" (reached a fluid self-consolidating consistency). Fibers were then added to the broken-over mixture and mixed until evenly dispersed (Figure 2f). Once fibers were dispersed, mixing was stopped (Figure 2g), and the mixture was placed into the cylindrical molds in two lifts. Between lifts, specimens were placed on a vibrating table for two minutes to remove air bubbles without altering fiber orientation (Figure $2 \mathrm{~h}$ ). After vibration, plastic bags were placed over the specimens and secured with a rubber band to prevent evaporation (Figure 2i).

\subsubsection{Casting thermodynamical property specimens}

Ten total thermodynamical property specimens had thermocouples (TC) placed throughout the specimens to measure temperature versus time during hydration. Three cubes with side lengths of $10 \mathrm{~cm}, 20 \mathrm{~cm}$, and 40 $\mathrm{cm}$ were cast into wooden molds. Three cylinders of dimensions $7.6 \mathrm{~cm}$ by $15.2 \mathrm{~cm}$ ( 3 in. by 6 in.), $10.2 \mathrm{~cm}$ by $20.3 \mathrm{~cm}$ ( 4 in. by 8 in.), and $15.2 \mathrm{~cm}$ by $30.5 \mathrm{~cm}$ (6 in. by $12 \mathrm{in}$.) were cast into standard polypropylene (PP) concrete cylinder molds to evaluate the effects of size. Additionally, four cylinders tested different boundary conditions using $15.2 \mathrm{~cm}$ by $15.2 \mathrm{~cm}$ (6 in. by 6 in.) and $15.2 \mathrm{~cm}$ by $30.5 \mathrm{~cm}$ (6 in. by $12 \mathrm{in}$.) cylinders made from both polyvinyl chloride pipe (PVC) and PP. Table 3 shows the total number of thermocouples used for each specimen, testing location, mold material, and each specimen's acronym to be used throughout the remainder of this report. All thermodynamical property specimens were mixed and tested at MSU, except for the 40-cm cube that occurred at ERDC. 
Table 3. Thermodynamical testing overview.

\begin{tabular}{|c|c|c|c|c|}
\hline Symbol & Dimensions & $\begin{array}{c}\text { Mold } \\
\text { Material }\end{array}$ & $\begin{array}{c}\text { Total TC } \\
\text { Used }\end{array}$ & $\begin{array}{c}\text { Test } \\
\text { Location }\end{array}$ \\
\hline $10 \mathrm{~cm}-\mathrm{Cu}$ & 10-cm cube & Wood & 17 & MSU \\
\hline $20 \mathrm{~cm}-\mathrm{Cu}$ & $20-\mathrm{cm}$ cube & Wood & 22 & MSU \\
\hline $40 \mathrm{~cm}-\mathrm{Cu}$ & $40-\mathrm{cm}$ cube & Wood & 46 & ERDC \\
\hline $7.6 \mathrm{~cm}-\mathrm{Cy}$ & $\begin{array}{c}7.6-\mathrm{cm} \text { diameter,15.2-cm } \\
\text { height cylinder }\end{array}$ & PP & 11 & MSU \\
\hline $10.2 \mathrm{~cm}-\mathrm{Cy}$ & $\begin{array}{c}10.2-\mathrm{cm} \text { diameter, } 20.3-\mathrm{cm} \\
\text { height cylinder }\end{array}$ & PP & 11 & MSU \\
\hline $15.2 \mathrm{~cm}-\mathrm{Cy}$ & $\begin{array}{c}15.2-\mathrm{cm} \text { diameter, 30.5-cm } \\
\text { height cylinder }\end{array}$ & PP & 14 & MSU \\
\hline $15.2 \times 15.2-\mathrm{PP}$ & $\begin{array}{c}15.2-\mathrm{cm} \text { diameter, 15.2-cm } \\
\text { height cylinder }\end{array}$ & PP & 8 & MSU \\
\hline $15.2 \times 30.5-\mathrm{PP}$ & $\begin{array}{c}15.2-\mathrm{cm} \text { diameter, 30.5-cm } \\
\text { height cylinder }\end{array}$ & PP & 8 & MSU \\
\hline $15.2 \times 15.2-\mathrm{PVC}$ & $\begin{array}{c}15.2-\mathrm{cm} \text { diameter, 15.2-cm } \\
\text { height cylinder }\end{array}$ & PVC & 8 & MSU \\
\hline $15.2 \times 30.5-\mathrm{PVC}$ & $\begin{array}{c}15.2-\mathrm{cm} \text { diameter, 30.5-cm } \\
\text { height cylinder }\end{array}$ & PVC & 8 & MSU \\
\hline
\end{tabular}

\subsubsection{Casting $10 \mathrm{~cm}-\mathrm{Cu}, 20 \mathrm{~cm}-\mathrm{Cu}$, and $40 \mathrm{~cm}-\mathrm{Cu}$}

Three cubes were constructed using a 19-mm-thick sheet of birch hardwood with sides of internal dimensions of $10 \mathrm{~cm}(10 \mathrm{~cm}-\mathrm{Cu}), 20 \mathrm{~cm}$ (20cm-Cu), and $40 \mathrm{~cm}(40 \mathrm{~cm}-\mathrm{Cu})$. Hardwood was cut into panels (Figure $3 \mathrm{a})$ that were then attached using 5.1-cm-long screws (Figure $3 \mathrm{~b}$ ). After each cube was constructed (Figure 3c), edges were sanded (Figure 3d). Six small holes were then drilled to allow thermocouples to be placed throughout each cube (Figure 3e). Thermocouples were attached to insulated copper wire via heat shrink and placed at known locations in each cube (Figures $3 \mathrm{f}-\mathrm{h}$ ). Winches were used to keep the copper wiring taut in the $40 \mathrm{~cm}-\mathrm{Cu}$ but not in $10 \mathrm{~cm}-\mathrm{Cu}$ and $20 \mathrm{~cm}-\mathrm{Cu}$ due to size constraints. Tables 4-7 define Cartesian coordinates for each thermocouple used in the three cubes. For each cube, the origin is defined as the bottom left corner as shown in Figure 4a.

The UHPC mixture for $40 \mathrm{~cm}-\mathrm{Cu}$ was prepared at ERDC using a high-shear mixer with a larger mixing capacity than the resources available at MSU. Materials were batched to yield $7.08 \times 10^{-2} \mathrm{~m}^{3}(2.5 \mathrm{ft} 3)$ of UHPC for $40 \mathrm{~cm}-$ 
$\mathrm{Cu}$. To produce $10 \mathrm{~cm}-\mathrm{Cu}$ and $20 \mathrm{~cm}-\mathrm{Cu}, 2$ batches of $5.38 \times 10^{-3} \mathrm{~m}^{3}(0.19$ $\mathrm{ft} 3$ ) were prepared simultaneously in the HL-200 mixer shown in Figure 2 and placed into the molds. For all three cube experiments, lids were fixed in place with screws after molds were filled.

Figure 3. Mold preparation for thermodynamical property specimens-cubes; (a) cut panels of 19-mm-thick birch hardwood, (b) constructing the cube, (c) built cube, (d) sanding edges, (e) running thermocouples, (f) finished $10 \mathrm{~cm}-\mathrm{Cu}$, (g) finished $20 \mathrm{~cm}-\mathrm{Cu}$, and $(\mathrm{h})$ finished $40 \mathrm{~cm}-\mathrm{Cu}$.
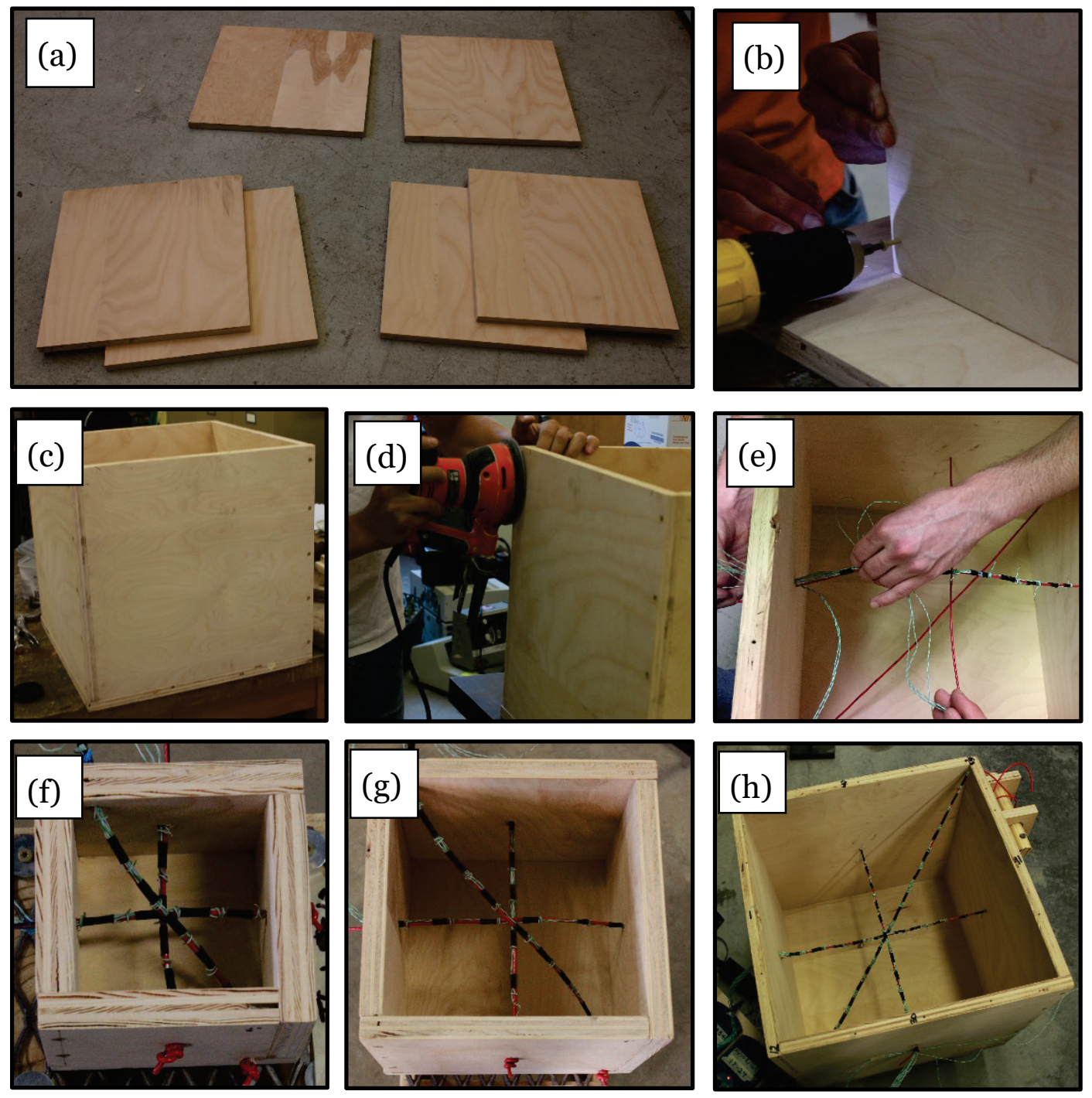
Table 4. Cartesian coordinates of thermocouples 1 to 34 in $40 \mathrm{~cm}-\mathrm{Cu}$.

\begin{tabular}{|c|c|c|c|}
\hline $\begin{array}{c}\text { Thermocouple } \\
\text { ID }\end{array}$ & $\begin{array}{l}x \text {-coordinate } \\
(\mathrm{cm})\end{array}$ & $\begin{array}{c}y \text {-coordinate } \\
(\mathrm{cm})\end{array}$ & $\begin{array}{l}\text { z-coordinate } \\
(\mathrm{cm})\end{array}$ \\
\hline $40 \mathrm{~cm}-1$ & 0 & 20 & 20 \\
\hline $40 \mathrm{~cm}-2$ & 4 & 20 & 20 \\
\hline $40 \mathrm{~cm}-3$ & 8 & 20 & 20 \\
\hline $40 \mathrm{~cm}-4$ & 12 & 20 & 20 \\
\hline $40 \mathrm{~cm}-5$ & 16 & 20 & 20 \\
\hline $40 \mathrm{~cm}-6$ & 20 & 20 & 20 \\
\hline $40 \mathrm{~cm}-7$ & 24 & 20 & 20 \\
\hline $40 \mathrm{~cm}-8$ & 28 & 20 & 20 \\
\hline $40 \mathrm{~cm}-9$ & 32 & 20 & 20 \\
\hline $40 \mathrm{~cm}-10$ & 36 & 20 & 20 \\
\hline $40 \mathrm{~cm}-11$ & 40 & 20 & 20 \\
\hline $40 \mathrm{~cm}-12$ & 0 & 0 & 0 \\
\hline $40 \mathrm{~cm}-13$ & 2.4 & 2.4 & 2.4 \\
\hline $40 \mathrm{~cm}-14$ & 4.7 & 4.7 & 4.7 \\
\hline $40 \mathrm{~cm}-15$ & 7.1 & 7.1 & 7.1 \\
\hline $40 \mathrm{~cm}-16$ & 9.4 & 9.4 & 9.4 \\
\hline $40 \mathrm{~cm}-17$ & 11.8 & 11.8 & 11.8 \\
\hline $40 \mathrm{~cm}-18$ & 14.1 & 14.1 & 14.1 \\
\hline 40cm-19 & 16.5 & 16.5 & 16.5 \\
\hline $40 \mathrm{~cm}-20$ & 18.8 & 18.8 & 18.8 \\
\hline $40 \mathrm{~cm}-21$ & 21.2 & 21.2 & 21.2 \\
\hline $40 \mathrm{~cm}-22$ & 23.5 & 23.5 & 23.5 \\
\hline $40 \mathrm{~cm}-23$ & 25.9 & 25.9 & 25.9 \\
\hline $40 \mathrm{~cm}-24$ & 28.2 & 28.2 & 28.2 \\
\hline $40 \mathrm{~cm}-25$ & 30.6 & 30.6 & 30.6 \\
\hline 40cm-26 & 32.9 & 32.9 & 32.9 \\
\hline $40 \mathrm{~cm}-27$ & 35.3 & 35.3 & 35.3 \\
\hline $40 \mathrm{~cm}-28$ & 37.6 & 37.6 & 37.6 \\
\hline $40 \mathrm{~cm}-29$ & 40 & 40 & 40 \\
\hline $40 \mathrm{~cm}-30$ & 20 & 0 & 20 \\
\hline
\end{tabular}




\begin{tabular}{|l|l|l|l|}
\hline $\begin{array}{c}\text { Thermocouple } \\
\text { ID }\end{array}$ & $\begin{array}{c}\text { x-coordinate } \\
(\mathrm{cm})\end{array}$ & $\begin{array}{c}\text { y-coordinate } \\
(\mathrm{cm})\end{array}$ & $\begin{array}{c}\text { z-coordinate } \\
(\mathrm{cm})\end{array}$ \\
\hline $40 \mathrm{~cm}-31$ & 20 & 4 & 20 \\
\hline $40 \mathrm{~cm}-32$ & 20 & 8 & 20 \\
\hline $40 \mathrm{~cm}-33$ & 20 & 12 & 20 \\
\hline $40 \mathrm{~cm}-34$ & 20 & 16 & 20 \\
\hline
\end{tabular}

Table 5. Cartesian coordinates of thermocouples 35 to 40 in $40 \mathrm{~cm}-\mathrm{Cu}$.

\begin{tabular}{|l|l|l|l|}
\hline $\begin{array}{c}\text { Thermocouple } \\
\text { ID }\end{array}$ & $\begin{array}{c}\text { x-coordinate } \\
(\mathrm{cm})\end{array}$ & $\begin{array}{c}y \text {-coordinate } \\
(\mathrm{cm})\end{array}$ & $\begin{array}{c}z \text {-coordinate } \\
(\mathrm{cm})\end{array}$ \\
\hline $40 \mathrm{~cm}-35$ & 20 & 20 & 20 \\
\hline $40 \mathrm{~cm}-36$ & 20 & 24 & 20 \\
\hline $40 \mathrm{~cm}-37$ & 20 & 28 & 20 \\
\hline $40 \mathrm{~cm}-38$ & 20 & 32 & 20 \\
\hline $40 \mathrm{~cm}-39$ & 20 & 36 & 20 \\
\hline $40 \mathrm{~cm}-40$ & 20 & 40 & 20 \\
\hline
\end{tabular}

Table 6: Cartesian coordinates of thermocouples in $20 \mathrm{~cm}-\mathrm{Cu}$.

\begin{tabular}{|l|l|l|l|}
\hline $\begin{array}{c}\text { Thermocouple } \\
\text { ID }\end{array}$ & $\begin{array}{c}\text { x-coordinate } \\
(\mathrm{cm})\end{array}$ & $\begin{array}{c}\text { y-coordinate } \\
(\mathrm{cm})\end{array}$ & $\begin{array}{c}\text { z-coordinate } \\
(\mathrm{cm})\end{array}$ \\
\hline $20 \mathrm{~cm}-1$ & 0 & 10 & 10 \\
\hline $20 \mathrm{~cm}-2$ & 4 & 10 & 10 \\
\hline $20 \mathrm{~cm}-3$ & 8 & 10 & 10 \\
\hline $20 \mathrm{~cm}-4$ & 12 & 10 & 10 \\
\hline $20 \mathrm{~cm}-5$ & 16 & 10 & 10 \\
\hline $20 \mathrm{~cm}-6$ & 20 & 10 & 10 \\
\hline $20 \mathrm{~cm}-7$ & 10 & 0 & 10 \\
\hline $20 \mathrm{~cm}-8$ & 10 & 4 & 10 \\
\hline $20 \mathrm{~cm}-9$ & 10 & 8 & 10 \\
\hline $20 \mathrm{~cm}-10$ & 10 & 12 & 10 \\
\hline $20 \mathrm{~cm}-11$ & 10 & 16 & 10 \\
\hline $20 \mathrm{~cm}-12$ & 10 & 20 & 10 \\
\hline $20 \mathrm{~cm}-13$ & 0 & 0 & 0 \\
\hline $20 \mathrm{~cm}-14$ & 2.5 & 2.5 & 2.5 \\
\hline
\end{tabular}




\begin{tabular}{|l|l|l|l|}
\hline $\begin{array}{c}\text { Thermocouple } \\
\text { ID }\end{array}$ & $\begin{array}{c}\text { x-coordinate } \\
(\mathbf{c m})\end{array}$ & $\begin{array}{c}\text { y-coordinate } \\
(\mathbf{c m})\end{array}$ & $\begin{array}{c}\text { z-coordinate } \\
(\mathbf{c m})\end{array}$ \\
\hline $20 \mathrm{~cm}-15$ & 5 & 5 & 5 \\
\hline $20 \mathrm{~cm}-16$ & 7.5 & 7.5 & 7.5 \\
\hline $20 \mathrm{~cm}-17$ & 10 & 10 & 10 \\
\hline $20 \mathrm{~cm}-18$ & 12.5 & 12.5 & 12.5 \\
\hline $20 \mathrm{~cm}-19$ & 15 & 15 & 15 \\
\hline $20 \mathrm{~cm}-20$ & 17.5 & 17.5 & 17.5 \\
\hline $20 \mathrm{~cm}-21$ & 20 & 20 & 20 \\
\hline
\end{tabular}

Table 7. Cartesian coordinates of thermocouples in $10 \mathrm{~cm}-\mathrm{Cu}$.

\begin{tabular}{|l|l|l|l|}
\hline $\begin{array}{c}\text { Thermocouple } \\
\text { ID }\end{array}$ & $\begin{array}{c}\text { x-coordinate } \\
(\mathrm{cm})\end{array}$ & $\begin{array}{c}\text { y-coordinate } \\
(\mathrm{cm})\end{array}$ & $\begin{array}{c}\text { z-coordinate } \\
(\mathrm{cm})\end{array}$ \\
\hline $10 \mathrm{~cm}-1$ & 0 & 5 & 5 \\
\hline $10 \mathrm{~cm}-2$ & 2.5 & 5 & 5 \\
\hline $10 \mathrm{~cm}-3$ & 5 & 5 & 5 \\
\hline $10 \mathrm{~cm}-4$ & 7.5 & 5 & 5 \\
\hline $10 \mathrm{~cm}-5$ & 10 & 5 & 5 \\
\hline $10 \mathrm{~cm}-6$ & 5 & 0 & 5 \\
\hline $10 \mathrm{~cm}-7$ & 5 & 2.5 & 5 \\
\hline $10 \mathrm{~cm}-8$ & 5 & 5 & 5 \\
\hline $10 \mathrm{~cm}-9$ & 5 & 7.5 & 5 \\
\hline $10 \mathrm{~cm}-10$ & 5 & 10 & 5 \\
\hline $10 \mathrm{~cm}-11$ & 0 & 0 & 0 \\
\hline $10 \mathrm{~cm}-12$ & 2 & 2 & 2 \\
\hline $10 \mathrm{~cm}-13$ & 4 & 4 & 4 \\
\hline $10 \mathrm{~cm}-14$ & 6 & 6 & 6 \\
\hline $10 \mathrm{~cm}-15$ & 8 & 8 & 10 \\
\hline $10 \mathrm{~cm}-16$ & 10 & 10 & \\
\hline
\end{tabular}


Figure 4. Origin for (a) cubes and (b) cylinders.
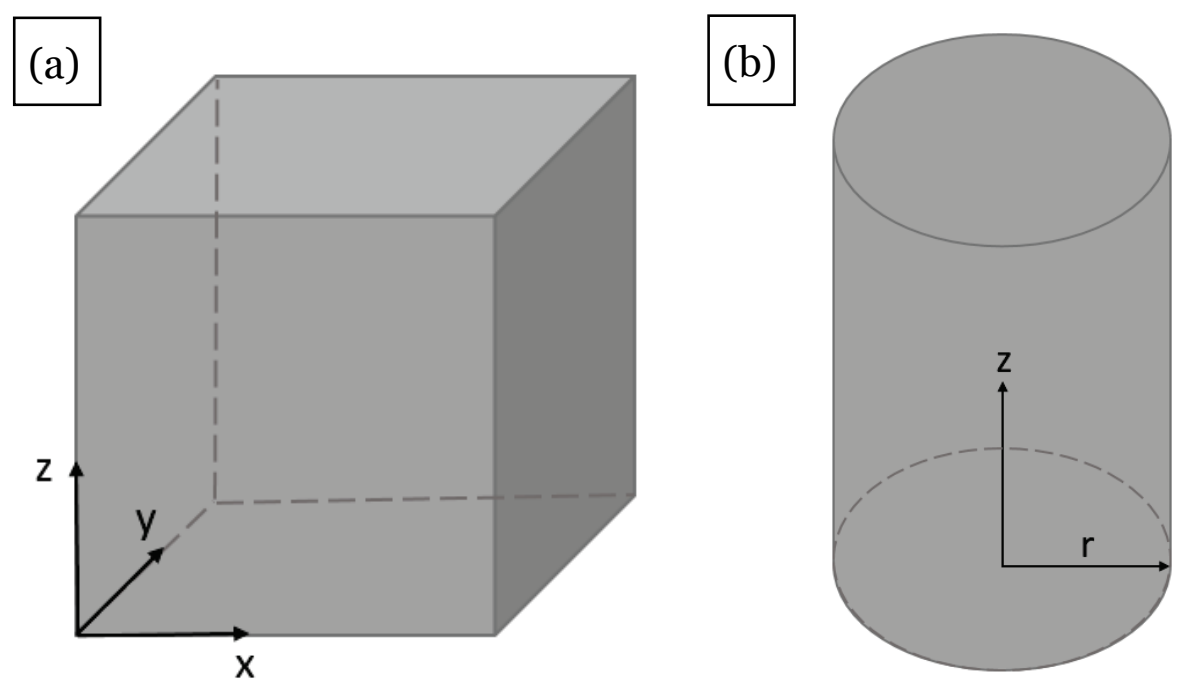

\subsubsection{Casting $7.6 \mathrm{~cm}-\mathrm{Cy}, 10.2 \mathrm{~cm}-\mathrm{Cy}$, and $15.2 \mathrm{~cm}-\mathrm{Cy}$}

Three cylinders were also produced for thermal testing to investigate size effects. $7.6-\mathrm{cm}$ by $15.2-\mathrm{cm}(7.6 \mathrm{~cm}-\mathrm{Cy}), 10.2-\mathrm{cm}$ by $20.3-\mathrm{cm}(10.2 \mathrm{~cm}-\mathrm{Cy})$, and $15.2-\mathrm{cm}$ by $30.5-\mathrm{cm}(15.2 \mathrm{~cm}-\mathrm{Cy})$ plastic concrete cylinder molds were used (Figure 5a). Thermocouples were attached to a plastic rod via heatshrink tubing at varying radial distances and were then taped inside cylinders at varying heights (Figure $5 \mathrm{~b}$ ). Tables 8 to 10 define radial coordinates for each thermocouple in the three cylinders. The origin is defined as the bottom center of a cylinder as shown in Figure $4 \mathrm{~b}$. To produce these specimens, two batches of $5.38 \times 10^{-3} \mathrm{~m}^{3}\left(0.19 \mathrm{ft}^{3}\right)$ size were prepared and placed into molds. 
Figure 5. Mold preparation for thermodynamical property specimens - cylinders;

(a) PP Gilson molds, (b) thermocouples attached, and (c) PVC molds.
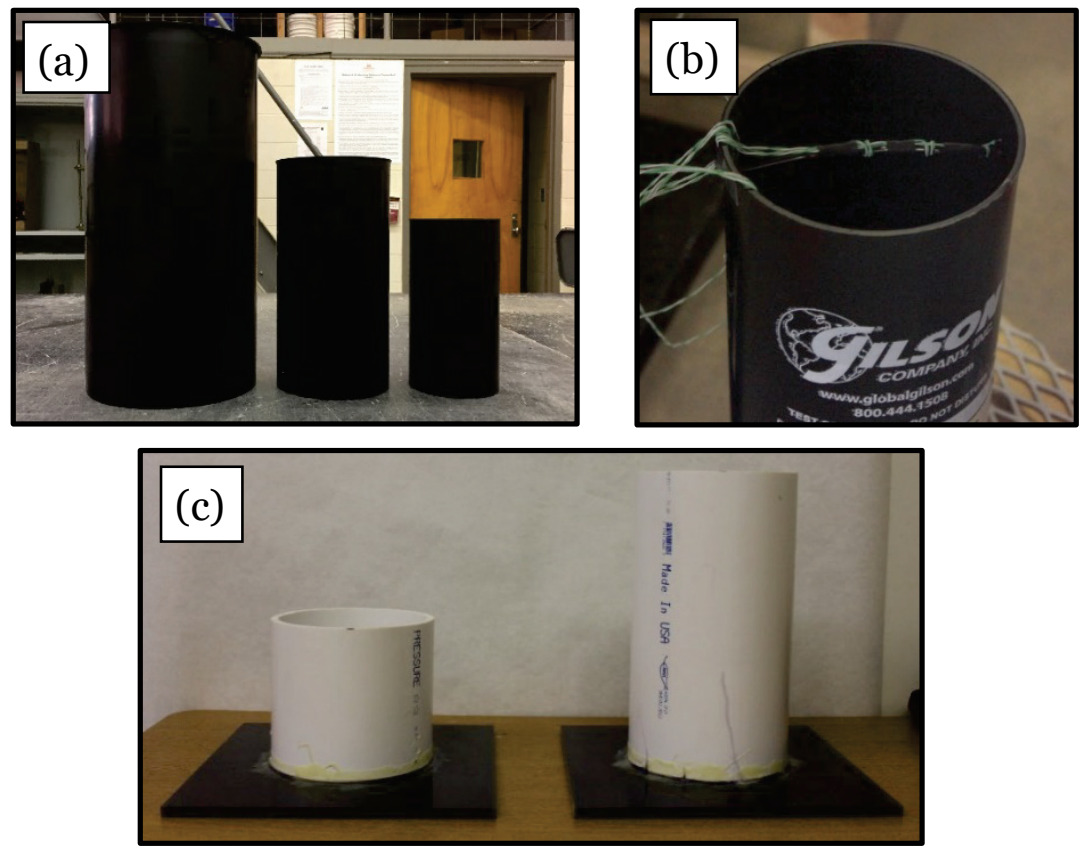

Table 8. Radial coordinates of thermocouples in 15.2cm-Cy.

\begin{tabular}{|l|l|l|}
\hline Thermocouple ID & r-coordinate $(\mathbf{c m})$ & z-coordinate $(\mathrm{cm})$ \\
\hline $15.2 \mathrm{~cm}-1$ & 7.6 & 0 \\
\hline $15.2 \mathrm{~cm}-2$ & 3.8 & 0 \\
\hline $15.2 \mathrm{~cm}-3$ & 0 & 0 \\
\hline $15.2 \mathrm{~cm}-4$ & 7.6 & 10.2 \\
\hline $15.2 \mathrm{~cm}-5$ & 3.8 & 10.2 \\
\hline $15.2 \mathrm{~cm}-6$ & 0 & 10.2 \\
\hline $15.2 \mathrm{~cm}-7$ & 7.6 & 20.3 \\
\hline $15.2 \mathrm{~cm}-8$ & 3.8 & 20.3 \\
\hline $15.2 \mathrm{~cm}-9$ & 0 & 20.3 \\
\hline $15.2 \mathrm{~cm}-10$ & 7.6 & 30.5 \\
\hline $15.2 \mathrm{~cm}-11$ & 3.8 & 30.5 \\
\hline $15.2 \mathrm{~cm}-12$ & 0 & 30.5 \\
\hline
\end{tabular}


Table 9. Radial coordinates of thermocouples in 10.2cm-Cy.

\begin{tabular}{|l|l|l|}
\hline Thermocouple ID & r-coordinate $(\mathrm{cm})$ & z-coordinate $(\mathrm{cm})$ \\
\hline $10.2 \mathrm{~cm}-1$ & 5.1 & 0 \\
\hline $10.2 \mathrm{~cm}-2$ & 2.5 & 0 \\
\hline $10.2 \mathrm{~cm}-3$ & 0 & 0 \\
\hline $10.2 \mathrm{~cm}-4$ & 5.1 & 10.2 \\
\hline $10.2 \mathrm{~cm}-5$ & 2.5 & 10.2 \\
\hline $10.2 \mathrm{~cm}-6$ & 0 & 10.2 \\
\hline $10.2 \mathrm{~cm}-7$ & 5.1 & 20.3 \\
\hline $10.2 \mathrm{~cm}-8$ & 2.5 & 20.3 \\
\hline $10.2 \mathrm{~cm}-9$ & 0 & 20.3 \\
\hline
\end{tabular}

Table 10. Radial coordinates of thermocouples in 7.6cm-Cy.

\begin{tabular}{|l|l|l|}
\hline Thermocouple ID & r-coordinate $(\mathbf{c m})$ & z-coordinate $(\mathrm{cm})$ \\
\hline $7.6 \mathrm{~cm}-1$ & 3.8 & 0 \\
\hline $7.6 \mathrm{~cm}-2$ & 1.9 & 0 \\
\hline $7.6 \mathrm{~cm}-3$ & 0 & 0 \\
\hline $7.6 \mathrm{~cm}-4$ & 3.8 & 7.6 \\
\hline $7.6 \mathrm{~cm}-5$ & 1.9 & 7.6 \\
\hline $7.6 \mathrm{~cm}-6$ & 0 & 7.6 \\
\hline $7.6 \mathrm{~cm}-7$ & 3.8 & 15.2 \\
\hline $7.6 \mathrm{~cm}-8$ & 1.9 & 15.2 \\
\hline $7.6 \mathrm{~cm}-9$ & 0 & 15.2 \\
\hline
\end{tabular}

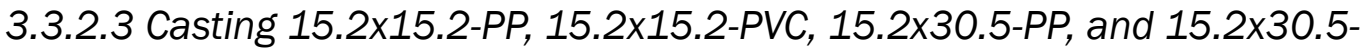
$P V C$

Four cylinders were also produced for thermal testing to investigate effects of varying boundary conditions. One $15.2-\mathrm{cm}$ by $30.5-\mathrm{cm}$ PP plastic concrete cylinder mold (15.2x30.5-PP), one modified $15.2-\mathrm{cm}$ by $15.2-\mathrm{cm}$ PP concrete cylinder mold (15.2x15.2-PP), one 15.2-cm by 30.5-cm PVC mold (15.2x30.5PVC), and one 15.2-cm by 15.2-cm PVC mold (15.2x15.2-PVC) were used. The 15.2X15.2-PP mold was made by cutting off the top of a standard $15.2-\mathrm{cm}$ by 30.5-cm PP mold. PVC molds were cut from 15.2-cm (6-in.) inner diameter 
PVC pipe and glued to a PVC base plate of the same thickness (Figure $5 \mathrm{c}$ ). PVC pipe used was schedule 40 PVC. Thermocouples were attached to plastic rods via heat-shrink tubing at various radial distances and were then taped inside cylinders at varying heights in a similar manner as previously described. Table 11 defines radial coordinates for $15.2 \times 15.2-\mathrm{PP}$ and $15.2 \times 15.2-$ PVC. Table 12 defines radial coordinates for 15.2x30.5-PP and 15.2x30.5PVC. To produce these specimens, four batches of $5.38 \times \times 10^{-3} \mathrm{~m}^{3}\left(0.19 \mathrm{ft}^{3}\right)$ were prepared and placed into the molds.

Table 11. Radial coordinates of thermocouples in 15.2x15.2-PP and 15.2x15.2-PVC.

\begin{tabular}{|l|l|l|}
\hline Thermocouple ID & r-coordinate $(\mathbf{c m})$ & z-coordinate $(\mathbf{c m})$ \\
\hline TC1 & 7.6 & 0 \\
\hline TC2 & 3.8 & 0 \\
\hline TC3 & 0 & 0 \\
\hline TC4 & 7.6 & 7.6 \\
\hline TC5 & 3.8 & 7.6 \\
\hline TC6 & 0 & 7.6 \\
\hline
\end{tabular}

Table 12. Radial coordinates of thermocouples in 15.2×30.5-PP and 15.2x30.5-PVC.

\begin{tabular}{|l|l|l|}
\hline Thermocouple ID & r-coordinate $(\mathrm{cm})$ & z-coordinate $(\mathrm{cm})$ \\
\hline TC1 & 7.6 & 0 \\
\hline TC2 & 3.8 & 0 \\
\hline TC3 & 0 & 0 \\
\hline TC4 & 7.6 & 10.2 \\
\hline TC5 & 3.8 & 10.2 \\
\hline TC6 & 0 & 10.2 \\
\hline
\end{tabular}

In addition to thermocouples (TCs) measuring temperature inside each mold, ambient temperature was measured at different locations (Figure 6). For all cubes and cylinders, TCs were attached directly to the exterior of each mold to measure air temperature. Additionally, TCs were placed $61 \mathrm{~cm}$ ( $2 \mathrm{ft}$ ) from specimens to measure ambient air temperature in each testing facility during testing. Figure 7 shows each mold in its testing location. All molds were placed on grated metal stands $15.2 \mathrm{~cm}$ (6 in.) above the ground to allow air flow below the mold to eliminate any ground insulation effects (Figures $7 \mathrm{a}, 7 \mathrm{~b}$, and $7 \mathrm{~d}$ ). The $40 \mathrm{~cm}-\mathrm{Cu}$ was placed on casters that raised the specimen $15.2 \mathrm{~cm}$ ( $6 \mathrm{in}$.) above the ground instead of on a stand due to its 
weight when filled with UHPC (Figure 7c). Thermocouples were then attached to data loggers. UHPC was produced identically to section 3.3.1 for the respective batch sizes required. After fiber addition and mixing, the mixture was then placed in molds with thermocouples to record temperatures over time in and around hydrating specimens. All materials were placed in one lift, and molds were not vibrated.

Figure 6: Ambient thermocouple layouts;

(a) $10 \mathrm{~cm}-\mathrm{Cu}$ and $20 \mathrm{~cm}-\mathrm{Cu}$, (b) $7.6 \mathrm{~cm}-\mathrm{Cy}, 10.2 \mathrm{~cm}-\mathrm{Cy}$, and $15.2 \mathrm{~cm}-\mathrm{Cy}$, (c) $40 \mathrm{~cm}-\mathrm{Cu}$,

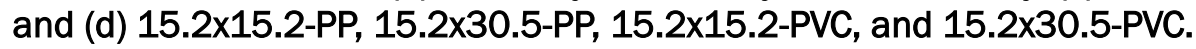
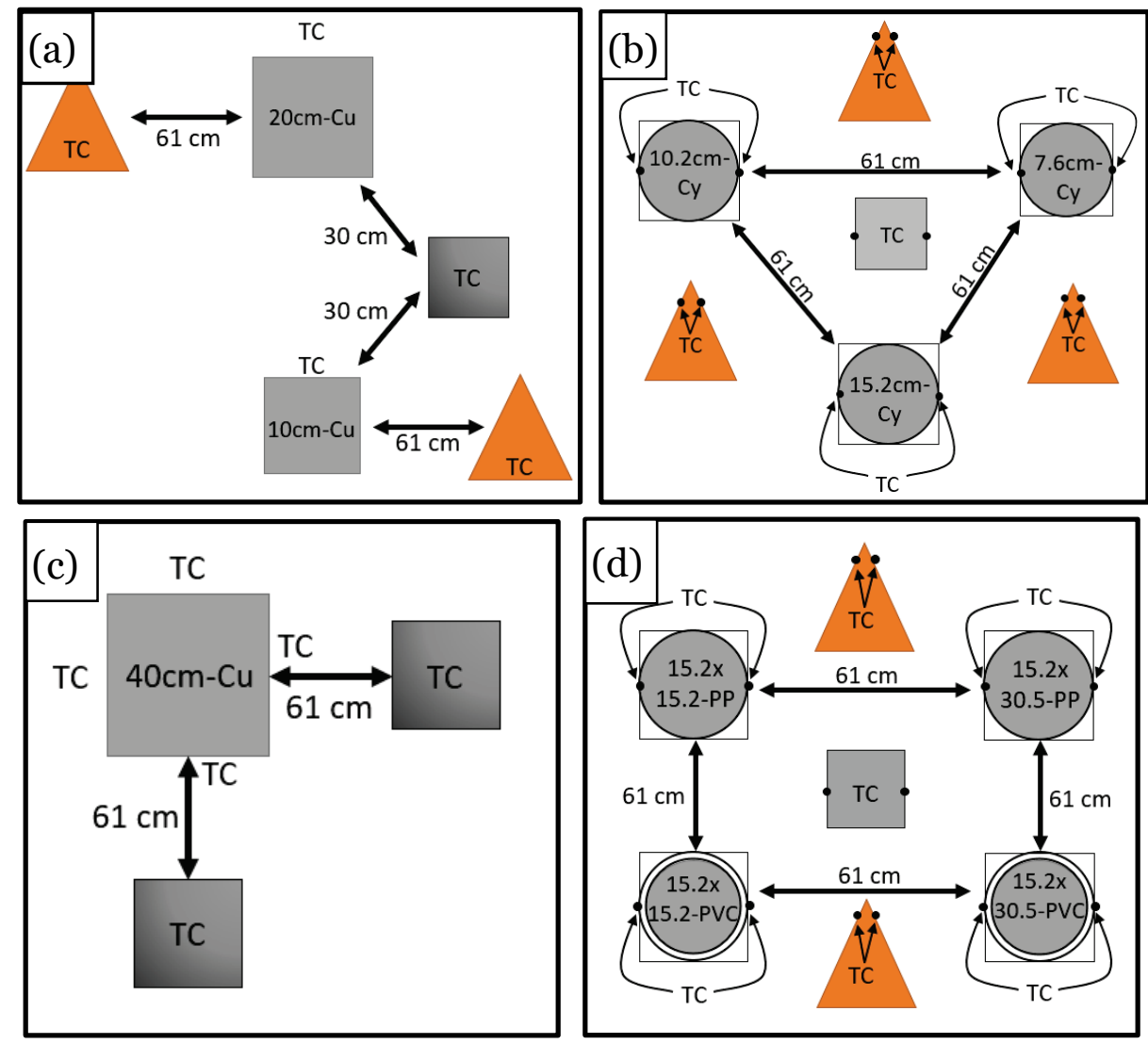
Figure 7. Thermodynamical testing setup;

(a) $10 \mathrm{~cm}-\mathrm{Cu}$ and $20 \mathrm{~cm}-\mathrm{Cu}$, (b) $7.6 \mathrm{~cm}-\mathrm{Cy}, 10.2 \mathrm{~cm}-\mathrm{Cy}$, and $15.2 \mathrm{~cm}-\mathrm{Cy}$, (c) $40 \mathrm{~cm}-\mathrm{Cu}$,

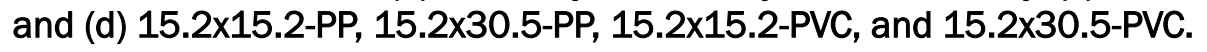
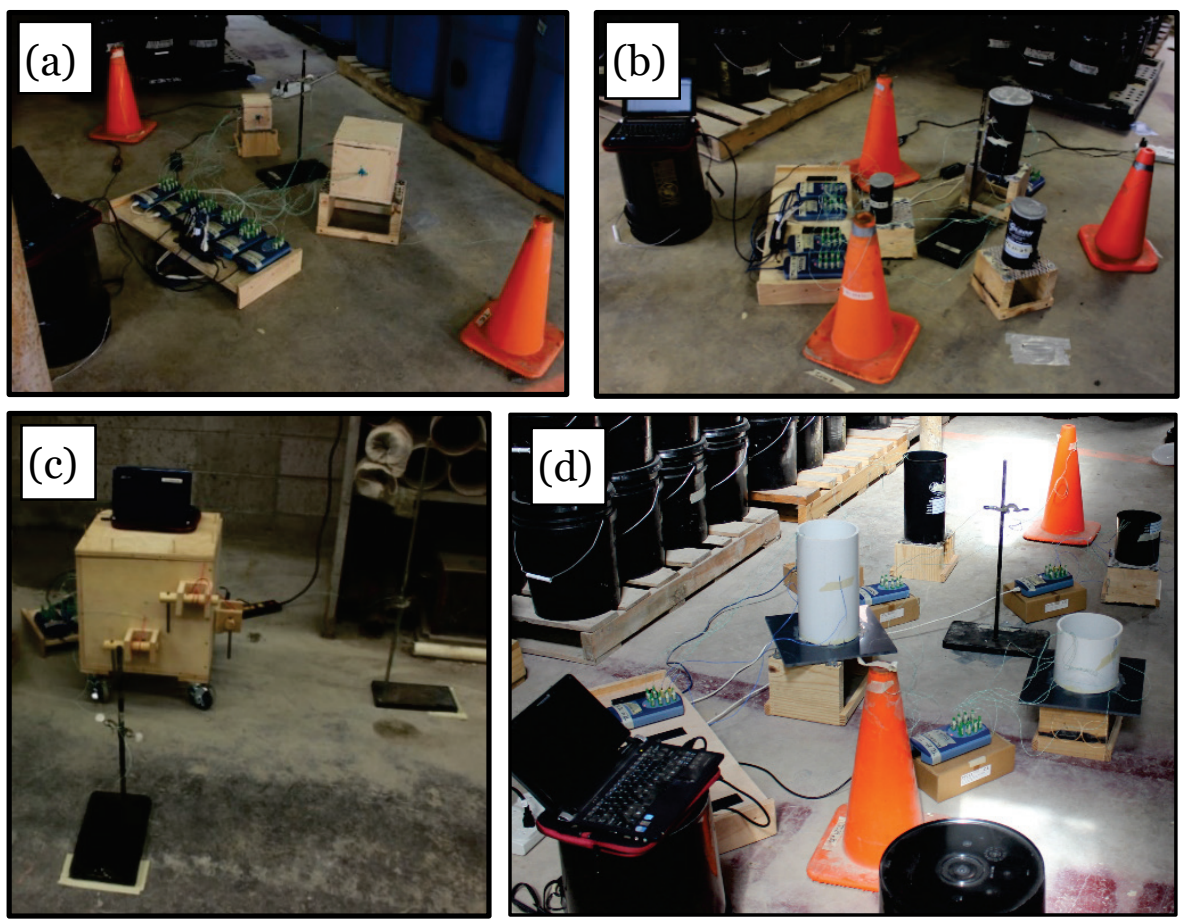

\subsection{Curing methods and maturity calculations for mechanical property data collection}

\subsubsection{Curing environments and temperature measurement}

This study utilized seven curing environments (CEs), denoted $\mathrm{CE}_{1}$ to $\mathrm{CE}_{7}$, which are described in Table 13 and shown in Figure 8. CEs were often kept in accordance to ASTM C192 (2016) Standard Practice for Making and Curing Concrete Test Specimens in the Laboratory. Curing Environments $\mathrm{CE}_{2}, \mathrm{CE}_{3}, \mathrm{CE}_{4}$, and $\mathrm{CE}_{5}$ were also maintained in accordance with ASTM C511 (2013) Standard Specifications for Mixing Rooms, Moist Cabinets, Moist Rooms, and Water Storage Tanks Used in the Testing of Hydraulic Cements and Concretes. All specimens placed in $\mathrm{CE}_{1}, \mathrm{CE}_{6}$, and $\mathrm{CE}_{7}$ were contained in plastic molds. Specimens were removed from plastic molds before placement in $\mathrm{CE}_{2}, \mathrm{CE}_{3}, \mathrm{CE}_{4}$, or $\mathrm{CE}_{5}$. A description of curing environments $\mathrm{CE}_{1}$ to $\mathrm{CE}_{7}$ are contained in the following sections. 
Table 13. Curing environment (CE) description and temperature setting.

\begin{tabular}{|l|l|l|}
\hline Curing Environment & \multicolumn{1}{|c|}{ Description } & \multicolumn{1}{c|}{ Temperature Setting } \\
\hline $\mathrm{CE}_{1}$ & Lab Bench & Room Temperature $\left(21 \pm 0.8^{\circ} \mathrm{C}\right)$ \\
\hline $\mathrm{CE}_{2}$ & Cold Bath & $10^{\circ} \mathrm{C}$ \\
\hline $\mathrm{CE}_{3}$ & Curing Room & $23 \pm 2{ }^{\circ} \mathrm{C}$ \\
\hline $\mathrm{CE}_{4}$ & Water Bath & Room Temperature $\left(21 \pm 0.8^{\circ} \mathrm{C}\right)$ \\
\hline $\mathrm{CE}_{5}$ & Hot Water Bath & $30,50,70,90^{\circ} \mathrm{C}$ \\
\hline $\mathrm{CE}_{6}$ & Hot Oven & $30,50,70,90^{\circ} \mathrm{C}$ \\
\hline $\mathrm{CE}_{7}$ & Modified Cold Bath & $10^{\circ} \mathrm{C}$ \\
\hline
\end{tabular}

Note: Direct measurement of room temperature over the duration of the study was determined as $21 \pm$ $0.8^{\circ} \mathrm{C}$. 
Figure 8. Curing environments; (a) $\mathrm{CE}_{1}$, (b) $\mathrm{CE}_{2}$, (c) $\mathrm{CE}_{3}$, (d) $\mathrm{CE}_{4}$, (e) $\mathrm{CE}_{5}$, (f) $\mathrm{CE}_{6}$, (g) $\mathrm{CE}_{7}$ (1 of 2), (h) $\mathrm{CE}_{7}$ (2 of 2).

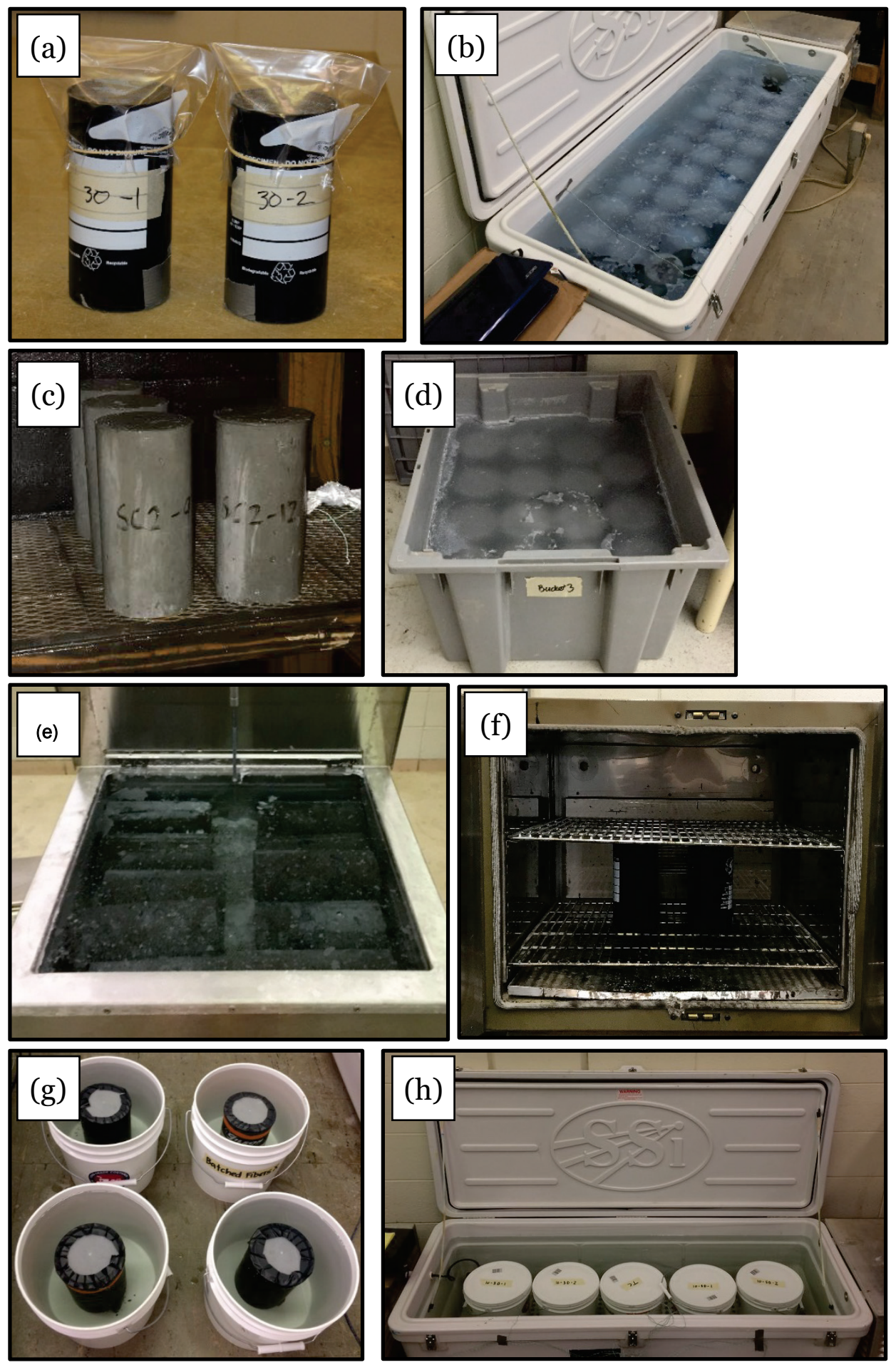


The thermal history of specimens was determined for calculation of maturity according to ASTM 1074 (2017) and described in section 3.4.2. To facilitate an accurate maturity determination for each specimen, the thermal history was approximated according to curing environment temperature. The temperature increase caused by release of hydration heat was therefore recorded for maturity calculation purposes. Temperature was continuously measured for $\mathrm{CE}_{1}, \mathrm{CE}_{2}, \mathrm{CE}_{3}$, and $\mathrm{CE}_{7}$. Temperature was verified intermittently for $\mathrm{CE}_{4}, \mathrm{CE}_{5}$, and $\mathrm{CE}_{6}$. Temperature measurements were collected with four different devices, i.e., (1) Pico $\AA$ Technology data logger model TC-08, (2) Omega ${ }^{\mathrm{TM}}$ data logger model HH309A, (3) Omega ${ }^{\mathrm{TM}}$ data logger model $\mathrm{HH}_{314}$, and (4) standard, hand-held digital thermometer.

\subsubsection{1 $C E_{1}$ : Lab bench}

The lab bench was approximately at room temperature and adjacent to the mixing station where specimens were prepared (Figure 8a). Batched quantities of materials were also kept in this controlled temperature laboratory space. After each batch was mixed, specimens were placed in molds and set on the lab bench for approximately $24 \mathrm{hr}$. Specimens kept on the lab bench were removed from molds and then placed in either $\mathrm{CE}_{2}, \mathrm{CE}_{3}, \mathrm{CE}_{4}$, or $\mathrm{CE}_{5}$.

An Omega ${ }^{\mathrm{TM}} \mathrm{HH} 314 \mathrm{~A}$ data logger with two type $\mathrm{K}$ bead TCs was used to monitor the temperature and humidity of the counter top and adjacent mixing station at a sample rate of $5 \mathrm{~min}$. One TC was fixed to a lab stand $61 \mathrm{~cm}(2 \mathrm{ft})$ above the counter top where specimens in molds were placed. A second TC was taped to the counter. The average temperature over the period of mixing and specimens setting on the counter was determined to be $21.0^{\circ} \mathrm{C}$ with a standard deviation of $0.8^{\circ} \mathrm{C}$.

\subsubsection{2 $\mathrm{CE}_{2}$ : Cold bath}

Two cooling tanks with circulation pumps were used to maintain water at $10^{\circ} \mathrm{C}$. Cooling tanks were Thermocure II Concrete Curing Boxes from Construction Innovations Co. Inc. Water was saturated with hydrated lime according to ASTM C511 (2013). Each cooling tank fit up to 30 fully submerged $10.2-\mathrm{cm}$ by $20.4-\mathrm{cm}$ cylinders that were upright in the water (Figure $8 \mathrm{~b}$ ). Cooling tanks were set to a temperature of $10^{\circ} \mathrm{C}$. A Pico $\AA$ data logger was used to collect temperature measurements from TCs for each cooling tank. Four TCs were fixed to the inner walls of each tank to monitor water temperature. Temperature measurements were collected 
every $5 \mathrm{~min}$. The average temperature in both tanks was determined as $50.5^{\circ} \mathrm{C}$ with a standard deviation of $0.72^{\circ} \mathrm{C}$.

\subsubsection{3 $\mathrm{CE}_{3}$ : Room temperature curing room}

A $100 \%$ relative humidity curing environment was maintained at $23 \pm 2^{\circ} \mathrm{C}$ for this study. All specimens placed in $\mathrm{CE}_{3}$ were placed on shelves in the curing room (Figure 8c). An Omega ${ }^{\mathrm{TM}} \mathrm{HH} 309 \mathrm{~A}$ data logger continuously monitored temperature of the curing room and recorded data at a sample rate of 1 hour. Table 14 shows the frequency and relative frequency of temperature measurements for the duration of study. Out of 7074 readings, none were outside of the specified range of $23 \pm 2^{\circ} \mathrm{C}$.

Table 14. $\mathrm{CE}_{3}$ temperature history for duration of study.

\begin{tabular}{|l|l|l|}
\hline \multicolumn{1}{|c|}{ Bin } & \multicolumn{1}{|c|}{$\begin{array}{c}\text { Frequency } \\
\text { (hr) }\end{array}$} & \multicolumn{1}{|c|}{$\begin{array}{c}\text { Relative Frequency } \\
\text { (\%) }\end{array}$} \\
\hline$<21.0^{\circ} \mathrm{C}$ & 0 & 0 \\
\hline $\begin{array}{l}21.0^{-} \\
21.5^{\circ} \mathrm{C}\end{array}$ & 4 & 0.06 \\
\hline $\begin{array}{l}21.5^{-} \\
22.0^{\circ} \mathrm{C}\end{array}$ & 27 & 0.38 \\
\hline $\begin{array}{l}22.0^{\circ} \\
22.5^{\circ} \mathrm{C}\end{array}$ & 207 & 2.93 \\
\hline $\begin{array}{l}22.5^{-} \\
23.0^{\circ} \mathrm{C}\end{array}$ & 1103 & 15.59 \\
\hline $\begin{array}{l}23.0^{-} \\
23.5^{\circ} \mathrm{C}\end{array}$ & 2824 & 39.92 \\
\hline $\begin{array}{l}23.5^{-} \\
24.0^{\circ} \mathrm{C}\end{array}$ & 2308 & 32.63 \\
\hline $\begin{array}{l}24.0^{\circ} \\
24.5^{\circ} \mathrm{C}\end{array}$ & 512 & 7.24 \\
\hline $\begin{array}{l}24.5^{-} \mathrm{C} \\
25.0^{\circ} \mathrm{C}\end{array}$ & 89 & 1.26 \\
\hline$>25.0^{\circ} \mathrm{C}$ & 0 & 0 \\
\hline
\end{tabular}

\subsubsection{4 $\mathrm{CE}_{4}$ : Room temperature water bath}

Four plastic bins were filled with water and maintained inside at room temperature. Each bin fit up to 15 upright, fully submerged 10.2-cm by 20.4-cm cylinders (Figure 8e). Water was saturated with hydrated lime according to ASTM $\mathrm{C}_{511}$ (2013). Temperature of $\mathrm{CE}_{4}$ baths was not 
monitored directly but was taken as the average room temperature measured in $\mathrm{CE}_{1}$ over the duration of the study which was $21.0^{\circ} \mathrm{C}$.

\subsubsection{5 $C E_{5}$ : Hot bath}

Twelve Ritehete $\mathrm{WB} 33 \mathrm{~S}$ hot water baths were used to produce a hot environment at a range of curing temperatures $\left(30\right.$ to $\left.90^{\circ} \mathrm{C}\right)$. Each hot bath fit up to 14 fully submerged $10.2-\mathrm{cm}$ by $20.4-\mathrm{cm}$ cylinders when laying on their sides (Figure 8d). Water was saturated with hydrated lime according to ASTM C511 (2013). Temperature was checked periodically with a hand-held digital thermometer.

\subsubsection{6 $C E_{6}:$ Oven}

An oven with forced convection fans was used to produce a hot environment at elevated temperatures (Figure $8 \mathrm{f}$ ). This curing environment was used to expose freshly cast specimens to high temperatures prior to removal from the mold. Instead of covering with a plastic bag and rubber band, molded specimens were sealed with a plastic lid and electrical tape. The oven reached set temperature very rapidly, i.e., within $10 \mathrm{~min}$, so temperature was not monitored throughout specimen exposure.

\subsubsection{CE7: Modified cold bath}

Two cooling tanks, $\mathrm{CE}_{2}$, and 2- gal buckets were used to expose freshly cast specimens to low temperatures prior to removal from the mold. Similar to $\mathrm{CE}_{6}$, specimens were sealed with a plastic lid and electric tape after molding. Sealed specimens were then placed into the 2-gal buckets filled with room temperature water (Figure 8g). Buckets were sealed with lids and placed into $\mathrm{CE}_{2}$ that had already reached a temperature of $10^{\circ} \mathrm{C}$ (Figure $8 \mathrm{~h}$ ). A previously molded control specimen instrumented with a thermocouple was exposed to the same conditions. The control temperature was recorded with an Omega HH309A data logger. Temperature of the water in the bath was monitored in the same manner as for $\mathrm{CE}_{2}$.

\subsubsection{Maturity calculations}

To compare the strength development as a function of time and temperature between curing data sets, ASTM C1074 (2017) maturity methods were used. The extent of mechanical property development within a cementitious mixture is often expressed as a function of maturity. Maturity as used herein is simply the area under the curve that describes the thermal history of a 
specimen or a coordinate in a structure. In other words, maturity is the timetemperature factor described in Equation 1 from ASTM C1074 (2017). For this study, the datum temperature is considered to be $\mathrm{o}^{\circ} \mathrm{C}$.

$$
\mathrm{M}_{1074}=\sum\left(\mathrm{T}-\mathrm{T}_{0}\right) \cdot \Delta \mathrm{t}
$$

where

$$
\begin{aligned}
& M_{1074}=\text { maturity, }{ }^{\circ} \mathrm{C} \text {-days } \\
& T=\text { temperature, }{ }^{\circ} \mathrm{C} \\
& T_{o}=\text { datum temperature, } O^{\circ} \mathrm{C} \\
& \Delta t=\text { duration of time, days }
\end{aligned}
$$

Final maturity, $\mathrm{M}$, was calculated using a baseline maturity, $\mathrm{M}_{\mathrm{B}}$, combined with two adjustments, $\mathrm{M}_{\text {adj, } 1}$ and $\mathrm{M}_{\mathrm{adj}, 2}$ (Equation 2). Comparisons between specimens utilize the final maturity. The calculation of maturity and adjustments are described in the sections 3.4.2.1 through 3.4.2.3.

$$
M=M_{B}+M_{a d j, 1}+M_{a d j, 2}
$$

where

$$
\begin{aligned}
& M=\text { final maturity, }{ }^{\circ} \mathrm{C} \text {-days } \\
& M_{B}=\text { baseline maturity, }{ }^{\circ} \mathrm{C} \text {-days } \\
& M_{a d j, 1}=\text { maturity adjustment for heat/cooling of curing } \\
& \quad \text { environment },{ }^{\circ} \mathrm{C} \text {-days } \\
& M_{a d j, 2}=\text { maturity adjustment for specimen preparation, }{ }^{\circ} \mathrm{C} \text {-days }
\end{aligned}
$$

\subsubsection{Baseline maturity, $M_{B}$}

During specimen mixing, curing, and testing, the timing of events was recorded on data sheets. Times were recorded for when water first contacted cement, specimens were molded, specimens were placed in a curing environment, specimens moved curing environments, specimens were removed from curing, and when mechanical testing began. From these recorded times, durations were calculated for each specimen that corresponded to the length of time spent in a given CE. As described in section 3.4.1, temperature of the environment was either actively monitored or intermittently verified. Using the temperature and durations in each environment, baseline maturity was calculated up to the end of curing for a given specimen, shown in Equation 3. 


$$
\mathrm{M}_{\mathrm{B}}=\sum_{\mathrm{i}}^{\mathrm{n}} \mathrm{T}_{\mathrm{i}} \cdot \Delta \mathrm{t}_{\mathrm{i}}
$$

where

$$
\begin{aligned}
& M_{B}=\text { baseline maturity, },{ }^{\circ} \mathrm{C} \text {-days } \\
& T_{i}=\text { average temperature of } C E_{i} \text { over duration } \Delta t_{i},{ }^{\circ} \mathrm{C} \\
& \Delta t_{i}=\text { duration of time in a } C E \text {, days }
\end{aligned}
$$

\subsubsection{Maturity adjustment $1, M_{a d j, 1}$}

Maturity adjustment $1, M_{\text {adj, }, 1}$, was calculated to account for the heating/cooling of a curing environment from ambient temperature to the designated curing temperature. To prevent thermal shocking of specimens, cold/hot baths were loaded at room temperature. The durations of time in the baseline maturity $\left(\mathrm{M}_{\mathrm{B}}\right)$ calculation (Equation 3) assume that the average temperature of the curing environment was constant and that specimen temperature changes instantly. This adjustment is needed to account for actual maturity accumulation while the curing environment reaches the designated temperature. This adjustment factor applies only to $\mathrm{CE}_{2}, \mathrm{CE}_{5}$, and $\mathrm{CE}_{7}$.

The amount of time it took for a CE to reach the set temperature varied depending on the curing temperature. $\mathrm{M}_{\mathrm{adj}, 1}$ was determined for each temperature for which specimens were cured. To develop these adjustment factors, thermal ramp tests were performed with an Omega ${ }^{\mathrm{TM}} \mathrm{HH} 309 \mathrm{~A}$ data logger for $\mathrm{CE}_{2}$ at $10^{\circ} \mathrm{C}, \mathrm{CE}_{5}$ at $30,5 \mathrm{O}, 7 \mathrm{O}$, and $90^{\circ} \mathrm{C}$, and for $\mathrm{CE}_{7}$ at $10^{\circ} \mathrm{C}$. Data was sampled every $1 \mathrm{~min}$. Thermal ramp tests used 4 type $\mathrm{k}$ thermocouples, i.e., one was embedded in a blank control specimen, and the other three monitored the bath water. Seven other specimens were placed in the curing environments to represent the thermal mass of cylinders. The data logger and bath were turned on simultaneously, and data were recorded until both water and control specimen reached the set temperature.

The duration of time required for the blank specimen to reach the set temperature of the bath was determined from the temperature data. Based on the starting temperature of the specimen, the maturity adjustment was calculated according to Equation 4, which assumes a linear ramp rate. Thermal ramp data confirmed linear ramping. Since $\mathrm{M}_{в}$ overestimated the maturity of specimens cured at high temperatures, the difference of $\mathrm{T}_{\mathrm{b}}$ and $\mathrm{T}_{\text {set }}$ in Equation 4 was negative. Conversely, maturity was underestimated for low-temperature curing, so this adjustment was positive. 


$$
M_{a d j, 1}=\frac{1}{2}\left(T_{b}-T_{s e t}\right) \cdot \frac{t_{s e t}}{1440}
$$

where

$T_{b}=$ specimen temperature at beginning of thermal ramp test, ${ }^{\circ} \mathrm{C}$

$T_{\text {set }}=$ temperature of curing environment,${ }^{\circ} \mathrm{C}$

$t_{\text {set }}=$ duration of time required to reach $T_{\text {set, }}$, minutes.

Results of the thermal ramp tests and $\mathrm{M}_{\mathrm{adj}, 1}$ values are summarized in Table 15. For $\mathrm{CE}_{5}$, the average temperature ramp rate was $0.29^{\circ} \mathrm{C} /$ minute, which is close to the ramp rate at temperatures 30,50 , 70 , and $90^{\circ} \mathrm{C}$, verifying that the ramp rate was linear.

Table 15. Maturity adjustment 1 (Madj,1).

\begin{tabular}{|l|l|l|l|l|l|}
\hline \multicolumn{1}{|c|}{$\mathrm{CE}$} & \multicolumn{1}{|c|}{$\mathrm{T}_{0}\left({ }^{\circ} \mathrm{C}\right)$} & \multicolumn{1}{|c|}{$\mathrm{T}_{\text {set }}\left({ }^{\circ} \mathrm{C}\right)$} & \multicolumn{1}{c|}{$\mathrm{t}_{\text {set }}(\mathrm{min})$} & Ramp rate $\left({ }^{\circ} \mathrm{C} / \mathrm{min}\right)$ & $\mathrm{M}_{\text {adj, } 1}\left({ }^{\circ} \mathrm{C}\right.$-days $)$ \\
\hline $\mathrm{CE}_{2}$ & 21.6 & 10 & 580 & -0.020 & +2.329 \\
\hline $\mathrm{CE}_{7}$ & 19.8 & 10 & 219 & -0.045 & +0.745 \\
\hline \multirow{5}{*}{$\mathrm{CE}_{5}$} & 18.4 & 30 & 45 & 0.258 & -0.181 \\
\cline { 2 - 7 } & 22.2 & 50 & 91 & 0.305 & -0.878 \\
\cline { 2 - 7 } & 23.2 & 70 & 151 & 0.310 & -2.454 \\
\cline { 2 - 6 } & 22.9 & 90 & 228 & 0.294 & -5.312 \\
\hline
\end{tabular}

\subsubsection{Maturity adjustment 2, Madj,2}

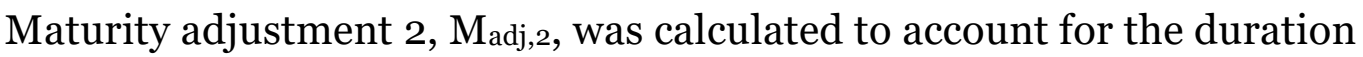
of time spent preparing certain specimens for mechanical testing and the change in specimen temperature as it equilibrates to room temperature. This duration of time, $t_{\text {prep }}$, was calculated as the average amount of time a specimen was removed from curing environment until the time the first mechanical test was started. Only isothermal specimens use $\mathbf{M}_{\mathrm{adj}, 2}$ because they were tested shortly after removal from curing, as discussed in section 3.5. Mixed temperature curing specimens were allowed to cool to room temperature before being stored for mechanical testing. As a result, maturity was calculated up to the end of curing. This adjustment was calculated after all of the physical property specimens were tested and shown in Equation 5, which assumes specimens cooled to $23^{\circ} \mathrm{C}$ by the end of testing. $\mathrm{M}_{\mathrm{adj}, 2}$ was calculated for each curing temperature but not for each curing environment. Table 16 shows the $\mathrm{M}_{\mathrm{adj}, 2}$ values for the isothermal specimens. 


$$
\mathrm{M}_{\mathrm{adj}, 2}=\frac{1}{2}\left(\mathrm{~T}_{\mathrm{set}}+23\right) \cdot \frac{\mathrm{t}_{\mathrm{prep}}}{1440}
$$

where

$T_{\text {set }}=$ set temperature of curing environment, ${ }^{\circ} \mathrm{C}$

$t_{\text {prep }}=$ average duration of time spent in preparation, minutes.

Table 16. Maturity adjustment 2 (Madj,2).

\begin{tabular}{|l|l|l|l|}
\hline \multicolumn{1}{|c|}{$\mathrm{CE}$} & \multicolumn{1}{c|}{$\mathrm{T}_{\text {set }}\left({ }^{\circ} \mathrm{C}\right)$} & \multicolumn{1}{|c|}{ Average $\mathrm{t}_{\text {prep }}$ (min.) } & $\mathrm{M}_{\text {adj,2 }}\left({ }^{\circ} \mathrm{C}\right.$-days) \\
\hline $\mathrm{CE}_{2}$ & 10 & 29.51 & 0.338 \\
\hline $\mathrm{CE}_{4}$ & 23 & 19.39 & 0.310 \\
\hline $\mathrm{CE}_{3}$ & 23 & 27.34 & 0.437 \\
\hline \multirow{3}{*}{$\mathrm{CE}_{5}$} & 30 & 24.75 & 0.455 \\
\cline { 2 - 4 } & 50 & 20.36 & 0.516 \\
\cline { 2 - 4 } & 70 & 24.39 & 0.787 \\
\cline { 2 - 4 } & 90 & 25.50 & 1.001 \\
\hline
\end{tabular}

\subsubsection{Curing protocols}

After mixing, specimens were immediately placed into designated curing environments. For this report, specimens were allocated into 2 categories of curing, i.e., isothermal curing and mixed temperature curing. The isothermal curing category subjected specimens to a constant temperature over a range of durations. The mixed temperature curing category subjected specimens to a series of curing conditions for specific durations.

\subsubsection{Isothermal curing}

For the purpose of this study, constant temperature curing conditions are described as isothermal. A total of 535 specimens were cured under isothermal conditions designated by a prefix "I" followed by a number representing the constant curing temperature in degrees Celsius, e.g., I30 is cured at $30^{\circ} \mathrm{C}$. Specimens cured in the moist curing room $\left(\mathrm{CE}_{3}\right)$ are designated I23CR where CR denotes curing room. All specimens were mixed at laboratory room temperature. Most specimens were then allowed to sit on the lab counter, $\mathrm{CE}_{1}$, for up to one day to facilitate demolding and specimen handling. The isothermal (constant temperature) data set was split into three data groups, i.e., A, B, and C. A summary of isothermal specimen curing is shown in Table 17. Isothermally cured specimens were used to calibrate the numerical model described in Chapter 5 . 
Table 17. Description of isothermal curing specimens.

\begin{tabular}{|c|c|c|c|c|c|c|}
\hline \multirow[b]{2}{*}{ Curing } & \multicolumn{5}{|c|}{ Mechanical Tests Performed } & \multirow[b]{2}{*}{ Description } \\
\hline & $\begin{array}{l}\text { Data } \\
\text { Group }\end{array}$ & \# Made & $\begin{array}{c}\text { \# as per } \\
\text { C39 }\end{array}$ & $\begin{array}{c}\text { \# as per } \\
\text { C469 }\end{array}$ & $\begin{array}{c}\# \\
\text { densities }\end{array}$ & \\
\hline \multirow{3}{*}{110} & A & 70 & 70 & 19 & 65 & 1 day $C E_{1}, X$ days $C E_{2}$ \\
\hline & B & 8 & 8 & 2 & 0 & $\mathrm{X}$ days $\mathrm{CE}_{2}$ \\
\hline & C & 8 & 8 & 0 & 3 & 1 day $\mathrm{CE}_{1}, 16$ days $\mathrm{CE}_{2}$ \\
\hline \multirow{3}{*}{123} & A & 77 & 77 & 23 & 43 & 1 day $C E_{1}, X$ days $C E_{4}$ \\
\hline & \multirow{2}{*}{ C } & 8 & 8 & 0 & 4 & 1 day $\mathrm{CE}_{1}, 7$ days $\mathrm{CE}_{4}$ \\
\hline & & 6 & 6 & 3 & 0 & 1 day $\mathrm{CE}_{1}, 13$ days $\mathrm{CE}_{4}$ \\
\hline I23CR & A & 76 & 76 & 17 & 46 & 1 day $C E_{1}, X$ days $\mathrm{CE}_{3}$ \\
\hline \multirow{3}{*}{130} & A & 43 & 43 & 15 & 37 & 1 day $\mathrm{CE}_{1}, \mathrm{X}$ days $\mathrm{CE}_{5} @ 30^{\circ} \mathrm{C}$ \\
\hline & B & 8 & 8 & 3 & 0 & 1 day $\mathrm{CE}_{6}, \mathrm{X}$ days $\mathrm{CE}_{5} @ 30^{\circ} \mathrm{C}$ \\
\hline & C & 8 & 8 & 0 & 0 & 1 day $\mathrm{CE}_{6}, 7$ days $\mathrm{CE}_{5} @ 30^{\circ} \mathrm{C}$ \\
\hline \multirow{4}{*}{150} & A & 50 & 50 & 15 & 38 & 1 day $\mathrm{CE}_{1}, \mathrm{X}$ days $\mathrm{CE}_{5} @ 50^{\circ} \mathrm{C}$ \\
\hline & B & 12 & 12 & 4 & 0 & 1 day $\mathrm{CE}_{6}, \mathrm{X}$ days $\mathrm{CE}_{5} @ 50^{\circ} \mathrm{C}$ \\
\hline & \multirow{2}{*}{ C } & 8 & 8 & 0 & 0 & 1 day $\mathrm{CE}_{6}, 7$ days $\mathrm{CE}_{5} @ 50^{\circ} \mathrm{C}$ \\
\hline & & 6 & 6 & 3 & 0 & 1 day $\mathrm{CE}_{1}, 13$ days $\mathrm{CE}_{5} @ 50^{\circ} \mathrm{C}$ \\
\hline \multirow{3}{*}{170} & A & 43 & 43 & 13 & 17 & 1 day $\mathrm{CE}_{1}, \mathrm{X}$ days $\mathrm{CE}_{5} @ 70^{\circ} \mathrm{C}$ \\
\hline & B & 6 & 6 & 2 & 0 & 1 day $\mathrm{CE}_{6}, \mathrm{X}$ days $\mathrm{CE}_{5} @ 70^{\circ} \mathrm{C}$ \\
\hline & C & 8 & 8 & 0 & 0 & 1 day $\mathrm{CE}_{6}, 7$ days $\mathrm{CE}_{5} @ 70^{\circ} \mathrm{C}$ \\
\hline \multirow{6}{*}{190} & A & 50 & 50 & 17 & 36 & 1 day $\mathrm{CE}_{1}, \mathrm{X}$ days $\mathrm{CE}_{5} @ 90^{\circ} \mathrm{C}$ \\
\hline & B & 12 & 12 & 5 & 0 & 1 day $\mathrm{CE}_{6}, \mathrm{X}$ days $\mathrm{CE}_{5} @ 90^{\circ} \mathrm{C}$ \\
\hline & \multirow{4}{*}{ C } & 6 & 6 & 3 & 0 & 1 day $\mathrm{CE}_{6}, 1$ days $\mathrm{CE}_{5} @ 90^{\circ} \mathrm{C}$ \\
\hline & & 8 & 8 & 1 & 4 & 1 day $\mathrm{CE}_{6}, 5$ days $\mathrm{CE}_{5} @ 90^{\circ} \mathrm{C}$ \\
\hline & & 8 & 8 & 2 & 4 & 1 day $\mathrm{CE}_{6}, 7$ days $\mathrm{CE}_{5} @ 90^{\circ} \mathrm{C}$ \\
\hline & & 6 & 6 & 3 & 0 & 1 day $C E_{6}, 13$ days $\mathrm{CE}_{5} @ 90^{\circ} \mathrm{C}$ \\
\hline
\end{tabular}

Note: $\mathrm{X}$ corresponds to a duration of time that varies between specimens.

Isothermal curing for Group A subjected specimens to their designated curing environment only after sitting on the lab bench, $\mathrm{CE}_{1}$, for 1 day and removed from molds with an air compressor. Specimens in Group A were cured over a range of durations and tested one specimen at a time, i.e., there is no replication. The data set associated with Group A captured the development of mechanical properties for specimens tested with the same maturity but cured at different temperatures. For this reason, most specimens were tested without replication on an interval associated with 
maturity. Additional specimens were added later to improve resolution at early ages. Cylinders cured at $10^{\circ} \mathrm{C}$ and $23^{\circ} \mathrm{C}$ were tested on an interval of $40^{\circ} \mathrm{C}$-days to a maturity of $2560^{\circ} \mathrm{C}$-days. Cylinders cured at $30,50,70$, and $90^{\circ} \mathrm{C}$ were tested on an interval of $50^{\circ} \mathrm{C}$-days to a maturity of $2150^{\circ} \mathrm{C}$-days.

Isothermal curing for Group B subjects specimens to their designated curing temperature immediately after mixing into either $\mathrm{CE}_{6}$ or $\mathrm{CE}_{7}$. Tests were conducted as early as $8 \mathrm{hr}$ after mixing. After 1 day, specimens in Group B were removed from sealed molds with compressed air and placed back into their designated curing environment. No specimens cured at $23^{\circ} \mathrm{C}$ are designated as Group B.

Isothermal curing for data group $\mathrm{C}$ is identical to Group $\mathrm{A}$, except that a group of specimens was cured for a specific duration of time. Compressive strength was collected for Group $\mathrm{C}$ specimens as needed to provide a statistical range of property values that can be compared against numerical predictions as discussed in Chapter 5 .

In addition to isothermal curing Groups $\mathrm{A}, \mathrm{B}$, and $\mathrm{C}$, early-age strength gain variability in UHPC specimens at room temperature conditions was also evaluated. After mixing and covering molds with plastic bags, 30 early-age variability (EAV) specimens were immediately placed into $\mathrm{CE}_{3}$ and cured for $24 \mathrm{hr}$. Also, two EAV specimens were cured in $\mathrm{CE}_{1}$ for $24 \mathrm{hr}$.

\subsubsection{Mixed temperature curing}

Mixed temperature curing subjected specimens to a combination of curing environments for different durations of time. A summary of mixed temperature curing procedures is given in Table 18. SC is the standard curing method used throughout this study and used in previous research efforts at MSU recommended by ERDC (Howard et al. 2018). This curing protocol is similar to one referenced by Wan et al. (2016) in which the aging degree was evaluated to be roughly $95 \%$. Modifications to the standard curing procedure were investigated in which the duration in the moist curing room $\left(\mathrm{CE}_{3}\right)$ was changed from 6 days to 2, 13, 20, and 27 days for groups denoted M2, M13, M20, and M27, respectively. All mixed temperature groups were placed in $\mathrm{CE}_{5}$ at $90^{\circ} \mathrm{C}$ for 7 days after curing in $\mathrm{CE}_{3}$. Mixed curing specimens were of secondary interest to SIF 1.0 and are intended for use in calibrating later versions of SIF. 
Table 18. Mixed temperature curing specimens.

\begin{tabular}{|l|l|l|l|l|l|l|l|l|}
\hline & \multicolumn{3}{|c|}{ Mechanical Tests Performed } & \multicolumn{5}{c|}{ Curing } \\
\cline { 2 - 9 } & $\begin{array}{c}\text { Group } \\
\text { Made }\end{array}$ & $\begin{array}{c}\text { \# as } \\
\text { per } \\
\text { C39 }\end{array}$ & $\begin{array}{c}\text { \# as } \\
\text { per } \\
\text { C469 }\end{array}$ & $\begin{array}{c}\# \\
\text { densities }\end{array}$ & $\begin{array}{c}\text { Days in } \\
\text { CE }_{1}\end{array}$ & $\begin{array}{c}\text { Days in } \\
\text { CE3 }\end{array}$ & $\begin{array}{c}\text { Days in } \\
\text { CE5 at } \\
90^{\circ} \text { C }\end{array}$ & $\begin{array}{c}\text { Target } \\
\text { Maturity } \\
\left({ }^{\circ} \text { C-days }\right)\end{array}$ \\
\hline SC & 30 & 8 & 6 & 30 & 1 & 6 & 7 & 791 \\
\hline M2 & 8 & 8 & 4 & 0 & 1 & 2 & 7 & 699 \\
\hline M13 & 8 & 8 & 4 & 0 & 1 & 13 & 7 & 952 \\
\hline M20 & 8 & 8 & 4 & 0 & 1 & 20 & 7 & 1113 \\
\hline M27 & 8 & 8 & 4 & 0 & 1 & 27 & 7 & 1251 \\
\hline
\end{tabular}

\subsubsection{Effect of specimen temperature on mechanical properties}

Twenty cylinders were made and cured following SC curing and then conditioned at a set temperature to evaluate the effects of testing temperature on compressive strength and elastic modulus. Ten specimens, designated FT, were allocated to test the effects of specimen temperature during testing on compressive strength. The remaining 10 specimens, designated ET, were allocated to test the effects of specimen temperature during testing on elastic modulus. Specimens were then divided into pairs, i.e., one specimen to be tested at room temperature (control specimen) and one specimen to be tested at a designated testing temperature for a total of five pairs of FT specimens and five pairs of ET specimens. Specimens designated for non-room temperature testing were conditioned for $24 \mathrm{hr}$ prior to testing at one of five temperatures, i.e., $10^{\circ} \mathrm{C}, 30^{\circ} \mathrm{C}, 50^{\circ} \mathrm{C}, 70^{\circ} \mathrm{C}$, and $90^{\circ} \mathrm{C}$. After conditioning, specimens were removed from their curing environment and immediately tested for compressive strength or elastic modulus so variations from the designated testing temperature would be minimized.

\subsection{Physical property data collection}

After curing, specimens were prepared for testing. Isothermally cured specimens were prepared for immediate testing. Isothermal specimens were prepared rapidly to maintain specimen temperature as close to curing temperature as possible. Mixed temperature specimens were allowed to cool to room temperature and were often stored prior to testing. Mechanical property testing was performed with a Forney compression machine with a 600-kip capacity at the Construction Materials Research Center (CMRC) at Mississippi State University. 


\subsubsection{Grinding}

After curing, specimens were prepared for testing. A Genec Inc. automatic concrete cylinder end grinder was used to plane the ends of specimens (Figure 9a). This end grinder uses a diamond grinder head with flowing water to prevent excess heat or dust. Ends were ground for at least $120 \mathrm{sec}$ on each side to achieve a smooth surface. Some specimens were cured only for up to 2 days and were still soft, so they were not ground. Unground specimens were tested with 70 durometer pad caps.

Figure 9. Specimen preparation and testing; (a) end grinder, (b) compression test, (c) elastic modulus - analog dial, and (d) elastic modulus - LVDT.
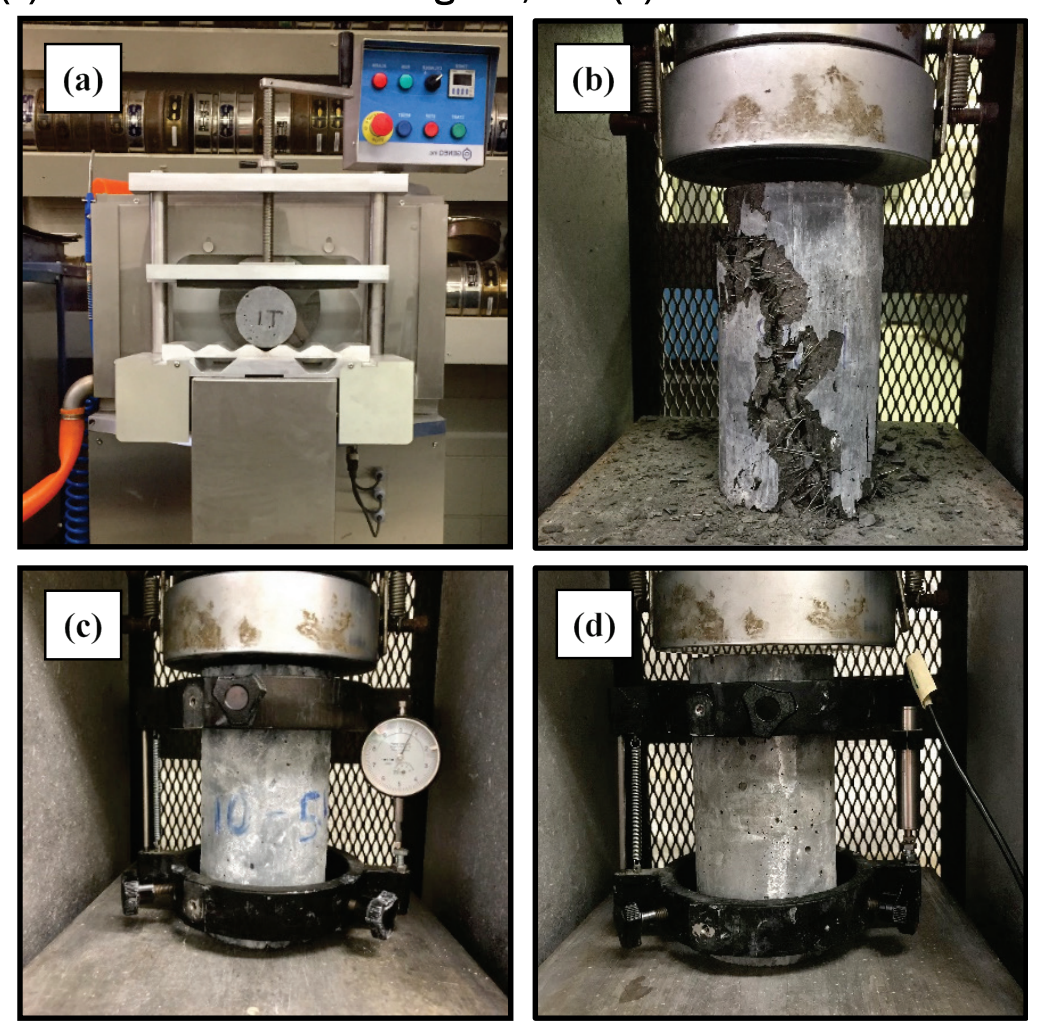

\subsubsection{Density}

Density ( $\rho$ ) was determined for 337 selected specimens after end grinding. Using digital calipers, diameter (D) was measured at two perpendicular locations on each end of the specimen to obtain four total diameter measurements. Height $(\mathrm{H})$ was measured at four evenly spaced locations around the circumference of the cylinder. Thereafter, mass was measured. Density was then calculated as mass divided by volume. After recording density measurements, specimens underwent compression testing or elastic modulus testing followed by compression testing. The average density of all specimens was $2.52 \mathrm{~g} / \mathrm{cm}^{3}$ with a standard deviation of $0.018 \mathrm{~g} / \mathrm{cm}^{3}$. 


\subsubsection{Moisture content}

Moisture content was determined for 12 specimens after compression testing. Moisture content specimens were placed into individual metal pans. The mass of the empty pan and the tested specimen were recorded. The specimen and pan were then placed into an oven at $110^{\circ} \mathrm{C}$. At periodic intervals, the pan and cylinders were weighed to measure water loss since time of compression testing. After roughly two months, the mass of specimens appeared constant and were removed from the oven. The moisture content was determined using Equation 6. Moisture content for the 12 specimens ranged from $3.67 \%$ to $4.35 \%$ with an average of $4.02 \%$.

$$
M C=\frac{m_{\text {spec,wet }}-m_{\text {pan }}}{m_{\text {spec }, d r y}-m_{\text {pan }}} \cdot 100
$$

where

$M C=$ moisture content as a percent

$m_{\text {spec,wet }}=$ mass of the cylinder immediately after testing in grams

$m_{\text {spec,dry }}=$ mass of cylinder after oven drying in grams

$m_{\text {pan }}=$ mass of pan in grams

\subsubsection{Compressive strength measurement}

Compression testing was conducted on all specimens in accordance with ASTM C39 (2016). Specimens with ground ends were placed into a Forney compression machine absent pad caps and compressed until failure (Figure 9b) although a few specimens at early age were tested with 70 durometer pad caps. Load recorded at failure was divided by original cross-sectional area to calculate compressive strength $\left(\mathrm{f}_{\mathrm{c}}\right)$ in Mega Pascals (MPa).

\subsubsection{Compressive strength versus temperature}

Following SC curing, FT specimens were ground and cooled to room temperature. As mentioned previously, one FT specimen from each batch was tested for $f_{c}$ at room temperature while the other was set aside for conditioning.

Results of $f_{c}$ versus temperature for FT specimens are presented in Figure 10 and are sorted in order of increasing $f_{c}$. Raw data for these test results are presented in Appendix A in Table A-1. In general, room temperature specimens resulted in slightly higher strengths. There is not a clear trend indicating compressive strength was affected by temperature. A two-tailed, 
paired t-test of unequal variance was conducted between the values of $23^{\circ} \mathrm{C}$ and conditioned FT specimens. The resulting p-value was 0.55 , indicating that the average compressive strength between room temperature and designated temperature testing was not statistically different. Due to these results, compressive strength of all specimens is reported as measured.

Figure 10. Compressive strength results of FT specimens.

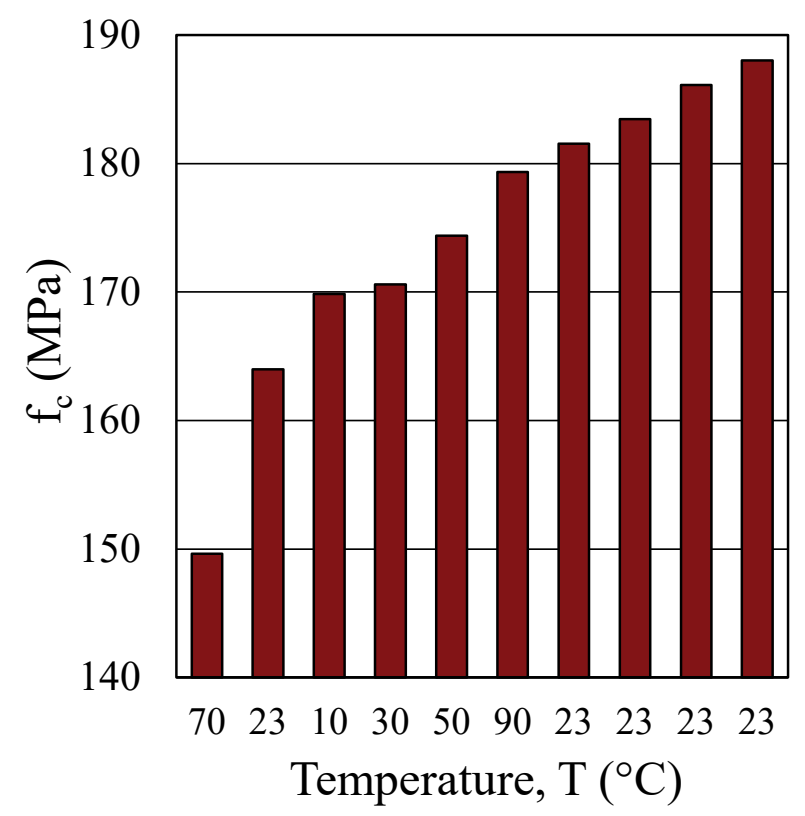

\subsubsection{Elastic modulus measurement}

Elastic modulus (E) testing was performed on selected specimens from each curing group according to ASCM C469 (2014). Elastic modulus was determined with two different methods, i.e., analog dial measurement and a linearly variable displacement transducer (LVDT). Most measurements were performed with the analog dial (Edial), and as such, E results are measured with this method unless stated otherwise. Section 6.2 of ASTM C469 stipulates that the applied load should be from the average compressive strength of two specimens; for isothermal specimens, this practice was not followed, rather load was determined using predicted strength based on trends from previously collected data on this same mixture. 


\subsubsection{Analog dial measurement}

For this method, cylinders were fit into a compressometer with dial attachment and placed into the compression machine (Figure 9c). The compressometer recorded elastic deformation with respect to applied load. Using Equation 7, deformation was converted to strain for 10.2 cm by $20.3 \mathrm{~cm}$ cylinders.

$$
\varepsilon=\frac{\left(d_{\text {dial }}\right)(0.0001)}{(2)(5.25)}
$$

where

$$
\begin{aligned}
\mathcal{E} & =\text { strain experienced by the specimen } \\
d_{\text {dial }} & =\text { reading as taken from the dial during testing }
\end{aligned}
$$

The load was then divided by the original cross-sectional area of the specimen to obtain stress. E Eial was taken as the slope of the linear portion of the stress-strain curve.

\subsubsection{LVDT measurement}

For this method, cylinders were fit into a compressometer with LVDT attachment and placed into the compression machine (Figure 9d). The LVDT used in this report is made by the manufacturer of the compression machine, Forney. This equipment is designed to interface with the data acquisition system and software of the compression machine. The LVDT was installed and calibrated by a representative of the manufacturer. The compressometer recorded elastic deformation with respect to the applied load. The LVDT allows for all test data to be acquired automatically and simultaneously, reporting ELVDT at the end of the test.

A study was conducted to determine if Edial and ELVDT measurements are statistically comparable. This study was conducted on ET specimens at room temperature. Each ET specimen was cooled to room temperature and tested with analog dial and LVDT twice. The average elastic modulus for Edial and ELVDT were compared and found to be statistically similar. A paired, two-tailed t-test gave a p-value of 0.81 , indicating that $\mathrm{E}_{\text {dial }}$ and ELVDT measurements are comparable. 


\subsubsection{Elastic modulus versus temperature}

As mentioned previously, isothermally cured specimens were tested for modulus at temperatures close to their curing temperature. It is known for many materials that elastic modulus tends to decrease as temperature increases. To account for testing temperature effects, a temperature relationship was determined using ET specimens to adjust $\mathrm{E}$ results to an equivalent $23^{\circ} \mathrm{C}$ measurement, $\mathrm{E}_{23}$. Raw mechanical testing data for ET specimens are shown in Tables A-2 and A-3. Results to develop this relationship are presented in Figure 11, which shows the average $E_{\text {dial }}$ (converted from ELVDT using Equation 6) and standard deviation for all 10 ET specimens. A linear trend-line is fit to the data and shows good agreement with a coefficient of determination $\left(\mathrm{R}^{2}\right)$ of 0.97 . The trend-line also passes through the bounds of the standard deviation. Based on this trend-line, Equation 8 is proposed to calculate $\mathrm{E}_{23}$.

$$
\mathrm{E}_{23} \cong \mathrm{E}_{\mathrm{T}}+0.081 \cdot\left(\mathrm{T}-23^{\circ} \mathrm{C}\right)
$$

Where

$$
\begin{aligned}
E_{23} & =E \text { adjusted to temperature of } 23^{\circ} \mathrm{C}, \mathrm{GPa} \\
E_{T} & =E_{L V D T} \text { or Edial at temperature } T, G P a \\
T & =\text { test temperature, }{ }^{\circ} \mathrm{C}
\end{aligned}
$$

Figure 11. Elastic modulus versus temperature of ET specimens.

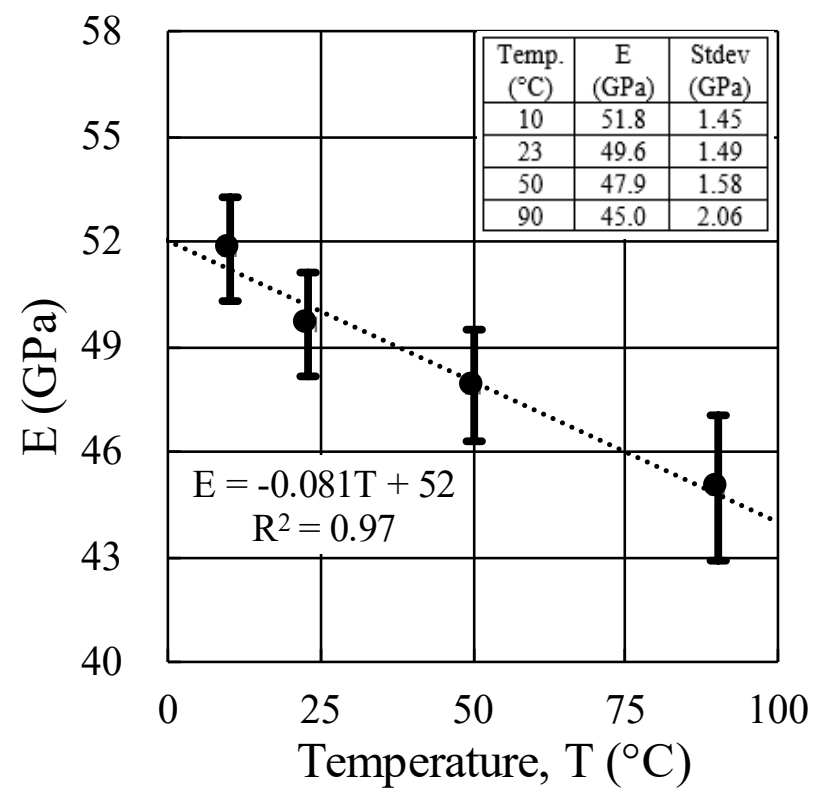




\subsubsection{ASTM C403 set time}

The set time of the Cor-Tuf mixture was investigated according to ASTM C4O3 (2016) and also according to a modified version of this protocol. Eight set-time tests were performed at three different temperatures. Materials were mixed for set-time tests in the same manner as previously described except that fibers were excluded. After mixing a $3.96 \times 10^{-3} \mathrm{~m}^{3}(0.14 \mathrm{ft} 3)$ batch of Cor-Tuf, the mixture was split between two molds. Set-time molds were made from $15.2 \mathrm{~cm}$ by $30.1 \mathrm{~cm}$ (6 in. by 12 in.) molds and cut in half to a height of $15.2 \mathrm{~cm}$ (6 in.). Four tests were conducted at room temperature, two at $50^{\circ} \mathrm{C}$ in $\mathrm{CE}_{6}$ and two at $17^{\circ} \mathrm{C}$ in a refrigerator. Two of the room temperature tests were performed uncovered as recommended by ASTM C4O3. The rest of the set-time tests were covered with plastic lids to minimize evaporation.

\subsection{Physical property test results}

The following sections provide explanation and discussion of experimental results. Raw data for all physical property tests are provided in Tables A-1 through A-28. Physical properties displayed include duration in $\mathrm{CE}_{1}$ and $\mathrm{CE}_{2}, \mathrm{CE}_{3}, \mathrm{CE}_{4}$, or $\mathrm{CE}_{5}$, final maturity (M), density ( $\rho$ ), compressive strength $\left(f_{c}\right)$, and elastic modulus (E). For type B isothermal specimens, only the duration in $\mathrm{CE}_{1}$ is shown, not in $\mathrm{CE}_{6}$ or $\mathrm{CE}_{7}$. All test data are contained within Observations Repository 1.o.

\subsubsection{Isothermal curing results - Group A}

Figures 12 and 13 show plots for elastic modulus and compressive strength measurements, respectively, for submerged isothermal specimens that were first placed in CE1 for 1 day. The raw, unadjusted data for these figures is contained in Tables A-4 to A-19 for specimens designated by Group A. Elastic modulus measurements in Figure 12 were adjusted to $23^{\circ} \mathrm{C}$ using Equation 6, yielding $\mathrm{E}_{23}$.

As seen in Figure 12, most cylinders recorded a modulus near 50 GPa regardless of curing temperature after maturities of $500^{\circ} \mathrm{C}$-days, similar to values reported in literature (Ahmad and Hakeem 2015, Graybeal 2011, Howard et al. 2018). Figure 13 shows that higher temperature curing conditions yielded higher $f_{c}$ than for colder conditions at a given maturity. 
Figure 12. Elastic modulus results for isothermal curing.

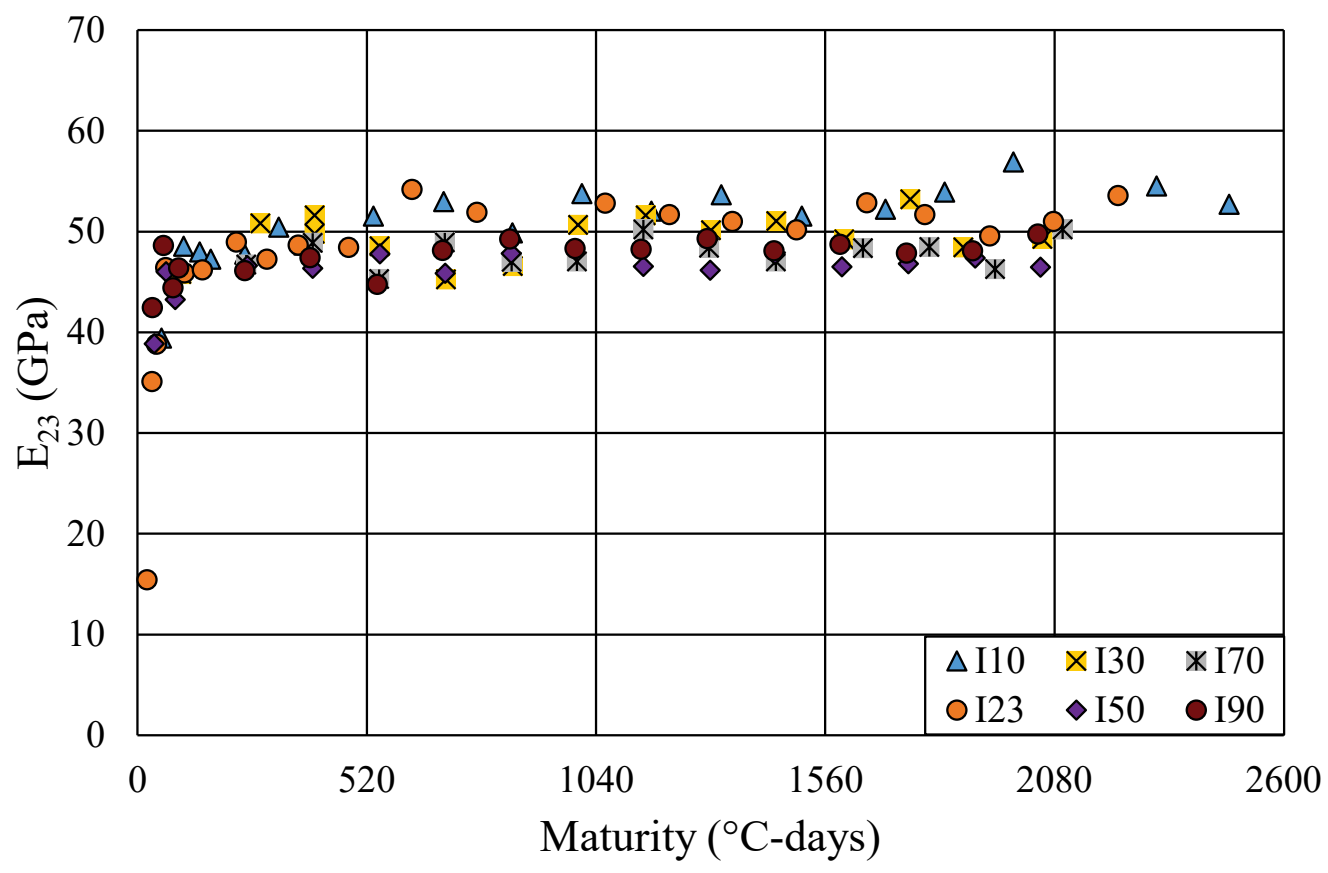

Figure 13. Compressive strength results for isothermal curing.

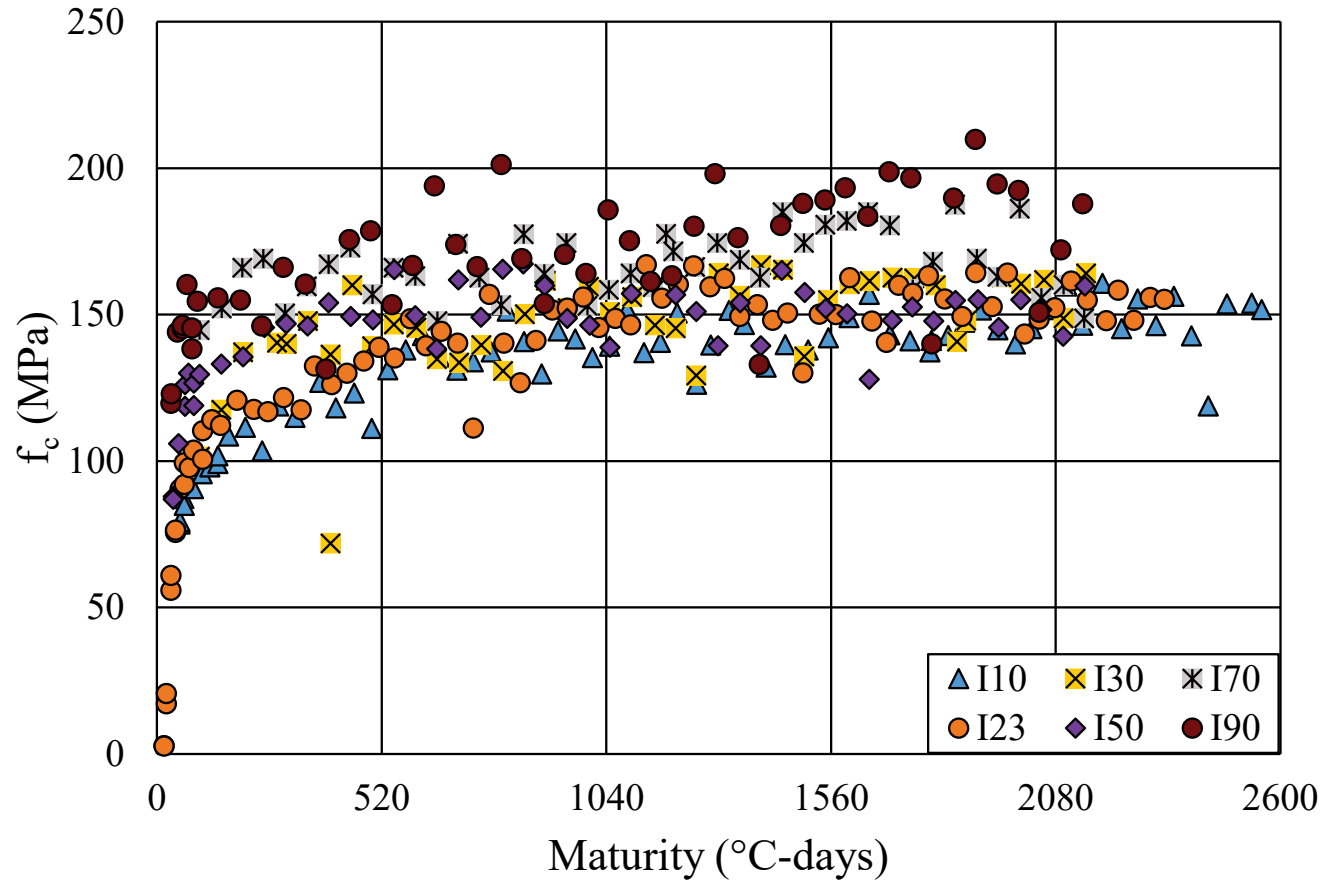




\subsubsection{Isothermal curing results - Group B}

For isothermally cured cylinders, Group B represents an attempt to expose specimens to curing temperatures as early as possible. Figure 14 shows plots of Group B (gray circular markers) and Group A (blue triangular markers), i.e., curing groups I10, I23, I30, I50, I70, and I90, for ages up to 14 days. The raw, unadjusted data for these figures is contained in Tables A-1 to A-16 for specimens designated by data group B.

At 0.74 days, I23 specimens showed a strength of $2.8 \mathrm{MPa}$ averaged over two specimens. At 1 day, I23 specimens showed a strength of $18.9 \mathrm{MPa}$ average over two specimens. At 1 day, Group B for I30, I50, I70, and I90 yielded replicate average strengths of 62.0, 107.2, 116.7, and 74.2 MPa, respectively, which are significantly higher than I23.

For I10 specimens, early-age exposure to cold temperatures resulted in delayed strength gain with $\mathrm{f}_{\mathrm{c}}$ less than $1 \mathrm{MPa}$ at 24 and $30 \mathrm{hr}$. These specimens were very soft and did not appear fully set when removed from molds. At 2 days, $f_{c}$ reached an average of 16.3 MPa and had fully set at which point the remaining four specimens were demolded. Further compressive strength and elastic modulus development of I10 Group B specimens appear to converge with Group A.

Group B specimens for I50 cover a range of ages from 8 to $24 \mathrm{hr}$ of age. It is evident in Figure 14 that I50 specimens in Group B developed consistently higher strengths than Group A. Elastic modulus also continues to increase from 30.2 to $43.9 \mathrm{GPa}$. Elastic modulus values for I70 data group B reached 34.3 and $35.7 \mathrm{GPa}$ at ages of 1.0 and 1.5 days, respectively.

Group B specimens for I90 cover a range of ages from 8 to $24 \mathrm{hr}$. The average $\mathrm{f}_{\mathrm{c}}$ for these 12 specimens is $70.4 \mathrm{MPa}$, which is achieved almost immediately with little change. Similarly, elastic modulus values appear to plateau with an average of $21.6 \mathrm{GPa}$. As seen in Figure 14, the addition of heat at early ages to I90 appears to stunt the development of compressive strength. However, for I30, I50, and I70 early-age heat did not affect compressive strength development.

These results show that early-age properties of specimens are influenced by specimen temperature. Further exploration of these curing methods should be conducted to investigate how early-age exposure affects the long-term development of mechanical properties. 
Figure 14. Compressive strength - isothermal Group A and B comparison.
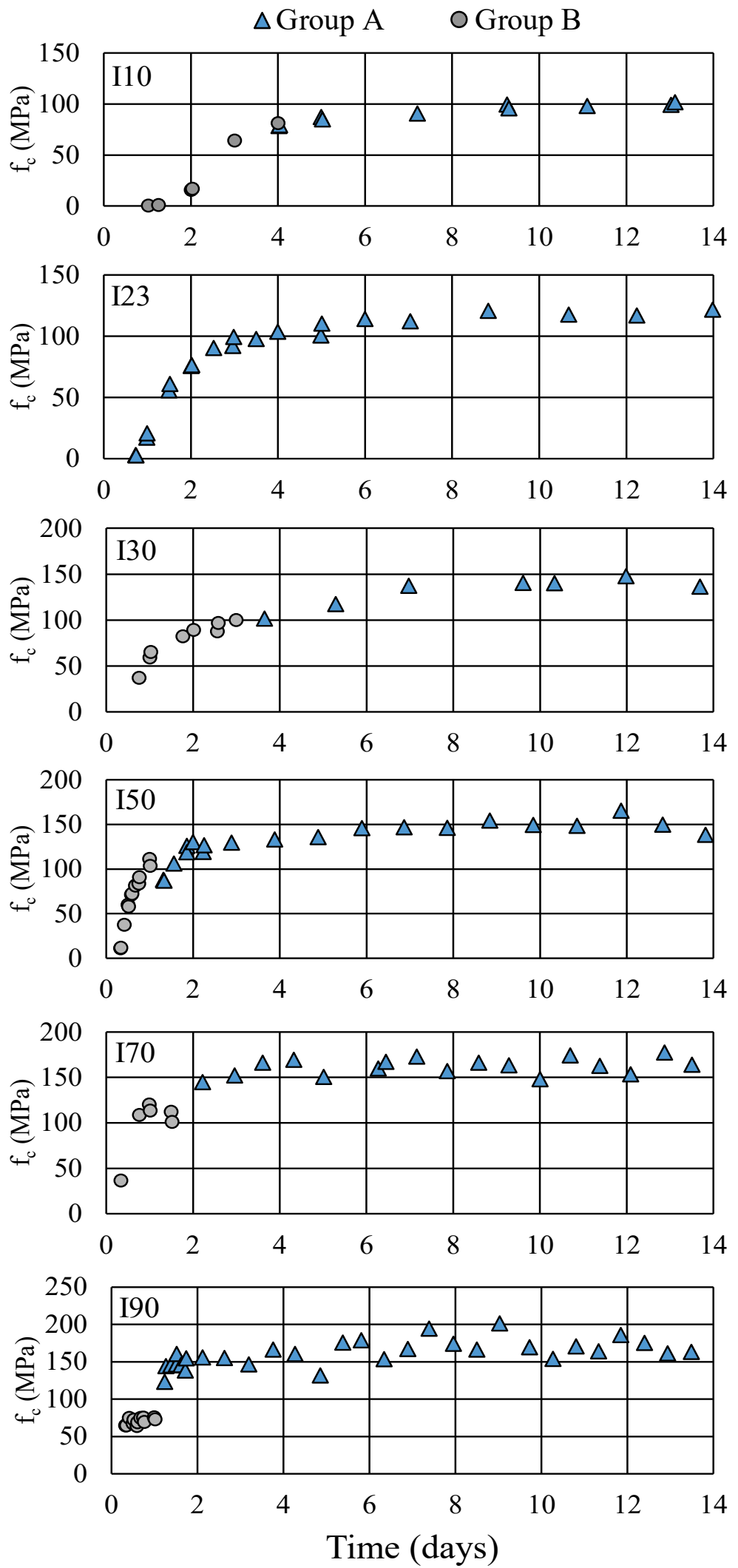


\subsubsection{Isothermal curing results -Group C}

Table 19 shows average compressive strength and adjusted elastic modulus results from the Group $\mathrm{C}$ for isothermal specimens.

Table 19. Isothermal curing results - Group C.

\begin{tabular}{|c|c|c|c|c|c|c|}
\hline \multirow[b]{2}{*}{$\begin{array}{l}\text { Curing } \\
\text { Group }\end{array}$} & \multirow[b]{2}{*}{ Age (days) } & \multicolumn{3}{|c|}{ Compressive Strength, $f_{c}$} & \multicolumn{2}{|c|}{ Elastic Modulus, $\mathrm{E}_{23}$} \\
\hline & & $\mathrm{n}$ & $\begin{array}{l}\text { Avg. } \\
\text { (MPa) }\end{array}$ & Stdev & $\mathrm{n}$ & $\begin{array}{l}\text { Avg. } \\
\text { (GPa) }\end{array}$ \\
\hline 110 & 17 & 8 & 103.2 & 8.2 & 0 & -- \\
\hline \multirow{2}{*}{123} & 8 & 8 & 112.8 & 4.4 & 0 & -- \\
\hline & 14 & 6 & 132.8 & 8.1 & 3 & 52.8 \\
\hline 130 & 8 & 8 & 123.3 & 11.9 & 0 & - \\
\hline \multirow{2}{*}{150} & 8 & 8 & 136.7 & 16.3 & 0 & -- \\
\hline & 14 & 6 & 162.2 & 7.9 & 3 & 51.6 \\
\hline 170 & 8 & 8 & 161.0 & 13.6 & 0 & - \\
\hline \multirow{4}{*}{190} & 2 & 6 & 159.0 & 7.3 & 3 & 53.4 \\
\hline & 6 & 8 & 170.8 & 6.9 & 1 & 52.8 \\
\hline & 8 & 8 & 170.9 & 12.5 & 2 & 51.4 \\
\hline & 14 & 6 & 188.5 & 34.3 & 3 & 55.1 \\
\hline
\end{tabular}

Results in Table 19 show again that the compressive strength increases with curing temperature. The lowest average $f_{c}$ was measured for group I10 even though they were cured longer than any other group. These average values and standard deviations are compared to model predictions in Chapter 5. Elastic modulus was only measured for a few groups but are similar to those plotted in Figure 12.

\subsubsection{Early-age variability results}

Compressive strength results of early-age variability (EAV) specimens are given in Appendix A Table A-20. At $24 \mathrm{hr}$, EAV specimens were still soft and had not quite set up entirely. The average compressive strength was recorded to be $1.98 \mathrm{MPa}$ with a standard deviation of $0.51 \mathrm{MPa}$ for EAV-1 to EAV-30, which were kept in the curing room $\left(\mathrm{CE}_{3}\right)$, while EAV-31 and EAV-32 $\left(\mathrm{CE}_{1}\right)$ recorded an $\mathrm{f}_{\mathrm{c}}$ of $1.6 \mathrm{MPa}$. Compared to I23 specimens, the compressive strength at 1 day for EAV specimens was much lower. 


\subsubsection{Isothermal curing results - Moisture Effects}

Figure 15 compares I23 (lime-water) and I23CR (moist curing room) curing methods using equality plots. Raw data for I23CR specimens is given in Appendix A Tables A-21 to A-23. Figure 15a compares compressive strengths for 71 specimens cured for the same duration and shows that the submerged lime-water bath recorded $11 \%$ higher strength (according to linear regression through the origin), highlighting the importance of moisture availability for UHPC strength gain.

Similarly, Figure 15b compares elastic modulus of 16 I23 and I23CR specimens. Elastic modulus for these two curing groups were collected at staggered times but with the same interval of time in between consecutive tests. The average age of I23 specimens is 1.4 days younger than corresponding I23CR specimens. Similar to $\mathrm{f}_{\mathrm{c}}$, E for I23 specimens is $12 \%$ higher than for I23CR. For all 16 pairs, I23 was stiffer than I23CR. These trends suggest that isothermal $f_{c}$ and E results of moist cured specimens could be approximately adjusted to submerged conditions by multiplying by a factor of 1.1 .

Figure 15. Moisture effects for (a) compressive strength (b) and elastic modulus.
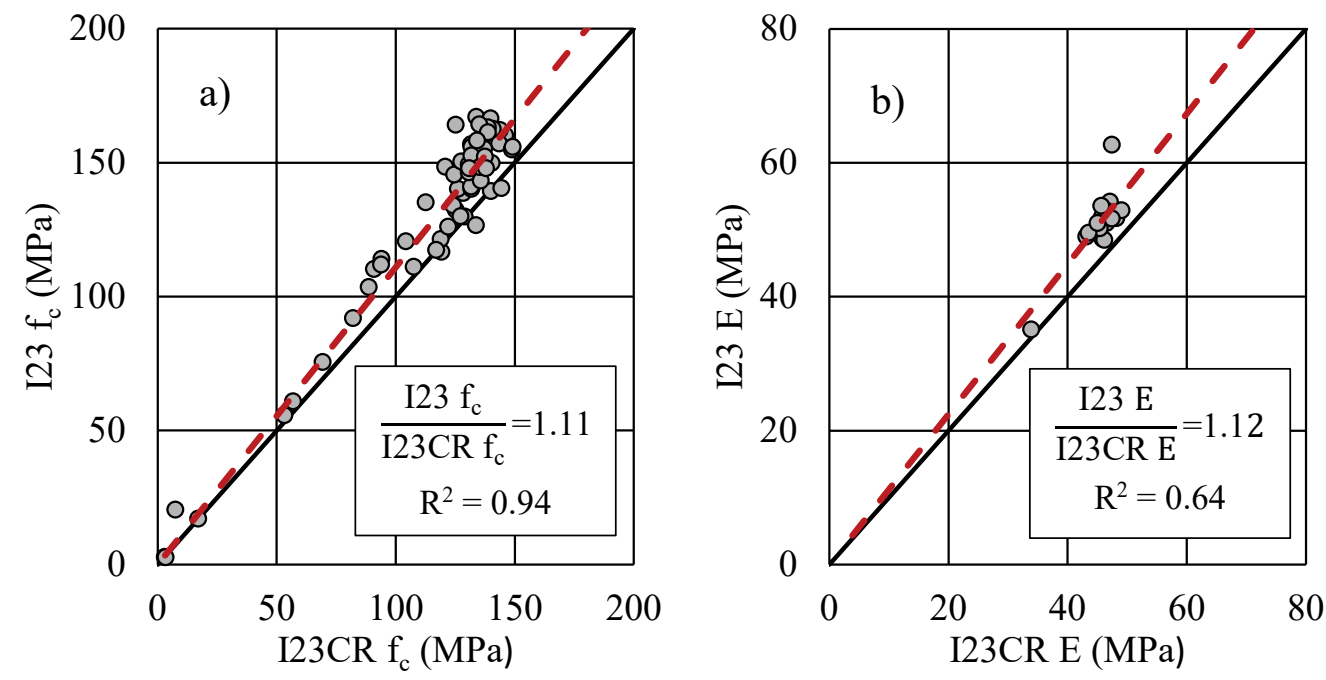

\subsubsection{Mixed temperature curing results}

Compressive strength and elastic modulus results for mixed temperature curing specimens are summarized in Tables 20 and 21, respectively. Raw data for groups SC, M2, M13, M2O, and M27 are provided in Appendix A Tables A-24 to A-28. As can be seen, $S C$ resulted in the highest $f_{c}$ 
compared to M2, M13, M2O, and M27. The coefficient of variation (COV) was also lowest for SC specimens. Elastic modulus was consistent across all five data sets with an overall average value of $50.4 \mathrm{GPa}$. There does not appear to be a clear trend indicating that the increased/decreased duration of time in the curing room $\left(\mathrm{CE}_{3}\right)$ is directly linked to higher compressive strength or elastic modulus for these specimens.

Table 20. Mixed temperature curing compressive strength results.

\begin{tabular}{|c|c|c|c|c|c|c|}
\hline \multirow[b]{2}{*}{ Data Set } & \multirow[b]{2}{*}{ Age } & \multirow[b]{2}{*}{ Maturity } & \multicolumn{4}{|c|}{$f_{c}$} \\
\hline & & & $\begin{array}{l}\text { Avg. } \\
\text { (MPa) }\end{array}$ & $\begin{array}{l}\text { Stdev } \\
\text { (MPa) }\end{array}$ & $\begin{array}{r}\text { COV } \\
(\%)\end{array}$ & $\mathrm{n}$ \\
\hline SC & 14.07 & 790.6 & 179.2 & 10.3 & $5.7 \%$ & 30 \\
\hline M2 & 10.03 & 698.2 & 175.4 & 13.1 & $7.5 \%$ & 8 \\
\hline M13 & 21.13 & 955.0 & 161.9 & 13.4 & $8.3 \%$ & 8 \\
\hline M20 & 28.01 & 1111.2 & 167.9 & 12.6 & $7.5 \%$ & 8 \\
\hline M27 & 34.99 & 1272.8 & 171.4 & 11.3 & $6.6 \%$ & 8 \\
\hline
\end{tabular}

Note: Avg. = average; Stdev = standard deviation; $\mathrm{COV}=$ coefficient of variation.

Table 21. Mixed temperature curing elastic modulus results.

\begin{tabular}{|c|c|c|c|c|}
\hline \multirow{2}{*}{ Data Set } & \multicolumn{4}{|c|}{$\mathrm{E}$} \\
\cline { 2 - 5 } & $\begin{array}{c}\text { Avg. } \\
(\mathrm{GPa})\end{array}$ & $\begin{array}{c}\text { Stdev } \\
(\mathrm{GPa})\end{array}$ & $\begin{array}{c}\text { COV } \\
(\%)\end{array}$ & $\mathrm{n}$ \\
\hline $\mathrm{SC}$ & 50.3 & 2.0 & $4.0 \%$ & 15 \\
\hline M2 & 50.4 & 3.3 & $6.5 \%$ & 4 \\
\hline M13 & 51.4 & 3.3 & $6.5 \%$ & 4 \\
\hline M20 & 49.5 & 1.2 & $2.5 \%$ & 4 \\
\hline M27 & 50.8 & 1.0 & $1.9 \%$ & 4 \\
\hline
\end{tabular}

Note: Avg. = average; Stdev = standard deviation; $\mathrm{COV}=$ coefficient of variation.

\subsubsection{Set time results}

The results of ASTM C4O3 (2016) set time are presented in Table 22. Higher temperature testing of covered specimens resulted in drastically lower time to set of roughly 6 to $7.5 \mathrm{hr}$. At room temperature and $17^{\circ} \mathrm{C}$, the set time of covered specimens was similar with an average of $15.0 \mathrm{hr}$. At room temperature, uncovered testing resulted in two very different results. Further testing should be conducted to better understand how specimen 
temperature affects the time to set and how best to cover specimens to represent an application of interest.

Table 22. ASTM C403 set time results.

\begin{tabular}{|c|c|}
\hline ID & $\begin{array}{c}\text { Set Time } \\
\text { (hours) }\end{array}$ \\
\hline $17^{\circ} \mathrm{C}-1$ & 15.0 \\
\hline $17^{\circ} \mathrm{C}-2$ & 15.5 \\
\hline $23^{\circ} \mathrm{C}-1$ & 14.0 \\
\hline $23^{\circ} \mathrm{C}-2$ & 16.0 \\
\hline $23^{\circ} \mathrm{C}-3$ (no top) & 7.0 \\
\hline $23^{\circ} \mathrm{C}-4$ (no top) & 15.0 \\
\hline $50^{\circ} \mathrm{C}-1$ & 6.0 \\
\hline $50^{\circ} \mathrm{C}-2$ & 7.5 \\
\hline
\end{tabular}

\subsection{Thermodynamical data collection}

Temperature measurements for thermodynamical testing were recorded using type $\mathrm{K}$ thermocouples. These TCs were then attached to a Pico ${ }^{\circledR}$ Technology data logger model TC-08. Each individual data logger had eight ports for thermocouples; so depending on the test run, four to six total data loggers were used to record temperature readings. A board was constructed to hold all data loggers in place throughout testing. Data loggers were attached to the board with Velcro then connected to a computer via USB hub (Figure 16). Using software provided by Pico $\circledR$ Technology, temperature measurements were taken every minute from the time UHPC was placed in the mold until thermal equilibrium was reached. The file containing all of the temperature versus time measurements were then converted into an excel file for further data processing and analysis. 
Figure 16. Data logger board configuration.

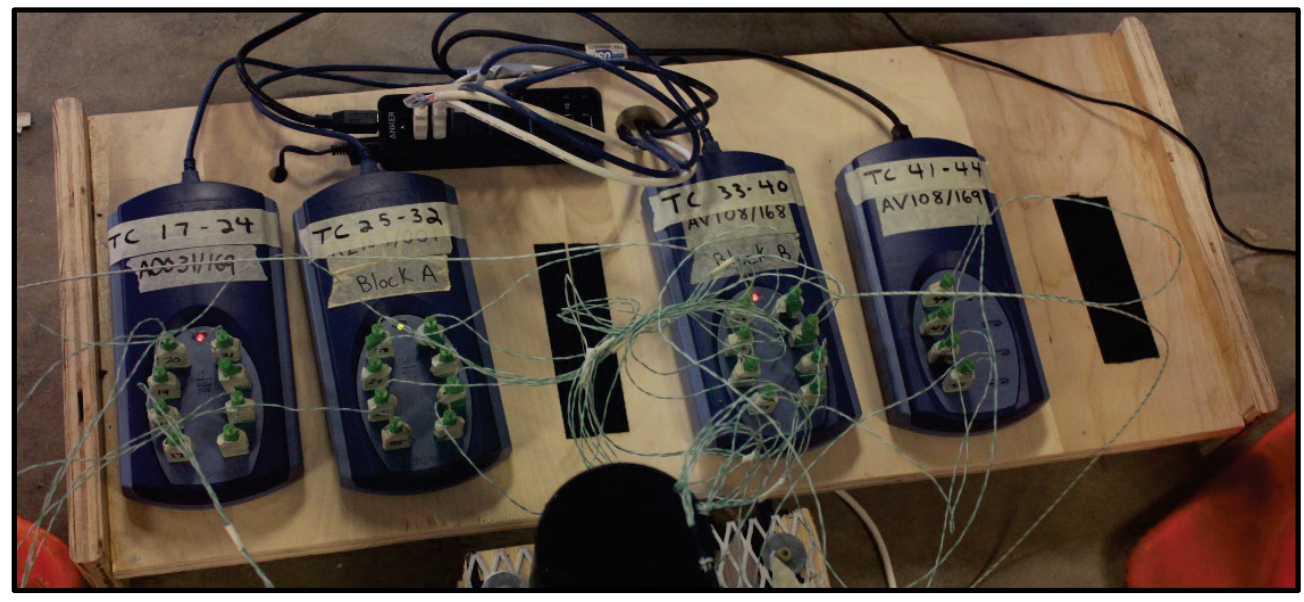




\subsection{Thermodynamical test results}

Temperature versus time data for all internal thermocouples were plotted for 10cm-Cu (Figure 17), 20cm-Cu (Figure 18), and 40cm-Cu (Figure 19). For all cylinders, temperatures at the surface $(\mathrm{r}=$ diameter $/ 2)$, half $(\mathrm{r}=$ diameter/4), and center $(\mathrm{r}=0)$ were averaged regardless of vertical height (Figure 20-26). These plots are intended to show general trends for all thermodynamical test results. Raw data for these plots can be found in OR1.o - Observations Repository (1 of 2) - Thermal Experiments.

Figure 17. 10cm-Cu recorded thermal profile.

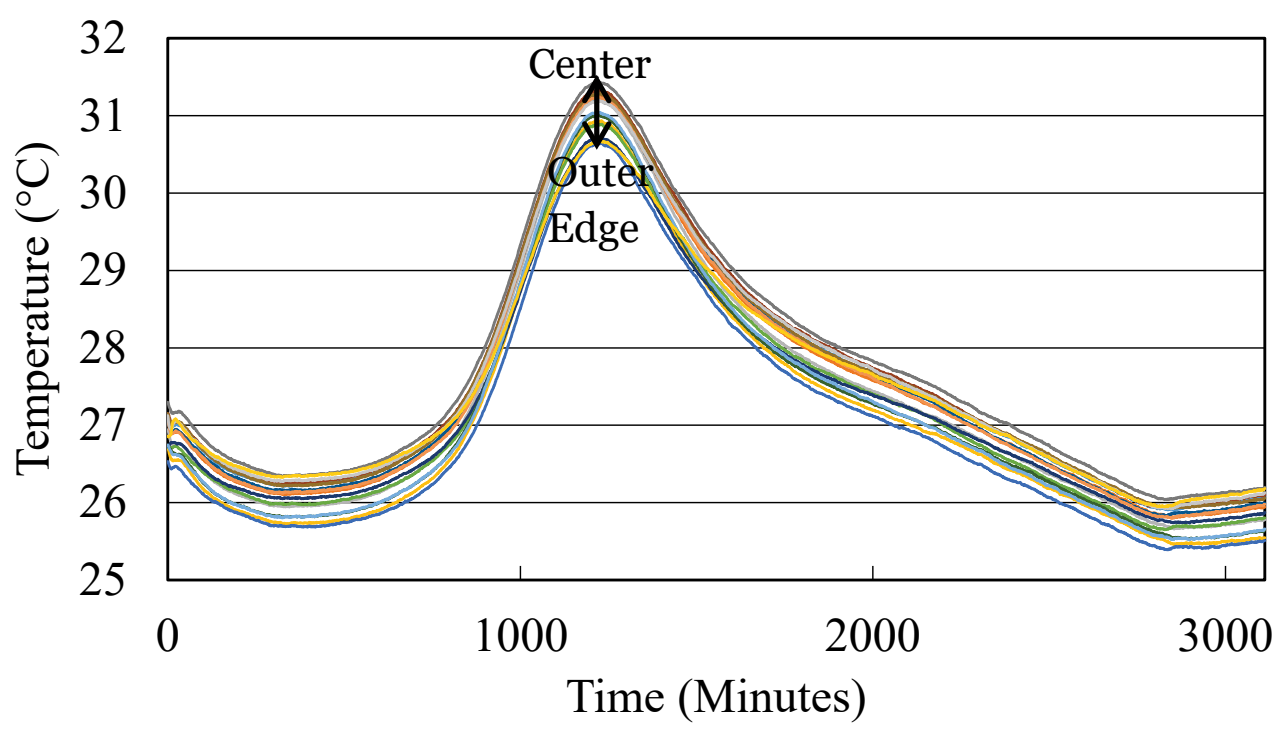


Figure $18.20 \mathrm{~cm}-\mathrm{Cu}$ recorded thermal profile.

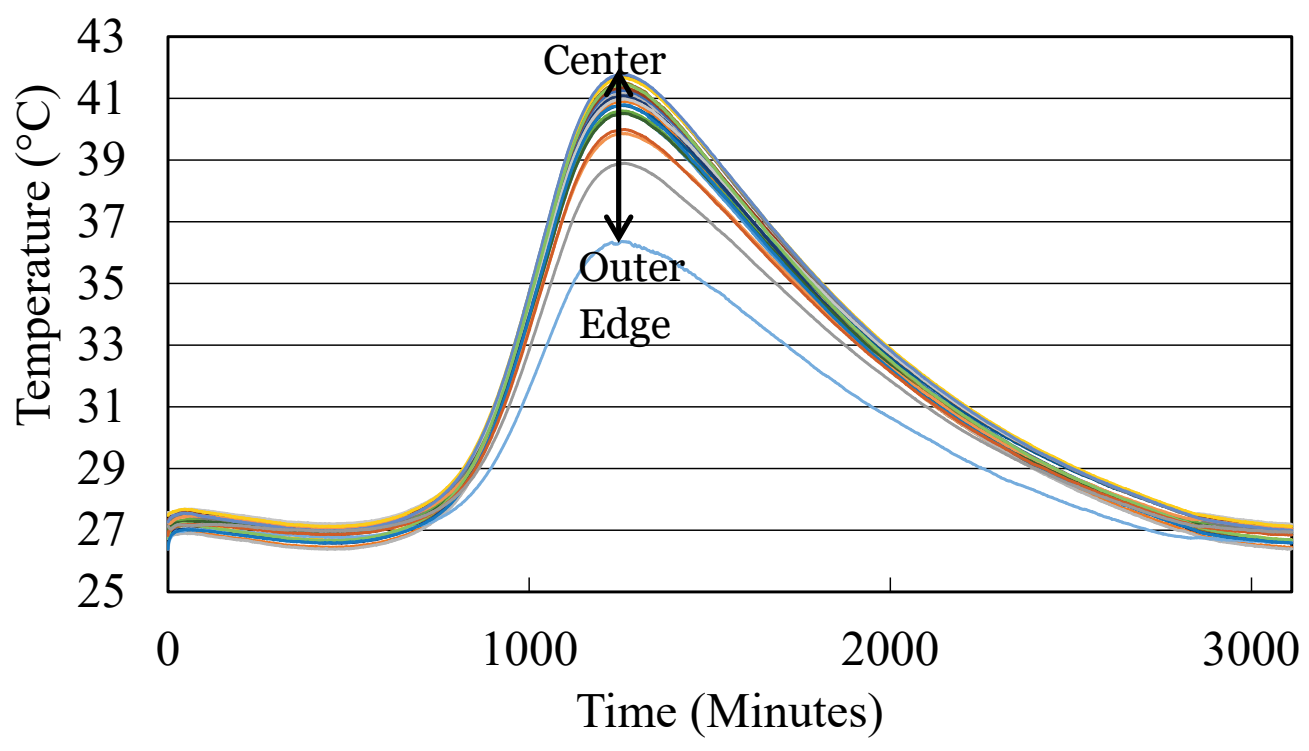

Figure $19.40 \mathrm{~cm}-\mathrm{Cu}$ recorded thermal profile.

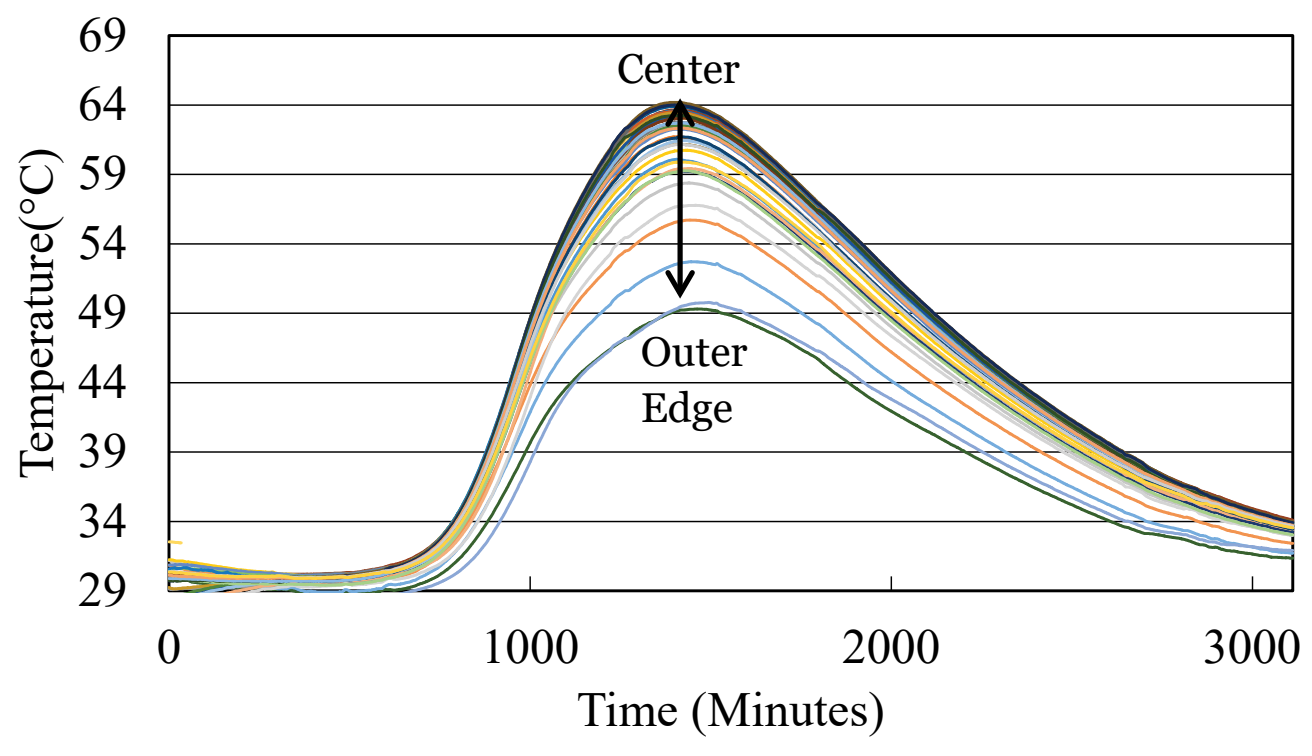


Figure 20. $7.6 \mathrm{~cm}-C y$ average thermal profile.

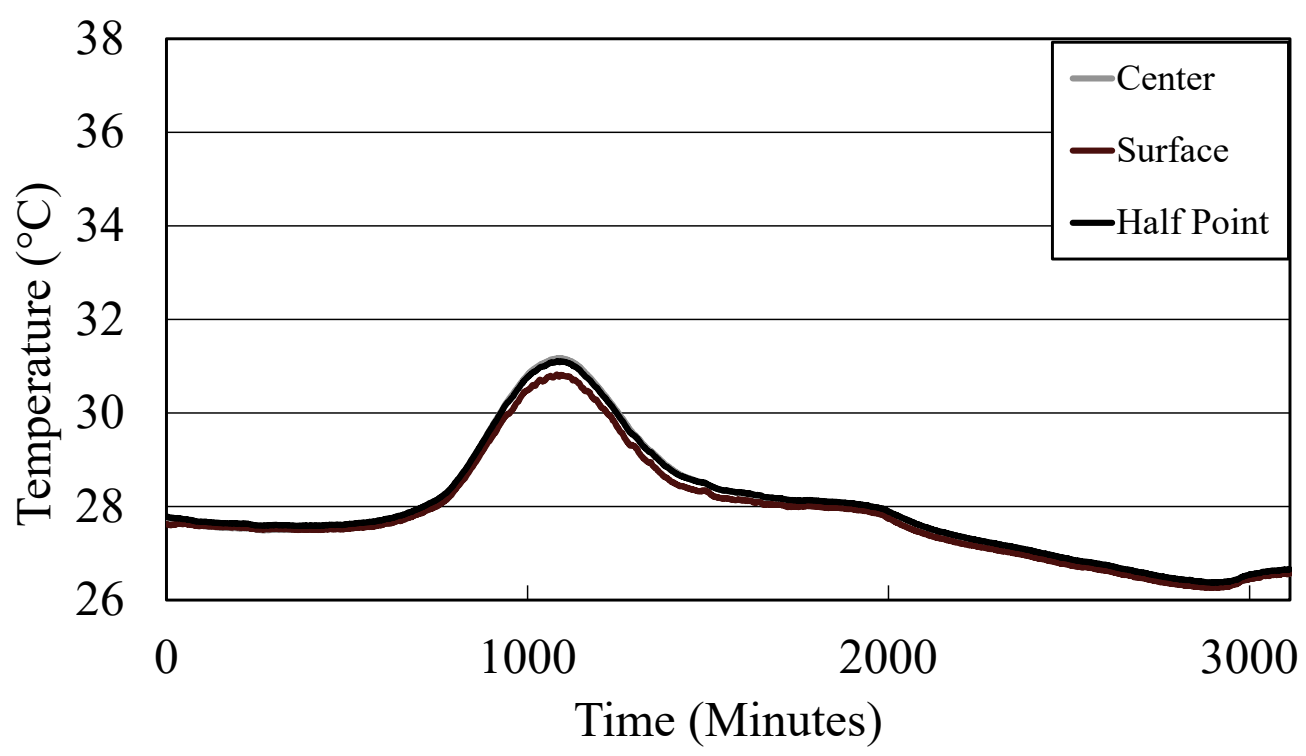

Figure 21. $10.2 \mathrm{~cm}$-Cy average thermal profile.

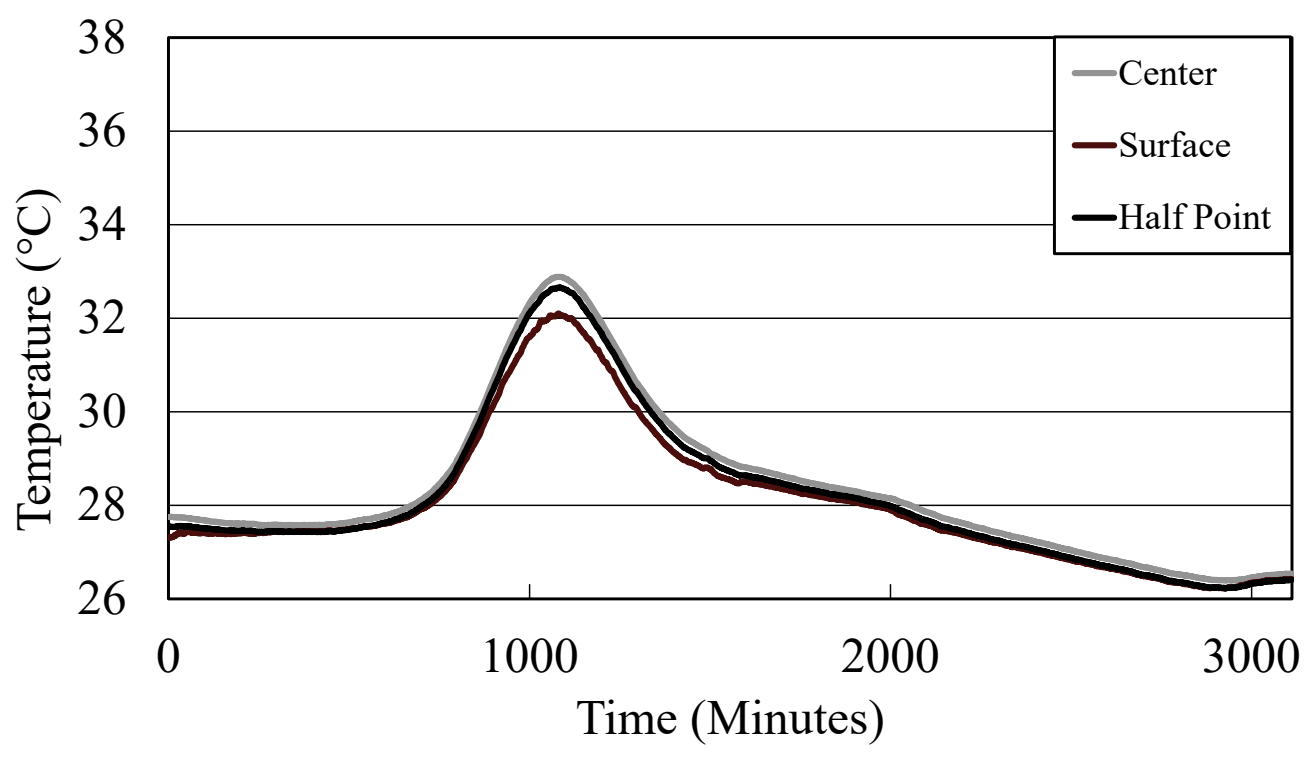


Figure 22. 15.2cm-Cy average thermal profile.

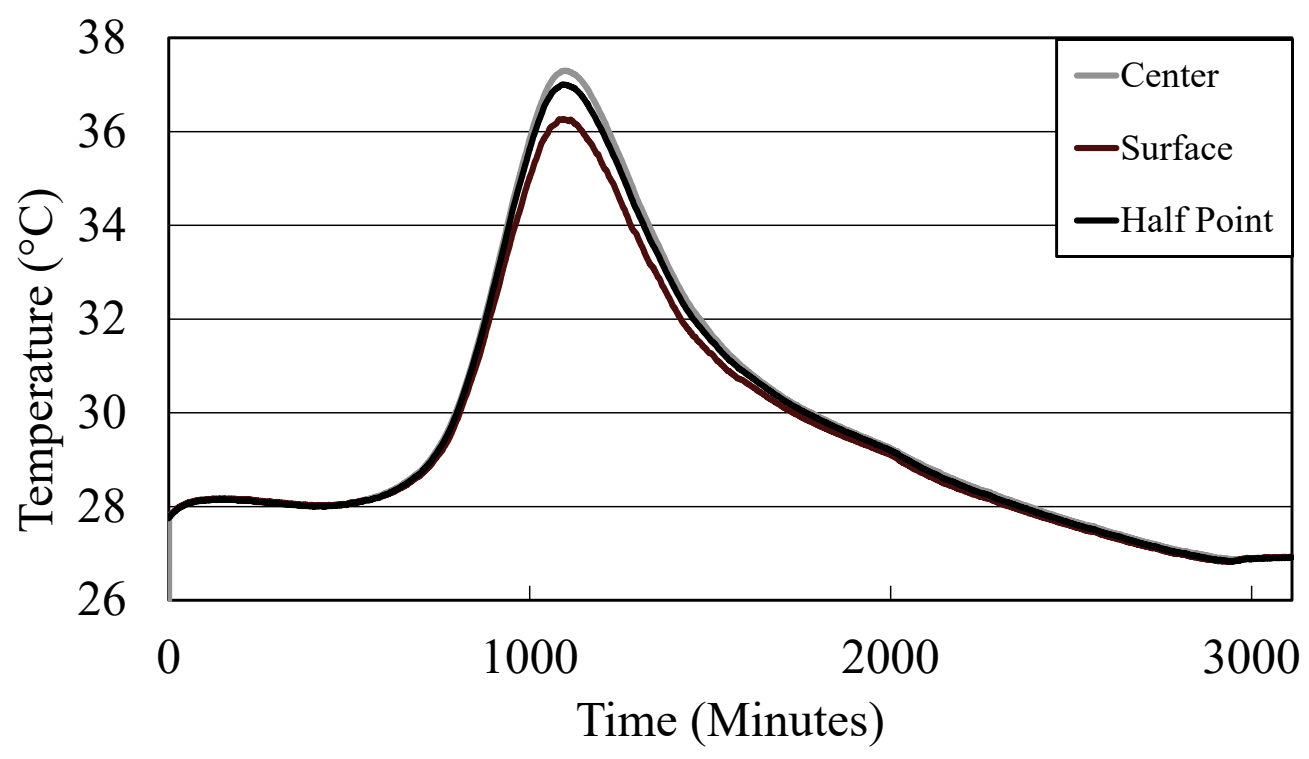

Figure 23. 15.2x15.2-PP average thermal profile.

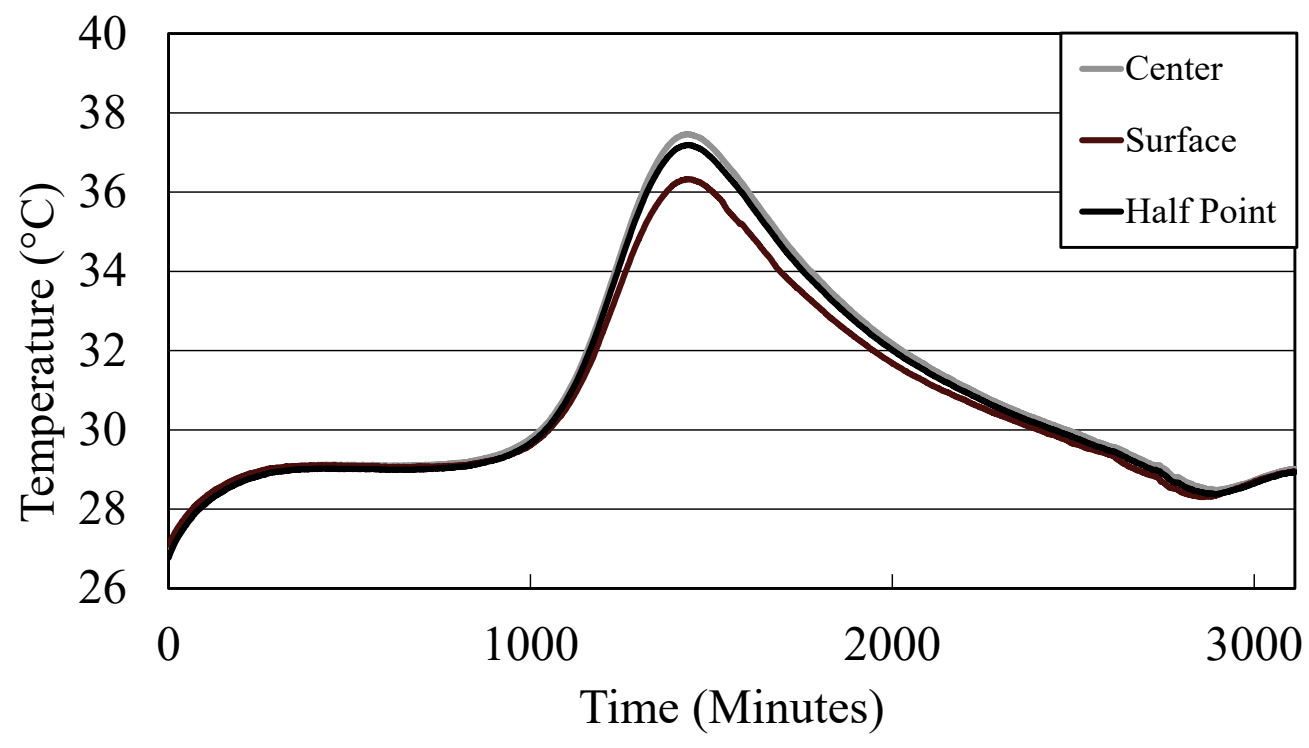


Figure 24. 15.2×30.5-PP average thermal profile.

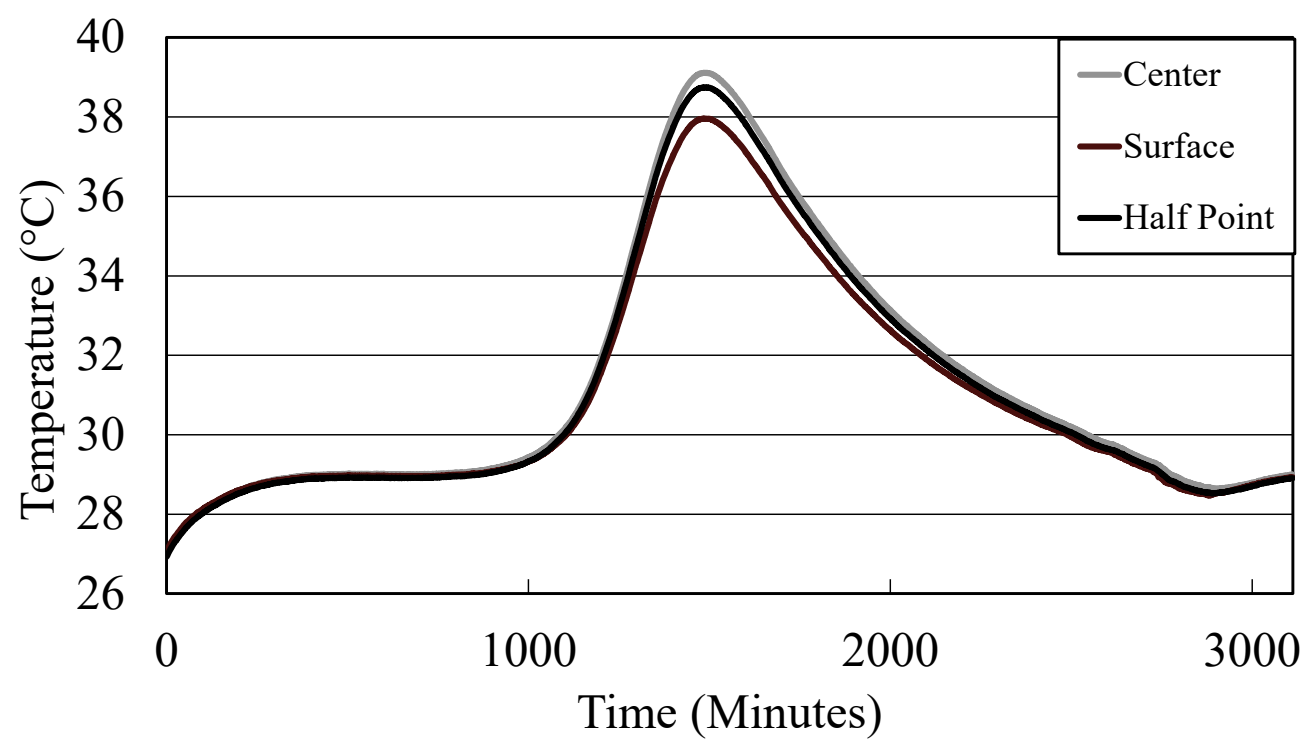

Figure 25. 15.2x15.2-PVC average thermal profile.

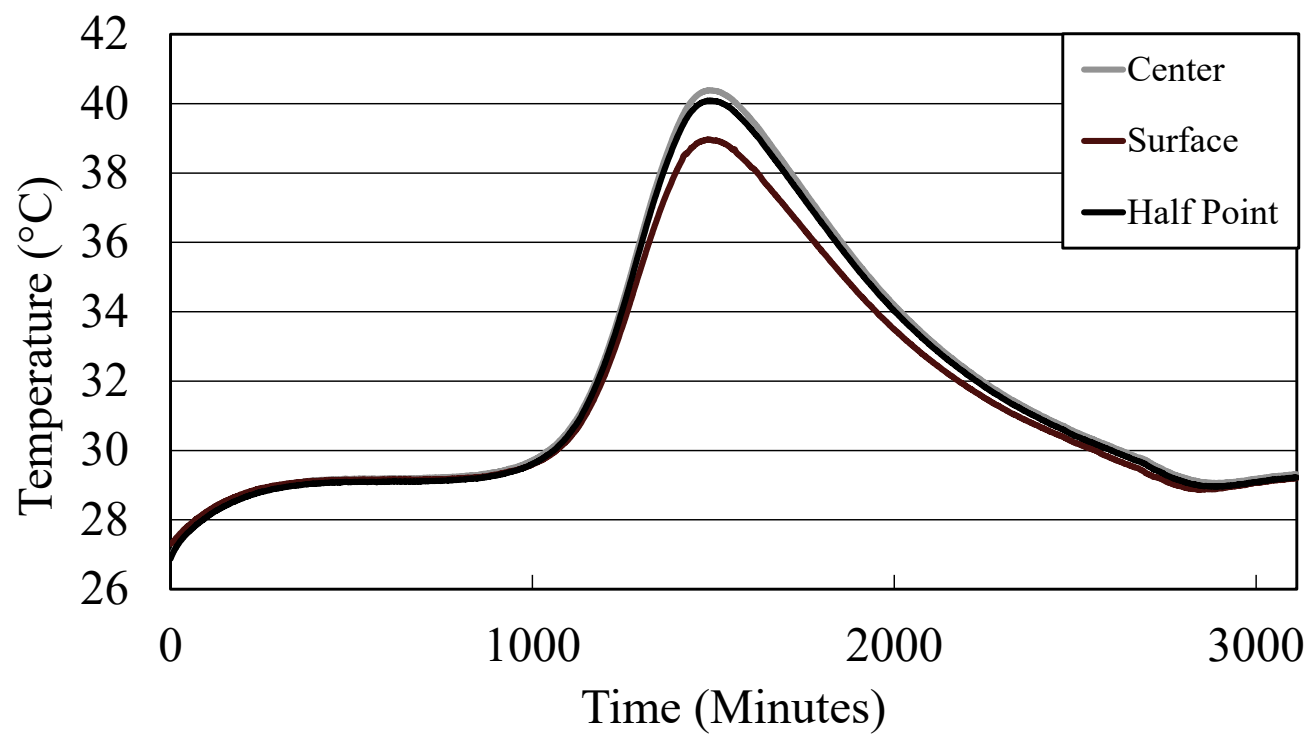


Figure 26. 15.2×30.5-PVC average thermal profile.

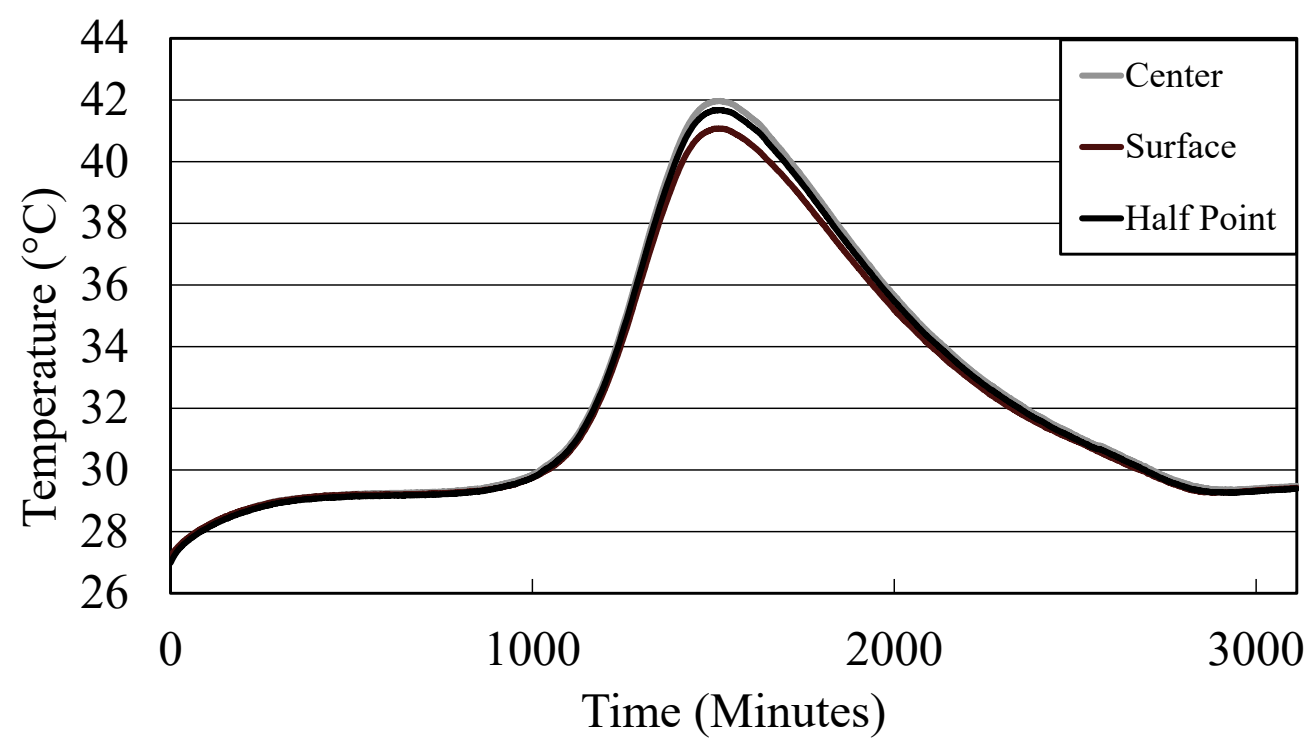

\subsection{Summary of observations repository $\mathbf{1 . 0}$}

A total of 649 specimens were tested for physical property experiments that included density (337 specimens), compressive strength (649 specimens), and elastic modulus (250 specimens). Additionally, ten thermodynamical experiments (three cubes and seven cylinders) were conducted where temperature was recorded during early-age hydration. Not all experiments described in this chapter were used in CORPS-STIF 1.o, but rather are envisioned to be used in future releases of CORPS-STIF. Thermal and mechanical experiments described in this chapter are considered the experimental program of the CORPS-STIF logic as illustrated in Figure 1. Some of these measurements were used refine the numerical models TIF and SIF (described in Chapters 4 and 5, respectively) for use in CORPS-STIF 1.0. 


\section{CORPS-STIF 1.0 Thermodynamical Model}

\subsection{Overview of thermodynamically modeling efforts}

In this chapter, a numerical model for cylindrical conduction through UHPC was developed and validated against experimentally measured thermal performance. The focus of the analysis contained in this chapter is to improve understanding of UHPC's thermal behavior by way of improved modeling of boundary conditions and determination of a convection heat transfer coefficient. While in literature it has been common to assume constant heat transfer coefficient values, this analysis shows that many commonly assumed coefficients over-estimate convection performance for natural convection environments. The findings of this chapter indicate that, for well-studied geometries, it is likely worthwhile to model convection coefficients as a function of time and temperature according to structure geometry, while a constant convection coefficient assumption may be equally valid for geometries that do not have robust correlations available. For well-studied geometries, temperature and time-dependent convection coefficient numerical solutions produced errors under $1 \%$ for all cases, whereas constant convection assumptions produced errors up to $10 \%$. For less-common geometries, model error ranged from $2 \%$ to $5 \%$. In the longer term, this numerical model is intended to be used to improve understanding of thermal convection characteristics of mass UHPC placements so temperature development within a structure can be accurately predicted.

\subsection{Thermodynamical experiments analysis}

As seen in Figures 20 through 26, temperature data for each cylinder was averaged and reduced to show an average temperature at three radial distances $(\mathrm{r})$, i.e., surface $(\mathrm{r}=$ diameter $/ 2)$, half $(\mathrm{r}=$ diameter $/ 4)$, and center $(\mathrm{r}=\mathrm{O})$. To produce these temperature plots it was assumed that there was negligible heat transfer in the $\mathrm{z}$-direction.

The seven cylinders used for numerical modeling were used to assess variable size and variable boundary conditions as shown in Table 23. Since these two experimental programs occurred on different days, different heat generation constants were used. As a result, effects of variable size is denoted as Batch 1 while effects of variable boundary conditions is denoted as Batch 2. 
Table 23. Cylinder experimental program details.

\begin{tabular}{|c|c|c|}
\hline ID & Experimental Program & Batch \\
\hline $7.6 \mathrm{~cm}-\mathrm{Cy}$ & Varying Sizes & 1 \\
\hline $10.2 \mathrm{~cm}-\mathrm{Cy}$ & Varying Sizes & 1 \\
\hline $15.2 \mathrm{~cm}-\mathrm{Cy}$ & Varying Sizes & 1 \\
\hline $15.2 \times 15.2-\mathrm{PP}$ & Varying BC & 2 \\
\hline $15.2 \times 30.5-\mathrm{PP}$ & Varying BC & 2 \\
\hline $15.2 \times 15.2-\mathrm{PVC}$ & Varying BC & 2 \\
\hline 15.2×30.5-PVC & Varying BC & 2 \\
\hline Cy $=$ Cylinder; PP = polypropylene; PVC = polyvinyl chloride pipe; BC = boundary condition.
\end{tabular}

\subsection{Numerical modeling}

Thermodynamic models were created using Python simulation software to determine a temperature profile within a cylinder, and these models were then validated against experimental data outlined previously. The experimental data comparison allows for refinement of model parameters, such as concrete properties (thermal conductivity, specific heat, density, etc.), surface parameters, and environmental parameters (convection coefficient), and provides evidence that modeling efforts accurately predict thermal gradients. The numerical model is for a transient, UHPC cylinder with the majority of heat transfer assumed to be in the radial direction, i.e., cylinder top and bottom will be at approximately same temperature and $\Delta \mathrm{T}_{\text {longitudinal is negligible (Bejan 2004). Mathematically, radial }}$ conduction through a cylinder is governed by the Energy Equation (incorporating Fourier's Law) (Equation 9), which includes heat generation to account for heat of hydration (Bergman et al. 2011).

$$
\frac{1}{r} \cdot \frac{\partial}{\partial r}\left(\kappa \cdot r \cdot \frac{\partial T}{\partial r}\right)+\dot{q}=\rho \cdot c_{p} \cdot \frac{\partial T}{\partial t}
$$

Where

$$
\begin{aligned}
r & =\text { radius } \\
\kappa & =\text { thermal conductivity } \\
T & =\text { temperature } \\
\dot{q} & =\text { heat generation } \\
\rho & =\text { density } \\
c_{p} & =\text { specific heat } \\
t & =\text { time }
\end{aligned}
$$


In this model, heat generation ( $\dot{\mathrm{q}})$ was determined using an Arrhenius type model similar to those outlined by Di Luzio and Cusatis (2009a), Ulm and Coussy (1995), and Cervera et al. (1999). Heat generation was modeled according to relationships defined by Di Luzio and Cusatis (2009a); however, hydration degree, $\alpha$, was modeled as a function of temperature and time based on the work of Ulm and Coussy (1995) and Cervera et al. (1999). Thus, the equations representing maturity of the UHPC, hydration degree, affinity, hydration degree rate, and subsequent heat generation due to cement hydration are as follows.

$$
\begin{gathered}
\mu(t)=K \cdot \exp \left(-\frac{E_{a c}}{R} \cdot \frac{1}{T_{\text {ref }}}\right) \cdot t \\
\alpha(t)=1-e^{-\mu(t)} \\
A f(t)=A_{c 1} \cdot\left(\frac{A_{c 2}}{\alpha_{c}^{\infty}}+\alpha(t)\right) \cdot\left(\alpha_{c}^{\infty}-\alpha(t)\right) \cdot \exp \left(-\frac{\eta \cdot \alpha(t)}{\alpha_{c}^{\infty}}\right) \\
\dot{\alpha}(t, T)=A f(t) \cdot \exp \left(-\frac{E_{a c}}{R} \cdot \frac{1}{T}\right) \\
\dot{\mathrm{Q}}(\mathrm{t}, \mathrm{T})=\dot{\alpha}(\mathrm{t}, \mathrm{T}) \cdot \mathrm{cm} \cdot \mathrm{Q}_{\mathrm{c}}^{\infty}
\end{gathered}
$$

where $\mu(t)$ is the UHPC maturity relationship, $E_{a c}$ is the cement hydration activation energy, $\mathrm{R}$ is the universal gas constant, $\mathrm{T}_{\text {ref }}$ is a reference temperature $\left(-10^{\circ} \mathrm{C}\right), \mathrm{t}$ is time, $\alpha$ is the hydration degree, Af is the affinity of the reaction, $\alpha_{c}{ }^{\infty}$ is asymptotic degree of hydration, $\dot{Q}$ is the rate of heat generated (per unit volume) due to cement hydration, $\mathrm{cm}$ is the cement mass content, and $\mathrm{Q}_{c^{\infty}}$ is the latent heat of reaction per unit hydrated mass. $\mathrm{K}, \mathrm{A}_{\mathrm{c} 1}, \mathrm{~A}_{\mathrm{c} 2}$, and $\eta$ are constants calibrated through experimental comparison. The value used for quantity Eac/R is $7000 \mathrm{~K}$ (consistent with range of $3000 \mathrm{~K}$ to $8000 \mathrm{~K}$ designated in Di Luzio and Cusatis [2009a]). The asymptotic degree of hydration is calculated based on UHPC batch mixtures (Equations 15-17, Di Luzio and Cusatis [2009a]) and is determined to be 0.485 for the UHPC batching quantities used (Table 2). 


$$
\begin{gathered}
\alpha_{\mathrm{s}}^{\infty}=0.89 \cdot \min \left(1, \frac{\mathrm{s} / \mathrm{c}_{\mathrm{req}}}{\mathrm{sm} / \mathrm{cm}}\right) \\
\mathrm{s} / \mathrm{c}_{\mathrm{req}}=\min (0.16,0.4 \cdot \mathrm{wm} / \mathrm{cm}) \\
\alpha_{\mathrm{c}}^{\infty}=\frac{1.032 \cdot(\mathrm{wm} / \mathrm{cm})-0.279 \cdot(\mathrm{sm} / \mathrm{cm}) \cdot \alpha_{\mathrm{s}}^{\infty}}{0.194+\mathrm{wm} / \mathrm{cm}}
\end{gathered}
$$

where $\alpha_{s}{ }^{\infty}$ is the asymptotic value for the degree of silica fume reaction, $\mathrm{sm}, \mathrm{cm}$, and $\mathrm{wm}$ are the mass quantities of silica fume, class $\mathrm{H}$ cement, and water, respectively, and $\mathrm{s} / \mathrm{c}_{\mathrm{req}}$ is the minimum required ratio for the silica fume reaction to consume all calcium hydroxide. The latent heat of reaction is assumed to be $550 \mathrm{~kJ} / \mathrm{kg}$, consistent with Di Luzio and Cusatis, (2009a). Values for $\mathrm{K}, \mathrm{A}_{\mathrm{c1}}, \mathrm{A}_{\mathrm{c} 2}$, and $\eta$ were updated for each batch and are listed in Table 24. Heat generation due to silica fume reaction was modeled in a similar fashion and found to be negligible.

Table 24. Calibrated heat generation constants.

\begin{tabular}{|c|c|c|}
\hline Parameter & Batch 1 & Batch 2 \\
\hline$K$ & $680 \cdot 10^{3}$ & $151 \cdot 10^{4}$ \\
\hline$A_{c 1}\left(h^{-1}\right)$ & $293 \cdot 10^{7}$ & 390 \\
\hline$A_{c 2}$ & $15 \cdot 10^{-3}$ & 25 \\
\hline$\eta$ & 6.5 & 7 \\
\hline
\end{tabular}

The value for density $(\rho)$ was determined using average values from previous experimental testing of the same UHPC. Values for thermal conductivity $(\kappa)$ and specific heat $\left(c_{p}\right)$ were determined using (Di Luzio and Cusatis 2009b). Final values utilized for thermal conductivity, density, and specific heat were assumed constant over the temperature ranges considered (Table 25), thus Equation 9 can be reduced to Equation 18 where aTD is thermal diffusivity.

$$
\frac{1}{\mathrm{r}} \cdot \frac{\partial}{\partial \mathrm{r}}\left(\mathrm{r} \cdot \frac{\partial \mathrm{T}}{\partial \mathrm{r}}\right)+\frac{\dot{\mathrm{q}}}{\kappa}=\frac{1}{\alpha_{\mathrm{TD}}} \cdot \frac{\partial \mathrm{T}}{\partial \mathrm{t}}
$$


Table 25. Constant concrete properties.

\begin{tabular}{|c|c|c|c|}
\hline Property & Symbol & Value & Units \\
\hline Thermal Conductivity & $\mathrm{K}$ & 2.3 & $\mathrm{~W} / \mathrm{m} \cdot \mathrm{K}$ \\
\hline Density & $\rho$ & 2520 & $\mathrm{Kg} / \mathrm{m}^{3}$ \\
\hline Specific Heat & $\mathrm{C}_{\mathrm{p}}$ & 1100 & $\mathrm{~J} / \mathrm{kg} \cdot \mathrm{K}$ \\
\hline Thermal Diffusivity & $\alpha_{\text {TD }}$ & $8.3 \times 10^{-7}$ & $\mathrm{~m}^{2} / \mathrm{s}$ \\
\hline
\end{tabular}

For this governing equation, two boundary conditions (BCs) and one initial condition (IC) are required. These are modeled for the cylinder by noting that maximum temperature should occur along the centerline, when $r=0$, and that the surface of the cylinder insulation is exposed to combined convection and radiative heat transfer. For the initial condition, the initial temperature of the cylinder is considered uniform and at the average experimentally-measured initial temperature of each batch $\left(300.9^{\circ} \mathrm{K}\right.$ and $300.1^{\circ} \mathrm{K}$, respectively), and the average ambient temperature for each batch, $\mathrm{T}_{\infty}$, is measured as $299.6^{\circ} \mathrm{K}$ and $301.6^{\circ} \mathrm{K}$, respectively. To determine the heat transfer coefficient (h), free convection average Nusselt number correlations for vertical cylinders were taken from Bejan (2004). For the cylinders with diameter-toheight ratio of 1:2, the following correlation was used.

$$
\overline{\mathrm{Nu}_{\mathrm{H}}}=\frac{4}{3} \cdot\left(\frac{7 \cdot \mathrm{Ra}_{\mathrm{H}} \cdot \mathrm{Pr}}{5 \cdot(20+21 \mathrm{Pr})}\right)^{\frac{1}{4}}+\frac{4(272+315 \mathrm{Pr}) \mathrm{H}}{35(64+63 \mathrm{Pr}) \mathrm{D}}
$$

where Raн is the Rayleigh number based on height, Pr is the Prandtl number of the fluid (air), and $\mathrm{H}$ and $\mathrm{D}$ are the height and diameter of the cylinder, respectively. For the cylinders with a diameter to height ratio of $1: 1$, the correlation used is

$$
\overline{\mathrm{Nu}_{\mathcal{L}}}=3.47+0.51 \cdot \mathrm{Ra}_{\mathcal{L}}^{1 / 4}
$$

where $\mathcal{L}$ is the square root of the area of the cylinder and $R a_{\mathcal{L}}$ is the Rayleigh number based on $\mathcal{L}$. Mathematical representations for boundary conditions and the initial condition are shown below in Equations 21-24. 


$$
\begin{gathered}
\left.\frac{\partial \mathrm{T}}{\partial \mathrm{r}}\right|_{\mathrm{r}=0}=0 \\
\left.\left.\kappa_{\text {concrete }} \cdot \frac{\partial \mathrm{T}}{\partial \mathrm{r}}\right|_{\mathrm{r}=\mathrm{R}}=\kappa_{\text {insulation }} \cdot \frac{\partial \mathrm{T}}{\partial \mathrm{r}}\right]_{\mathrm{r}=\mathrm{R}} \\
\left.\kappa_{\text {insulation }} \cdot \frac{\mathrm{dT}}{\mathrm{dr}}\right]_{\mathrm{r}=\mathrm{R}+\mathrm{th}_{\text {ins }}}=\mathrm{h} \cdot\left(\mathrm{T}_{\mathrm{s}}-\mathrm{T}_{\infty}\right)+\varepsilon_{\text {ins }} \cdot \sigma \cdot\left(\mathrm{T}_{\mathrm{s}}^{4}-\mathrm{T}_{\infty}^{4}\right) \\
\mathrm{T}(\mathrm{r}, \mathrm{t}=0)=\mathrm{T}_{\text {ini }}
\end{gathered}
$$

where $\mathrm{h}$ is the convection heat transfer coefficient, $\mathrm{T}_{\mathrm{s}}$ is the surface temperature, $\mathrm{T}_{\text {ini }}$ is the average initial temperature of the concrete, $\mathrm{T}_{\infty}$ is the average ambient air temperature, $\varepsilon_{\text {ins }}$ is the emissivity of the insulation material (discussed in the following section), and $\sigma$ is the Stefan-Boltzmann constant.

Using a finite difference approach to approximate derivatives, Equations 18 through 24 can be derived to numerically approximate temperatures at each (radial) nodal location within the cylinder. To run the simulation, an explicit solution for temperature (as a function of radial location and time) was developed in Python. For all simulations, a mesh size of $0.00254 \mathrm{~m}$ (o.1 in) was used, and a time step of $3 \mathrm{sec}$ was used.

\subsection{Numerical modeling results}

After calibrating the heat generation data against a single test specimen for each batch, the integrity of the boundary condition model is examined. Results are shown for Batch 1 in Figures 27 through 33, and for Batch 2 in Figures 34 through 37.

\subsubsection{Effects of size}

As can be seen from examining Figure 27, the heat generation model used does not completely follow the experimental time scale. However, this analysis is focused primarily on examining boundary conditions and boundary model effects. The maximum temperatures achieved and cooling behavior after reaching the maximum temperatures of the numerical model closely approximate experimental behavior. For $7.6 \mathrm{~cm}-\mathrm{Cy}, 10.2 \mathrm{~cm}-$ $\mathrm{Cy}$, and $15.2 \mathrm{~cm}-\mathrm{Cy}$ specimens, a convection coefficient was determined 
using the Nusselt number correlation presented in Equation 19. For $7.6 \mathrm{~cm}-\mathrm{Cy}$, the calculated convection coefficient is shown in Figure 28.

Figure 27. (a) Experimental and (b) simulation temperature versus time results for three temperature locations at a center cross section of $7.6 \mathrm{~cm}-\mathrm{Cy}$.
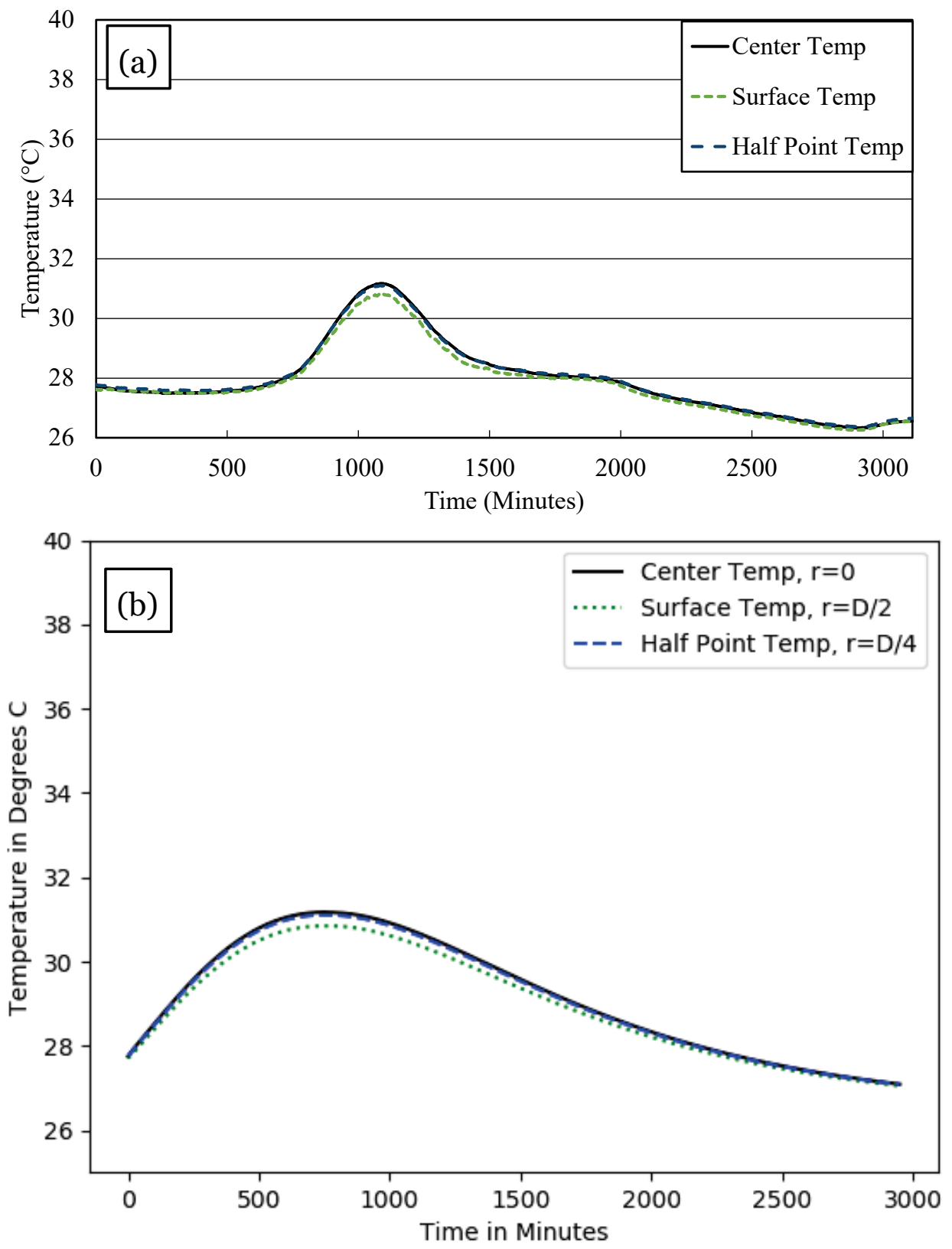
Figure 28. Convection coefficient calculated for $7.6 \mathrm{~cm}-\mathrm{Cy}$.

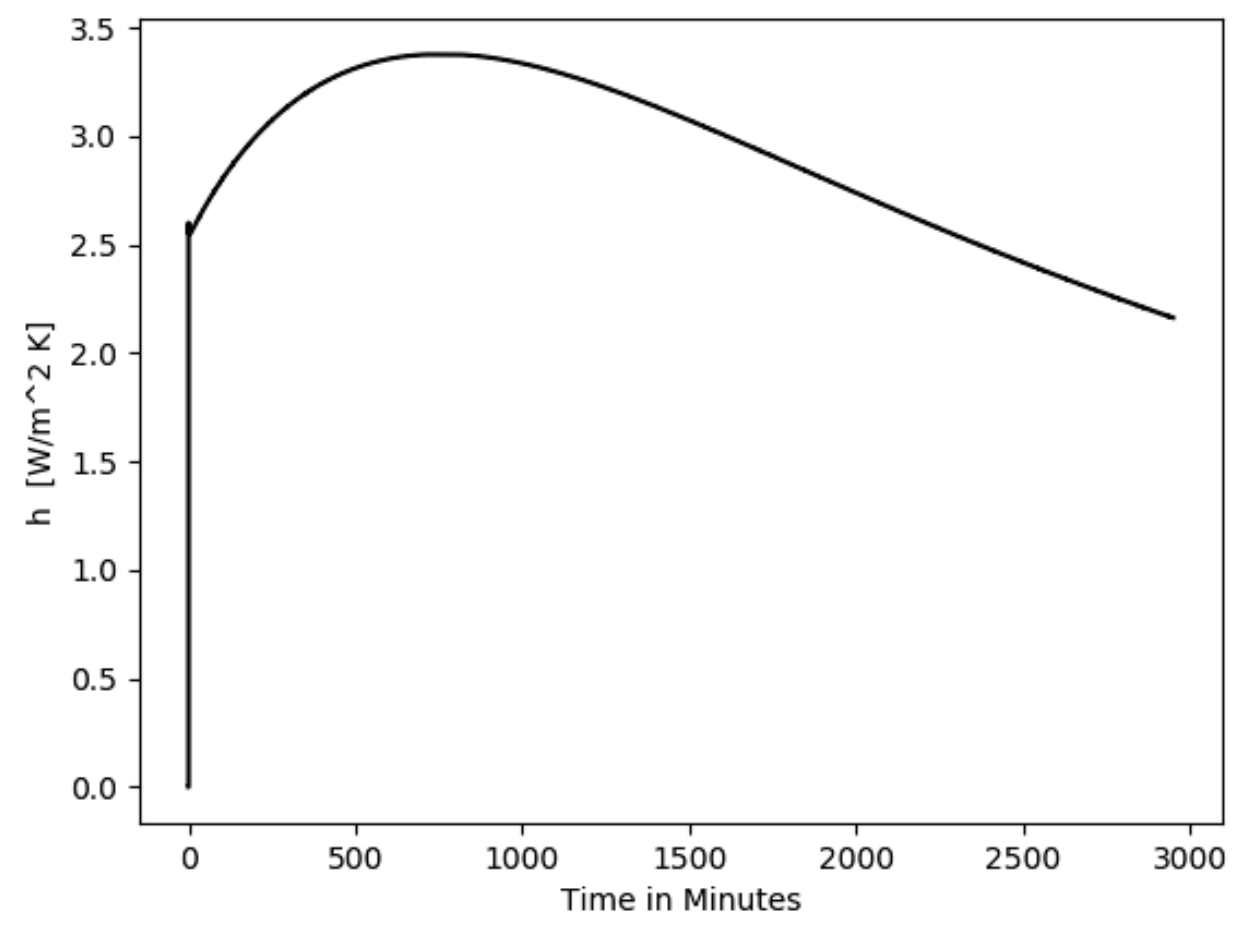

The maximum temperatures attained in the numerical model for $7.6 \mathrm{~cm}-\mathrm{Cy}$ are $31.17^{\circ} \mathrm{C}$ for the center temperature ( $\mathrm{r}=0$, "Center"), $31.10^{\circ} \mathrm{C}$ for the "halfway temperature" ( $\mathrm{r}=$ diameter $/ 4$, "Half Point"), and $30.84^{\circ} \mathrm{C}$ for the surface temperature of the cylinder not the polypropylene sleeve $(\mathrm{r}=$ diameter $/ 2$, "Surface"). The corresponding experimental average temperatures for these locations are $31.17^{\circ} \mathrm{C}, 31.10^{\circ} \mathrm{C}$, and $30.82^{\circ} \mathrm{C}$, respectively. Thus, the numerical model is in very good agreement with experimental data. The $7.6 \mathrm{~cm}-\mathrm{Cy}$ model was refined by adjusting heat generation parameters $\mathrm{K}, \mathrm{A}_{\mathrm{c} 1}, \mathrm{~A}_{\mathrm{c} 2}$, and $\eta$ until the model showed proper agreement. However, these same parameters were held constant for subsequent comparative data between the experimental and numerical results, but these parameters were recalibrated for Batch 2. The intent of this study is to highlight the effectiveness of using appropriate, time- and temperature-dependent correlations to determine convection heat transfer coefficients.

Since previous studies found in literature have assumed constant convection coefficients, differences associated with the correlation-based solution compared to several assumed constant $\mathrm{h}$ values are highlighted in this analysis. The constant values compared to the correlation data are 10 $\mathrm{W} / \mathrm{m}^{2} \cdot \mathrm{K}, 7.5 \mathrm{~W} / \mathrm{m}^{2} \cdot \mathrm{K}$, and $4.5 \mathrm{~W} / \mathrm{m}^{2} \cdot \mathrm{K}$ to be representative of the range of constant values used in literature. It can be seen in Figure 28 that, for the 
$7.6 \mathrm{~cm}$-Cy specimen, all of the constant values selected from literature are likely high for the application of these cylinders under the conditions described in the experimental set up. Therefore, a constant convection coefficient value of $2.2 \mathrm{~W} / \mathrm{m}^{2} \cdot \mathrm{K}$, i.e., the average value for convection coefficient from the correlation result, is also utilized for comparison. Table 26 gives the maximum temperature values achieved and percent error for all coefficients examined for $7.6 \mathrm{~cm}-\mathrm{Cy}$, and Figures 29 and 30 show the temperature versus time plot for each constant coefficient scenario.

Table 26. Error associated with varying $h$ values for $7.6 \mathrm{~cm}-C y$.

\begin{tabular}{|c|c|c|c|c|c|c|c|c|c|c|c|}
\hline \multirow{2}{*}{ Location } & \multirow{2}{*}{$\begin{array}{c}\text { Measured } \\
\text { Temp } \\
\left({ }^{\circ} \mathrm{C}\right)\end{array}$} & \multicolumn{2}{|c|}{$\begin{array}{c}\mathrm{h} \text { from Eq. } 19 \\
\text { correlation }\end{array}$} & \multicolumn{2}{|c|}{$\begin{array}{c}\mathrm{h}=10 \\
\mathrm{~W} / \mathrm{m}^{2} \cdot \mathrm{K}\end{array}$} & \multicolumn{2}{|c|}{$\begin{array}{c}\mathrm{h}=7.5 \\
\mathrm{~W} / \mathrm{m}^{2} \cdot \mathrm{K}\end{array}$} & \multicolumn{2}{|c|}{$\begin{array}{c}\mathrm{h}=4.5 \\
\mathrm{~W} / \mathrm{m}^{2} \cdot \mathrm{K}\end{array}$} & \multicolumn{3}{c|}{$\begin{array}{c}\mathrm{h}=2.2 \\
\mathrm{~W} / \mathrm{m}^{2} \mathrm{~K}\end{array}$} \\
\cline { 3 - 13 } & & $\begin{array}{c}\text { Temp } \\
\left({ }^{\circ} \mathrm{C}\right)\end{array}$ & $\begin{array}{c}\text { Error } \\
(\%)\end{array}$ & $\begin{array}{c}\text { Temp } \\
\left({ }^{\circ} \mathrm{C}\right)\end{array}$ & $\begin{array}{c}\text { Error } \\
(\%)\end{array}$ & $\begin{array}{c}\text { Temp } \\
\left({ }^{\circ} \mathrm{C}\right)\end{array}$ & $\begin{array}{c}\text { Error } \\
(\%)\end{array}$ & $\begin{array}{c}\text { Temp } \\
\left({ }^{\circ} \mathrm{C}\right)\end{array}$ & $\begin{array}{c}\text { Error } \\
(\%)\end{array}$ & $\begin{array}{c}\text { Temp } \\
\left({ }^{\circ} \mathrm{C}\right)\end{array}$ & $\begin{array}{c}\text { Error } \\
(\%)\end{array}$ \\
\hline Center & 31.17 & 31.17 & 0.00 & 29.38 & -5.74 & 29.84 & -4.27 & 30.67 & -1.60 & 31.74 & 1.83 \\
\hline Half Point & 31.10 & 31.10 & 0.00 & 29.32 & -5.72 & 29.78 & -4.24 & 30.61 & -1.58 & 31.67 & 1.83 \\
\hline Surface & 30.82 & 30.84 & 0.06 & 29.07 & -5.68 & 29.52 & -4.22 & 30.35 & -1.52 & 31.42 & 1.95 \\
\hline
\end{tabular}


Figure 29. Simulation temperature results for $7.6 \mathrm{~cm}-\mathrm{Cy}$, assuming constant convection coefficient of (a) $10 \mathrm{~W} / \mathrm{m}^{2} \cdot \mathrm{K}$ and (b) $7.5 \mathrm{~W} / \mathrm{m}^{2} \cdot \mathrm{K}$.
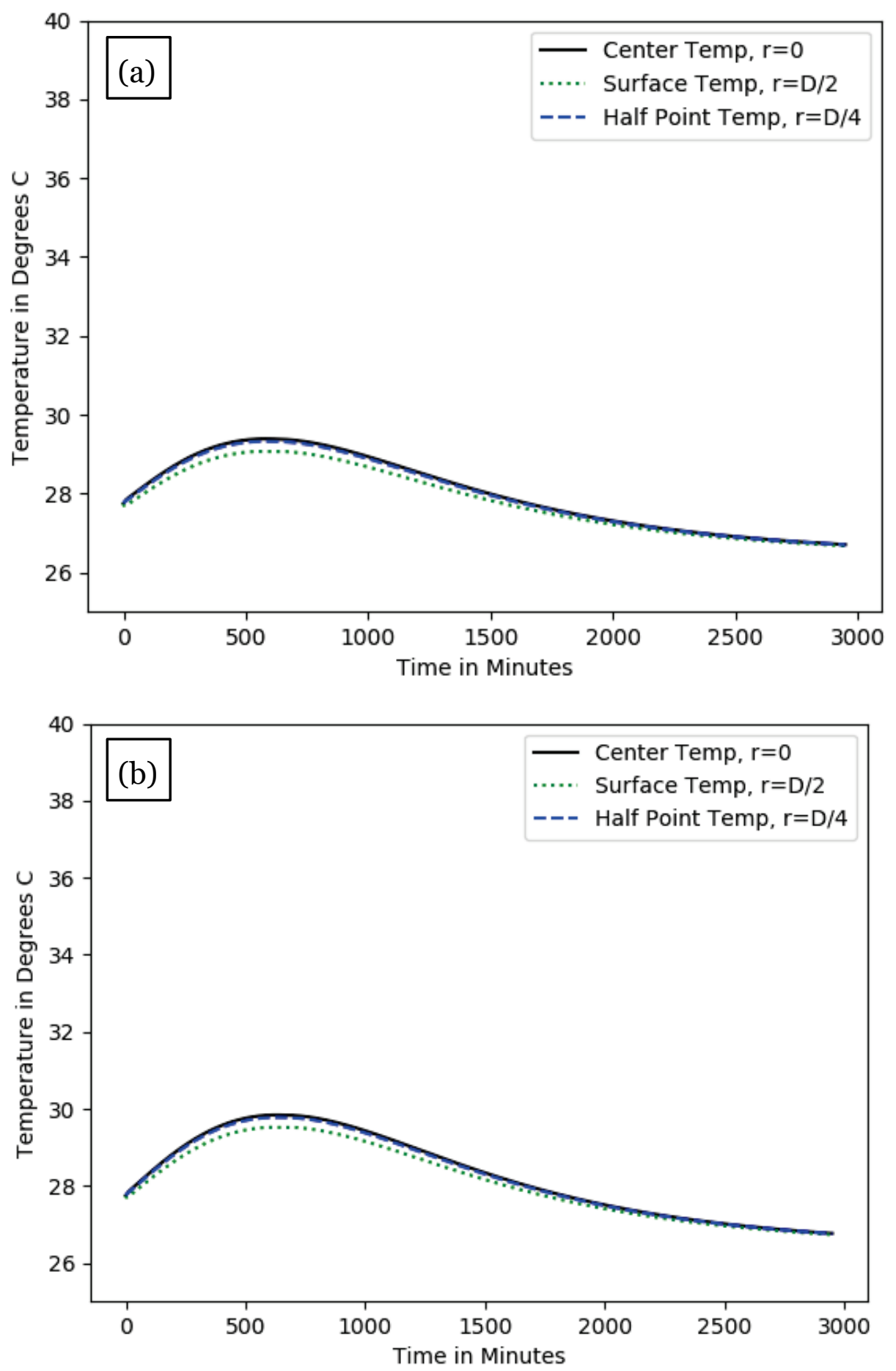
Figure 30. Simulation temperature results for $7.6 \mathrm{~cm}-\mathrm{Cy}$, assuming constant convection coefficient of (a) $4.5 \mathrm{~W} / \mathrm{m}^{2} \cdot \mathrm{K}$ and (b) $2.2 \mathrm{~W} / \mathrm{m}^{2} \cdot \mathrm{K}$.
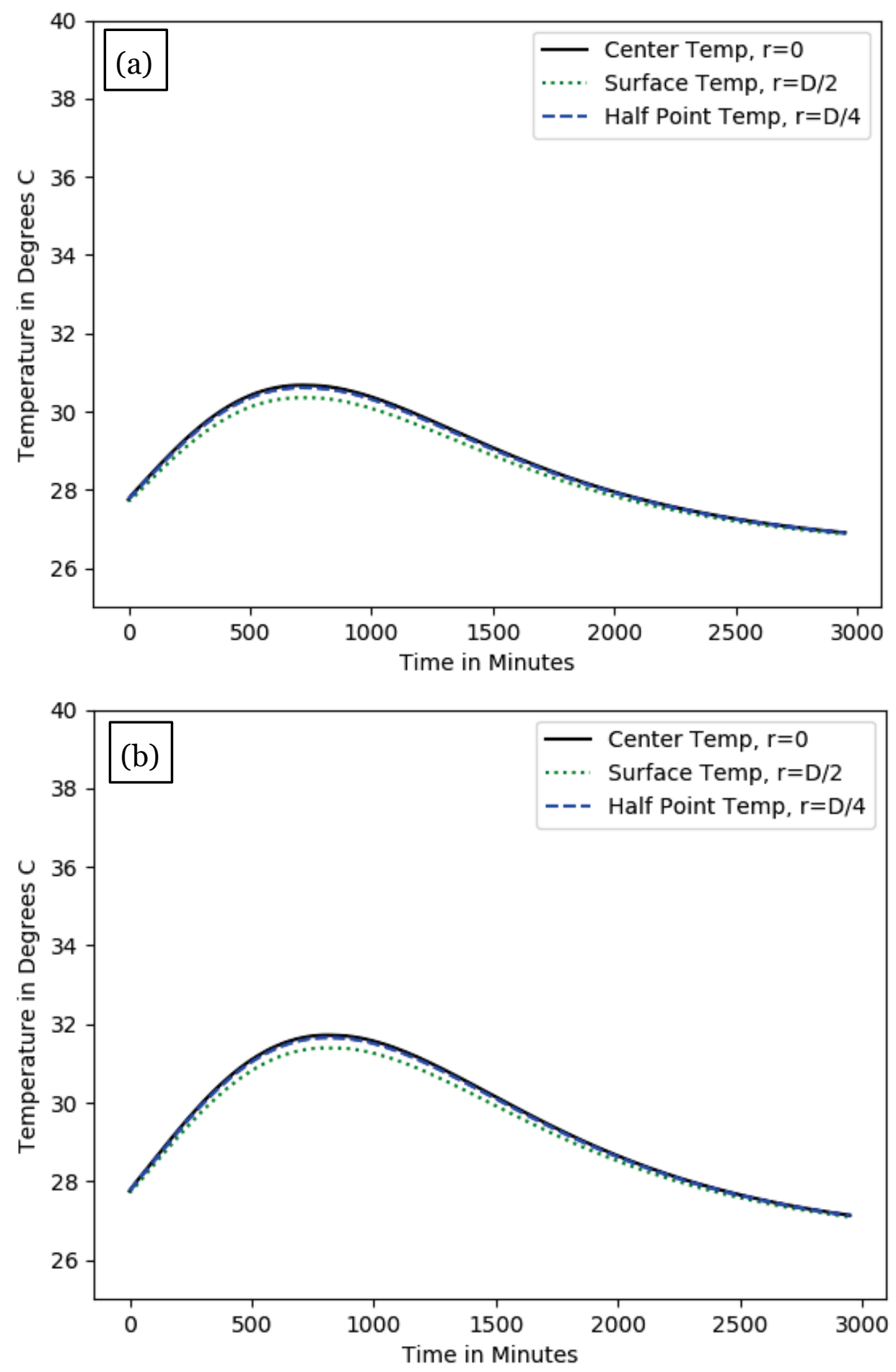

For natural convection in the near-stagnant, hot-air environment in which the experimental data were acquired, it is evident that the typically assumed values for convection coefficient, $10,7 \cdot 5$, and $4.5 \mathrm{~W} / \mathrm{m}^{2} \cdot \mathrm{K}$, over 
predict the convection performance for this environment. When using a constant value for convection coefficient that is closer to the average value calculated over time, the performance for $7.6 \mathrm{~cm}-\mathrm{Cy}$ is better, but still shows error above $1 \%$ and under predicts convection heat transfer performance. However, since h scales with cylinder size according to $\bar{h}=$ $\left(\overline{N u_{H}} \cdot k_{f}\right) / H$ (for a vertical cylinder with natural convection boundary layers on lateral surfaces [Bejan, 2004]), it is expected that the error will increase for subsequent cases when cylinder size varies.

Using the same values for heat generation parameters as those refined for the $7.6 \mathrm{~cm}$-Cy specimen, numerical simulations were also conducted for the $10.2 \mathrm{~cm}$-Cy and $15.2 \mathrm{~cm}-\mathrm{Cy}$ specimens for each convection coefficient scenario. Results for the 10.2cm-Cy are shown in Figures 31 through 33 and Table 27. 
Figure 31 (a) experimental and (b) simulation temperature versus time results for three locations at a center cross section of $10.2 \mathrm{~cm}-\mathrm{Cy}$ and (c) convection coefficient calculated for $10.2 \mathrm{~cm}-\mathrm{Cy}$.
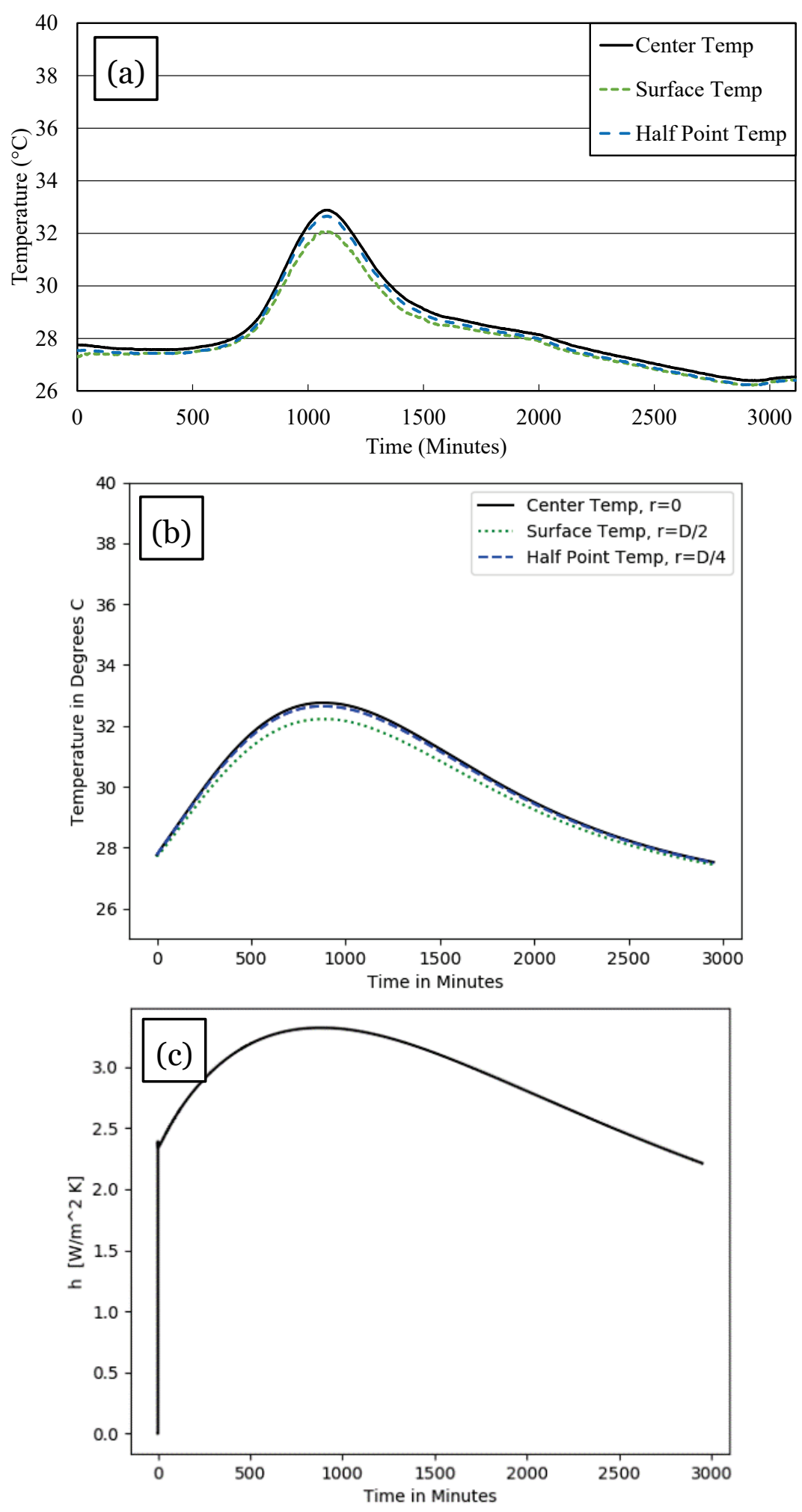
Figure 32. Simulation temperature results for $10.2 \mathrm{~cm}-\mathrm{Cy}$ assuming constant convection coefficient of (a) $10 \mathrm{~W} / \mathrm{m}^{2} \cdot \mathrm{K}$ and (b) $7.5 \mathrm{~W} / \mathrm{m}^{2} \cdot \mathrm{K}$.
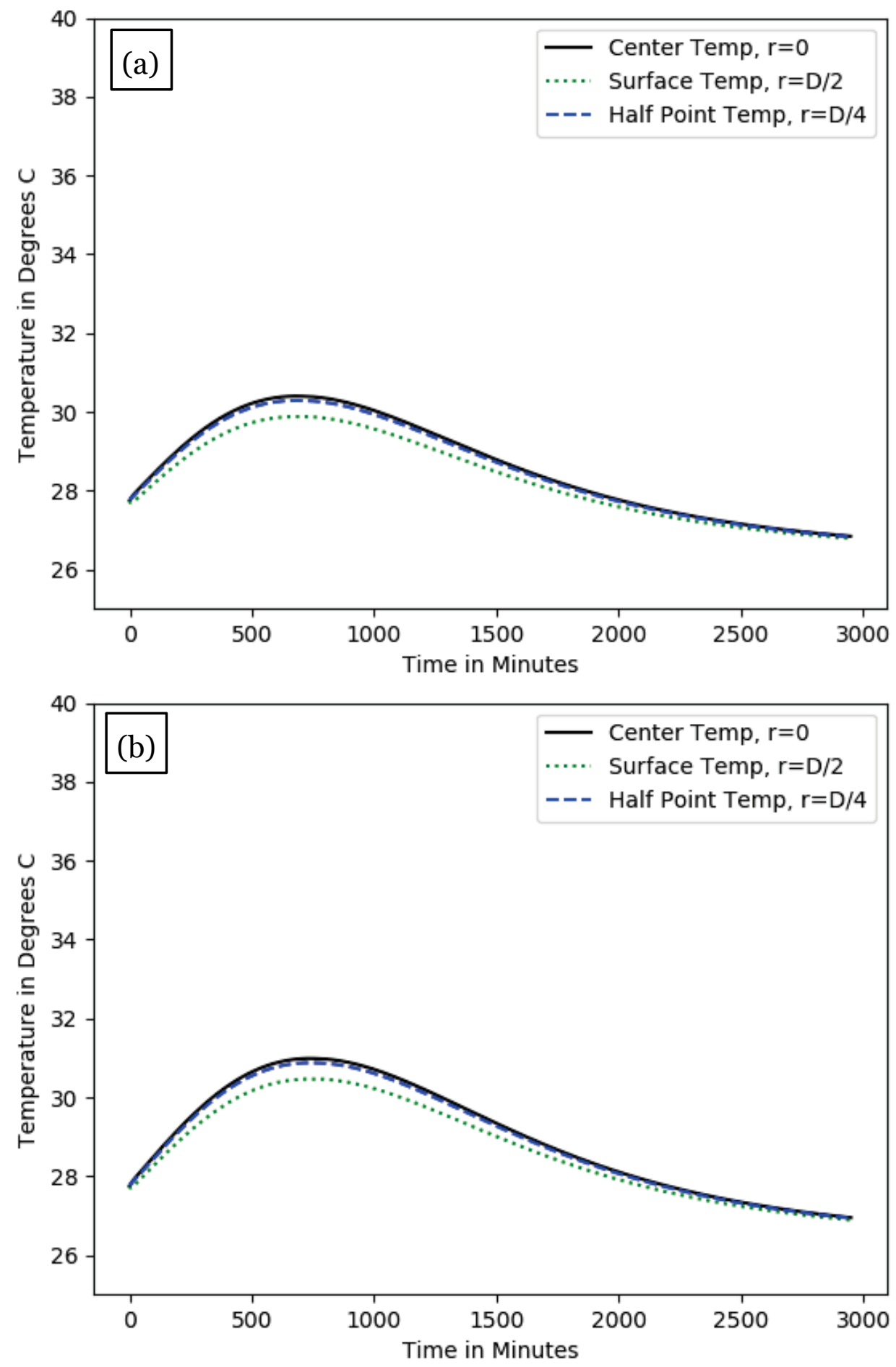
Figure 33. Simulation temperature results for $10.2 \mathrm{~cm}-\mathrm{Cy}$, assuming constant convection coefficient of (a) $4.5 \mathrm{~W} / \mathrm{m}^{2} \cdot \mathrm{K}$ and (b) $2.2 \mathrm{~W} / \mathrm{m}^{2} \cdot \mathrm{K}$.
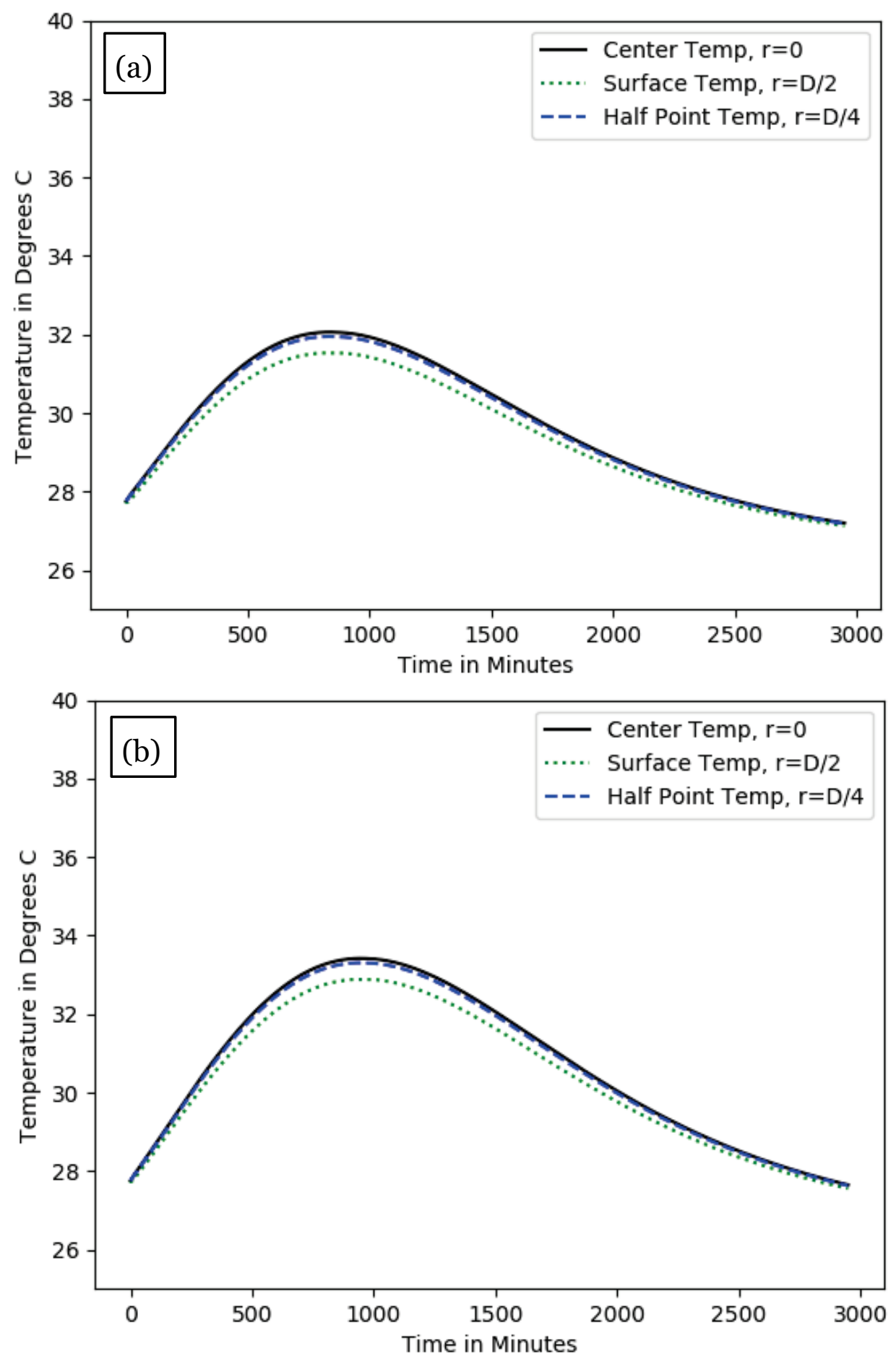
Table 27. Error associated with varying $h$ values for $10.2 \mathrm{~cm}-\mathrm{Cy}$.

\begin{tabular}{|c|c|c|c|c|c|c|c|c|c|c|c|}
\hline \multirow{2}{*}{ Location } & \multirow{2}{*}{$\begin{array}{c}\text { Measured } \\
\text { Temp } \\
\left({ }^{\circ} \mathrm{C}\right)\end{array}$} & \multicolumn{2}{|c|}{$\begin{array}{c}\mathrm{h} \text { from Eq. } 19 \\
\text { correlation }\end{array}$} & \multicolumn{2}{|c|}{$\begin{array}{c}\mathrm{h}=10 \\
\mathrm{~W} / \mathrm{m}^{2} \mathrm{~K}\end{array}$} & \multicolumn{2}{|c|}{$\begin{array}{c}\mathrm{h}=7.5 \\
\mathrm{~W} / \mathrm{m}^{2} \mathrm{~K}\end{array}$} & \multicolumn{2}{|c|}{$\begin{array}{c}\mathrm{h}=4.5 \\
\mathrm{~W} / \mathrm{m}^{2} \cdot \mathrm{K}\end{array}$} & \multicolumn{2}{c|}{$\begin{array}{c}\mathrm{h}=2.2 \\
\mathrm{~W} / \mathrm{m}^{2} \cdot \mathrm{K}\end{array}$} \\
\cline { 3 - 15 } & & $\begin{array}{c}\text { Temp } \\
\left({ }^{\circ} \mathrm{C}\right)\end{array}$ & $\begin{array}{c}\text { Error } \\
(\%)\end{array}$ & $\begin{array}{c}\text { Temp } \\
\left({ }^{\circ} \mathrm{C}\right)\end{array}$ & $\begin{array}{c}\text { Error } \\
(\%)\end{array}$ & $\begin{array}{c}\text { Temp } \\
\left({ }^{\circ} \mathrm{C}\right)\end{array}$ & $\begin{array}{c}\text { Error } \\
(\%)\end{array}$ & $\begin{array}{c}\text { Temp } \\
\left({ }^{\circ} \mathrm{C}\right)\end{array}$ & $\begin{array}{c}\text { Error } \\
(\%)\end{array}$ & $\begin{array}{c}\text { Temp } \\
\left({ }^{\circ} \mathrm{C}\right)\end{array}$ & $\begin{array}{c}\text { Error } \\
(\%)\end{array}$ \\
\hline Center & 32.89 & 32.76 & -0.40 & 30.4 & -7.57 & 30.99 & -5.78 & 32.06 & -2.52 & 33.45 & 1.70 \\
\hline Half Point & 32.66 & 32.64 & -0.06 & 30.29 & -7.26 & 30.87 & -5.48 & 31.95 & -2.17 & 33.34 & 2.08 \\
\hline Surface & 32.1 & 32.22 & 0.37 & 29.88 & -6.92 & 30.46 & -5.11 & 31.53 & -1.78 & 32.91 & 2.52 \\
\hline
\end{tabular}

As shown in Table 27 and Figures 31 through 33, numerical simulations for $10.2 \mathrm{~cm}$-Cy follow a similar pattern as those for the $7.6 \mathrm{~cm}-\mathrm{Cy}$. The temperature and time-dependent value of $\mathrm{h}$ from empirical correlation yields error under $1 \%$, while constant coefficients from literature overpredict convection performance, and the average coefficient from $7.6 \mathrm{~cm}-\mathrm{Cy}$ correlation underpredicts convection performance with greater error, as expected due to size variance.

The same performance parameters were also examined for $15.2 \mathrm{~cm}-\mathrm{Cy}$. Figures 34 through 36 and Table 28 display the results of the numerical simulation compared to the experimentally acquired experimental data. 
Figure 34. (a) experimental and (b) simulation temperature versus time results for three temperature locations at a center cross section of $15.2 \mathrm{~cm}-\mathrm{Cy}$ and (c) convection coefficient calculated for $15.2 \mathrm{~cm}-\mathrm{Cy}$.
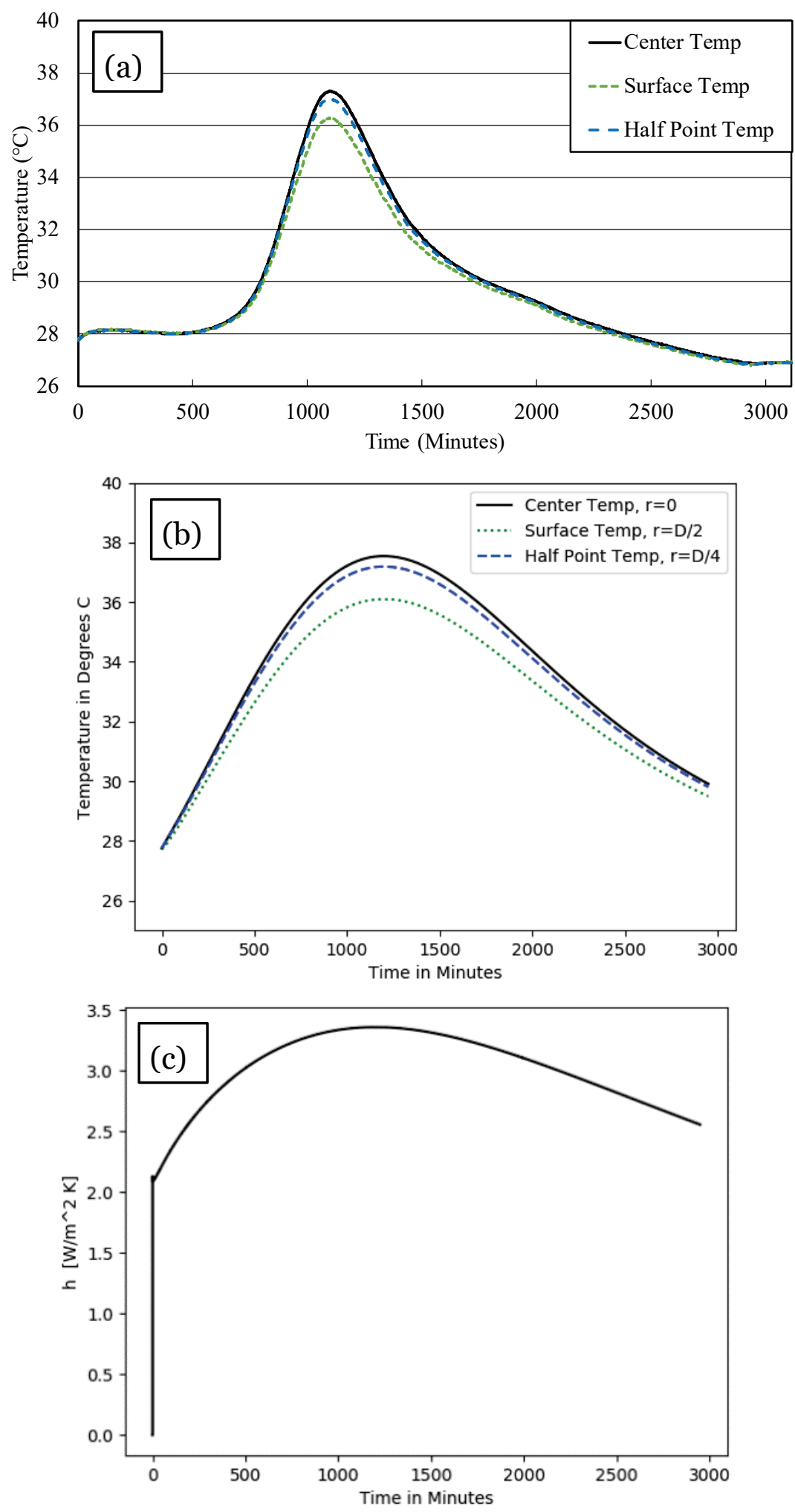
Figure 35. Simulation temperature results for $15.2 \mathrm{~cm}-\mathrm{Cy}$ assuming constant convection coefficient of (a) $10 \mathrm{~W} / \mathrm{m}^{2} \cdot \mathrm{K}$ and (b) $7.5 \mathrm{~W} / \mathrm{m}^{2} \cdot \mathrm{K}$.
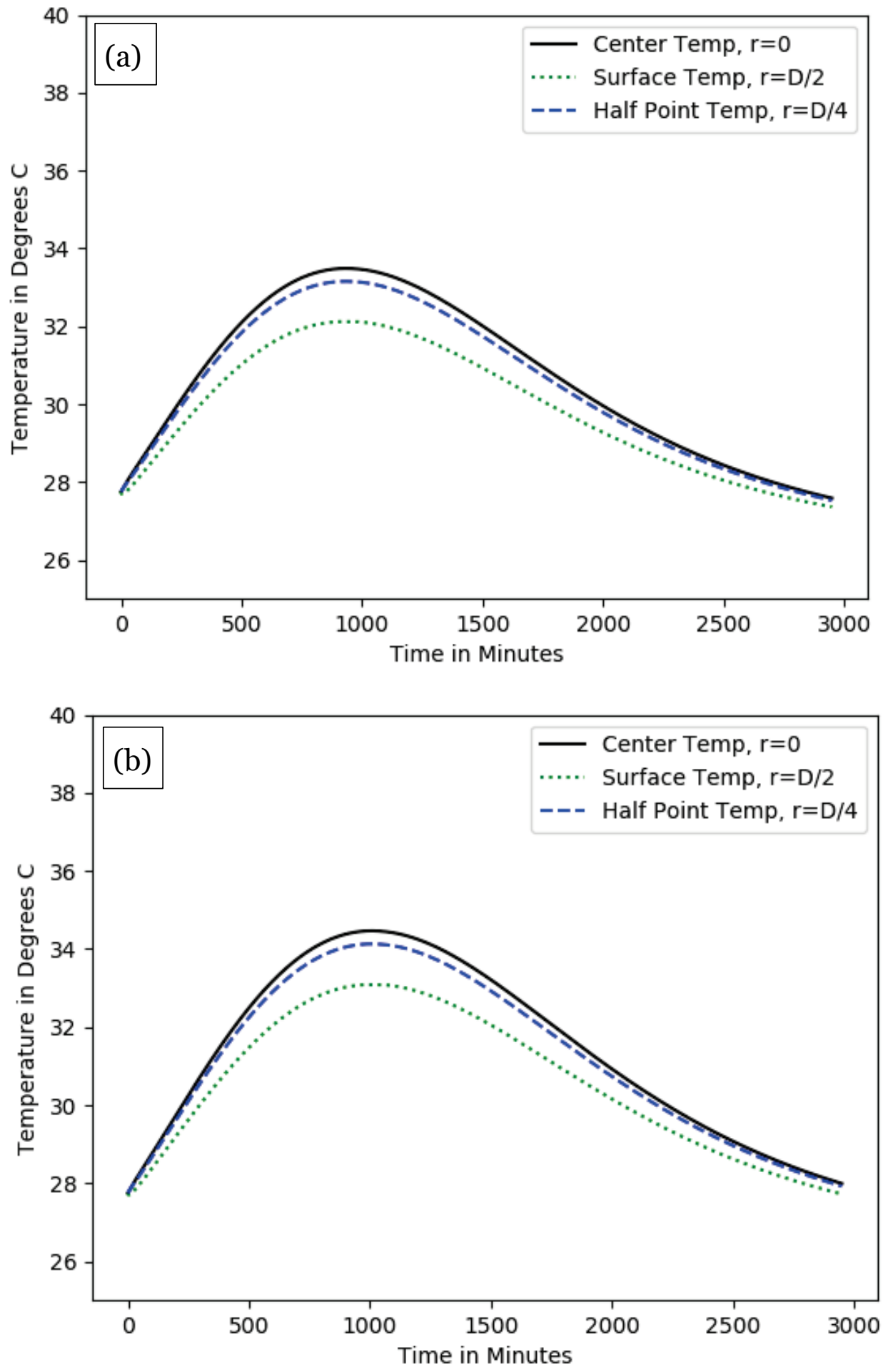
Figure 36. Simulation temperature results for $15.2 \mathrm{~cm}-\mathrm{Cy}$ assuming constant convection coefficient of (a) $4.5 \mathrm{~W} / \mathrm{m}^{2} \cdot \mathrm{K}$ and (b) $2.2 \mathrm{~W} / \mathrm{m}^{2} \cdot \mathrm{K}$.
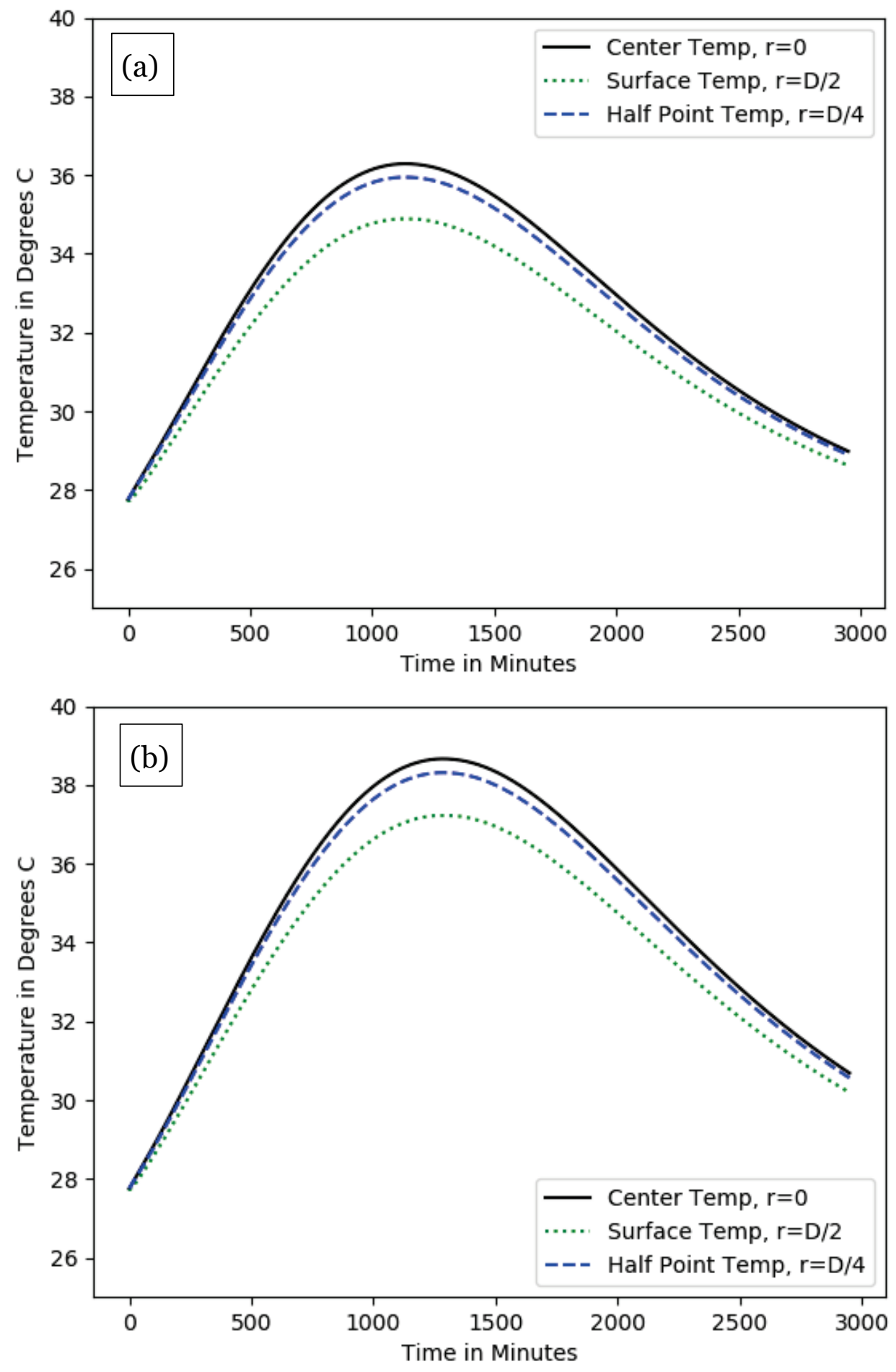
Table 28. Error associated with varying $h$ values for $15.2 \mathrm{~cm}-C y$.

\begin{tabular}{|c|c|c|c|c|c|c|c|c|c|c|c|}
\hline \multirow{2}{*}{ Location } & \multirow{2}{*}{$\begin{array}{c}\text { Measured } \\
\text { Temp } \\
\left({ }^{\circ} \mathrm{C}\right)\end{array}$} & \multicolumn{2}{|c|}{$\begin{array}{l}\mathrm{h} \text { from Eq. } 19 \\
\text { correlation }\end{array}$} & \multicolumn{2}{|c|}{$\begin{array}{l}h=10 \\
W / m^{2} \cdot K\end{array}$} & \multicolumn{2}{|c|}{$\begin{array}{l}h=7.5 \\
W / m^{2} \cdot K\end{array}$} & \multicolumn{2}{|c|}{$\begin{array}{l}h=4.5 \\
W / m^{2} \cdot K\end{array}$} & \multicolumn{2}{|c|}{$\begin{array}{l}h=2.2 \\
W / m^{2} \cdot K\end{array}$} \\
\hline & & $\begin{array}{l}\text { Temp } \\
\left({ }^{\circ} \mathrm{C}\right)\end{array}$ & $\begin{array}{l}\text { Error } \\
\text { (\%) }\end{array}$ & $\begin{array}{l}\text { Temp } \\
\left({ }^{\circ} \mathrm{C}\right)\end{array}$ & $\begin{array}{c}\text { Error } \\
(\%)\end{array}$ & $\begin{array}{l}\text { Temp } \\
\left({ }^{\circ} \mathrm{C}\right)\end{array}$ & $\begin{array}{l}\text { Error } \\
\text { (\%) }\end{array}$ & $\begin{array}{l}\text { Temp } \\
\left({ }^{\circ} \mathrm{C}\right)\end{array}$ & $\begin{array}{l}\text { Error } \\
(\%)\end{array}$ & $\begin{array}{l}\text { Temp } \\
\left({ }^{\circ} \mathrm{C}\right)\end{array}$ & $\begin{array}{l}\text { Error } \\
(\%)\end{array}$ \\
\hline Center & 37.30 & 37.54 & 0.64 & 33.49 & -10.21 & 34.47 & -7.59 & 36.29 & -2.71 & 38.72 & 3.81 \\
\hline Half Point & 37.01 & 37.19 & 0.49 & 33.15 & -10.43 & 34.13 & -7.78 & 35.95 & -2.86 & 38.37 & 3.67 \\
\hline Surface & 36.26 & 36.09 & -0.47 & 32.12 & -11.42 & 33.08 & -8.77 & 34.89 & -3.78 & 37.28 & 2.81 \\
\hline
\end{tabular}

The same trends seen in $7.6 \mathrm{~cm}-\mathrm{Cy}$ and $10.2 \mathrm{~cm}-\mathrm{Cy}$ were witnessed for $15.2 \mathrm{~cm}$-Cy as well where the constant $\mathrm{h}$ values from literature over predicted convection heat transfer, and the average value from the $7.6 \mathrm{~cm}-\mathrm{Cy}$ correlation underpredicted convection heat transfer from the cylinder. In all cases examined above, the convection coefficient determined from the correlation data had less than $1 \%$ error, while all of the constant convection coefficient values experienced greater error. From the initial analysis, it would appear that choosing the correct correlation can noticeably reduce error from convection coefficient determination, particularly in regard to applications of similar geometry but with varying characteristic length.

\subsubsection{Effects of boundary conditions}

To further examine the numerical performance and boundary condition model, a second experimental program was conducted (Batch 2). Due to inevitably small variations from batch to batch of UHPC, the heat generation model parameters had to be recalibrated for day 2 of testing and are presented in Table 24. For the second experimental program, concrete cylinders of two different sizes, i.e., $15.2 \mathrm{~cm}$ by $30.5 \mathrm{~cm}$ and 15.2 $\mathrm{cm}$ by $15.2 \mathrm{~cm}$, were compared with differing types of insulation, i.e., the polypropylene sleeves used in the first set of testing and schedule-40 PVC insulation. Table 29 gives the relevant heat transfer parameters for each insulation type. Since the ratio between diameter and height is no longer consistent for each cylinder, two separate Nu correlations must be used for the numerical simulation comparison as described in section 4.2. 
Table 29. Relevant thermal properties of insulation for boundary condition model.

\begin{tabular}{|c|c|c|}
\hline Parameter & PP & PVC \\
\hline $\begin{array}{c}\text { Thermal Conductivity } \\
(\mathrm{W} / \mathrm{m} \cdot \mathrm{K})\end{array}$ & 0.2 & 0.19 \\
\hline $\begin{array}{c}\text { Insulation Thickness } \\
(\mathrm{m})\end{array}$ & 0.0017 & 0.015 \\
\hline Emissivity & 0.97 & 0.93 \\
\hline
\end{tabular}

For 15.2x30.5-PP and 15.2x30.5-PVC, the Nusselt number correlation (Equation 19) continued to model temperature values with less than $1 \%$ error, as shown in Table 30 and Figures 37 and 38 . However, for 15.2x15.2-PP and 15.2X15.2-PVC, the best Nusselt number correlation studied yielded error under $5 \%$. This could be due to two factors, i.e., the short cylinder has been less extensively studied and published correlations are not as robust (Bejan (2004) indicates an error under $10 \%$ is acceptable for one short cylinder correlation presented and/or the relative area of the top and bottom surface to the vertical surface area is larger for the short cylinder and, therefore, the effects of convection from those surfaces are more evident.

Table 30. Temperature predication and error for $15.2 \times 30.5-P P$ and $15.2 \times 30.5-P V C$.

\begin{tabular}{|c|c|c|c|c|c|c|}
\hline \multirow{3}{*}{ Location } & \multicolumn{3}{|c|}{ PP } & \multicolumn{3}{c|}{ PVC } \\
\cline { 2 - 7 } & $\begin{array}{c}\text { Measured } \\
\text { Temp. } \\
\left({ }^{\circ} \mathrm{C}\right)\end{array}$ & $\begin{array}{c}\text { Model } \\
\text { Temperature } \\
\left({ }^{\circ} \mathrm{C}\right)\end{array}$ & $\begin{array}{c}\text { Model } \\
\text { Error } \\
(\%)\end{array}$ & $\begin{array}{c}\text { Measured } \\
\text { Temp. } \\
\left({ }^{\circ} \mathrm{C}\right)\end{array}$ & $\begin{array}{c}\text { Model } \\
\text { Temperature } \\
\left({ }^{\circ} \mathrm{C}\right)\end{array}$ & $\begin{array}{c}\text { Model } \\
\text { Error } \\
(\%)\end{array}$ \\
\hline Center & 39.11 & 39.09 & -0.05 & 41.97 & 42.27 & 0.71 \\
\hline Half Point & 38.74 & 38.76 & 0.05 & 41.68 & 41.99 & 0.74 \\
\hline Surface & 37.96 & 37.71 & -0.66 & 41.08 & 41.13 & 0.12 \\
\hline
\end{tabular}


Figure 37. Comparative temperature data for $15.2 \times 30.5-\mathrm{PP}$ (a) experimental results and (b) simulation results.
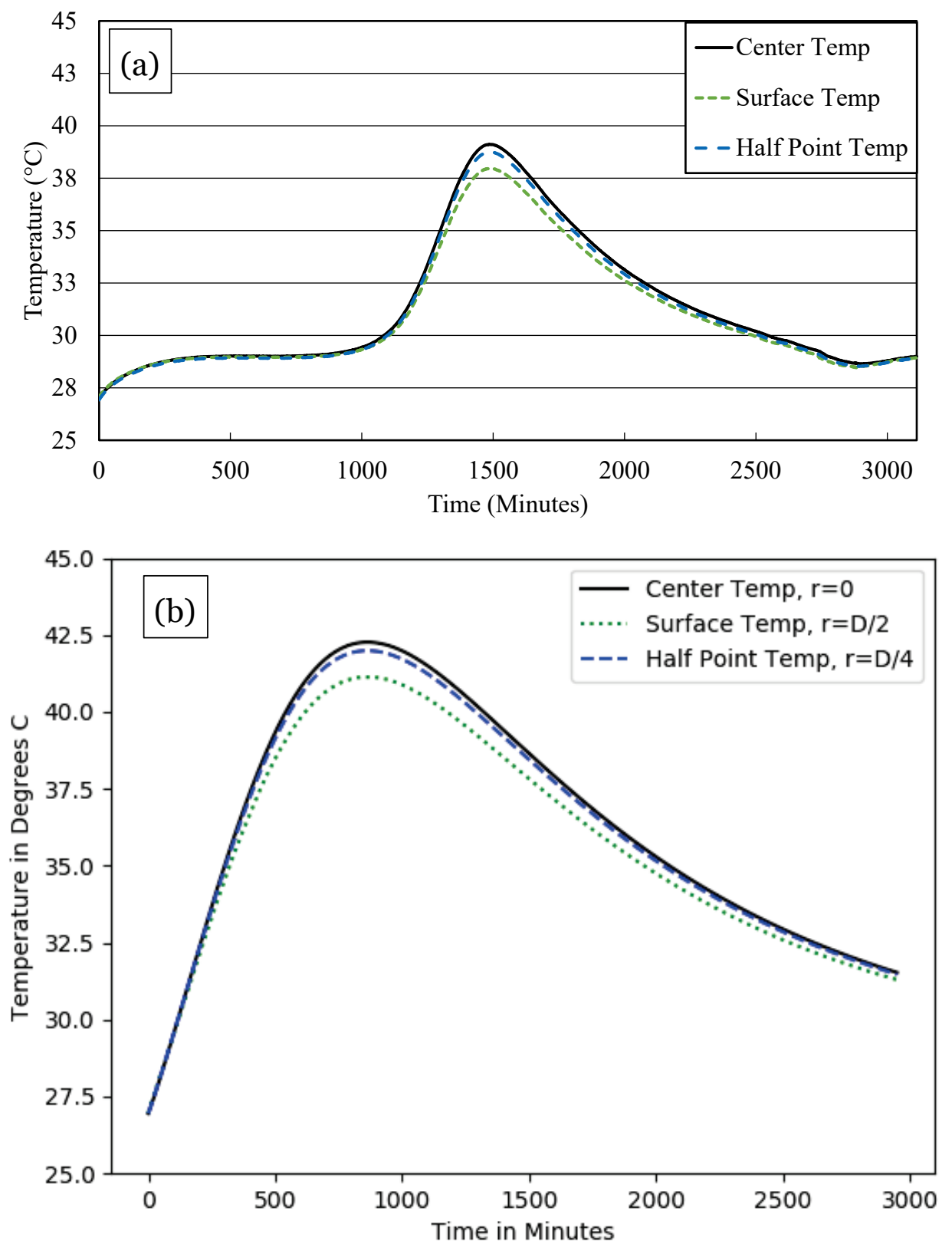
Figure 38. Comparative temperature data for $15.2 \times 30.5-\mathrm{PVC}(\mathrm{a})$ experimental results and (b) simulation results.
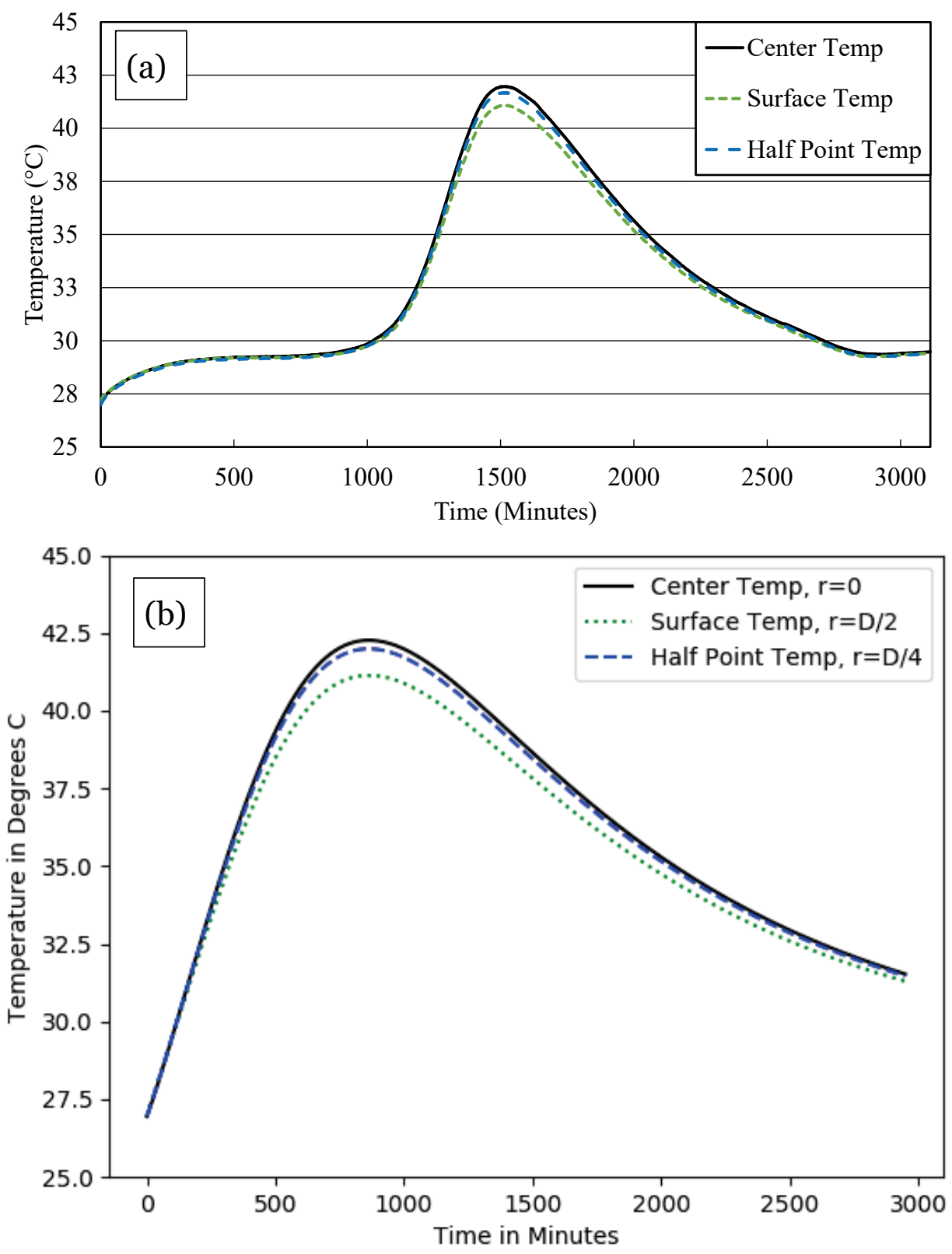

Table 31 gives the temperature data for the selected Nusselt number correlation for 15.2X15.2-PP and 15.2X15.2-PVC (Equation 20). Several short cylinder correlations were initially investigated for 15.2X15.2-PP. The potential correlations investigated are listed in Equations 25 - 27, and the error associated with each correlation is displayed in Table 32. Figures 39 and 40 present the temperature plots for the experimental and numerical models for the short cylinder. 
Table 31. Temperature prediction and error for 15.2x15.2-PP and 15.2x15.2-PVC.

\begin{tabular}{|c|c|c|c|c|c|c|}
\hline \multirow{2}{*}{ Location } & \multicolumn{3}{|c|}{ PP } & \multicolumn{3}{c|}{ PVC } \\
\cline { 2 - 7 } & $\begin{array}{c}\text { Measured } \\
\text { Temp. } \\
\left({ }^{\circ} \mathrm{C}\right)\end{array}$ & $\begin{array}{c}\text { Model } \\
\text { Temperature } \\
\left({ }^{\circ} \mathrm{C}\right)\end{array}$ & $\begin{array}{c}\text { Model } \\
\text { Error } \\
(\%)\end{array}$ & $\begin{array}{c}\text { Measured } \\
\text { Temp. } \\
\left({ }^{\circ} \mathrm{C}\right)\end{array}$ & $\begin{array}{c}\text { Model } \\
\text { Temperature } \\
\left({ }^{\circ} \mathrm{C}\right)\end{array}$ & $\begin{array}{c}\text { Model } \\
\text { Error } \\
(\%)\end{array}$ \\
\hline Center & 37.46 & 38.60 & 3.04 & 40.39 & 41.88 & 3.69 \\
\hline Half Point & 37.19 & 38.25 & 2.85 & 40.09 & 41.59 & 3.74 \\
\hline Surface & 36.33 & 37.18 & 2.34 & 38.97 & 40.72 & 4.49 \\
\hline
\end{tabular}

$$
\begin{gathered}
\overline{N u_{\mathcal{L}}}=\overline{N u_{\mathcal{L}}^{0}}+\frac{0.67 \cdot G_{\mathcal{L}} \cdot R a_{\mathcal{L}}^{1 / 4}}{\left(1+\left(\frac{0.492}{P r}\right)^{\frac{9}{16}}\right)^{4 / 9}} \\
\overline{N u_{D}}=0.775 \cdot R a_{D}^{0.208} \\
\overline{N u_{l}}=0.52 \cdot R a_{l}^{1 / 4}
\end{gathered}
$$

Table 32. Error associated with each Nu correlation for 15.2x15.2-PP.

\begin{tabular}{|c|c|c|c|}
\hline $\begin{array}{c}\text { Equation } \\
\text { Number }\end{array}$ & $\begin{array}{c}\text { Center Temp. Error } \\
\text { (\%) }\end{array}$ & $\begin{array}{c}\text { Half Point Temp. } \\
\text { Error (\%) }\end{array}$ & $\begin{array}{c}\text { Surface Temp. Error } \\
\text { (\%) }\end{array}$ \\
\hline 20 & 3.04 & 2.85 & 2.34 \\
\hline 25 & 3.15 & 2.98 & 2.45 \\
\hline 26 & 4.89 & 4.73 & 4.38 \\
\hline 27 & 4.70 & 4.57 & 4.18 \\
\hline
\end{tabular}


Figure 39. Comparative temperature data for 15.2x15.2-PP (a) experimental results and (b) simulation results.
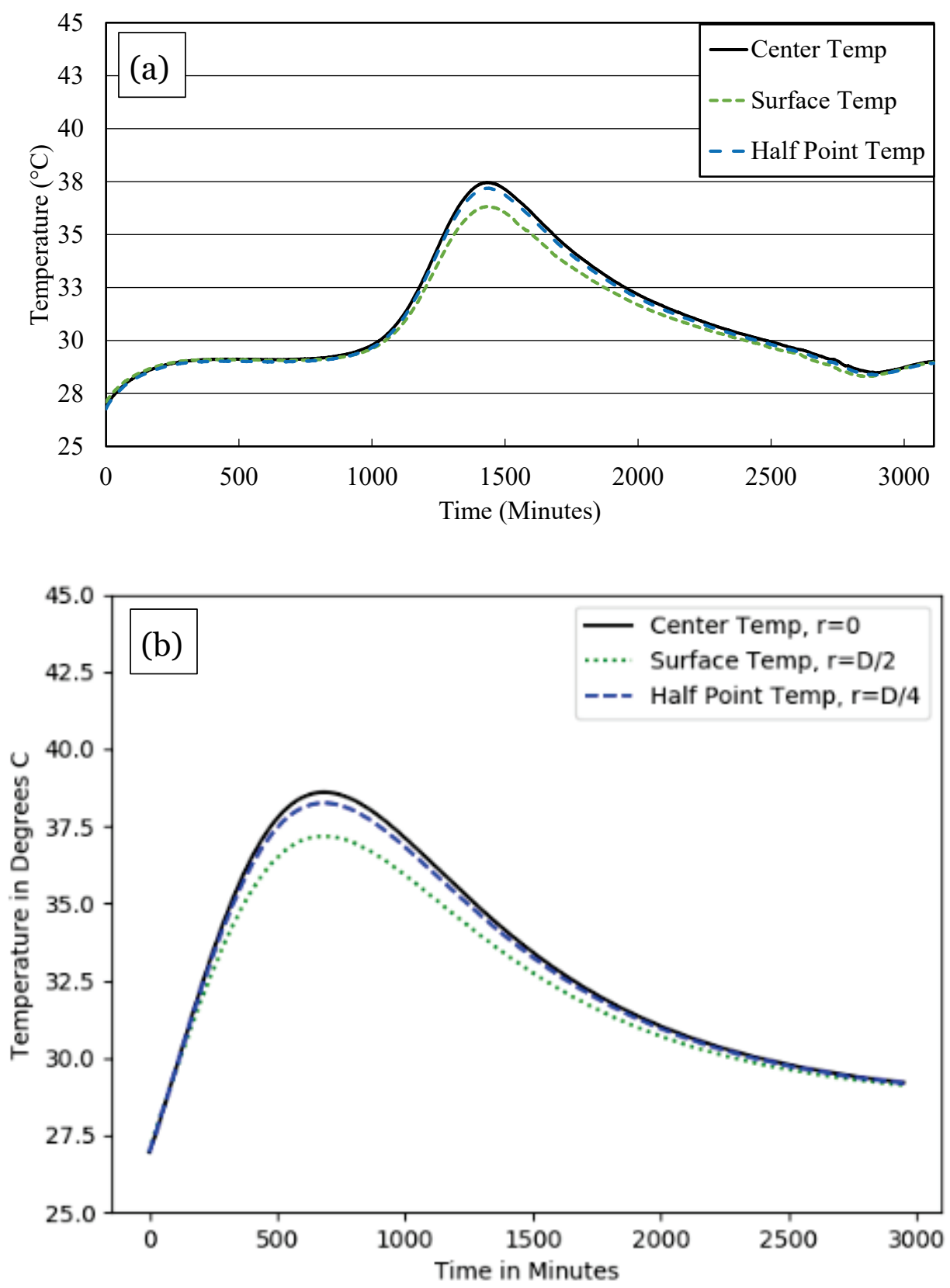
Figure 40. Comparative temperature data for 15.2x15.2-PVC (a) experimental and (b) simulation results.
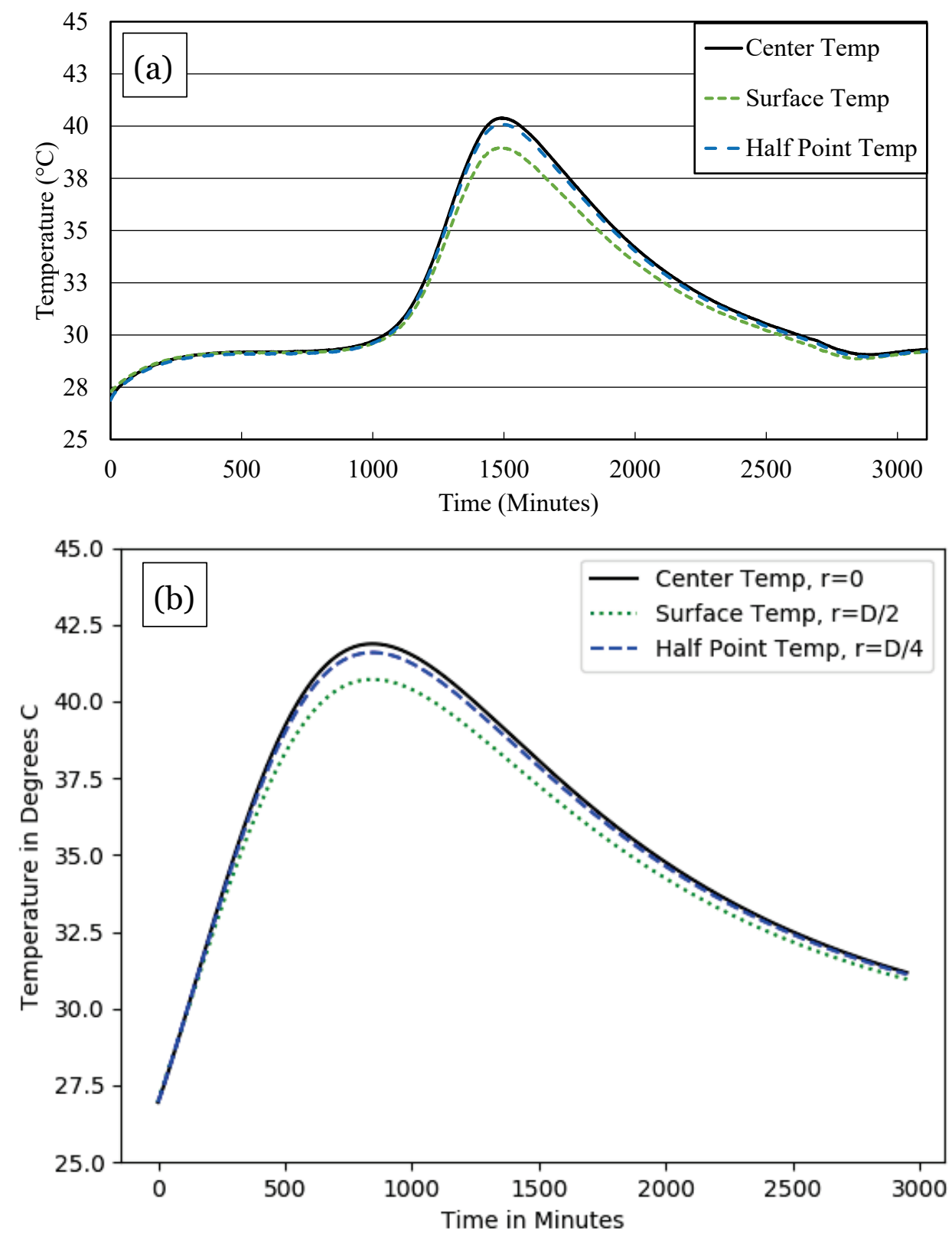

\subsection{Summary of thermodynamcial modeling and TIF}

As shown in section 4.3, using an appropriate Nusselt number correlation for convection modeling of thermal boundary layers can noticeably reduce modeling error for well-studied geometries that have robust correlations available. For all of the cylinders with a 1:2 diameterto-height ratio, utilizing a standard average Nusselt number correlation to calculate a convection coefficient as a function of temperature and time provided very good temperature determination agreement with 
experimental data, with error under $1 \%$ for each case using that correlation. In previous literature, it is common to assume a constant value for convection coefficient. However, as shown in this research, it is likely that commonly used constant values for convection coefficient (most notably $10 \mathrm{~W} / \mathrm{m}^{2} \cdot \mathrm{K}$ ) overestimate natural convection cooling mechanisms for stagnant environments, particularly for geometries of similar length scale to those studied herein. The constant convection coefficient of $10 \mathrm{~W} / \mathrm{m}^{2} \cdot \mathrm{K}$ produced error of up to nearly $11.5 \%$, while the smallest constant convection coefficient, $2.16 \mathrm{~W} / \mathrm{m}^{2} \cdot \mathrm{K}$, still yielded error of up to $3.8 \%$. While the smaller value produced reasonable error, this convection coefficient value was only determined by examining the calculated temperature and time-dependent value for convection coefficient of the $7.6 \mathrm{~cm}-\mathrm{Cy}$ specimen geometry.

When examining the 1:1 diameter-to-height ratio cylinders, the correlation was not as robust. For each short cylinder case, the error was still within $5 \%$, but the correlation was not shown to be as robust as the 1:2 ratio cylinder. Thus, it can be said that for well-studied geometries with robust Nusselt number correlations, it is worthwhile to use the correlation (updated at each time step and temperature value) to calculate convection coefficient when numerically modeling convection boundary conditions. When the model does not provide for well-studied geometries, it is less useful to rely on correlation data. From all cases, however, it is evident that careful consideration should be given to any convection coefficient determination, as typical estimations for constant convection values can easily overestimate the natural convection contribution of open-air, low-velocity environments.

This numerical model is the thermal integrated framework (TIF) and is used in tandem with a mechanical properties model (presented in Chapter 5) as shown in Figure 1. TIF consists of three files described in Table 1. Not all thermodynamical experiments outlined in Chapter 3 are used in this version of TIF but are envisioned to be used in later versions of TIF that account for Cartesian coordinates. By predicting the temperature profile, TIF can provide input to a finite element model to help optimize construction parameters such as geometry, lift height, and formwork. 


\section{CORPS-STIF 1.0 Isothermal Curing Model}

\subsection{Overview of structural modeling efforts}

A numerical model is proposed that captures applicable experimental trends presented in Chapter 3 to predict the development of compressive strength and elastic modulus of Cor-Tuf UHPC cylinders following curing under submerged and isothermal conditions. The general relationship used in this study is a hyperbolic expression proposed by Carino (1984) for isothermal curing conditions. This chapter describes the numerical analyses conducted to evaluate an appropriate model formulation that is compared to experimental output presented in Chapter 3. Then the resulting analytical equations are discretized and implemented in the Abaqus finite element (FE) software for the CORPS-STIF 1.o framework. To verify the formulation, curing and compression testing of cylindrical specimens was simulated and compared to analytical outputs.

\subsection{Numerical model development}

As seen in Figures 12 and 13 of Chapter 3, the rate of development for adjusted elastic modulus $\left(\mathrm{E}_{23}\right)$ and compressive strength $\left(\mathrm{f}_{\mathrm{c}}\right)$ were influenced by curing temperature albeit to different extents. Additionally, the overall extent of $f_{c}$ development was increased by higher temperature curing. The following section describes the development of numerical models to describe these observed trends and the subsequent discretization for implementation in FE software, described in section 5.3.

\subsubsection{Numerical model development}

The hyperbolic expression proposed by Carino (1984) is shown in Equation 28, which can be applied for an arbitrary property denoted, $S$. This formulation is shown in Carino and Lew (2001) to accurately describe the strength development of isothermally cured conventional concrete specimens. The numerical formulation presented herein modifies this expression to apply to $\mathrm{f}_{\mathrm{c}}$ and $\mathrm{E}_{23}$ separately by substituting individual terms with parametric functions that vary with time and curing temperature. Only isothermal specimens from Group A for curing groups I10, I23, I30, I50, I70, and I90 are considered.

$$
S=S_{\text {lim }} \frac{k\left(t-t_{0}\right)}{1+k\left(t-t_{0}\right)} \text { for } t \geq t_{0}
$$


Where

Slim = the limiting mechanical property achieved after infinite curing time (more specific terms are flim and Elim which refer to limiting compressive strength (MPa) and elastic modulus (GPa))

$k=$ the rate constant, $(1 /$ day $)$

$T=$ time, days

$t_{o}=$ offset time corresponding to start of strength development, days

To account for observed $\mathrm{f}_{\mathrm{c}}$ trends, it was assumed that the limit strength, $S_{\text {lim, }}$ is a linearly increasing function of curing temperature. For $\mathrm{E}_{23}$ prediction, it was assumed that the limit modulus, $E_{l i m}$, is a quadratic function of curing temperature. Since all specimens considered for this model formulation spent the first day on the lab counter $\left(\mathrm{CE}_{1}\right)$, a single value for $t_{o}$ was found for both $\mathrm{f}_{\mathrm{c}}$ and $\mathrm{E}_{23}$.

The rate term, $k$, was described by a descending power function, shown in Equation 29, which reflects that early UHPC strength gain occurs more rapidly than at later ages. The rate functions for $\mathrm{f}_{\mathrm{c}}$ and $\mathrm{E}_{23}$ depend on both time and temperature. Quadratic functions of temperature were used to represent the parametric functions $a(T)$ and $b(T)$. For Equation 29 to remain positive and decrease with time, parametric functions $a(T)$ and $b(T)$ must remain positive for all curing temperatures.

$$
k(t, T)=a(T) t^{-b(T)} \text { for } t \geq t_{0}
$$

Where

$T=$ curing temperature,${ }^{\circ} \mathrm{C}$

$a(T)=$ parametric function of temperature that scales the rate with curing temperature

$b(T)=$ parametric function of temperature that affects decay of development rate with curing temperature

Table 33 summarizes the parametric functions and dependent coefficients selected for this study. First, the $\mathrm{f}_{\mathrm{c}}$ model was calibrated by simultaneously fitting coefficients $c_{o}$ through $c_{8}$. Then, the $\mathrm{E}_{23}$ model was fit with coefficients $d_{o}$ through $d_{8}$ using the offset term, $t_{o}$, fit for $\mathrm{f}_{\mathrm{c}}$ data. 
Table 33. Numerical models and parametric functions.

\begin{tabular}{|c|c|c|}
\hline Equation & Compressive Strength $\left(\mathrm{f}_{\mathrm{c}}\right)$ & Elastic Modulus $\left(\mathrm{E}_{23}\right)$ \\
\hline Hyperbolic Model & $\mathrm{f}_{\mathrm{c}}(\mathrm{t}, \mathrm{T})=\mathrm{f}_{\text {lim }}(\mathrm{T}) \frac{\mathrm{k}_{\mathrm{f}}(\mathrm{t}, \mathrm{T})\left(\mathrm{t}-\mathrm{t}_{0}\right)}{1+\mathrm{k}_{\mathrm{f}}(\mathrm{t}, \mathrm{T})\left(\mathrm{t}-\mathrm{t}_{0}\right)}$ & $\mathrm{E}_{23}(\mathrm{t}, \mathrm{T})=\mathrm{E}_{\text {lim }}(\mathrm{T}) \frac{\mathrm{k}_{\mathrm{E}}(\mathrm{t}, \mathrm{T})\left(\mathrm{t}-\mathrm{t}_{0}\right)}{1+\mathrm{k}_{\mathrm{E}}(\mathrm{t}, \mathrm{T})\left(\mathrm{t}-\mathrm{t}_{0}\right)}$ \\
\hline Limit Term & $\mathrm{f}_{\text {lim }}(\mathrm{T})=\mathrm{c}_{0}+\mathrm{c}_{1} \mathrm{~T}$ & $\mathrm{E}_{\text {lim }}(\mathrm{T})=\mathrm{d}_{0}+\mathrm{d}_{1} \mathrm{~T}+\mathrm{d}_{2} \mathrm{~T}^{2}$ \\
\hline \multirow{2}{*}{ Rate Term } & $\mathrm{k}_{\mathrm{f}}(\mathrm{t}, \mathrm{T})=\mathrm{a}_{\mathrm{f}}(\mathrm{T}) \mathrm{t}^{-\mathrm{b}_{\mathrm{f}}(\mathrm{T})}$ & $\mathrm{k}_{\mathrm{E}}(\mathrm{t}, \mathrm{T})=\mathrm{a}_{\mathrm{E}}(\mathrm{T}) \mathrm{t}^{-\mathrm{b}_{\mathrm{E}}(\mathrm{T})}$ \\
\hline \multirow{2}{*}{ Rate Parameters } & $\mathrm{a}_{\mathrm{f}}(\mathrm{T})=\mathrm{c}_{2}+\mathrm{c}_{3} \mathrm{~T}+\mathrm{c}_{4} \mathrm{~T}^{2}$ & $\mathrm{a}_{\mathrm{E}}(\mathrm{T})=\mathrm{d}_{3}+\mathrm{d}_{4} \mathrm{~T}+\mathrm{d}_{5} \mathrm{~T}^{2}$ \\
\cline { 2 - 3 } & $\mathrm{b}_{\mathrm{f}}(\mathrm{T})=\mathrm{c}_{5}+\mathrm{c}_{6} \mathrm{~T}+\mathrm{c}_{7} \mathrm{~T}^{2}$ & $\mathrm{~b}_{\mathrm{E}}(\mathrm{T})=\mathrm{d}_{6}+\mathrm{d}_{7} \mathrm{~T}+\mathrm{d}_{8} \mathrm{~T}^{2}$ \\
\hline Offset Term & $\mathrm{t}_{0}=\mathrm{c}_{8}$ & $\mathrm{t}_{0}=\mathrm{c}_{8}$ \\
\hline
\end{tabular}

Best fit coefficients are determined using the Nelder-Mead Simplex algorithm implemented in Python (Rossum 1995). Error minimization is performed by considering all six curing groups simultaneously. Index $k$ is used to denote a data point in a curing group. Index $j$ is used to denote one of the six curing groups. The number of points in a curing group is denoted $n_{j}$, and the total number of points is denoted $N$. For minimization, the root mean square percent error (RMSPE) was determined between predicted and measured values for each curing group, calculated according to Equation 30. For statistical comparisons, mean absolute percent error (MAPE) was also calculated, shown in Equation 31. An objective function was defined as the weighted RMSPE for each curing group calculated according to Equation 32. Model calibration was performed in Python using the minimization function in the SciPy package (Oliphant 2007) by iteratively changing coefficient values ( $c_{o}$ through $c_{8}$ or $d_{o}$ through $d_{8}$ ) until the objective function was minimized. Similar to Carino (1984), it was assumed that concrete temperatures were equal to the curing temperature for all ages. Table 34 shows the resulting best fit coefficients from the minimization analysis for this data set.

$$
\begin{gathered}
\operatorname{RMSPE}_{j}=\sqrt{\frac{1}{n_{j}} \sum_{k=1}^{n_{j}}\left(\frac{\text { predicted }_{k}-\text { measured }_{k}}{\text { measured }_{k}}\right)^{2}} \\
\text { MAPE }_{j}=\frac{1}{n_{j}} \sum_{k=1}^{n_{j}}\left|\frac{\text { predicted }_{k}-\text { measured }_{k}}{\text { measured }_{k}}\right| \\
\text { Objective }=\left(\frac{n_{j}}{N}\right) \mathrm{RMSPE}_{j}
\end{gathered}
$$


Table 34. Fit coefficients from isothermal models.

\begin{tabular}{|l|c|c|c|}
\hline \multicolumn{2}{|c|}{$\begin{array}{c}\text { Compressive } \\
\text { Strength }\left(f_{c}\right)\end{array}$} & \multicolumn{2}{c|}{$\begin{array}{c}\text { Elastic Modulus } \\
\left(\mathrm{E}_{23}\right)\end{array}$} \\
\hline$c_{0}$ & 160.2 & $d_{0}$ & 57.5 \\
\hline$c_{1}$ & $2.53 \mathrm{E}-01$ & $d_{1}$ & $-2.89 \mathrm{E}-01$ \\
\hline$c_{2}$ & $3.33 \mathrm{E}-01$ & $d_{2}$ & $2.75 \mathrm{E}-03$ \\
\hline$c_{3}$ & $1.19 \mathrm{E}-01$ & $d_{3}$ & $3.40 \mathrm{E}-03$ \\
\hline$c_{4}$ & $4.93 \mathrm{E}-04$ & $d_{4}$ & $-7.08 \mathrm{E}-04$ \\
\hline$c_{5}$ & $4.90 \mathrm{E}-01$ & $d_{5}$ & $3.16 \mathrm{E}-03$ \\
\hline$c_{6}$ & $-2.88 \mathrm{E}-03$ & $d_{6}$ & $1.31 \mathrm{E}-01$ \\
\hline$c_{7}$ & $3.35 \mathrm{E}-05$ & $d_{7}$ & $-2.18 \mathrm{E}-03$ \\
\hline$c_{8}$ & $7.45 \mathrm{E}-01$ & $d_{8}$ & $4.79 \mathrm{E}-05$ \\
\hline
\end{tabular}

Figure 41 presents the experimental data, model predictions, and fit statistics for $\mathrm{f}_{\mathrm{c}}$ of curing groups I10, I23, I30, I50, I70, and I90. The model shows reasonable agreement with the experimental data in which RMSPE ranges from $5.9 \%$ to $11.5 \%$ and MAPE ranges from $4.3 \%$ to $7.7 \%$, although some $\mathrm{R}^{2}$ values are low. I50 data appears to be overpredicted at late ages. Curing group I90 shows high variability with measured values scattering below $150 \mathrm{MPa}$ and above $200 \mathrm{MPa}$, but the predicted trend agrees well with the overall dataset. 
Figure 41. Compressive strength measurements and numerical predictions.
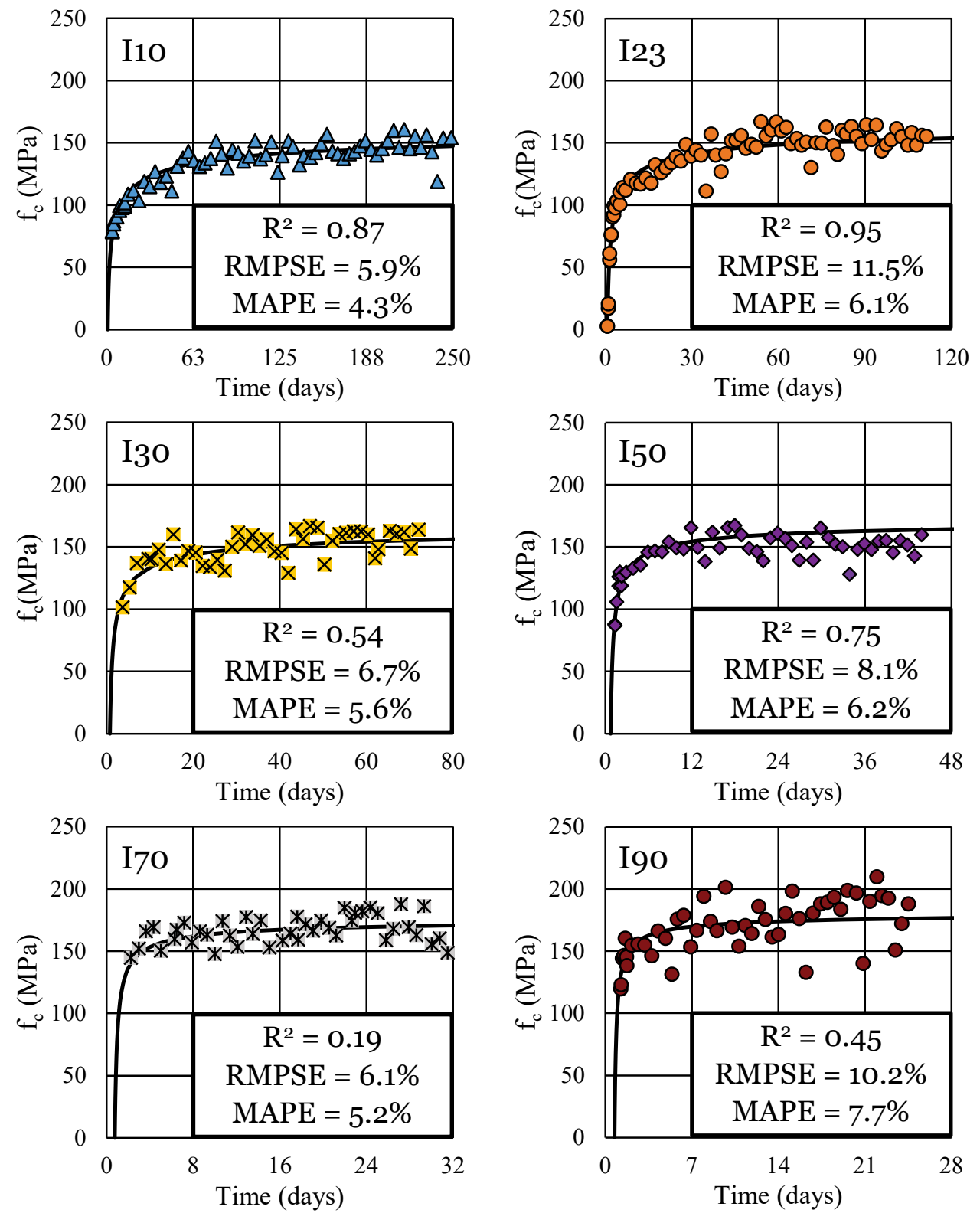

Similarly, Figure 42 presents the experimental data, model predictions, and fit statistics for $\mathrm{E}_{23}$ of the six submerged and isothermal curing groups. The regression analysis indicates decent agreement between experimental data and model predictions in which RMSPE ranges from $2.5 \%$ to $10.2 \%$ and MAPE from $1.8 \%$ to $6.0 \%$, although some $\mathrm{R}^{2}$ values are low. 
Figure 42. Elastic modulus measurements and numerical predictions.
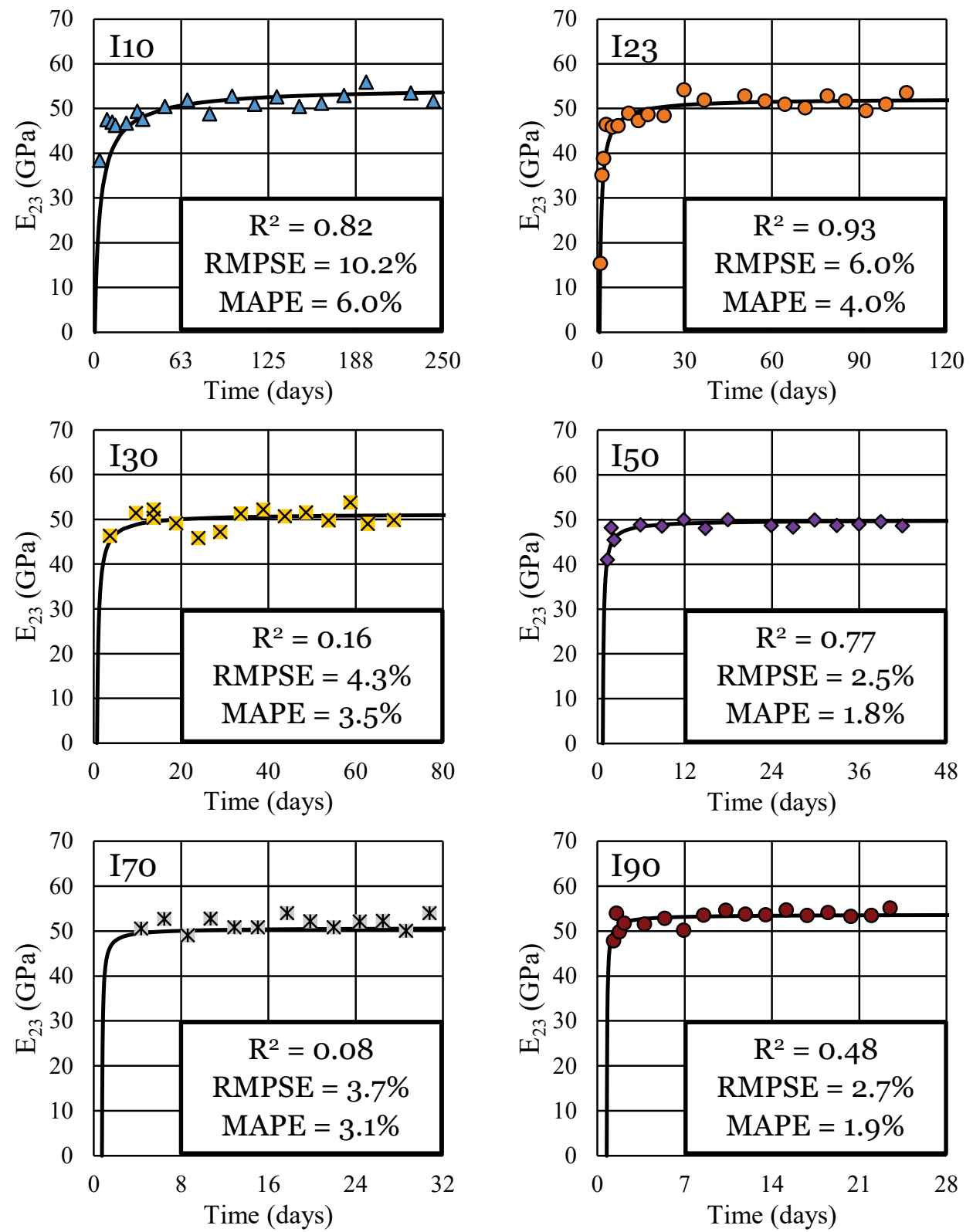

Figure 43 shows the relationship between parametric functions versus dependent variables for both $\mathrm{f}_{\mathrm{c}}$ and $\mathrm{E}_{23}$ models. Limit strength, $\mathrm{flim}_{\text {lim, (Figure }}$ 43a), limit elastic modulus, Elim, (Figure 43b), functions af(T) and aE(T) (Figures 43c and 43d), and functions $b_{f}(T)$ and $b_{E}(T)$ (Figures 43e and 43f) are plotted against curing temperature. The rate functions, $\mathrm{kf}_{\mathrm{f}}$ (Figure 43g) and $\mathrm{k}_{\mathrm{E}}$ (Figure $43 \mathrm{~h}$ ), are plotted for each curing temperature against time starting when time is greater than the offset value, to. Compressive strength and elastic modulus development trends at the six temperatures are shown in Figures 43i and 43j, respectively. Curves between the 6 
curing temperatures can be differentiated by location on plots $43 \mathrm{~g}$ to $43 \mathrm{j}$, i.e., higher values correspond to higher curing temperature.

Figure 43. Parametric functions and output of numerical models.
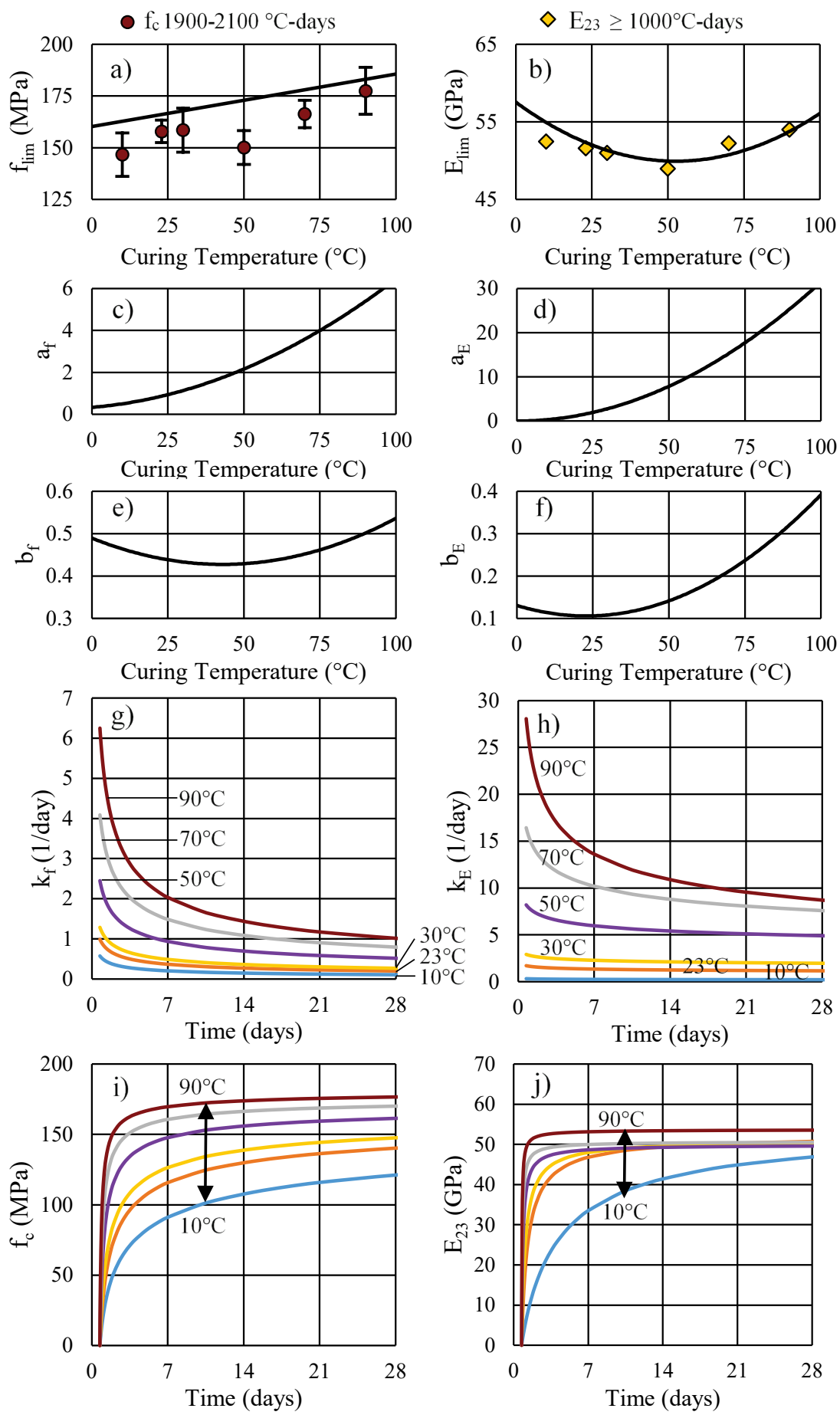
To verify the limit strength, $f_{\text {lim }}$, average and standard deviation of selected $f_{c}$ values from $1900-2100{ }^{\circ} \mathrm{C}$-days are shown in Figure 43a, most of which approach the trend. To verify the limit modulus, $E_{\text {lim }}$, average $\mathrm{E}_{23}$ values after $1000^{\circ} \mathrm{C}$-days are plotted in Figure $43 \mathrm{~b}$, which agree well with the trend.

At 28 days, Figure 43i shows the predicted compressive strength ranges from 121 to $177 \mathrm{MPa}$, while Figure 43j shows that $\mathrm{E}_{23}$ is expected to be similar regardless of curing temperature. The limit strength in Figure 43a indicates that the highest potential $f_{c}$ can only be achieved for higher curing temperatures. Furthermore, predictions of $90^{\circ} \mathrm{C}$ indicate that this limiting strength can be achieved within 7 days that equals or exceeds the 28-day strength of lower curing temperatures (Figure 43i).

\subsubsection{Discretization of numerical model}

The numerical model described in the previous section was implemented in Abaqus by performing a first order Taylor series expansion with respect to time to discretize the equations into a stepwise format suitable for a computation system. After derivation, the resulting formulae were coded into the user defined field variable (USDFLD) subroutine. Derivation of the expressions to approximate compressive strength, $\mathrm{f}_{\mathrm{c}}$, are shown herein, but an identical procedure was performed for elastic modulus using functions in Table 33.

The Taylor expansion for compressive strength predicts $\mathrm{f}_{\mathrm{c}}$ for the next step $(i+1)$, by considering the current $f_{c}$ and the slope of $f_{c}$ with respect to both time and temperature, shown in Equation 33.

$$
\mathrm{f}_{\mathrm{c}}\left(\mathrm{t}_{\mathrm{i}+1}, \mathrm{~T}_{\mathrm{i}+1}\right) \approx \mathrm{f}_{\mathrm{c}}\left(\mathrm{t}_{\mathrm{i}}, \mathrm{T}_{\mathrm{i}}\right)+\Delta \mathrm{t} \frac{\partial}{\partial \mathrm{t}} \mathrm{f}_{\mathrm{c}}\left(\mathrm{t}_{\mathrm{i}}, \mathrm{T}_{\mathrm{i}}\right)
$$

The derivative of the strength function is shown in Equation 34. The limit term does not change as a function of time, so only the asymptotic expression needs to be differentiated. The time derivative of the rate term is shown in Equation 35 required for calculation in Equation 34.

$$
\begin{aligned}
& \frac{\partial}{\partial t} f(t, T)=f_{l i m}(T)\left(\frac{k_{f}+\dot{k}_{f}\left(t-t_{0}\right)}{1+k_{f}\left(t-t_{0}\right)}-\frac{k_{f}{ }^{2}\left(t-t_{0}\right)+\dot{k}_{f}\left(t-t_{0}\right)^{2}}{\left(1+k_{f}\left(t-t_{0}\right)\right)^{2}}\right) \\
& \dot{k}_{f}(t, T)=-a_{f}(T) b_{f}(T) t^{-\left(b_{f}(T)+1\right)} \text { for } t \geq t_{0}
\end{aligned}
$$


These formulas were coded into a USDFLD subroutine in FORTRAN. When implemented, Equation 33 predicts $\mathrm{f}_{\mathrm{c}}$ or $\mathrm{E}_{23}$ for the following time increment by calculating the slope of the function at the previous time step, multiplying by the amount of time since the previous increment, and adding it to the previous value of the function. Because this formulation is only first order accurate, approximation error is proportional to the square of the time step. As the time step is decreased, error is expected to decrease. Using small time steps during large increases in strength generally yields more accurate results.

To capture temperature effects on mechanical property development of specimens exposed to curing temperatures at early ages or delayed heat treatment, e.g., curing of mixed temperature specimens, modifications are needed. At present, this formulation is accurate only for isothermally cured specimens.

\subsection{Finite element implementation}

This section describes the implementation of the numerical models in the Abaqus finite element (FE) analysis software. First, the discretized parametric functions for compressive strength and elastic modulus were written into a USDFLD subroutine to calculate and assign $\mathrm{f}_{\mathrm{c}}$ and $\mathrm{E}_{23}$ values for the FE model at each integration point. For simplicity, the selected FE simulation employs elasticity and perfectly plastic material descriptions using the $\mathrm{E}_{23}$ and $\mathrm{f}_{\mathrm{c}}$ values, respectively, calculated by the USDFLD subroutine. To verify the validity of this FE formulation, curing and compression testing of cylindrical specimens are simulated in Abaqus and compared to output from the analytical models presented in section 5.2.1.

\subsubsection{Finite element model description}

Twenty-four simulations were performed, corresponding to six curing temperatures $\left(10,23,30,50,70\right.$, and $\left.90^{\circ} \mathrm{C}\right)$ and four curing durations $(3,7,14$, and 28 days) to test the implementation of the isothermal strength development models. All simulations had the same cylindrical geometry with a diameter of $10.2 \mathrm{~cm}$ (4 in.) and height of $20.3 \mathrm{~cm}(8$ in.). Section 5.3.2 discusses the selected mesh resolution and number of elements selected. Eight noded, linear continuum brick elements formulated for coupled thermal-stress analyses (C3D8T) were used. Figure 44 shows the cylinder geometry. 
Figure 44. Cylinder geometry.

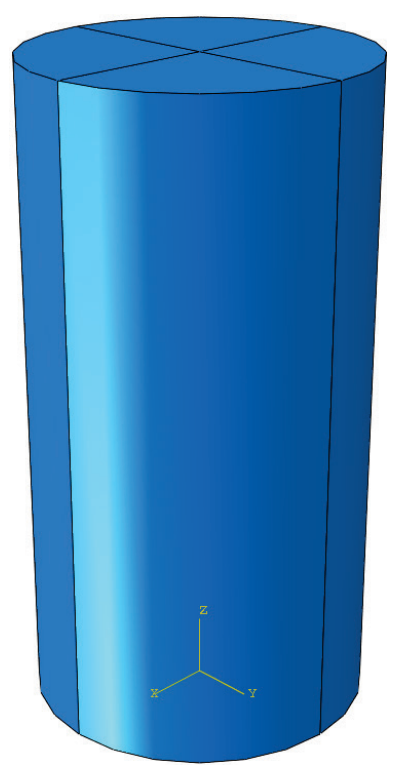

Curing was simulated for the six curing temperatures by setting thermal boundary conditions on the surface of the cylinder equal to the curing temperature. Curing was divided into two steps to provide more resolution at early ages when the most strength gain occurs. All units of the simulation were in the "SI kg-m" system.

After the two curing steps, compression testing according to ASTM C39 (2016) was simulated. The bottom of the cylinder was fixed from displacement but allowed to expand diametrically. This prevented the development of confinement stresses that can occur if all points on a surface are fully fixed. Loading was applied by displacing the top surface of the cylinder at a rate of $1.0 \times 10^{-6} \mathrm{~m} / \mathrm{s}$. This displacement induces a uniform, uniaxial stress state. The selected loading rate corresponds to the ASTM C39 stress rate of $0.24 \mathrm{MPa} / \mathrm{s}$ (35 psi/s) for a cylinder with a modulus of $49 \mathrm{GPa}$. For the goals of these simulations, this loading configuration was deemed suitable. Table 35 shows the incrementation details for each of these three simulation steps. 
Table 35. Incrementation details for each step.

\begin{tabular}{|c|c|c|c|}
\hline Parameter & Cure Step 1 & Cure Step 2 & C39 Loading \\
\hline Duration $(\mathrm{s})$ & 7200 & Age[s]-7200 & 1800 \\
\hline Initial $\Delta \mathrm{t}(\mathrm{s})$ & 1 & 30 & 1 \\
\hline Minimum $\Delta \mathrm{t}(\mathrm{s})$ & 1 & 30 & 0.05 \\
\hline Maximum $\Delta \mathrm{t}(\mathrm{s})$ & 60 & 120 & 30 \\
\hline $\begin{array}{c}\text { Maximum number } \\
\text { of increments }\end{array}$ & 3600 & 3600 & 1000 \\
\hline
\end{tabular}

Input files were modified to work with the USDFLD subroutine. The Abaqus FE software performed this subroutine for each integration point in an element. The $\mathrm{C}_{3} \mathrm{D} 8 \mathrm{~T}$ element has eight integration points. Six dependent variables were passed through the subroutine for each calculation. Two of these variables were $\mathrm{E}_{23}$ and $\mathrm{f}_{\mathrm{c}}$, while the other four kept track of time, time increment, slope of the $\mathrm{E}_{23}$ function, and slope of the $\mathrm{f}_{\mathrm{c}}$ function. The GETVRM utility subroutine passes material point information into the USDFLD routine and was used to access temperature data. The calculated values of $\mathrm{E}_{23}$ and $\mathrm{f}_{\mathrm{c}}$ were assigned to the elastic modulus and the perfectly plastic yield limit at each integration point as each time increment was calculated. It is unreasonable to assume that a perfect plasticity definition describes the response of this material but allowed for easy sampling of the developed mechanical property data. Other mechanical property definitions included the Poisson ratio of 0.15 and density of $2520 \mathrm{~kg} / \mathrm{m}^{3}$. Thermal input properties included specific heat of $1100 \mathrm{~J} / \mathrm{kg} \cdot \mathrm{K}$ and thermal conductivity of $2.3 \mathrm{~W} / \mathrm{m} \cdot \mathrm{K}$ that are the same as those used in Chapter 4 for thermodynamical modeling.

\subsubsection{Mesh convergence and selection}

A mesh convergence study was conducted to determine an appropriate mesh size. Section 5.3.3 discusses the accuracy of the compressive strength and elastic modulus models compared to analytical results. To provide the best comparisons between results, it was determined that a sufficiently fine mesh was required that did not unnecessarily affect computational time and resources.

Six mesh sizes were tested ranging from 320 to 244,800 elements. Identical material properties were assigned for mesh convergence corresponding to an elastic modulus of $50 \mathrm{GPa}$ and a perfectly plastic yield limit of $180 \mathrm{MPa}$. Loading was identical to those described previously with 
the same incrementation parameters presented in Table 35 under " $\mathrm{C} 39$ Loading." Results are shown in Table 36 and Figure 45.

Table 36. Mesh convergence summary.

\begin{tabular}{|c|c|c|c|}
\hline Seed Size $(\mathrm{mm})$ & $\begin{array}{c}\text { Number of } \\
\text { Elements }\end{array}$ & $\begin{array}{c}\text { Final Average } \\
\text { Stress (MPa) }\end{array}$ & $\begin{array}{c}\text { Relative Error } \\
(\%)\end{array}$ \\
\hline 20 & 320 & 175.41 & 2.55 \\
\hline 15 & 616 & 177.05 & 1.64 \\
\hline 10 & 1,920 & 178.85 & 0.64 \\
\hline 5 & 15,744 & 179.71 & 0.16 \\
\hline 3 & 78,880 & 179.90 & 0.06 \\
\hline 2 & 244,800 & 179.95 & 0.03 \\
\hline
\end{tabular}

Figure 45. Mesh convergence.

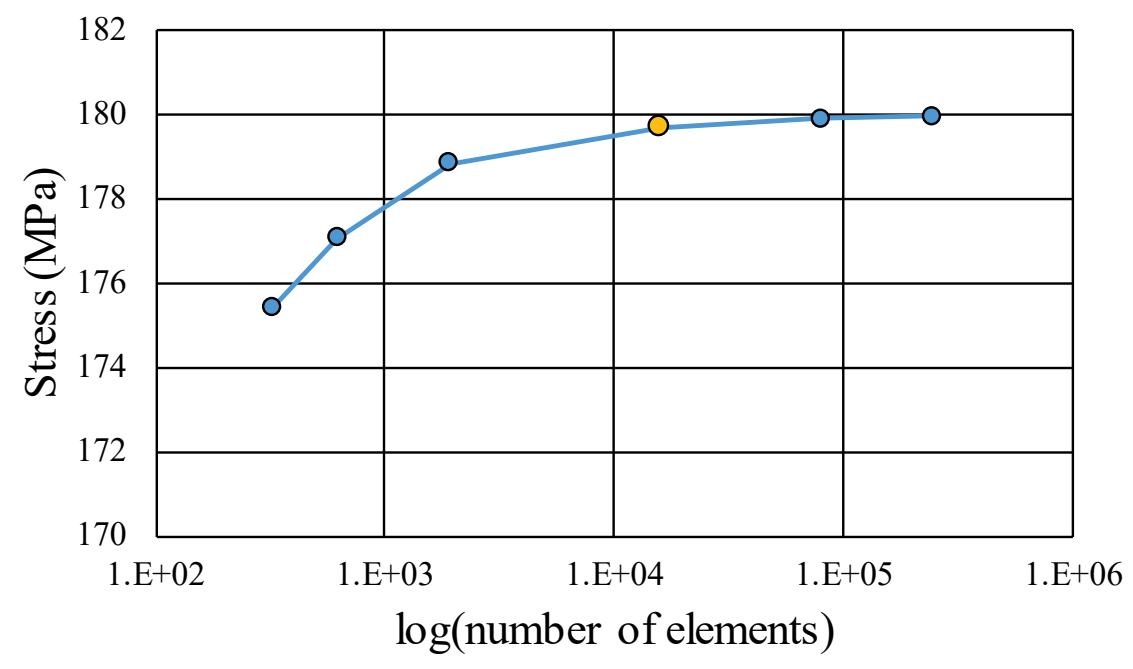

The results of the convergence study show that the final average stress approached the yield limit of $180 \mathrm{MPa}$ for increasingly finer meshes. The third finest mesh of 15,744 elements provided similar accuracy to meshes of 78,880 and 244,800 elements with far fewer elements. This mesh was selected for further FE simulation of the numerical models. The final meshed geometry is shown in Figure 46. 
Figure 46. Final meshed geometry of $10.2 \mathrm{~cm}$ by $20.3 \mathrm{~cm}$ tall cylinder.

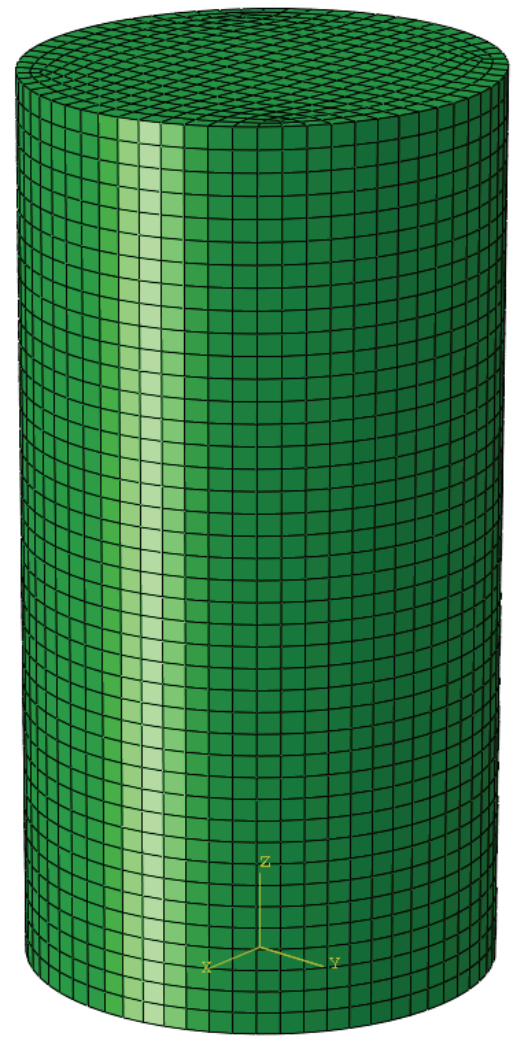

\subsubsection{Finite element model results}

The maximum principal stress was seen to be constant, indicating the uniaxial stress state was achieved. Tables 37 and 38 summarize the resulting compressive strength and elastic modulus values that developed during the curing stage of FE simulations. Figure 44 shows the stress versus strain output from the loading step of each simulation. These plots show the slope of the loading curve was constant, corresponding to the elastic modulus, until the "yield limit" was reached, which corresponded to the compressive strength set as the plastic limit.

As mentioned in section 5.3.1, $\mathrm{f}_{\mathrm{c}}$ and $\mathrm{E}_{23}$ values are calculated at each integration point, corresponding to 125,952 values per time step. To compute global $f_{c}$ and $E_{23}$ values for the entire cylinder, the average total force and displacement acting on the upper surface of the cylinder were projected to a single point and queried using History Output in Abaqus. The stresses and strains shown in Figure 47 were calculated from these projected quantities. Resulting $\mathrm{f}_{\mathrm{c}}$ in Table 37 was sampled from the final stress value shown by the 
flat line in Figure 47, and $\mathrm{E}_{23}$ in Table 38 was calculated using the slope of the loading curve before reaching the yield limit.

Table 37. Compressive strength results.

\begin{tabular}{|c|c|c|c|c|c|c|c|c|}
\hline \multirow{2}{*}{$\begin{array}{c}\text { Curing } \\
\text { Temp. } \\
\left({ }^{\circ} \mathbf{C}\right)\end{array}$} & \multicolumn{6}{|c|}{ Compressive Strength (MPa) and [Relative Error] } \\
\cline { 2 - 9 } & \multicolumn{2}{|c|}{3 day } & \multicolumn{2}{|c|}{7 day } & \multicolumn{2}{|c|}{$14-$ day } & \multicolumn{3}{c|}{28 day } \\
\hline 10 & 65.92 & {$[-0.20 \%]$} & 90.97 & {$[0.07 \%]$} & 107.68 & {$[-0.11 \%]$} & 120.89 & {$[-0.15 \%]$} \\
\hline 23 & 90.82 & {$[-0.12 \%]$} & 115.57 & {$[0.10 \%]$} & 129.84 & {$[-0.02 \%]$} & 139.99 & {$[-0.15 \%]$} \\
\hline 30 & 103.03 & {$[-0.08 \%]$} & 126.21 & {$[0.11 \%]$} & 138.75 & {$[0.02 \%]$} & 147.30 & {$[-0.16 \%]$} \\
\hline 50 & 130.11 & {$[-0.05 \%]$} & 147.45 & {$[0.13 \%]$} & 155.80 & {$[0.08 \%]$} & 161.12 & {$[-0.16 \%]$} \\
\hline 70 & 147.74 & {$[0.06 \%]$} & 160.39 & {$[0.14 \%]$} & 166.16 & {$[0.11 \%]$} & 169.77 & {$[-0.16 \%]$} \\
\hline 90 & 160.33 & {$[-0.12 \%]$} & 169.37 & {$[0.15 \%]$} & 173.61 & {$[0.12 \%]$} & 176.29 & {$[-0.16 \%]$} \\
\hline
\end{tabular}

Note: Relative Error is calculated as $100 \% *[($ analytical - predicted)/analytical].

Table 38. Elastic modulus results.

\begin{tabular}{|c|c|c|c|c|c|c|c|c|}
\hline \multirow{2}{*}{$\begin{array}{c}\text { Curing } \\
\text { Temp. } \\
\left({ }^{\circ} \mathbf{C}\right)\end{array}$} & \multicolumn{6}{|c|}{ Elastic Modulus (GPa) and [Relative Error] } \\
\cline { 2 - 9 } & \multicolumn{2}{|c|}{3 day } & \multicolumn{2}{|c|}{7 day } & \multicolumn{2}{|c|}{14 day } & \multicolumn{2}{c|}{28 day } \\
\hline 10 & 20.90 & {$[-0.65 \%]$} & 33.20 & {$[0.85 \%]$} & 41.10 & {$[0.68 \%]$} & 46.39 & {$[0.96 \%]$} \\
\hline 23 & 39.80 & {$[-1.04 \%]$} & 46.29 & {$[1.03 \%]$} & 48.86 & {$[0.97 \%]$} & 50.27 & {$[0.88 \%]$} \\
\hline 30 & 43.14 & {$[-1.06 \%]$} & 47.49 & {$[0.96 \%]$} & 49.09 & {$[0.92 \%]$} & 49.92 & {$[0.88 \%]$} \\
\hline 50 & 46.90 & {$[-0.13 \%]$} & 48.20 & {$[0.87 \%]$} & 48.81 & {$[0.86 \%]$} & 49.12 & {$[0.88 \%]$} \\
\hline 70 & 48.63 & {$[-0.68 \%]$} & 49.62 & {$[0.69 \%]$} & 49.97 & {$[0.68 \%]$} & 50.15 & {$[0.69 \%]$} \\
\hline 90 & 52.90 & {$[-0.82 \%]$} & 52.78 & {$[0.69 \%]$} & 53.03 & {$[0.68 \%]$} & 53.17 & {$[0.69 \%]$} \\
\hline
\end{tabular}

Note: Relative Error is calculated as $100 \% *$ [(analytical - predicted)/analytical]. 
Figure 47. Finite element simulation results.

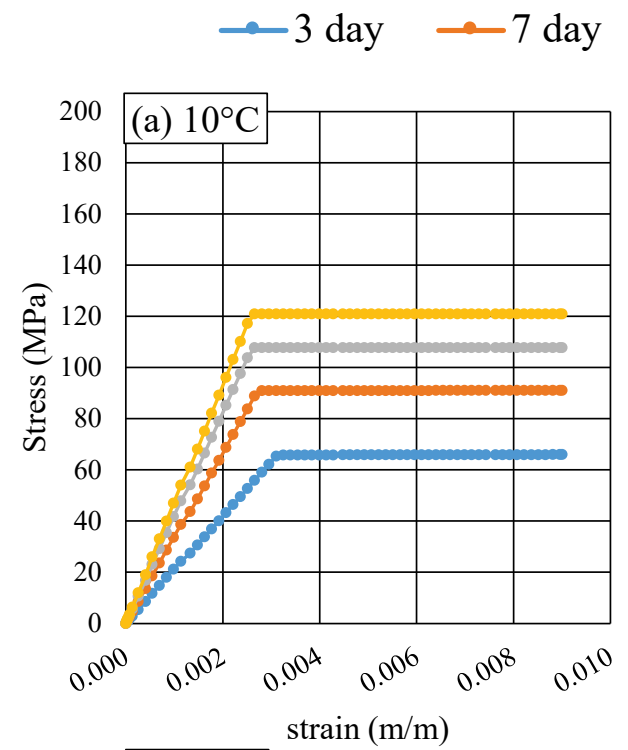

$\simeq 14$ day $\simeq 28$ day
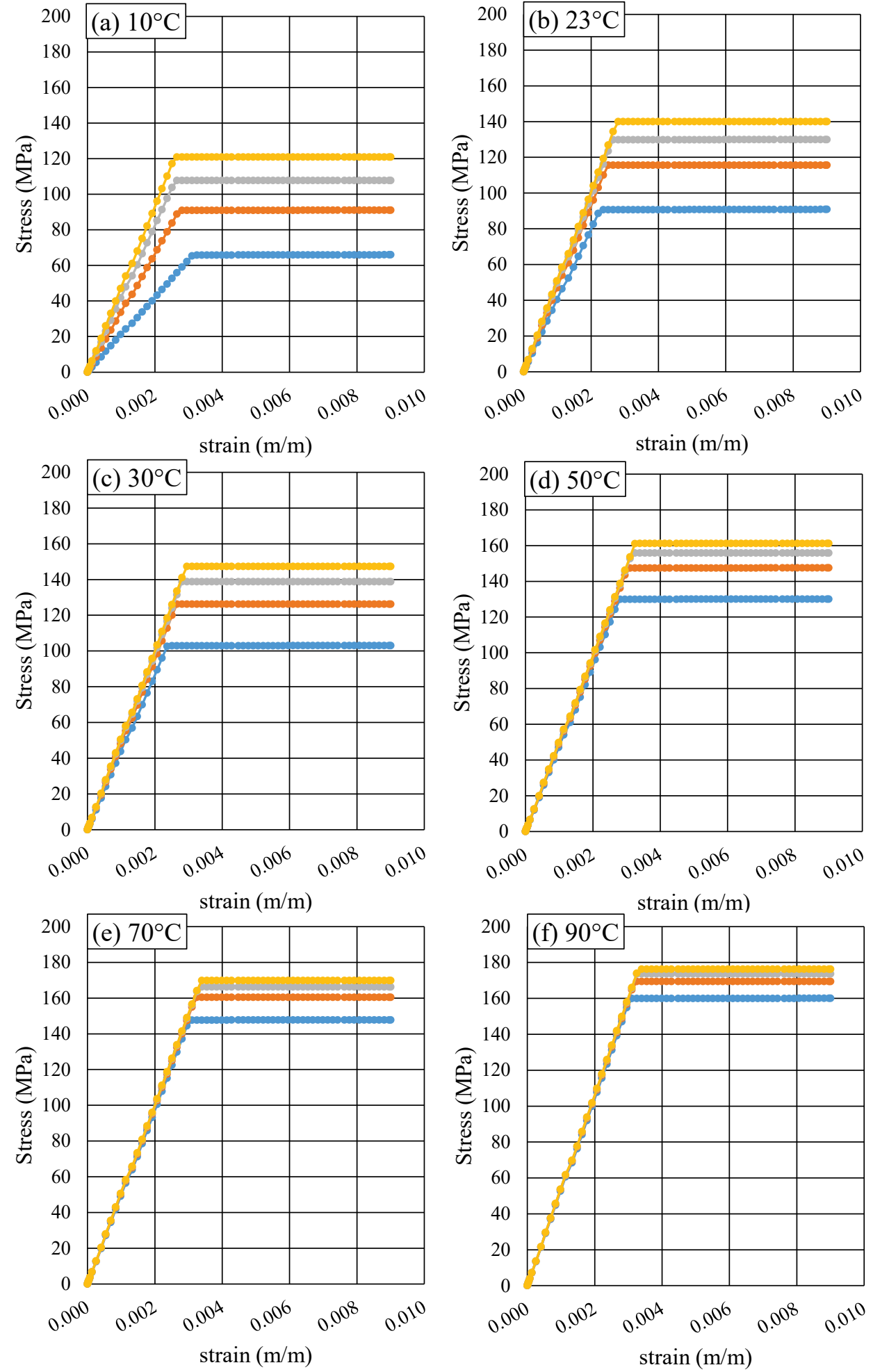
Results in Tables 37 and 38 indicate that the numerically developed values for $\mathrm{f}_{\mathrm{c}}$ and $\mathrm{E}_{23}$ correspond very closely with the analytical values. Analytical values were calculated by directly inputting best fit coefficient values from Table 34 into the equations shown in Table 33. Relative error for $f_{c}$ was always $0.16 \%$ or lower. For $\mathrm{E}_{23}$, the error was around $1 \%$ at 3 and 7 days and always less $1 \%$ at 14 and 28 days. Differences between analytically and numerically calculated values may be due to the sampling process or from second order errors in the discretization process. These results indicate the proposed numerical model was successfully discretized and implemented in Abaqus FE software.

\subsection{Summary of isothermal curing modeling and SIF}

The mechanical model presented in this chapter showed that rate of compressive strength and elastic modulus development for Cor-Tuf UHPC cured under isothermal and submerged conditions was dramatically accelerated by higher temperature curing conditions. Although the final elastic modulus appears to be unaffected by temperature, much higher compressive strength was achieved with higher curing temperatures compared to ambient conditions.

This isothermal curing numerical model is the structural integrated framework (SIF) and is used with TIF to form the numerical framework used in CORPS-STIF 1.o. SIF consists of two files both described in Table 1. Not all mechanical data detailed in Chapter 3 and OR1.o were used to develop this version of SIF, but are envisioned to be used in future versions of SIF. Data presented in Figures 12 and 13 (and Appendix A Tables 4 through 19) were used to refine SIF. By predicting strength as a function of temperature, SIF can provide input to a finite element model to optimize material properties throughout large structural members as temperatures change. 


\section{Summary, Conclusions, and Path Forward}

\subsection{Summary}

In this report, the Concrete Observations Repository and Predictive Software-Structural and Thermodynamical Integrated Framework (CORPS-STIF) was developed. CORPS-STIF's ultimate goal is to optimize constituent materials for mass concrete applications; this report describes release 1.o. Chapter 2 provided a review of current literature on UHPC characteristics and modeling efforts of mass concrete structures. Chapter 3 outlined the mechanical and thermodynamical testing that comprises the observations repository (OR), which is a database containing thermodynamical and mechanical properties for use within this framework. Some of these experiments were used herein as input to numerical models, whereas other experiments are intended to be used to refine future releases of CORPS-STIF.

A thermodynamical model, described in Chapter 4, used cylinder experiments described in Chapter 3 to improve boundary condition characterization. As documented in Chapter 2, most mass concrete models to date have assumed thermal properties of concrete to be constant. In the current TIF model, the heat transfer coefficient (h) was modeled as a function of temperature using robust correlations for common geometries that were calculated at every time step. A mechanical numerical model (SIF), described in Chapter 5, was developed to predict compressive strength and elastic modulus of isothermally cured cylinders. By using strength gain equations found in literature, strength development of UHPC could be determined over a defined amount of time. The structural and thermal integrated framework (STIF), which is a combination of SIF and TIF, represents a step toward understanding and predicting strength gain of UHPC for full-scale structures and, especially, mass concrete.

\subsection{Conclusions}

This report provides evidence that CORPS-STIF is a feasible concept and that the Figure 1 flowchart should be able to be improved over time toward better understanding of mass concrete. The following list contains the major findings of this report. 
- Most isothermally cured Cor-Tuf specimens recorded an ASTM C469 elastic modulus near $50 \mathrm{GPa}$ regardless of curing temperature after a maturity of $500^{\circ} \mathrm{C}$-days was achieved.

- General thermodynamic trends showed that larger specimens produced larger thermal gradients, and that TIF could represent the behaviors of the relatively small specimens evaluated in this report.

- The convection heat transfer coefficient is more accurate when modeled as a function of temperature rather than a constant value for geometries with robust correlations.

- The rate of compressive strength and elastic modulus development for Cor-Tuf UHPC cured under isothermal and submerged conditions was dramatically accelerated by higher temperature curing conditions.

\subsection{Path forward}

At present, CORPS-STIF only uses Cor-Tuf UHPC in material models. Future work is envisioned to look into expanding material options and having a library of available concrete mixtures that CORPS-STIF users could select. By understanding how a variety of materials react under a range of curing conditions, CORPS-STIF can be expanded to provide more material options for optimization modeling of mass concrete structures. This optimization process could help determine mechanical and thermal properties of various UHPC mixtures and provide insight to make a structure "optimal" given the project constraints.

To date, experiments have been on relatively small specimens, and obtaining thermodynamical data for larger shapes is desired. Also, more understanding is needed for tensile properties, e.g., direct tension, of UHPC at a range of curing conditions. Collecting additional data of this nature for a range of concrete mixtures should help further develop the overall CORPS-STIF framework.

With a more robust TIF and SIF and more understanding of what inputs are needed for optimized property determinations, a user-friendly version of CORPS-STIF is envisioned where a manual accompanying the software not only describes how to perform calculations, but also describes the specific steps needed to measure all mechanical and thermodynamical inputs provided a user would like to use a mixture that is not in the CORPS-STIF library. It is envisioned that these inputs would be measurable in a reasonably equipped laboratory absent especially sophisticated equipment. 


\section{References}

ACI Committee 207. 2005. Specifications for structural concrete: ACI 207.1R-o5. Farmington Hills, MI: American Concrete Institute.

. 2007. Specifications for structural concrete: ACI 207.2R-07. Farmington Hills, MI: American Concrete Institute.

ACI Committee 301. 2016. Specifications for structural concrete: ACI 301-16. Farmington Hills, MI: American Concrete Institute.

ACI Committee 318. 2013. Building code requirements for structural concrete: ACI 31811; and commentary (ACI 318R-11). Farmington Hills, MI: American Concrete Institute.

Adley, M. D., A. O. Frank, K. T. Danielson, S. A. Akers, and J. L. O’Daniel. 2010. The Advanced Fundamental Concrete (AFC) model. ERDC/GSL TR-10-51.

Vicksburg, MS: U.S. Army Engineer and Research and Development Center.

Ahmad, S., and I. Hakeem. 2015. Effect of curing, fibre content and exposures on compressive strength and elasticity of UHPC. Advances in Cement Research 27(4):233-239.

Ali, W., and G. Urgessa. 2012. Numerical prediction model for temperature distributions in concrete at early ages. American Journal of Engineering and Applied Sciences 5(4):282-290.

Alsalman, A., C. N. Dang, G. S. Prinz, and W. M. Hale. 2017. Evaluation of modulus of elasticity of ultra-high performance concrete. Construction and Building Materials 153:918-928.

Ardiaca, D. H. 2009. Mohr-Coulomb parameters for modelling of concrete structures. Plaxis (Spring) Bulletin, pp. 12-15. Exton, PA: Bentley Systems.

American Society of Testing and Materials (ASTM). 2016. Standard practice for making and curing concrete test specimens in the laboratory. Standard C192/C192M. West Conshohocken, PA: ASTM International. 2016. Standard test method for compressive strength of cylindrical concrete specimens. Standard C39/C39M. West Conshohocken, PA: ASTM International.

. 2016. Standard test method for time of setting of concrete mixtures by penetration resistance. Standard $\mathrm{C} 403 / \mathrm{C} 403 \mathrm{M}$. West Conshohocken, PA: ASTM International.

. 2014. Standard test method for static modulus of elasticity and poisson's ratio of concrete in compression. Standard C469/C469M. West Conshohocken, PA: ASTM Internationals.

. 2013. Standard specification for mixing rooms, moist cabinets, moist rooms, and water storage tanks used in the testing of hydraulic cements and concretes. Standard C511 12. West Conshohocken, PA: ASTM International. 
. 2006. Standard test method for flexural toughness and first-crack strength of fiber reinforced concrete (using beam with third-point loading. Standard C1018 97. West Conshohocken, PA: ASTM International.

. 2017. Standard practice for estimating concrete strength by the maturity method. Standard C1074. West Conshohocken, PA: ASTM International.

Azenha, M., R. Faria, and D. Ferreira. 2009. Identification of early-age concrete temperatures and strains: Monitoring and numerical simulation. Cement and Concrete Composites 31:369-378.

Ballim, Y. 2004. A numerical model and associated calorimeter for predicting temperature profiles in mass concrete. Cement and Concrete Composites 26:695703 .

Bejan, A. 2004. Convection heat transfer ( $3^{\text {rd }}$ ed.). Hoboken, NJ: John Wiley and Sons.

Bentz, D. P., V. Waller, and F. de Larrard. 1998. Prediction of adiabatic temperature rise in conventional and high-performance concretes using a 3-D microstructural model. Cement and Concrete Research 28(2):285-297.

Bergman, T. L., A. S. Lavine, F. P. Incropera, and D. P. Dewitt. 2011. Fundamentals of heat and mass transfer ( $7^{\text {th }}$ ed.). Hoboken, NJ: John Wiley and Sons.

Bombich, A. A., S. Garner, and C. D. Norman. 1991. Evaluation of parameters affecting thermal stresses in mass concrete. SL-91-2. Vicksburg, MS: U.S. Army Engineer Waterways Experiment Station.

Carino, N. J. 1984. The maturity method: Theory and application. Cement, Concrete, and Aggregates 6(2):61-73.

Carino, N. J. and H. S. Lew. 2001. The maturity method: From theory to application. In Proceedings, 2001 Structures Congress \& Exposition, American Society of Civil Engineers, 21-23 May. Washington, DC.

Cervera, M., R. Faria, J. Oliver, and T. Prato. 2002. Numerical modelling of concrete curing, regarding hydration and temperature phenomena. Computers and Structures 80:1511-1521.

Cervera, M., J. Oliver, and T. Prato. 1999. Thermo-chemo-mechanical model for concrete. I: hydration and aging. Journal of Engineering Mechanics 125(9):1018-1027.

Chandler, M., J. Peters, and D. Pelessone. 2012. Modeling nanomechanical behavior of calcium-silicate-hydrate. ERDC/GSL TR-12-30. Vicksburg, MS: U.S. Army Engineer and Research and Development Center.

Chini, A. R. and A. Parham. 2005. Adiabatic temperature rise of mass concrete in Florida. Contract No. BD-529. Tallahassee, FL: Florida Department of Transportation.

D'Aloia, L., and G. Chanvillard. 2002. Determining the "apparent" activation energy of concrete $\mathrm{E}_{\mathrm{a}}-$ Numerical simulations of the heat of hydration of cement. Cement and Concrete Research 32:1277-1289. 
Department of the Army. 1994. Nonlinear, incremental structural analysis of massive concrete structures. Technical Letter No. 1110-2-365. Washington, DC: Department of the Army.

Di Luzio, G., and G. Cusatis. 2009a. Hygro-thermo-chemical modeling of high performance concrete. I: Theory. Cement and Concrete Composites 31:301-308.

Di Luzio, G., and G. Cusatis. 2009b. Hygro-thermo-chemical modeling of high performance concrete. II: Numerical implementation, calibration, and validation. Cement and Concrete Composites 31:309-324.

Fairbairn, E. M. R., M. M. Silvoso, R. D. Toledo Filho, J. L. D. Alves, and N. F. F. Ebecken. 2004. Optimization of mass concrete construction using genetic algorithms. Computers and Structures 82:281-299.

Faria, R., M. Azenha, and J. A. Figueiras. 2006. Modelling of concrete at early ages: Application to an externally restrained slab. Cement \& Concrete Composites 28:572-585.

Ferrier, E., L. Michel, B. Zuber, and G. Chanvillard. 2015. Mechanical behavior of ultrahigh-performance short-fibre-reinforced concrete beams with internal fibre reinforced polymer bars. Composites: Part B 68:246-258.

Garner, S. B., and M. I. Hammons. 1991. Development and implementation of timedependent cracking material model for concrete. SL-91-7. Vicksburg, MS: U.S. Army Engineer Waterways Experiment Station.

Ge, Z., K. Wang, P. J. Sandberg, and J. M. Ruiz. 2009. Characterization and performance prediction of cement-based materials using a simple isothermal calorimeter. Journal of Advanced Concrete Technology 7(3):355-366.

Graybeal, B. A. 2006. Material property characterization of ultra-high performance concrete. FHWA-HRT-06-103. McLean, VA: Federal Highway Administration. . 2011. Ultra-high performance concrete. FHWA-HRT-11-038. McLean, VA: Federal Highway Administration.

Green, B. H., R. D. Moser, D. A. Scott, and W. R. Long. 2014. Ultra-high performance concrete history and usage by the Corps of Engineers. Advances in Civil Engineering Materials 4(2):132-143.

Habel, K., M. Viviani, E. Denarie, and E. Bruhwiler. 2006. Development of the mechanical properties of an Ultra-High Performance Fiber Reinforced Concrete (UHPFRC). Cement and Concrete Research 36(6):1362-1370.

Howard, I. L., A. Carey, M. Burcham, D. A. Scott, J. D. Shannon, R. D. Moser, and M. F. Horstemeyer. 2018. Mechanical behavior of Cor-Tuf ultra-high-performance concrete considering aggregate and paste effects. ERDC/GSL TR-18-31. Vicksburg, MS: U.S. Army Engineer Research and Development Center. 
Isaacs, J., J. Magallanes, M. Rebentrost, and G. Wight. 2009. Exploratory dynamic material characterizing tests on ultra-high performance fibre reinforced concrete. In Proceedings from the 8th International Conference on Shock and Impact Loads on Structures, 2-4 December. Adelaide, Australia.

Isgor, O. B., and A. G. Razaqpur. 2004. Finite element modeling of coupled heat transfer, moisture transport and carbonation processes in concrete structures. Cement and Concrete Composites 26:57-73.

Kim, J. K., Y. H. Moon, and S. H. Eo. 1998. Compressive strength development of concrete with different curing time and temperature. Cement and Concrete Research 28(12):1761-1773.

Kodur, V. K. R., P. P. Bhatt, P. Soroushian, and A. Arablouei. 2016. Temperature and stress development in ultra-high performance concrete during curing. Construction and Building Materials 122:63-71.

Kuriakose, B., B. Nageswara Rao, and G. R. Dodagoudar. 2016. Early-age temperature distribution in a massive concrete foundation. Procedia Technology 25:107-114.

Lawrence, A. M., M. Tia, C. C. Ferraro, and M. Bergin. 2012. Effect of early age strength on cracking in mass concrete containing different supplementary cementitious materials: Experimental and finite-element investigation. Journal of Materials in Civil Engineering 24(4):362-372.

Lee, C., S. Lee, and N. Nguyen. 2016. Modeling of compressive strength development of high-early-strength-concrete at different curing temperatures. International Journal of Concrete Structures and Materials 10(2):205-219.

Maruyama, I., M. Suzuki, and R. Sato. 2012. Stress distribution and crack formation in full-scaled ultra-high strength concrete columns. Materials and Structures 45(12):1829-1847.

Oliphant, T. E. 2007. Python for scientific computing. Computing in Science \& Engineering 9(3):10-20.

Portland Cement Association. 1997. Portland cement, concrete, and heat of hydration. Concrete Technology Today 18(2):1-4.

Potgieter, I. C., and W. L. Gamble. 1983. Response of highway bridges to nonlinear temperature distributions. FHWA/IL/UI-201. Urbana, IL: University of Illinois at Urbana-Champaign Department of Civil Engineering.

Prem, P. R., A. R. Murthy, and B. H. Bharatkumar. 2015. Influence of curing regime and steel fibres on the mechanical properties of UHPC. Magazine of Concrete Research 67(18):988-1002.

Radovanović, S. 1998. Thermal and structural finite element analysis of early age mass concrete structures. MS thesis, University of Manitoba.

Riding, K. A., J. L. Poole, A. K. Schindler, M. C. G. Juenger, and K. J. Folliard. 2007. Temperature boundary condition models for concrete bridge members. $A C I$ Materials Journal 104(4)379-387. 
Riding, K. A., J. L. Poole, A. K. Schindler, M. C. G. Juenger, and K. J. Folliard. 2006. Evaluation of temperature prediction methods for mass concrete members. ACI Materials Journal 103(5):357-365.

Rossum, G. V. 1995. Python tutorial. Technical Report CS-R9526. Amsterdam: Centrum voor Wiskunde en Informatica (CWI).

Roth, M. J. 2008. Flexural and tensile properties of thin, very high-strength, fiberreinforced concrete panels. ERDC/GSL TR-08-24. Vicksburg, MS: U.S. Army Engineer Research and Development Center.

Schindler, A. K., R. W. Barnes, A. D. Eiland, and E. D. Gross. 2017. Requirements for mass concrete construction in Alabama. $6 \mathrm{O}^{\text {th }}$ Transportation Conference. Montgomery, AL.

Tia, M., C. Ferraro, A. Lawrence, S. Smith, and E. Ochiai. 2010. Development of design parameters for mass concrete using finite element analysis. Contract No. BD545 \#60. Tallahassee, FL: Department of Transportation.

Tia, M., A. Lawrence, T. A. Do, D. Verdugo, S. Han, M. Almarshoud, B. Ferrante, and A. Markandeya. 2016. Maximum heat of mass Concrete - Phase 2. Contract No. BDV31-977-07. Tallahassee, FL: Florida Department of Transportation.

Tia, M., A. Lawrence, C. Ferraro, T. A. Do, and Y. Chen. 2013. Pilot project for maximum heat of mass concrete. Contract No. BDK75 977-47. Tallahassee, FL: Department of Transportation.

Ulm, F., and O. Coussy. 1995. Modeling of thermochemomechanical couplings of concrete at early ages. Journal of Engineering Mechanics 121(7):785-794.

Wan, L., R. Wendner, B. Liang, and G. Cusatis. 2016. Analysis of the behavior of ultrahigh performance concrete at early ages. Cement and Concrete Composites 74:120-135.

Wille, K., S. El-Tawil, and A. E. Naaman. 2014. Properties of strain hardening ultra-high performance fiber reinforced concrete (UHP-FRC) under direct tensile loading. Cement and Concrete Composites 48:53-66.

Wille, K., A. E. Naaman, S. El-Tawil, and G. J. Parra-Montesinos. 2012. Ultra-high performance concrete and fiber reinforced concrete: Achieving strength and ductility without heat curing. Materials and Structures 45:309-324.

$\mathrm{Wu}, \mathrm{Y}$., and R. Luna. 2001. Numerical implementation of temperature and creep in mass concrete. Finite Elements in Analysis and Design 37:97-106.

Wu, Z., C. Shi, W. He, and L. Wu. 2016. Effects of steel fiber content and shape on mechanical properties of ultra-high performance concrete. Construction and Building Materials 103:8-14.

Yang, J., Y. Hu, Z. Zuo, F. Jin, and Q. Li. 2012. Thermal analysis of mass concrete embedded with double-layer staggered heterogeneous cooling water pipes. Applied Thermal Engineering 35:145-156. 
Yu, T., J. G. Teng, Y. L. Wong, and S. L. Dong. 2010. Finite element modeling of confined concrete-II: Plastic-damage model. Engineering Structures 32(3):680-691.

Yunchuan, A., B. Liang, S. Yang, and C. Guting. 2012. Simulation analysis of mass concrete temperature field. Procedia Earth and Planetary Science 5:5-12.

Zhou, C., X. Shu, and B. Huang. 2014. Predicting concrete coefficient of thermal expansion with an improved micromechanical model. Construction and Building Materials 68:10-16. 


\section{Appendix A: Raw Data Tables}

Table A1. Compressive strength test results - FT.

\begin{tabular}{|c|c|c|}
\hline ID & $\begin{array}{c}\text { Temperature } \\
\left({ }^{\circ} \mathrm{C}\right)\end{array}$ & $\mathbf{f}_{\mathrm{c}}(\mathrm{MPa})$ \\
\hline FT-1a & 23 & 188.0 \\
\hline FT-1b & 90 & 179.4 \\
\hline FT-2a & 23 & 186.1 \\
\hline FT-2b & 70 & 149.6 \\
\hline FT-3a & 23 & 164.0 \\
\hline FT-3b & 50 & 174.4 \\
\hline FT-4a & 23 & 181.6 \\
\hline FT-4b & 30 & 169.8 \\
\hline FT-5a & 23 & 183.5 \\
\hline FT-5b & 10 & 169.8 \\
\hline
\end{tabular}

Table A2. Compressive strength test results - ET.

\begin{tabular}{|c|c|c|c|c|c|c|}
\hline Specimen ID & $\begin{array}{c}\text { Time in } \\
\mathrm{CE}_{1} \text { (days) }\end{array}$ & $\begin{array}{c}\text { Time in } \\
\mathrm{CE}_{3} \text { (days) }\end{array}$ & $\begin{array}{c}\text { Time in } \\
\mathrm{CE}_{5} \text { (days) }\end{array}$ & $\mathbf{M}\left({ }^{\circ} \mathrm{C}\right.$-days) & $f_{c}(\mathrm{MPa})$ & $\rho\left(\mathrm{g} / \mathrm{cm}^{3}\right)$ \\
\hline ET-1 & 1.03 & 6.00 & 7.00 & 783.19 & 161.1 & 2.510 \\
\hline ET-2 & 1.03 & 6.00 & 7.00 & 783.19 & 178.9 & 2.518 \\
\hline ET-3 & 1.03 & 6.00 & 7.00 & 783.19 & 179.9 & 2.500 \\
\hline ET-4 & 1.03 & 6.00 & 7.00 & 783.19 & 187.8 & 2.505 \\
\hline ET-5 & 1.00 & 6.00 & 7.00 & 782.53 & 162.1 & 2.502 \\
\hline ET-6 & 1.00 & 6.00 & 7.00 & 782.53 & 170.0 & 2.526 \\
\hline ET-7 & 0.97 & 6.00 & 7.00 & 781.98 & 173.6 & 2.508 \\
\hline ET-8 & 0.97 & 6.00 & 7.00 & 781.98 & 153.2 & 2.479 \\
\hline ET-9 & 0.97 & 6.00 & 7.00 & 781.98 & 162.9 & 2.495 \\
\hline ET-10 & 0.97 & 6.00 & 7.00 & 781.98 & 169.7 & 2.514 \\
\hline
\end{tabular}


Table A3. Elastic modulus test results - ET.

\begin{tabular}{|c|c|c|c|c|c|c|c|}
\hline \multirow{2}{*}{ Specimen ID } & \multicolumn{7}{|c|}{$\mathrm{E}(\mathrm{MPa})$} \\
\hline & $\begin{array}{c}\text { Dial Test } 1 \\
\text { @ } 23^{\circ} \mathrm{C}\end{array}$ & $\begin{array}{c}\text { Dial Test } 2 \\
@ 23^{\circ} \mathrm{C}\end{array}$ & $\begin{array}{l}\text { LVDT Test } 1 \\
\text { @ } 23^{\circ} \mathrm{C}\end{array}$ & $\begin{array}{l}\text { LVDT Test } 2 \\
\text { @ } 23^{\circ} \mathrm{C}\end{array}$ & $\begin{array}{l}\text { LVDT Test } \\
\text { @ } 10^{\circ} \mathrm{C}\end{array}$ & $\begin{array}{l}\text { LVDT Test } \\
\text { @ } 50^{\circ} \mathrm{C}\end{array}$ & $\begin{array}{l}\text { LVDT Test } \\
\text { @ } 90^{\circ} \mathrm{C}\end{array}$ \\
\hline ET-1 & 49,650 & 50,021 & 48,791 & 48,796 & 52,998 & 48,590 & 45,886 \\
\hline ET-2 & 50,436 & 50,909 & 50,898 & 50,425 & 53,559 & 47,848 & 48,166 \\
\hline ET-3 & 49,478 & 48,991 & 49,207 & 49,416 & 53,095 & 51,060 & 47,087 \\
\hline ET-4 & 50,114 & 50,439 & 49,056 & 49,412 & 50,509 & 47,591 & 46,924 \\
\hline ET-5 & 49,932 & 50,205 & 50,158 & 49,610 & 52,955 & 48,432 & 43,979 \\
\hline ET-6 & 48,815 & 48,813 & 47,983 & 46,003 & 50,278 & 47,867 & 44,116 \\
\hline ET-7 & 51,104 & 50,207 & 51,896 & 51,633 & 50,134 & 49,056 & 43,960 \\
\hline ET-8 & 47,019 & 48,331 & 51,410 & 51,332 & 53,191 & 46,468 & 44,573 \\
\hline ET-9 & 49,889 & 49,887 & 49,792 & 50,757 & 51,148 & 46,677 & 44,053 \\
\hline ET-10 & 48,042 & 47,999 & 47,635 & 48,447 & 50,219 & 45,251 & 41,033 \\
\hline
\end{tabular}


Table A4. Physical property test results - I10-01 to I10-30.

\begin{tabular}{|c|c|c|c|c|c|c|c|}
\hline Specimen ID & $\begin{array}{l}\text { Time in } \mathrm{CE}_{1} \\
\text { (days) }\end{array}$ & $\begin{array}{l}\text { Time in } \mathrm{CE}_{2} \\
\text { (days) }\end{array}$ & $\mathrm{M}\left({ }^{\circ} \mathrm{C}\right.$-days $)$ & $\mathrm{f}_{\mathrm{c}}(\mathrm{MPa})$ & $\mathrm{E}(\mathrm{MPa})$ & $\rho\left(\mathrm{g} / \mathrm{cm}^{3}\right)$ & $\begin{array}{l}\text { Data } \\
\text { Group }\end{array}$ \\
\hline $\mid 10-01$ & 1.24 & 15.88 & 194.71 & 100.5 & - & - & C \\
\hline $\mid 10-02$ & 1.24 & 15.88 & 194.71 & 107.5 & - & - & $\mathrm{C}$ \\
\hline $\mid 10-03$ & 1.21 & 15.88 & 194.24 & 87.5 & - & - & C \\
\hline $110-04$ & 1.21 & 15.88 & 194.24 & 106.6 & - & - & C \\
\hline $110-05$ & 1.19 & 15.88 & 193.78 & 102.8 & - & - & C \\
\hline $110-06$ & 1.19 & 33.67 & 377.23 & 126.8 & 48,659 & - & A \\
\hline $\mid 10-07$ & 1.17 & 37.46 & 414.43 & 118.1 & - & - & $A$ \\
\hline $110-08$ & 1.17 & 41.73 & 456.76 & 123.3 & - & - & $A$ \\
\hline $110-09$ & 1.15 & 45.85 & 497.26 & 111.2 & - & - & A \\
\hline $\mid 10-10$ & 1.15 & 49.61 & 534.54 & 131.1 & 51,533 & - & A \\
\hline $\mid 10-11$ & 1.12 & 53.83 & 575.60 & 137.9 & - & 2.522 & $A$ \\
\hline $\mid 10-12$ & 1.12 & 57.77 & 614.47 & 142.8 & - & 2.562 & A \\
\hline $\mid 10-13$ & 1.10 & 61.79 & 653.75 & 135.6 & - & 2.540 & A \\
\hline $\mid 10-14$ & 1.10 & 65.87 & 693.94 & 131.0 & 52,968 & 2.517 & A \\
\hline $\mid 10-15$ & 1.08 & 69.80 & 732.26 & 133.8 & - & 2.566 & A \\
\hline $\mid 10-16$ & 1.08 & 73.98 & 773.49 & 137.2 & - & 2.537 & A \\
\hline $\mid 10-17$ & 1.03 & 77.86 & 810.74 & 151.2 & - & 2.567 & A \\
\hline $\mid 10-18$ & 1.03 & 81.85 & 850.10 & 140.8 & 49,879 & 2.547 & A \\
\hline $\mid 10-19$ & 1.01 & 86.01 & 890.67 & 129.7 & - & 2.539 & A \\
\hline $\mid 10-20$ & 1.01 & 89.85 & 928.51 & 144.4 & - & 2.534 & $A$ \\
\hline $\mid 10-21$ & 0.98 & 93.90 & 967.96 & 141.7 & - & 2.529 & A \\
\hline $\mid 10-22$ & 0.98 & 97.92 & 1007.66 & 135.3 & 53,781 & 2.538 & A \\
\hline $\mid 10-23$ & 0.96 & 102.04 & 1047.81 & 139.2 & - & 2.516 & A \\
\hline I10-24 & 0.96 & 106.15 & 1088.40 & 151.7 & - & 2.560 & A \\
\hline $\mid 10-25$ & 0.94 & 110.12 & 1127.03 & 137.0 & - & 2.543 & $A$ \\
\hline $\mid 10-26$ & 0.94 & 114.02 & 1165.51 & 140.5 & 52,046 & 2.549 & $A$ \\
\hline $\mid 10-27$ & 0.92 & 118.00 & 1204.41 & 150.6 & - & 2.551 & A \\
\hline $110-28$ & 0.92 & 122.55 & 1249.29 & 126.3 & - & - & A \\
\hline $\mid 10-29$ & 0.90 & 125.89 & 1281.75 & 139.6 & - & 2.566 & A \\
\hline $\mid 10-30$ & 0.90 & 130.13 & 1323.89 & 151.4 & 53,668 & 2.527 & $A$ \\
\hline
\end{tabular}


Table A5. Physical property test results - I10-31 to 162.

\begin{tabular}{|c|c|c|c|c|c|c|c|}
\hline Specimen ID & Time in $\mathrm{CE}_{1}$ & Time in $\mathrm{CE}_{5}$ & $\mathrm{M}\left({ }^{\circ} \mathrm{C}\right.$-days $)$ & $\mathrm{f}_{\mathrm{c}}(\mathrm{MPa})$ & $\mathrm{E}(\mathrm{MPa})$ & $\rho\left(\mathrm{g} / \mathrm{cm}^{3}\right)$ & $\begin{array}{l}\text { Data } \\
\text { Group }\end{array}$ \\
\hline $\mid 10-31$ & 1.20 & 133.29 & 1359.14 & 146.7 & - & 2.541 & A \\
\hline $\mid 10-32$ & 1.20 & 137.53 & 1409.64 & 132.1 & - & 2.541 & A \\
\hline $\mid 10-33$ & 1.18 & 141.33 & 1454.12 & 139.8 & - & 2.541 & A \\
\hline $110-34$ & 1.18 & 145.79 & 1506.93 & 138.0 & 51,540 & 2.530 & A \\
\hline $110-35$ & 1.15 & 149.81 & 1553.91 & 142.1 & - & 2.562 & A \\
\hline $110-36$ & 1.15 & 153.81 & 1601.25 & 148.9 & - & 2.517 & A \\
\hline $110-37$ & 1.13 & 157.82 & 1648.09 & 156.8 & - & 2.537 & A \\
\hline $110-38$ & 1.13 & 161.88 & 1696.21 & 143.1 & 52,201 & 2.544 & A \\
\hline I10-39 & 1.11 & 165.85 & 1742.64 & 141.0 & - & 2.547 & A \\
\hline $\mid 10-40$ & 1.11 & 169.78 & 1789.17 & 137.3 & - & 2.526 & A \\
\hline $\mid 10-41$ & 1.10 & 173.95 & 1792.19 & 141.2 & - & 2.546 & A \\
\hline $\mid 10-42$ & 1.10 & 177.92 & 1830.96 & 142.9 & 53,926 & 2.535 & A \\
\hline $110-43$ & 1.07 & 181.92 & 1869.60 & 147.4 & - & 2.541 & A \\
\hline $\mid 10-44$ & 1.07 & 185.90 & 1908.44 & 151.6 & - & 2.548 & A \\
\hline $110-45$ & 1.05 & 189.84 & 1946.55 & 144.7 & - & 2.550 & A \\
\hline $110-46$ & 1.05 & 194.00 & 1987.10 & 140.0 & 56,925 & 2.551 & A \\
\hline $110-47$ & 1.01 & 197.97 & 2024.95 & 145.2 & - & 2.559 & A \\
\hline $110-48$ & 1.01 & 201.97 & 2064.02 & 151.7 & - & 2.549 & A \\
\hline $110-49$ & 0.99 & 206.32 & 2105.99 & 159.8 & - & 2.556 & A \\
\hline $110-50$ & 0.99 & 210.04 & 2142.36 & 146.4 & - & 2.527 & A \\
\hline $\mid 10-51$ & 0.97 & 213.80 & 2188.63 & 160.7 & - & 2.541 & A \\
\hline $110-52$ & 0.97 & 218.10 & 2232.46 & 145.2 & - & 2.526 & A \\
\hline $110-53$ & 0.95 & 221.81 & 2269.83 & 155.4 & - & 2.544 & A \\
\hline $110-54$ & 0.95 & 225.93 & 2311.85 & 146.2 & 54,519 & 2.532 & A \\
\hline $110-55$ & 0.92 & 230.09 & 2353.87 & 156.2 & - & 2.536 & A \\
\hline $110-56$ & 0.92 & 234.02 & 2393.97 & 142.8 & - & 2.532 & A \\
\hline $110-57$ & 0.90 & 237.90 & 2433.08 & 118.8 & - & - & A \\
\hline $110-58$ & 0.90 & 242.12 & 2476.06 & 153.7 & 52,701 & 2.530 & A \\
\hline $110-59$ & 0.88 & 247.86 & 2534.22 & 153.9 & - & 2.546 & A \\
\hline $110-60$ & 0.88 & 250.10 & 2557.09 & 151.6 & - & 2.558 & A \\
\hline $\mid 10-61$ & 1.02 & 14.36 & 165.80 & 108.5 & 47,252 & 2.517 & A \\
\hline $\mid 10-62$ & 1.02 & 18.26 & 204.32 & 111.5 & - & 2.522 & A \\
\hline
\end{tabular}


Table A6. Physical property test results - I10-63 to I10-86.

\begin{tabular}{|c|c|c|c|c|c|c|c|}
\hline Specimen ID & $\begin{array}{c}\text { Time in } \mathrm{CE}_{1} \\
\text { (days) }\end{array}$ & $\begin{array}{c}\text { Time in } \mathrm{CE}_{5} \\
\text { (days) }\end{array}$ & $\mathrm{M}\left({ }^{\circ} \mathrm{C}\right.$-days $)$ & $\mathrm{f}_{\mathrm{c}}(\mathrm{MPa})$ & $\mathrm{E}(\mathrm{MPa})$ & $\rho\left(\mathrm{g} / \mathrm{cm}^{3}\right)$ & $\begin{array}{l}\text { Data } \\
\text { Group }\end{array}$ \\
\hline $\mid 10-63$ & 1.00 & 22.25 & 243.22 & 103.4 & 47,756 & 2.533 & $A$ \\
\hline $\mid 10-64$ & 1.00 & 26.15 & 281.71 & 118.8 & - & 2.514 & $A$ \\
\hline $110-65$ & 0.97 & 30.08 & 319.98 & 114.9 & 50,447 & 2.511 & $A$ \\
\hline $\mid 10-66$ & 0.97 & 4.04 & 63.16 & 84.8 & - & 2.504 & $A$ \\
\hline $\mid 10-67$ & 0.95 & 4.04 & 62.62 & 87.3 & - & 2.513 & $A$ \\
\hline $110-68$ & 0.95 & 6.24 & 84.37 & 90.6 & - & - & A \\
\hline $\mid 10-69$ & 0.93 & 8.33 & 104.44 & 99.3 & - & 2.527 & A \\
\hline $\mid 10-70$ & 0.93 & 8.36 & 104.77 & 95.7 & 48,560 & 2.525 & A \\
\hline $\mid 10-71$ & 0.91 & 10.19 & 122.34 & 98.0 & - & 2.529 & $A$ \\
\hline $\mid 10-72$ & 0.91 & 12.11 & 141.29 & 99.2 & - & 2.526 & $A$ \\
\hline $110-73$ & 0.89 & 12.13 & 141.04 & 101.8 & 47,964 & 2.532 & $A$ \\
\hline $110-74$ & 0.89 & 16.35 & 182.71 & 108.9 & - & 2.517 & C \\
\hline $110-75$ & 0.87 & 16.36 & 182.34 & 97.6 & - & 2.521 & C \\
\hline $\mid 10-76$ & 0.87 & 16.36 & 182.34 & 114.1 & - & 2.535 & C \\
\hline $110-77$ & 1.01 & 3.01 & 53.83 & 78.4 & - & 2.496 & A \\
\hline $110-78$ & 1.01 & 3.01 & 53.84 & 79.2 & 39,447 & 2.514 & A \\
\hline I10-79 & 0.03 & 0.99 & 11.60 & 0.3 & - & - & $B$ \\
\hline $\mid 10-80$ & 0.03 & 1.23 & 13.94 & 0.9 & - & - & B \\
\hline $\mid 10-81$ & 0.03 & 2.01 & 21.77 & 16.9 & - & - & B \\
\hline |10-82 & 0.03 & 1.97 & 21.37 & 15.7 & 13,313 & - & $B$ \\
\hline |10-83 & 0.03 & 2.98 & 31.41 & 64.1 & - & - & B \\
\hline |10-84 & 0.03 & 4.00 & 41.64 & 72.5 & - & - & $B$ \\
\hline $110-85$ & 0.03 & 3.96 & 41.26 & 81.2 & 41,086 & - & B \\
\hline I10-86 & 0.03 & 4.96 & 51.27 & 94.4 & - & - & B \\
\hline
\end{tabular}


Table A7. Physical property test results - 123-01 to I23-32.

\begin{tabular}{|c|c|c|c|c|c|c|c|}
\hline Specimen ID & $\begin{array}{c}\text { Time in } \mathrm{CE}_{1} \\
\text { (days) }\end{array}$ & $\begin{array}{c}\text { Time in } \mathrm{CE}_{4} \\
\text { (days) }\end{array}$ & M ( ${ }^{\circ} \mathrm{C}$-days) & $\mathrm{f}_{\mathrm{c}}(\mathrm{MPa})$ & $\mathrm{E}(\mathrm{MPa})$ & $\rho\left(\mathrm{g} / \mathrm{cm}^{3}\right)$ & $\begin{array}{l}\text { Data } \\
\text { Group }\end{array}$ \\
\hline $123-01$ & 0.97 & 7.14 & 170.66 & 119.6 & - & - & C \\
\hline $123-02$ & 0.97 & 7.14 & 170.66 & 109.9 & - & - & C \\
\hline $123-03$ & 0.95 & 7.15 & 170.55 & 116.6 & - & - & C \\
\hline $123-04$ & 0.95 & 7.15 & 170.55 & 115.2 & - & - & $\mathrm{C}$ \\
\hline $123-05$ & 1.30 & 6.75 & 169.97 & 114.8 & - & - & $\mathrm{C}$ \\
\hline $123-06$ & 1.30 & 6.75 & 169.97 & 110.6 & - & - & C \\
\hline $123-07$ & 1.28 & 6.75 & 169.44 & 109.0 & - & - & $\mathrm{C}$ \\
\hline $123-08$ & 1.28 & 6.75 & 169.44 & 106.6 & - & - & C \\
\hline $123-09$ & 1.26 & 14.63 & 333.98 & 117.5 & - & - & $A$ \\
\hline $123-10$ & 1.26 & 16.09 & 364.74 & 132.4 & 48,659 & - & A \\
\hline |23-11 & 1.23 & 18.01 & 404.38 & 126.1 & - & - & $A$ \\
\hline |23-12 & 1.23 & 19.70 & 439.82 & 129.9 & - & - & A \\
\hline $123-13$ & 1.21 & 21.58 & 478.65 & 134.1 & 48,440 & - & $A$ \\
\hline I23-14 & 1.21 & 23.24 & 513.51 & 138.8 & - & - & A \\
\hline |23-15 & 1.19 & 24.99 & 549.72 & 135.2 & - & - & A \\
\hline |23-16 & 1.19 & 26.76 & 586.79 & 148.6 & - & - & A \\
\hline |23-17 & 1.14 & 28.51 & 622.25 & 139.4 & 54,204 & - & A \\
\hline $123-18$ & 1.14 & 30.21 & 657.95 & 144.3 & - & 2.503 & A \\
\hline 123-19 & 1.12 & 32.05 & 696.07 & 140.3 & - & 2.515 & $A$ \\
\hline $123-20$ & 1.12 & 33.78 & 732.28 & 111.2 & - & 2.520 & $A$ \\
\hline $123-21$ & 1.10 & 35.57 & 769.50 & 156.9 & 51,918 & - & A \\
\hline $123-22$ & 1.10 & 37.17 & 802.86 & 140.3 & - & - & A \\
\hline $123-23$ & 1.08 & 38.99 & 840.70 & 126.7 & - & - & $A$ \\
\hline $123-24$ & 1.08 & 40.72 & 876.92 & 141.2 & - & - & $A$ \\
\hline $123-25$ & 1.06 & 42.57 & 915.24 & 151.5 & 62,698 & - & A \\
\hline $123-26$ & 1.06 & 44.20 & 949.30 & 152.3 & - & 2.530 & $A$ \\
\hline $123-27$ & 1.04 & 45.99 & 986.45 & 156.0 & - & 2.542 & A \\
\hline $123-28$ & 1.04 & 47.73 & 1022.93 & 145.6 & - & 2.509 & $A$ \\
\hline $123-29$ & 1.02 & 49.56 & 1060.74 & 148.8 & 52,843 & - & A \\
\hline $123-30$ & 1.02 & 51.23 & 1095.82 & 146.5 & - & 2.509 & $A$ \\
\hline |23-31 & 1.01 & 52.99 & 1132.19 & 167.1 & - & 2.528 & A \\
\hline 123-32 & 1.01 & 54.71 & 1168.39 & 155.5 & - & 2.534 & A \\
\hline
\end{tabular}


Table A8. Physical property test results - 123-33 to 123-64.

\begin{tabular}{|c|c|c|c|c|c|c|c|}
\hline Specimen ID & $\begin{array}{l}\text { Time in } \mathrm{CE}_{1} \\
\text { (days) }\end{array}$ & $\begin{array}{l}\text { Time in } \mathrm{CE}_{5} \\
\text { (days) }\end{array}$ & $\mathrm{M}$ ( ${ }^{\circ} \mathrm{C}$-days) & $\mathrm{f}_{\mathrm{c}}(\mathrm{MPa})$ & $\mathrm{E}(\mathrm{MPa})$ & $\rho\left(\mathrm{g} / \mathrm{cm}^{3}\right)$ & $\begin{array}{l}\text { Data } \\
\text { Group }\end{array}$ \\
\hline $123-33$ & 0.99 & 56.55 & 1206.39 & 160.3 & 51,687 & 2.519 & A \\
\hline $123-34$ & 0.99 & 58.26 & 1242.27 & 166.6 & - & - & A \\
\hline $123-35$ & 1.23 & 59.83 & 1280.17 & 159.5 & - & 2.505 & A \\
\hline $123-36$ & 1.23 & 61.44 & 1313.88 & 162.3 & - & - & $A$ \\
\hline $123-37$ & 1.21 & 63.13 & 1348.86 & 149.3 & 50,990 & 2.518 & $A$ \\
\hline $123-38$ & 1.21 & 65.08 & 1389.61 & 153.4 & - & 2.551 & A \\
\hline $123-39$ & 1.19 & 66.76 & 1424.53 & 148.0 & - & 2.491 & A \\
\hline $123-40$ & 1.19 & 68.43 & 1459.46 & 150.5 & - & 2.538 & $A$ \\
\hline $123-41$ & 1.17 & 70.14 & 1494.82 & 130.1 & 50,193 & - & A \\
\hline $123-42$ & 1.17 & 71.94 & 1532.58 & 150.1 & - & 2.539 & A \\
\hline $123-43$ & 1.15 & 73.81 & 1571.19 & 150.0 & - & 2.525 & A \\
\hline $123-44$ & 1.15 & 75.36 & 1603.73 & 162.7 & - & 2.552 & A \\
\hline $123-45$ & 1.12 & 77.80 & 1654.23 & 147.8 & 52,864 & 2.523 & A \\
\hline $123-46$ & 1.12 & 79.40 & 1687.84 & 140.5 & - & 2.523 & $A$ \\
\hline $123-47$ & 1.10 & 80.80 & 1716.62 & 160.0 & - & 2.543 & A \\
\hline $123-48$ & 1.10 & 82.37 & 1749.46 & 157.2 & - & 2.525 & A \\
\hline $123-49$ & 1.08 & 84.12 & 1785.81 & 163.3 & 51,672 & 2.533 & A \\
\hline $123-50$ & 1.08 & 85.92 & 1823.40 & 155.3 & - & 2.542 & A \\
\hline $123-51$ & 1.03 & 87.86 & 1862.97 & 149.4 & - & 2.514 & A \\
\hline $123-52$ & 1.03 & 89.39 & 1894.99 & 164.3 & - & 2.542 & A \\
\hline $123-53$ & 1.01 & 91.22 & 1932.91 & 152.7 & 49,556 & 2.514 & A \\
\hline $123-54$ & 1.01 & 92.91 & 1968.25 & 164.2 & - & 2.557 & A \\
\hline $123-55$ & 0.98 & 94.84 & 2008.20 & 143.4 & - & 2.536 & A \\
\hline $123-56$ & 0.98 & 96.42 & 2041.27 & 148.5 & - & 2.508 & A \\
\hline $123-57$ & 0.96 & 98.17 & 2077.49 & 152.4 & 50,990 & 2.539 & A \\
\hline $123-58$ & 0.96 & 99.99 & 2115.67 & 161.5 & - & 2.532 & A \\
\hline $123-59$ & 0.94 & 101.82 & 2153.43 & 155.0 & - & 2.544 & A \\
\hline $123-60$ & 0.94 & 103.90 & 2197.03 & 148.0 & - & 2.538 & A \\
\hline |23-61 & 0.92 & 105.22 & 2224.36 & 158.4 & 53,583 & 2.532 & A \\
\hline $123-62$ & 0.92 & 106.98 & 2261.09 & 148.0 & - & 2.526 & A \\
\hline $123-63$ & 0.89 & 108.82 & 2299.16 & 155.9 & - & 2.527 & A \\
\hline $123-64$ & 0.89 & 110.38 & 2331.87 & 155.3 & - & 2.530 & A \\
\hline
\end{tabular}


Table A9. Physical property test results - 123-65 to I23-91.

\begin{tabular}{|c|c|c|c|c|c|c|c|}
\hline Specimen ID & $\begin{array}{l}\text { Time in } \mathrm{CE}_{1} \\
\text { (days) }\end{array}$ & $\begin{array}{l}\text { Time in } \mathrm{CE}_{5} \\
\text { (days) }\end{array}$ & $\mathrm{M}\left({ }^{\circ} \mathrm{C}\right.$-days $)$ & $\mathrm{f}_{\mathrm{c}}(\mathrm{MPa})$ & $\mathrm{E}(\mathrm{MPa})$ & $\rho\left(\mathrm{g} / \mathrm{cm}^{3}\right)$ & $\begin{array}{l}\text { Data } \\
\text { Group }\end{array}$ \\
\hline $123-65$ & 1.00 & 5.99 & 147.15 & 112.1 & 46,189 & 2.517 & $A$ \\
\hline $123-66$ & 1.00 & 7.81 & 185.43 & 120.7 & - & 2.535 & $A$ \\
\hline $123-67$ & 1.00 & 9.65 & 223.98 & 117.6 & 48,968 & 2.536 & $A$ \\
\hline $123-68$ & 1.00 & 11.23 & 257.03 & 116.8 & - & 2.498 & $A$ \\
\hline $123-69$ & 0.98 & 12.98 & 293.15 & 121.6 & 47,274 & 2.507 & $A$ \\
\hline $123-70$ & 0.74 & 0.00 & 16.14 & 2.9 & - & - & $\mathrm{B}$ \\
\hline $123-71$ & 0.74 & 0.00 & 16.21 & 2.7 & - & - & $\mathrm{B}$ \\
\hline $123-72$ & 0.98 & 0.00 & 21.47 & 17.1 & - & - & $\mathrm{B}$ \\
\hline $123-73$ & 0.99 & 0.00 & 21.70 & 20.6 & 15,441 & - & $\mathrm{B}$ \\
\hline $123-74$ & 1.02 & 0.48 & 32.25 & 55.8 & - & - & $\mathrm{B}$ \\
\hline $123-75$ & 1.02 & 0.49 & 32.49 & 61.0 & 35,121 & - & $\mathrm{B}$ \\
\hline $123-76$ & 1.00 & 1.00 & 43.14 & 75.7 & - & - & $\mathrm{B}$ \\
\hline $123-77$ & 1.00 & 1.01 & 43.36 & 76.4 & 38,829 & - & $\mathrm{B}$ \\
\hline $123-78$ & 1.00 & 1.51 & 53.94 & 90.4 & - & - & $\mathrm{B}$ \\
\hline $123-79$ & 1.01 & 1.95 & 63.22 & 92.0 & - & - & B \\
\hline $123-80$ & 1.01 & 1.96 & 63.44 & 99.5 & 46,442 & - & $B$ \\
\hline $123-81$ & 1.00 & 2.49 & 74.49 & 97.7 & - & - & B \\
\hline $123-82$ & 1.00 & 2.99 & 84.84 & 103.7 & - & - & B \\
\hline $123-83$ & 1.01 & 3.98 & 105.65 & 100.6 & - & - & B \\
\hline $123-84$ & 1.01 & 3.98 & 105.79 & 110.4 & 45,889 & - & B \\
\hline $123-85$ & 1.00 & 4.99 & 126.74 & 114.1 & - & - & B \\
\hline $123-86$ & 1.06 & 12.90 & 319.18 & 135.0 & - & - & $C$ \\
\hline $123-87$ & 1.06 & 12.90 & 319.18 & 132.7 & - & - & $C$ \\
\hline $123-88$ & 1.06 & 12.90 & 319.18 & 117.7 & - & - & $C$ \\
\hline 123-89 & 1.06 & 12.90 & 319.18 & 132.3 & 50,407 * & - & $C$ \\
\hline $123-90$ & 1.02 & 12.90 & 318.44 & 141.2 & $56,745^{*}$ & - & C \\
\hline |23-91 & 1.02 & 12.90 & 318.44 & 138.0 & $51,152 *$ & - & C \\
\hline
\end{tabular}

* LVDT Elastic Modulus as measured. 
Table A10. Physical property test results - I30-01 to I30-32.

\begin{tabular}{|c|c|c|c|c|c|c|c|}
\hline Specimen ID & $\begin{array}{c}\text { Time in } \mathrm{CE}_{1} \\
\text { (days) }\end{array}$ & $\begin{array}{c}\text { Time in } \mathrm{CE}_{5} \\
\text { (days) }\end{array}$ & M ( ${ }^{\circ} \mathrm{C}$-days) & $\mathrm{f}_{\mathrm{c}}(\mathrm{MPa})$ & $\mathrm{E}(\mathrm{MPa})$ & $\rho\left(\mathrm{g} / \mathrm{cm}^{3}\right)$ & $\begin{array}{l}\text { Data } \\
\text { Group }\end{array}$ \\
\hline $130-01$ & 1.34 & 6.66 & 228.53 & 127.9 & - & - & C \\
\hline $130-02$ & 1.34 & 6.66 & 228.53 & 122.0 & - & - & C \\
\hline 130-03 & 1.31 & 6.66 & 227.93 & 128.6 & - & - & C \\
\hline 130-04 & 1.31 & 6.66 & 227.93 & 94.6 & - & - & $\mathrm{C}$ \\
\hline $130-05$ & 1.29 & 6.66 & 227.49 & 125.7 & - & - & $\mathrm{C}$ \\
\hline $130-06$ & 1.29 & 6.66 & 227.49 & 130.7 & - & - & C \\
\hline $130-07$ & 1.27 & 6.66 & 227.03 & 128.4 & - & - & $\mathrm{C}$ \\
\hline 130-08 & 1.27 & 6.66 & 227.03 & 128.7 & - & - & C \\
\hline $130-09$ & 1.25 & 35.77 & 1099.81 & 156.0 & - & 2.525 & $A$ \\
\hline $130-10$ & 1.25 & 37.53 & 1152.74 & 146.4 & 51,632 & - & A \\
\hline |30-11 & 1.23 & 39.14 & 1200.56 & 145.3 & - & 2.517 & $A$ \\
\hline $130-12$ & 1.23 & 40.74 & 1248.46 & 129.2 & - & 2.508 & A \\
\hline $130-13$ & 1.18 & 42.50 & 1300.53 & 164.1 & 50,127 & - & $A$ \\
\hline 130-14 & 1.18 & 44.13 & 1349.37 & 156.4 & - & 2.509 & A \\
\hline $130-15$ & 1.16 & 45.79 & 1398.71 & 166.8 & - & 2.527 & $A$ \\
\hline $130-16$ & 1.16 & 47.45 & 1448.53 & 165.4 & 51,036 & - & A \\
\hline $130-17$ & 1.16 & 49.13 & 1498.68 & 135.7 & - & 2.519 & A \\
\hline |30-18 & 1.16 & 50.94 & 1552.95 & 154.9 & - & 2.529 & A \\
\hline |30-19 & 1.12 & 52.65 & 1603.09 & 160.4 & 49,220 & 2.529 & $A$ \\
\hline $130-20$ & 1.12 & 54.19 & 1649.26 & 161.4 & - & 2.529 & $A$ \\
\hline $130-21$ & 1.10 & 55.96 & 1702.04 & 162.6 & - & 2.505 & A \\
\hline $130-22$ & 1.10 & 57.66 & 1753.06 & 162.4 & 53,216 & 2.528 & A \\
\hline $130-23$ & 1.07 & 59.32 & 1802.32 & 160.0 & - & 2.507 & $A$ \\
\hline $130-24$ & 1.07 & 60.96 & 1851.55 & 140.8 & - & 2.527 & $A$ \\
\hline $130-25$ & 1.05 & 61.69 & 1872.94 & 147.9 & 48,424 & 2.546 & $A$ \\
\hline $130-26$ & 1.05 & 64.39 & 1953.94 & 162.8 & - & 2.516 & $A$ \\
\hline $130-27$ & 1.03 & 65.95 & 2000.26 & 160.6 & - & 2.526 & A \\
\hline $130-28$ & 1.03 & 67.70 & 2052.78 & 161.9 & 49,271 & 2.509 & A \\
\hline $130-29$ & 1.18 & 69.10 & 2098.08 & 148.7 & - & 2.534 & A \\
\hline $130-30$ & 1.18 & 70.85 & 2150.54 & 164.0 & - & 2.527 & $A$ \\
\hline $130-31$ & 1.16 & 29.18 & 900.10 & 161.6 & - & 2.534 & A \\
\hline $130-32$ & 1.16 & 30.86 & 950.47 & 152.2 & - & 2.514 & A \\
\hline
\end{tabular}


Table A11. Physical property test results - I30-33 to I30-59.

\begin{tabular}{|c|c|c|c|c|c|c|c|}
\hline Specimen ID & $\begin{array}{c}\text { Time in } \mathrm{CE}_{1} \\
\text { (days) }\end{array}$ & $\begin{array}{c}\text { Time in } \mathrm{CE}_{5} \\
\text { (days) }\end{array}$ & $\mathrm{M}\left({ }^{\circ} \mathrm{C}\right.$-days $)$ & $\mathrm{f}_{\mathrm{c}}(\mathrm{MPa})$ & $\mathrm{E}(\mathrm{MPa})$ & $\rho\left(\mathrm{g} / \mathrm{cm}^{3}\right)$ & $\begin{array}{l}\text { Data } \\
\text { Group }\end{array}$ \\
\hline 130-33 & 1.14 & 32.52 & 999.69 & 159.4 & 50,684 & - & $A$ \\
\hline 130-34 & 1.14 & 34.15 & 1048.74 & 150.8 & - & 2.532 & A \\
\hline 130-35 & 1.04 & 2.59 & 99.16 & 101.5 & 45,772 & - & $A$ \\
\hline 130-36 & 1.04 & 4.25 & 148.70 & 117.5 & - & 2.517 & $A$ \\
\hline 130-37 & 1.02 & 5.94 & 199.30 & 137.1 & - & 2.538 & A \\
\hline 130-38 & 1.02 & 8.58 & 278.26 & 140.4 & 50,835 & 2.521 & A \\
\hline 130-39 & 1.00 & 9.33 & 300.44 & 140.0 & - & 2.503 & A \\
\hline $130-40$ & 1.00 & 10.98 & 349.98 & 147.8 & - & 2.534 & A \\
\hline $130-41$ & 0.98 & 12.71 & 401.61 & 71.9 & 49,815 & 2.531 & $A$ \\
\hline $130-42$ & 0.98 & 14.39 & 452.01 & 160.1 & - & 2.536 & A \\
\hline $130-43$ & 1.70 & 15.47 & 497.77 & 139.2 & - & 2.500 & A \\
\hline 130-44 & 1.70 & 17.15 & 548.42 & 146.7 & 48,567 & - & $A$ \\
\hline $130-45$ & 1.67 & 18.90 & 600.26 & 145.6 & - & 2.517 & A \\
\hline $130-46$ & 1.67 & 20.48 & 647.83 & 134.8 & - & 2.490 & A \\
\hline $130-47$ & 1.65 & 22.23 & 699.80 & 133.6 & 45,244 & 2.502 & A \\
\hline $130-48$ & 1.65 & 23.92 & 750.57 & 139.6 & - & 2.520 & A \\
\hline $130-49$ & 1.63 & 25.62 & 801.27 & 130.8 & - & 2.509 & A \\
\hline $130-50$ & 1.63 & 27.28 & 851.11 & 150.1 & 46,595 & 2.517 & A \\
\hline $130-51$ & 0.98 & 12.69 & 401.42 & 136.4 & 51,617 & 2.516 & A \\
\hline $130-52$ & 0.00 & 0.75 & 22.50 & 37.0 & - & - & B \\
\hline $130-53$ & 0.00 & 1.00 & 30.00 & 59.0 & - & - & B \\
\hline $130-54$ & 0.00 & 1.01 & 30.40 & 65.1 & 31,001 & - & B \\
\hline $130-55$ & 0.00 & 1.76 & 53.30 & 82.3 & - & - & B \\
\hline $130-56$ & 0.00 & 2.00 & 60.40 & 89.1 & 39,459 & - & B \\
\hline $130-57$ & 0.00 & 2.56 & 77.30 & 87.5 & - & - & B \\
\hline $130-58$ & 0.00 & 2.57 & 77.40 & 96.7 & 49,006 & - & B \\
\hline $130-59$ & 0.00 & 3.00 & 90.30 & 99.8 & - & - & B \\
\hline
\end{tabular}


Table A12. Physical property test results - 150-01 to I50-32.

\begin{tabular}{|c|c|c|c|c|c|c|c|}
\hline Specimen ID & $\begin{array}{c}\text { Time in } \mathrm{CE}_{1} \\
\text { (days) }\end{array}$ & $\begin{array}{c}\text { Time in } \mathrm{CE}_{5} \\
\text { (days) }\end{array}$ & M ( ${ }^{\circ} \mathrm{C}$-days) & $\mathrm{f}_{\mathrm{c}}(\mathrm{MPa})$ & $\mathrm{E}(\mathrm{MPa})$ & $\rho\left(\mathrm{g} / \mathrm{cm}^{3}\right)$ & $\begin{array}{l}\text { Data } \\
\text { Group }\end{array}$ \\
\hline $150-01$ & 1.19 & 6.94 & 371.68 & 158.2 & - & - & C \\
\hline $150-02$ & 1.19 & 6.94 & 371.68 & 127.5 & - & - & C \\
\hline $150-03$ & 1.17 & 6.94 & 371.24 & 129.8 & - & - & C \\
\hline $150-04$ & 1.17 & 6.94 & 371.24 & 108.2 & - & - & $\mathrm{C}$ \\
\hline $150-05$ & 1.14 & 6.97 & 372.41 & 137.8 & - & - & $\mathrm{C}$ \\
\hline $150-06$ & 1.14 & 6.97 & 372.41 & 135.0 & - & - & C \\
\hline $150-07$ & 1.12 & 6.97 & 371.98 & 139.6 & - & - & $\mathrm{C}$ \\
\hline $150-08$ & 1.12 & 6.97 & 371.98 & 157.6 & - & - & C \\
\hline $150-09$ & 1.54 & 1.35 & 99.01 & 129.6 & - & - & $A$ \\
\hline $150-10$ & 1.54 & 2.34 & 148.84 & 133.1 & - & - & A \\
\hline $150-11$ & 1.52 & 3.36 & 199.13 & 135.6 & - & - & $A$ \\
\hline $150-12$ & 1.52 & 4.35 & 248.85 & 145.7 & 46,631 & - & A \\
\hline $150-13$ & 1.50 & 5.36 & 298.98 & 146.9 & - & - & $A$ \\
\hline $150-14$ & 1.50 & 6.35 & 348.66 & 146.1 & - & - & A \\
\hline $150-15$ & 1.49 & 7.34 & 397.46 & 154.1 & 46,368 & - & $A$ \\
\hline $150-16$ & 1.49 & 8.35 & 448.12 & 149.3 & - & - & A \\
\hline $150-17$ & 1.47 & 9.38 & 499.36 & 148.2 & - & - & $A$ \\
\hline $150-18$ & 1.47 & 10.38 & 549.32 & 165.3 & 47,807 & - & A \\
\hline $150-19$ & 1.45 & 11.37 & 598.29 & 149.6 & - & 2.501 & $A$ \\
\hline $150-20$ & 1.45 & 12.35 & 647.52 & 138.2 & - & 2.485 & $A$ \\
\hline $150-21$ & 1.44 & 13.37 & 698.13 & 161.8 & 45,854 & - & A \\
\hline $150-22$ & 1.44 & 14.40 & 749.73 & 149.1 & - & 2.510 & $A$ \\
\hline $150-23$ & 1.56 & 29.36 & 1499.15 & 157.6 & - & 2.510 & $A$ \\
\hline $150-24$ & 1.56 & 30.34 & 1548.04 & 152.0 & - & 2.515 & $A$ \\
\hline $150-25$ & 1.53 & 31.34 & 1597.47 & 150.2 & 46,505 & 2.503 & $A$ \\
\hline $150-26$ & 1.53 & 32.37 & 1648.79 & 127.9 & - & 2.532 & $A$ \\
\hline $150-27$ & 1.56 & 33.41 & 1701.39 & 148.1 & - & 2.511 & A \\
\hline $150-28$ & 1.56 & 34.35 & 1748.30 & 152.7 & 46,816 & 2.503 & A \\
\hline $150-29$ & 1.55 & 35.34 & 1797.74 & 147.8 & - & 2.515 & A \\
\hline $150-30$ & 1.55 & 36.35 & 1848.22 & 154.8 & - & 2.527 & $A$ \\
\hline $150-31$ & 1.53 & 37.40 & 1900.36 & 155.1 & 47,369 & 2.529 & $A$ \\
\hline $150-32$ & 1.53 & 38.35 & 1948.00 & 145.6 & - & 2.496 & A \\
\hline
\end{tabular}


Table A13. Physical property test results - 150-33 to I50-64.

\begin{tabular}{|c|c|c|c|c|c|c|c|}
\hline Specimen ID & $\begin{array}{c}\text { Time in } \mathrm{CE}_{1} \\
\text { (days) }\end{array}$ & $\begin{array}{c}\text { Time in } \mathrm{CE}_{5} \\
\text { (days) }\end{array}$ & M ( ${ }^{\circ} \mathrm{C}$-days $)$ & $\mathrm{f}_{\mathrm{c}}(\mathrm{MPa})$ & $\mathrm{E}(\mathrm{MPa})$ & $\rho\left(\mathrm{g} / \mathrm{cm}^{3}\right)$ & $\begin{array}{l}\text { Data } \\
\text { Group }\end{array}$ \\
\hline $150-33$ & 1.51 & 39.39 & 1999.47 & 155.1 & - & 2.510 & A \\
\hline $150-34$ & 1.51 & 40.36 & 2048.04 & 151.8 & 46,462 & 2.511 & A \\
\hline $150-35$ & 1.51 & 41.35 & 2097.57 & 142.6 & - & 2.526 & A \\
\hline $150-36$ & 1.51 & 42.36 & 2147.77 & 159.7 & - & 2.512 & $A$ \\
\hline $150-37$ & 1.57 & 15.38 & 800.04 & 165.5 & - & 2.535 & A \\
\hline $150-38$ & 1.57 & 16.34 & 847.96 & 167.3 & 47,820 & 2.514 & A \\
\hline $150-39$ & 1.55 & 17.33 & 897.44 & 159.9 & - & 2.489 & A \\
\hline $150-40$ & 1.55 & 18.38 & 949.83 & 148.7 & - & 2.516 & A \\
\hline $150-41$ & 1.53 & 19.43 & 1002.11 & 146.4 & - & 2.517 & A \\
\hline $150-42$ & 1.53 & 20.36 & 1048.53 & 138.8 & - & 2.526 & A \\
\hline $150-43$ & 1.52 & 21.36 & 1098.30 & 157.2 & - & 2.521 & A \\
\hline $150-44$ & 1.52 & 22.35 & 1147.60 & 161.1 & 46,525 & 2.504 & A \\
\hline $150-45$ & 1.50 & 23.42 & 1200.61 & 156.7 & - & 2.522 & $A$ \\
\hline $150-46$ & 1.50 & 24.38 & 1248.63 & 151.1 & - & 2.533 & A \\
\hline $150-47$ & 1.48 & 25.39 & 1298.89 & 139.3 & 46,156 & 2.502 & A \\
\hline $150-48$ & 1.48 & 26.41 & 1350.10 & 154.0 & - & 2.530 & A \\
\hline $150-49$ & 1.47 & 27.37 & 1397.58 & 139.3 & - & - & A \\
\hline $150-50$ & 1.47 & 28.35 & 1446.33 & 165.1 & 47,734 & 2.518 & A \\
\hline $150-51$ & 0.96 & 0.36 & 37.47 & 87.9 & - & 2.495 & A \\
\hline $150-52$ & 0.96 & 0.36 & 37.78 & 86.9 & 38,862 & 2.514 & A \\
\hline $150-53$ & 0.93 & 0.61 & 49.89 & 106.0 & - & 2.482 & A \\
\hline $150-54$ & 0.93 & 0.92 & 65.06 & 118.7 & - & 2.501 & A \\
\hline $150-55$ & 0.91 & 0.93 & 64.97 & 126.1 & 46,006 & 2.524 & A \\
\hline $150-56$ & 0.91 & 1.09 & 73.06 & 130.0 & - & 2.541 & A \\
\hline $150-57$ & 0.88 & 1.35 & 85.43 & 119.0 & - & 2.506 & A \\
\hline $150-58$ & 0.88 & 1.35 & 85.39 & 126.7 & 43,265 & 2.492 & A \\
\hline $150-59$ & 0.02 & 0.31 & 16.48 & 10.9 & - & - & B \\
\hline $150-60$ & 0.02 & 0.31 & 16.72 & 11.5 & - & - & B \\
\hline $150-61$ & 0.02 & 0.39 & 20.63 & 37.4 & - & - & B \\
\hline $150-62$ & 0.02 & 0.48 & 24.87 & 59.7 & - & - & B \\
\hline $150-63$ & 0.02 & 0.48 & 25.22 & 58.0 & 30,213 & - & B \\
\hline $150-64$ & 0.03 & 0.55 & 28.35 & 71.1 & - & - & B \\
\hline
\end{tabular}


Table A14. Physical property test results - I50-64 to I50-76.

\begin{tabular}{|c|c|c|c|c|c|c|c|}
\hline Specimen ID & $\begin{array}{c}\text { Time in } \mathrm{CE}_{1} \\
\text { (days) }\end{array}$ & $\begin{array}{c}\text { Time in CE5 } \\
\text { (days) }\end{array}$ & $\mathbf{M}\left({ }^{\circ} \mathrm{C}\right.$-days) & $\mathrm{f}_{\mathrm{c}}(\mathrm{MPa})$ & $\mathrm{E}(\mathrm{MPa})$ & $\boldsymbol{\rho}\left(\mathrm{g} / \mathrm{cm}^{3}\right)$ & $\begin{array}{c}\text { Data } \\
\text { Group }\end{array}$ \\
\hline $150-65$ & 0.03 & 0.55 & 28.60 & 72.0 & 37,255 & - & $\mathrm{B}$ \\
\hline $150-66$ & 0.02 & 0.65 & 33.34 & 81.4 & - & - & $\mathrm{B}$ \\
\hline $150-67$ & 0.02 & 0.72 & 37.07 & 83.7 & - & - & $\mathrm{B}$ \\
\hline $150-68$ & 0.02 & 0.73 & 37.42 & 90.8 & 35,313 & - & $\mathrm{B}$ \\
\hline $150-69$ & 0.03 & 0.97 & 49.44 & 111.1 & - & - & $\mathrm{B}$ \\
\hline $150-70$ & 0.03 & 0.97 & 49.79 & 103.3 & 43,878 & - & $\mathrm{B}$ \\
\hline $150-71$ & 1.06 & 12.75 & 659.56 & 165.4 & - & & $\mathrm{C}$ \\
\hline $150-72$ & 1.06 & 12.76 & 660.11 & 159.9 & - & & $\mathrm{C}$ \\
\hline $150-73$ & 1.02 & 12.77 & 659.63 & 172.8 & - & & $\mathrm{C}$ \\
\hline $150-74$ & 1.02 & 12.78 & 660.08 & 163.3 & $50,504 *$ & & $\mathrm{C}$ \\
\hline $150-75$ & 1.02 & 12.81 & 661.47 & 163.2 & $48,303^{*}$ & & $\mathrm{C}$ \\
\hline $150-76$ & 1.02 & 12.84 & 663.07 & 148.6 & $49,373 *$ & & $\mathrm{C}$ \\
\hline
\end{tabular}

* LVDT Elastic Modulus as measured. 
Table A15. Physical property test results - 170-01 to 170-32.

\begin{tabular}{|c|c|c|c|c|c|c|c|}
\hline Specimen ID & $\begin{array}{c}\text { Time in } \mathrm{CE}_{1} \\
\text { (days) }\end{array}$ & $\begin{array}{c}\text { Time in } \mathrm{CE}_{5} \\
\text { (days) }\end{array}$ & M ( ${ }^{\circ} \mathrm{C}$-days $)$ & $\mathrm{f}_{\mathrm{c}}(\mathrm{MPa})$ & $\mathrm{E}(\mathrm{MPa})$ & $\rho\left(\mathrm{g} / \mathrm{cm}^{3}\right)$ & $\begin{array}{l}\text { Data } \\
\text { Group }\end{array}$ \\
\hline $170-01$ & 1.77 & 18.77 & 1348.84 & 168.7 & - & 2.541 & A \\
\hline $170-02$ & 1.75 & 19.44 & 1395.58 & 162.7 & - & 2.507 & $A$ \\
\hline $170-03$ & 1.75 & 20.19 & 1447.94 & 184.9 & 47,018 & 2.538 & A \\
\hline $170-04$ & 1.73 & 20.90 & 1497.43 & 174.4 & - & 2.527 & A \\
\hline $170-05$ & 1.22 & 6.93 & 509.07 & 137.1 & - & - & $\mathrm{C}$ \\
\hline $170-06$ & 1.22 & 6.93 & 509.07 & 163.4 & - & - & C \\
\hline $170-07$ & 1.19 & 6.93 & 508.56 & 146.8 & - & - & C \\
\hline $170-08$ & 1.19 & 6.93 & 508.56 & 180.4 & - & - & C \\
\hline $170-09$ & 1.18 & 6.98 & 512.01 & 169.1 & - & - & C \\
\hline $170-10$ & 1.18 & 6.98 & 512.01 & 160.4 & - & - & C \\
\hline $170-11$ & 1.16 & 6.98 & 511.50 & 161.6 & - & - & C \\
\hline $170-12$ & 1.16 & 6.98 & 511.50 & 169.1 & - & - & C \\
\hline $170-13$ & 1.17 & 30.33 & 2145.97 & 148.7 & - & 2.511 & A \\
\hline $170-14$ & 1.17 & 21.78 & 1547.18 & 180.7 & - & - & A \\
\hline $170-15$ & 1.15 & 22.48 & 1595.93 & 182.0 & - & - & A \\
\hline $170-16$ & 1.15 & 23.19 & 1645.75 & 185.0 & 48,357 & - & A \\
\hline $170-17$ & 1.13 & 23.93 & 1696.53 & 180.4 & - & - & A \\
\hline $170-18$ & 1.13 & 24.68 & 1749.23 & 158.8 & - & - & A \\
\hline $170-19$ & 1.11 & 25.36 & 1796.15 & 168.0 & 48,486 & - & A \\
\hline $170-20$ & 1.11 & 26.09 & 1847.34 & 187.6 & - & - & A \\
\hline $170-21$ & 1.09 & 26.81 & 1897.44 & 169.2 & - & - & A \\
\hline $170-22$ & 1.09 & 27.49 & 1945.37 & 162.9 & 46,271 & - & A \\
\hline $170-23$ & 1.07 & 28.23 & 1996.38 & 186.2 & - & 2.502 & A \\
\hline $170-24$ & 1.07 & 28.95 & 2046.84 & 155.7 & - & 2.521 & A \\
\hline $170-25$ & 1.05 & 29.69 & 2098.14 & 160.2 & 50,200 & - & A \\
\hline $170-26$ & 1.05 & 16.54 & 1178.22 & 177.6 & - & - & A \\
\hline $170-27$ & 1.07 & 3.94 & 296.35 & 150.4 & - & - & A \\
\hline $170-28$ & 1.07 & 13.94 & 996.50 & 152.9 & 47,045 & 2.490 & A \\
\hline $170-29$ & 1.05 & 5.39 & 397.28 & 167.1 & 48,903 & - & A \\
\hline $170-30$ & 1.05 & 6.11 & 447.98 & 172.9 & - & - & A \\
\hline $170-31$ & 1.03 & 6.84 & 498.61 & 156.8 & - & - & A \\
\hline $170-32$ & 1.03 & 7.54 & 547.85 & 166.0 & 45,291 & - & A \\
\hline
\end{tabular}


Table A16. Physical property test results - 170-33 to I70-57.

\begin{tabular}{|c|c|c|c|c|c|c|c|}
\hline Specimen ID & $\begin{array}{c}\text { Time in } \mathrm{CE}_{1} \\
\text { (days) }\end{array}$ & $\begin{array}{c}\text { Time in } \mathrm{CE}_{5} \\
\text { (days) }\end{array}$ & $\mathrm{M}$ ( ${ }^{\circ} \mathrm{C}$-days) & $\mathrm{f}_{\mathrm{c}}(\mathrm{MPa})$ & $\mathrm{E}(\mathrm{MPa})$ & $\rho\left(\mathrm{g} / \mathrm{cm}^{3}\right)$ & $\begin{array}{l}\text { Data } \\
\text { Group }\end{array}$ \\
\hline $170-33$ & 1.01 & 8.27 & 598.08 & 163.1 & - & - & A \\
\hline $170-34$ & 1.01 & 8.99 & 648.78 & 147.8 & - & - & A \\
\hline $170-35$ & 0.99 & 9.69 & 697.13 & 174.2 & 48,944 & - & A \\
\hline $170-36$ & 0.99 & 10.39 & 746.42 & 162.7 & - & - & $A$ \\
\hline $170-37$ & 0.97 & 11.12 & 796.80 & 153.2 & - & - & $A$ \\
\hline $170-38$ & 0.97 & 11.85 & 848.57 & 177.4 & 47,011 & - & $A$ \\
\hline $170-39$ & 0.95 & 12.54 & 896.46 & 163.9 & - & 2.508 & A \\
\hline $170-40$ & 0.95 & 13.28 & 947.69 & 174.5 & - & 2.491 & A \\
\hline $170-41$ & 1.12 & 1.09 & 98.24 & 144.6 & - & - & A \\
\hline $170-42$ & 1.12 & 1.83 & 150.20 & 152.0 & - & - & A \\
\hline $170-43$ & 1.08 & 2.53 & 197.81 & 166.0 & - & - & A \\
\hline $170-44$ & 1.08 & 3.22 & 246.61 & 169.1 & 46,732 & - & A \\
\hline $170-45$ & 1.83 & 4.44 & 346.66 & 159.7 & - & 2.549 & $A$ \\
\hline $170-46$ & 1.83 & 14.43 & 1046.12 & 158.5 & - & 2.490 & A \\
\hline $170-47$ & 1.81 & 15.16 & 1096.63 & 164.1 & - & 2.516 & A \\
\hline $170-48$ & 1.81 & 15.88 & 1147.04 & 159.3 & 50,222 & 2.514 & A \\
\hline $170-49$ & 1.79 & 16.57 & 1195.39 & 171.6 & - & 2.527 & A \\
\hline $170-50$ & 1.79 & 17.29 & 1245.27 & 166.3 & - & 2.523 & A \\
\hline $170-51$ & 1.77 & 18.03 & 1296.77 & 174.5 & 48,389 & 2.528 & $A$ \\
\hline $170-52$ & 0.00 & 0.33 & 23.63 & 36.6 & - & - & B \\
\hline $170-53$ & 0.00 & 0.76 & 53.92 & 108.7 & - & - & B \\
\hline $170-54$ & 0.00 & 0.99 & 69.82 & 120.1 & - & - & B \\
\hline $170-55$ & 0.00 & 0.99 & 69.82 & 113.3 & 34,334 & - & B \\
\hline $170-56$ & 0.00 & 1.49 & 105.40 & 112.2 & - & - & B \\
\hline $170-57$ & 0.00 & 1.50 & 105.88 & 101.0 & 35,742 & - & B \\
\hline
\end{tabular}


Table A17. Physical property test results - 190-01 to 190-32.

\begin{tabular}{|c|c|c|c|c|c|c|c|}
\hline Specimen ID & $\begin{array}{l}\text { Time in } \mathrm{CE}_{1} \\
\text { (days) }\end{array}$ & $\begin{array}{l}\text { Time in } \mathrm{CE}_{5} \\
\text { (days) }\end{array}$ & $\mathrm{M}\left({ }^{\circ} \mathrm{C}\right.$-days $)$ & $\mathrm{f}_{\mathrm{c}}(\mathrm{MPa})$ & $\mathrm{E}(\mathrm{MPa})$ & $\rho\left(\mathrm{g} / \mathrm{cm}^{3}\right)$ & $\begin{array}{l}\text { Data } \\
\text { Group }\end{array}$ \\
\hline $190-01$ & 0.94 & 5.02 & 465.26 & 172.7 & - & - & $\mathrm{C}$ \\
\hline $190-02$ & 0.94 & 5.02 & 465.26 & 167.5 & - & - & $C$ \\
\hline $190-03$ & 0.92 & 5.02 & 464.77 & 163.3 & - & - & $C$ \\
\hline 190-04 & 0.92 & 5.02 & 464.77 & 169.5 & - & - & C \\
\hline $190-05$ & 1.13 & 7.03 & 650.82 & 148.4 & - & - & $\mathrm{C}$ \\
\hline $190-06$ & 1.13 & 7.03 & 650.82 & 158.1 & - & - & $\mathrm{C}$ \\
\hline $190-07$ & 1.11 & 7.03 & 650.31 & 184.8 & - & - & $\mathrm{C}$ \\
\hline $190-08$ & 1.11 & 7.03 & 650.31 & 183.6 & - & - & $C$ \\
\hline $190-09$ & 1.10 & 19.19 & 1744.45 & 196.7 & 47,883 & - & $A$ \\
\hline $190-10$ & 1.10 & 19.73 & 1793.45 & 140.0 & - & - & A \\
\hline $190-11$ & 1.08 & 20.30 & 1844.13 & 189.8 & - & - & $A$ \\
\hline $190-12$ & 1.08 & 20.86 & 1894.32 & 209.8 & 48,081 & - & $A$ \\
\hline $190-13$ & 0.98 & 7.04 & 648.57 & 173.2 & - & 2.537 & $C$ \\
\hline $190-14$ & 0.98 & 7.04 & 648.57 & 178.4 & 46,870 & 2.497 & $\mathrm{C}$ \\
\hline $190-15$ & 1.27 & 0.83 & 93.59 & 154.6 & 46,393 & - & $A$ \\
\hline $190-16$ & 1.27 & 1.36 & 141.28 & 155.7 & - & 2.498 & $A$ \\
\hline $190-17$ & 1.25 & 1.94 & 192.95 & 155.0 & - & 2.529 & $A$ \\
\hline $190-18$ & 1.25 & 2.49 & 243.08 & 146.2 & 46,122 & - & $A$ \\
\hline $190-19$ & 1.22 & 3.04 & 291.85 & 166.2 & - & 2.507 & $A$ \\
\hline $190-20$ & 1.22 & 3.61 & 343.42 & 160.4 & - & 2.517 & $A$ \\
\hline $190-21$ & 1.20 & 4.15 & 391.39 & 131.4 & 47,420 & 2.523 & $A$ \\
\hline $190-22$ & 1.00 & 4.79 & 445.25 & 175.7 & - & 2.533 & $A$ \\
\hline $190-23$ & 1.00 & 5.33 & 494.12 & 178.6 & - & 2.518 & $A$ \\
\hline $190-24$ & 0.98 & 5.89 & 543.70 & 153.3 & 44,769 & - & $A$ \\
\hline $190-25$ & 0.95 & 6.43 & 591.61 & 166.8 & - & 2.495 & $A$ \\
\hline $190-26$ & 0.95 & 6.99 & 642.05 & 194.0 & - & 2.545 & $A$ \\
\hline $190-27$ & 0.93 & 7.55 & 691.79 & 173.9 & 48,123 & - & $A$ \\
\hline $190-28$ & 0.93 & 8.09 & 740.92 & 166.4 & - & - & $A$ \\
\hline $190-29$ & 1.02 & 8.69 & 796.52 & 201.2 & - & 2.510 & $A$ \\
\hline $190-30$ & 1.02 & 9.22 & 844.46 & 169.2 & 49,250 & - & A \\
\hline $190-31$ & 0.99 & 9.80 & 896.22 & 153.8 & - & 2.510 & A \\
\hline $190-32$ & 0.99 & 10.33 & 943.53 & 170.6 & - & 2.526 & $A$ \\
\hline
\end{tabular}


Table A18. Physical property test results - 190-33 to 190-64.

\begin{tabular}{|c|c|c|c|c|c|c|c|}
\hline Specimen ID & $\begin{array}{l}\text { Time in } \mathrm{CE}_{1} \\
\text { (days) }\end{array}$ & $\begin{array}{l}\text { Time in } \mathrm{CE}_{5} \\
\text { (days) }\end{array}$ & $\mathrm{M}\left({ }^{\circ} \mathrm{C}\right.$-days $)$ & $\mathrm{f}_{\mathrm{c}}(\mathrm{MPa})$ & $\mathrm{E}(\mathrm{MPa})$ & $\rho\left(\mathrm{g} / \mathrm{cm}^{3}\right)$ & $\begin{array}{l}\text { Data } \\
\text { Group }\end{array}$ \\
\hline $190-33$ & 0.93 & 10.89 & 992.73 & 164.0 & 48,330 & - & $A$ \\
\hline $190-34$ & 0.93 & 11.46 & 1044.16 & 185.8 & - & 2.535 & A \\
\hline $190-35$ & 0.91 & 12.01 & 1093.69 & 175.3 & - & 2.529 & $A$ \\
\hline $190-36$ & 0.91 & 12.55 & 1142.19 & 161.3 & 48,253 & - & $A$ \\
\hline $190-37$ & 0.89 & 13.11 & 1192.06 & 163.2 & - & 2.489 & $A$ \\
\hline $190-38$ & 0.89 & 13.68 & 1242.93 & 180.1 & - & 2.531 & $A$ \\
\hline $190-39$ & 0.87 & 14.23 & 1291.93 & 198.2 & 49,305 & - & $A$ \\
\hline $190-40$ & 0.87 & 14.81 & 1344.49 & 176.3 & - & 2.500 & $A$ \\
\hline $190-41$ & 0.85 & 15.36 & 1393.86 & 133.0 & - & 2.491 & $A$ \\
\hline $190-42$ & 0.85 & 15.92 & 1443.74 & 180.5 & 48,093 & 2.514 & A \\
\hline $190-43$ & 0.92 & 16.47 & 1494.84 & 187.9 & - & 2.522 & $A$ \\
\hline $190-44$ & 0.92 & 17.04 & 1546.40 & 189.1 & - & 2.503 & $A$ \\
\hline $190-45$ & 0.90 & 17.56 & 1593.09 & 193.3 & 48,727 & - & $A$ \\
\hline $190-46$ & 0.90 & 18.14 & 1644.84 & 183.6 & - & 2.495 & $A$ \\
\hline $190-47$ & 0.88 & 18.69 & 1694.53 & 198.8 & - & 2.500 & $A$ \\
\hline $190-48$ & 0.88 & 21.47 & 1944.16 & 194.6 & - & 2.527 & $A$ \\
\hline $190-49$ & 0.86 & 22.02 & 1993.60 & 192.4 & - & 2.500 & A \\
\hline $190-50$ & 0.86 & 22.56 & 2042.03 & 150.8 & 49,741 & 2.533 & $A$ \\
\hline $190-51$ & 0.84 & 23.12 & 2092.29 & 172.1 & - & 2.489 & $A$ \\
\hline $190-52$ & 0.84 & 23.68 & 2142.16 & 187.9 & - & 2.477 & $A$ \\
\hline $190-53$ & 1.05 & 0.18 & 32.44 & 119.7 & - & 2.504 & $A$ \\
\hline $190-54$ & 1.05 & 0.19 & 33.25 & 122.9 & 42,457 & 2.499 & $A$ \\
\hline $190-55$ & 1.03 & 0.35 & 47.07 & 144.1 & - & 2.503 & $A$ \\
\hline $190-56$ & 1.03 & 0.48 & 58.95 & 146.3 & - & 2.487 & $A$ \\
\hline $190-57$ & 1.01 & 0.48 & 58.44 & 145.2 & 48,606 & 2.496 & $A$ \\
\hline $190-58$ & 1.01 & 0.61 & 69.81 & 160.3 & - & 2.462 & $A$ \\
\hline $190-59$ & 0.98 & 0.73 & 80.63 & 145.4 & - & 2.487 & $A$ \\
\hline $190-60$ & 0.98 & 0.73 & 80.63 & 138.3 & 44,421 & 2.483 & $A$ \\
\hline $190-61$ & 1.04 & 4.97 & 463.68 & 160.3 & - & 2.512 & $C$ \\
\hline $190-62$ & 1.04 & 4.97 & 463.68 & 176.8 & 47,402 & 2.532 & C \\
\hline $190-63$ & 1.02 & 5.00 & 465.72 & 176.3 & - & 2.504 & C \\
\hline $190-64$ & 1.02 & 5.00 & 465.72 & 179.9 & - & 2.515 & $C$ \\
\hline
\end{tabular}


Table A19. Physical property test results - 190-65 to 190-90.

\begin{tabular}{|c|c|c|c|c|c|c|c|}
\hline Specimen ID & $\begin{array}{l}\text { Time in } \mathrm{CE}_{1} \\
\text { (days) }\end{array}$ & $\begin{array}{l}\text { Time in } \mathrm{CE}_{5} \\
\text { (days) }\end{array}$ & $\mathrm{M}\left({ }^{\circ} \mathrm{C}\right.$-days $)$ & $\mathrm{f}_{\mathrm{c}}(\mathrm{MPa})$ & $\mathrm{E}(\mathrm{MPa})$ & $\rho\left(\mathrm{g} / \mathrm{cm}^{3}\right)$ & $\begin{array}{l}\text { Data } \\
\text { Group }\end{array}$ \\
\hline $190-65$ & 1.00 & 7.01 & 646.45 & 170.8 & 45,089 & 2.531 & C \\
\hline $190-66$ & 1.00 & 7.01 & 646.45 & 170.0 & - & 2.495 & $\mathrm{C}$ \\
\hline $190-67$ & 0.02 & 0.31 & 29.25 & 64.7 & - & - & $\mathrm{B}$ \\
\hline $190-68$ & 0.02 & 0.32 & 29.87 & 64.8 & 21,822 & - & B \\
\hline $190-69$ & 0.03 & 0.39 & 36.21 & 74.6 & - & - & $\mathrm{B}$ \\
\hline $190-70$ & 0.02 & 0.47 & 44.13 & 67.4 & - & - & $\mathrm{B}$ \\
\hline $190-71$ & 0.02 & 0.48 & 44.95 & 72.5 & 22,098 & - & $\mathrm{B}$ \\
\hline $190-72$ & 0.02 & 0.56 & 52.14 & 64.0 & - & - & $\mathrm{B}$ \\
\hline $190-73$ & 0.02 & 0.58 & 53.26 & 68.9 & 22,269 & - & $\mathrm{B}$ \\
\hline $190-74$ & 0.03 & 0.65 & 59.90 & 74.9 & - & - & $\mathrm{B}$ \\
\hline $190-75$ & 0.03 & 0.72 & 66.21 & 75.0 & - & - & $\mathrm{B}$ \\
\hline $190-76$ & 0.03 & 0.73 & 67.09 & 69.5 & 21,173 & - & $\mathrm{B}$ \\
\hline $190-77$ & 0.02 & 0.97 & 88.95 & 75.6 & - & - & B \\
\hline $190-78$ & 0.02 & 0.98 & 89.45 & 72.7 & 20,439 & - & $\mathrm{B}$ \\
\hline $190-79$ & 1.02 & 1.02 & 106.97 & 156.6 & - & - & C \\
\hline $190-80$ & 1.02 & 1.04 & 108.84 & 153.2 & - & - & C \\
\hline $190-81$ & 1.02 & 1.05 & 110.16 & 152.3 & - & - & C \\
\hline $190-82$ & 1.02 & 1.06 & 111.09 & 165.4 & $47,337 *$ & - & $C$ \\
\hline $190-83$ & 0.99 & 1.10 & 113.59 & 156.0 & $46,865 *$ & - & $C$ \\
\hline $190-84$ & 0.99 & 1.13 & 116.65 & 170.3 & $49,713 *$ & - & C \\
\hline $190-85$ & 1.05 & 12.94 & 1181.24 & 192.2 & - & - & C \\
\hline $190-86$ & 1.05 & 12.96 & 1182.62 & 188.4 & - & - & C \\
\hline $190-87$ & 1.05 & 12.97 & 1183.74 & 253.3 & - & - & C \\
\hline $190-88$ & 1.05 & 12.99 & 1184.99 & 158.8 & $53,883 *$ & - & C \\
\hline $190-89$ & 1.02 & 13.02 & 1187.81 & 166.0 & $46,757^{*}$ & - & C \\
\hline $190-90$ & 1.02 & 13.05 & 1190.31 & 172.2 & $48,484 *$ & - & C \\
\hline
\end{tabular}

* LVDT Elastic Modulus as measured. 
Table A20. Physical property test results - EAV.

\begin{tabular}{|c|c|c|c|c|}
\hline Specimen ID & $\begin{array}{c}\text { Time in } \mathrm{CE}_{1} \\
\text { (days) }\end{array}$ & $\begin{array}{l}\text { Time in } \mathrm{CE}_{3} \\
\text { (days) }\end{array}$ & $\mathrm{M}\left({ }^{\circ} \mathrm{C}\right.$-days $)$ & $\mathrm{f}_{\mathrm{c}}(\mathrm{MPa})$ \\
\hline EAV-1 & 0.02 & 0.98 & 22.98 & 2.5 \\
\hline EAV-2 & 0.02 & 0.99 & 23.14 & 2.5 \\
\hline EAV-3 & 0.02 & 0.98 & 22.98 & 1.4 \\
\hline EAV-4 & 0.02 & 0.98 & 22.98 & 1.5 \\
\hline EAV-5 & 0.02 & 0.98 & 22.98 & 2.1 \\
\hline EAV-6 & 0.02 & 0.98 & 22.98 & 2.0 \\
\hline EAV-7 & 0.02 & 0.98 & 22.98 & 3.3 \\
\hline EAV-8 & 0.02 & 0.98 & 23.06 & 3.2 \\
\hline EAV-9 & 0.05 & 0.98 & 23.64 & 2.0 \\
\hline EAV-10 & 0.05 & 0.98 & 23.64 & 2.0 \\
\hline EAV-11 & 0.02 & 0.98 & 22.98 & 3.2 \\
\hline EAV-12 & 0.02 & 0.98 & 23.05 & 2.3 \\
\hline EAV-13 & 0.02 & 0.98 & 22.98 & 1.8 \\
\hline EAV-14 & 0.02 & 0.98 & 23.04 & 2.0 \\
\hline EAV-15 & 0.03 & 0.97 & 22.97 & 1.4 \\
\hline EAV-16 & 0.03 & 0.97 & 22.97 & 1.8 \\
\hline EAV-17 & 0.02 & 0.98 & 22.98 & 1.7 \\
\hline EAV-18 & 0.02 & 0.98 & 22.98 & 1.5 \\
\hline EAV-19 & 0.03 & 0.97 & 22.97 & 1.7 \\
\hline EAV-20 & 0.03 & 0.97 & 22.97 & 2.0 \\
\hline EAV-21 & 0.02 & 0.98 & 22.98 & 1.9 \\
\hline EAV-22 & 0.02 & 0.98 & 22.99 & 1.8 \\
\hline EAV-23 & 0.02 & 0.98 & 22.98 & 1.8 \\
\hline EAV-24 & 0.02 & 0.98 & 22.99 & 2.1 \\
\hline EAV-25 & 0.03 & 0.97 & 22.97 & 1.7 \\
\hline EAV-26 & 0.03 & 0.98 & 22.99 & 1.7 \\
\hline EAV-27 & 0.03 & 0.97 & 22.97 & 1.7 \\
\hline EAV-28 & 0.03 & 0.97 & 22.97 & 1.5 \\
\hline EAV-29 & 0.02 & 0.98 & 23.04 & 1.7 \\
\hline EAV-30 & 0.02 & 0.98 & 23.04 & 1.6 \\
\hline EAV-31 & 1.01 & - & 22.18 & 1.6 \\
\hline EAV-32 & 1.01 & - & 22.18 & 1.5 \\
\hline
\end{tabular}


Table A21. Physical property test results - I23CR-01 to I23CR-32.

\begin{tabular}{|c|c|c|c|c|c|c|c|}
\hline Specimen ID & $\begin{array}{c}\text { Time in } \mathrm{CE}_{1} \\
\text { (days) }\end{array}$ & $\begin{array}{c}\text { Time in } \mathrm{CE}_{3} \\
\text { (days) }\end{array}$ & M ( ${ }^{\circ} \mathrm{C}$-days) & $\mathrm{f}_{\mathrm{c}}(\mathrm{MPa})$ & $\mathrm{E}(\mathrm{MPa})$ & $\rho\left(\mathrm{g} / \mathrm{cm}^{3}\right)$ & $\begin{array}{l}\text { Data } \\
\text { Group }\end{array}$ \\
\hline |23CR-01 & 1.32 & 4.72 & 137.31 & 94.1 & - & - & A \\
\hline I23CR-02 & 1.32 & 5.67 & 159.22 & 93.9 & - & - & A \\
\hline I23CR-03 & 1.30 & 7.62 & 203.56 & 104.2 & - & - & A \\
\hline I23CR-04 & 1.30 & 108.43 & 2522.18 & 149.1 & - & - & $A$ \\
\hline I23CR-05 & 1.28 & 11.00 & 280.76 & 119.2 & - & - & A \\
\hline I23CR-06 & 1.28 & 12.74 & 320.88 & 118.9 & - & - & A \\
\hline I23CR-07 & 1.26 & 14.55 & 362.03 & 117.0 & - & - & A \\
\hline I23CR-08 & 1.26 & 16.17 & 399.27 & 125.1 & 45,816 & - & $A$ \\
\hline I23CR-09 & 1.24 & 18.06 & 442.51 & 122.0 & - & - & $A$ \\
\hline I23CR-10 & 1.24 & 19.73 & 480.74 & 128.9 & - & - & A \\
\hline I23CR-11 & 1.23 & 21.59 & 523.16 & 124.0 & - & - & A \\
\hline I23CR-12 & 1.23 & 23.29 & 562.27 & 128.4 & 46,165 & - & A \\
\hline I23CR-13 & 1.21 & 25.05 & 602.35 & 112.5 & - & 2.518 & $A$ \\
\hline I23CR-14 & 1.21 & 26.70 & 640.27 & 120.7 & - & - & A \\
\hline I23CR-15 & 1.16 & 28.61 & 683.15 & 140.0 & - & - & $A$ \\
\hline I23CR-16 & 1.16 & 30.17 & 718.96 & 134.1 & 47,074 & - & A \\
\hline I23CR-17 & 1.14 & 32.02 & 761.04 & 126.0 & - & - & A \\
\hline I23CR-18 & 1.14 & 33.74 & 800.70 & 107.5 & - & - & A \\
\hline I23CR-19 & 1.12 & 35.49 & 840.66 & 131.7 & - & - & $A$ \\
\hline I23CR-20 & 1.12 & 37.17 & 879.17 & 131.7 & 45,759 & - & $A$ \\
\hline I23CR-21 & 1.10 & 39.00 & 920.90 & 133.6 & - & - & A \\
\hline I23CR-22 & 1.10 & 40.73 & 960.57 & 131.7 & - & 2.503 & A \\
\hline I23CR-23 & 1.08 & 42.38 & 998.24 & 137.5 & - & 2.518 & $A$ \\
\hline I23CR-24 & 1.08 & 44.27 & 1041.65 & 136.7 & 47,400 & 2.520 & $A$ \\
\hline I23CR-25 & 1.07 & 46.04 & 1082.11 & 131.8 & - & 2.517 & $A$ \\
\hline I23CR-26 & 1.07 & 47.70 & 1120.30 & 124.6 & - & 2.492 & $A$ \\
\hline I23CR-27 & 1.05 & 49.47 & 1160.54 & 132.8 & - & 2.524 & A \\
\hline I23CR-28 & 1.05 & 51.15 & 1199.22 & 130.6 & 46,496 & 2.506 & $A$ \\
\hline I23CR-29 & 1.03 & 53.00 & 1241.28 & 133.9 & - & 2.506 & $A$ \\
\hline I23CR-30 & 1.03 & 54.68 & 1279.97 & 135.8 & - & 2.494 & $A$ \\
\hline I23CR-31 & 1.25 & 56.14 & 1318.48 & 145.9 & - & 2.535 & A \\
\hline I23CR-32 & 1.25 & 57.98 & 1360.63 & 139.9 & 48,197 & 2.520 & A \\
\hline
\end{tabular}


Table A22. Physical property test results - I23CR-33 to I23CR-64.

\begin{tabular}{|c|c|c|c|c|c|c|c|}
\hline Specimen ID & $\begin{array}{c}\text { Time in } \mathrm{CE}_{1} \\
\text { (days) }\end{array}$ & $\begin{array}{c}\text { Time in } \mathrm{CE}_{5} \\
\text { (days) }\end{array}$ & $\mathrm{M}\left({ }^{\circ} \mathrm{C}\right.$-days $)$ & $\mathrm{f}_{\mathrm{c}}(\mathrm{MPa})$ & $\mathrm{E}(\mathrm{MPa})$ & $\rho\left(\mathrm{g} / \mathrm{cm}^{3}\right)$ & $\begin{array}{l}\text { Data } \\
\text { Group }\end{array}$ \\
\hline I23CR-33 & 1.23 & 59.80 & 1402.24 & 140.1 & - & 2.509 & A \\
\hline I23CR-34 & 1.00 & 0.51 & 33.25 & 56.9 & 33,891 & 2.502 & B \\
\hline I23CR-35 & 1.21 & 63.17 & 1479.29 & 136.0 & - & 2.519 & A \\
\hline I23CR-36 & 1.21 & 64.98 & 1521.10 & 134.7 & 46,543 & 2.536 & $A$ \\
\hline I23CR-37 & 1.20 & 66.77 & 1561.94 & 133.6 & - & 2.519 & A \\
\hline I23CR-38 & 1.20 & 68.44 & 1600.20 & 127.5 & - & 2.519 & A \\
\hline I23CR-39 & 1.18 & 70.13 & 1638.60 & 127.2 & - & 2.514 & A \\
\hline I23CR-40 & 1.18 & 71.98 & 1681.22 & 137.0 & 45,364 & 2.522 & A \\
\hline I23CR-41 & 1.16 & 73.78 & 1722.36 & 140.3 & - & 2.517 & A \\
\hline I23CR-42 & 1.16 & 75.35 & 1758.31 & 140.8 & - & 2.522 & A \\
\hline I23CR-43 & 1.14 & 77.14 & 1799.22 & 134.1 & - & 2.523 & A \\
\hline I23CR-44 & 1.14 & 78.85 & 1838.42 & 144.3 & 49,054 & 2.527 & A \\
\hline I23CR-45 & 1.08 & 80.74 & 1880.57 & 136.7 & - & 2.526 & $A$ \\
\hline I23CR-46 & 1.08 & 82.39 & 1918.43 & 143.4 & - & 2.497 & A \\
\hline I23CR-47 & 1.06 & 84.27 & 1961.22 & 138.6 & - & 2.508 & A \\
\hline I23CR-48 & 1.06 & 85.98 & 2000.73 & 137.2 & 47,417 & 2.538 & A \\
\hline I23CR-49 & 1.04 & 87.74 & 2040.76 & 130.7 & - & 2.529 & $A$ \\
\hline I23CR-50 & 1.04 & 89.40 & 2079.03 & 135.2 & - & 2.486 & A \\
\hline I23CR-51 & 1.03 & 91.21 & 2120.23 & 131.7 & - & 2.509 & A \\
\hline I23CR-52 & 1.03 & 93.01 & 2161.69 & 125.1 & 43,489 & 2.523 & A \\
\hline I23CR-53 & 0.98 & 94.73 & 2200.07 & 135.7 & - & 2.522 & A \\
\hline I23CR-54 & 0.98 & 96.39 & 2238.42 & 135.3 & - & 2.512 & A \\
\hline I23CR-55 & 0.97 & 98.21 & 2279.89 & 137.5 & - & 2.512 & A \\
\hline I23CR-56 & 0.97 & 100.02 & 2321.41 & 138.8 & 45,028 & 2.516 & A \\
\hline I23CR-57 & 0.95 & 101.80 & 2361.97 & 148.8 & - & 2.528 & A \\
\hline I23CR-58 & 0.95 & 103.39 & 2398.49 & 130.9 & - & 2.510 & A \\
\hline I23CR-59 & 0.93 & 104.77 & 2429.84 & 134.1 & - & 2.513 & A \\
\hline I23CR-60 & 0.93 & 107.04 & 2482.12 & 138.0 & 45,639 & 2.519 & A \\
\hline I23CR-61 & 1.00 & 61.82 & 1443.66 & 143.7 & - & 2.516 & A \\
\hline I23CR-62 & 1.02 & 0.00 & 21.34 & 7.5 & - & - & B \\
\hline I23CR-63 & 1.00 & 9.55 & 240.99 & 118.0 & 43,143 & - & A \\
\hline I23CR-64 & 1.00 & 2.00 & 67.56 & 82.1 & - & - & B \\
\hline
\end{tabular}


Table A23. Physical property test results - I23CR-65 to I23CR-76.

\begin{tabular}{|c|c|c|c|c|c|c|c|}
\hline Specimen ID & $\begin{array}{c}\text { Time in CE } \\
\text { (days) }\end{array}$ & $\begin{array}{c}\text { Time in CE5 } \\
\text { (days) }\end{array}$ & $\mathbf{M}\left({ }^{\circ}\right.$ C-days) & $f_{c}(\mathrm{MPa})$ & $E(\mathrm{MPa})$ & $\rho\left(g / \mathrm{cm}^{3}\right)$ & $\begin{array}{c}\text { Data } \\
\text { Group }\end{array}$ \\
\hline I23CR-65 & 0.98 & 3.00 & 90.17 & 88.6 & - & - & $\mathrm{B}$ \\
\hline I23CR-66 & 1.19 & 3.86 & 114.31 & 90.9 & - & - & $\mathrm{B}$ \\
\hline I23CR-67 & 0.98 & 1.08 & 44.45 & 69.3 & - & - & $\mathrm{B}$ \\
\hline I23CR-68 & 1.20 & 0.33 & 32.13 & 55.4 & - & - & $\mathrm{B}$ \\
\hline I23CR-69 & 1.73 & 0.00 & 36.19 & 66.2 & - & - & $\mathrm{B}$ \\
\hline I23CR-70 & 0.78 & 0.00 & 16.46 & 3.1 & - & 2.493 & $\mathrm{~B}$ \\
\hline I23CR-71 & 0.78 & 0.00 & 16.46 & 3.4 & - & 2.488 & $\mathrm{~B}$ \\
\hline I23CR-72 & 0.96 & 0.00 & 20.33 & 17.0 & - & 2.505 & $\mathrm{~B}$ \\
\hline I23CR-73 & 0.98 & 0.15 & 24.23 & 33.1 & - & - & $\mathrm{B}$ \\
\hline I23CR-74 & 0.96 & 0.16 & 23.98 & 23.5 & 14.535 & - & $\mathrm{B}$ \\
\hline I23CR-75 & 0.96 & 0.27 & 26.58 & 33.5 & - & - & $\mathrm{B}$ \\
\hline I23CR-76 & 1.00 & 0.51 & 33.25 & 53.3 & - & 2.514 & $\mathrm{~B}$ \\
\hline
\end{tabular}


Table A24. Physical property test results - SC.

\begin{tabular}{|c|c|c|c|c|c|c|c|}
\hline Specimen ID & $\begin{array}{c}\text { Time in } \\
\mathrm{CE}_{1} \text { (days) }\end{array}$ & $\begin{array}{c}\text { Time in } \\
\mathrm{CE}_{3} \text { (days) }\end{array}$ & $\begin{array}{c}\text { Time in } \\
\mathrm{CE}_{5} \text { (days) }\end{array}$ & $\mathrm{M}\left({ }^{\circ} \mathrm{C}\right.$-days $)$ & $\mathrm{f}_{\mathrm{c}}(\mathrm{MPa})$ & $\mathrm{E}(\mathrm{MPa})$ & $\rho\left(\mathrm{g} / \mathrm{cm}^{3}\right)$ \\
\hline SC-1 & 1.29 & 5.96 & 6.96 & 784.25 & 200.3 & - & 2.498 \\
\hline SC-2 & 1.29 & 5.96 & 6.96 & 784.25 & 190.4 & - & 2.509 \\
\hline SC-3 & 1.27 & 5.96 & 6.96 & 783.86 & 165.8 & 53,930 & 2.529 \\
\hline SC-4 & 1.27 & 5.96 & 6.96 & 783.86 & 185.8 & 49,155 & 2.528 \\
\hline SC-5 & 1.26 & 5.96 & 6.96 & 783.54 & 178.0 & 50,285 & 2.508 \\
\hline SC-6 & 1.26 & 5.96 & 6.96 & 783.54 & 193.3 & 50,874 & 2.520 \\
\hline SC-7 & 1.24 & 5.96 & 6.96 & 783.18 & 196.3 & 49,914 & 2.505 \\
\hline SC-8 & 1.24 & 5.96 & 6.96 & 783.18 & 159.1 & 54,953 & 2.515 \\
\hline SC-9 & 1.05 & 6.00 & 7.00 & 784.23 & 167.5 & - & 2.493 \\
\hline SC-10 & 1.05 & 6.00 & 7.00 & 784.23 & 179.0 & - & 2.500 \\
\hline SC-11 & 1.05 & 6.00 & 7.00 & 784.18 & 181.5 & - & 2.500 \\
\hline SC-12 & 1.05 & 6.00 & 7.00 & 784.18 & 173.6 & - & 2.508 \\
\hline SC-13 & 1.02 & 6.00 & 7.00 & 783.65 & 177.4 & - & 2.508 \\
\hline SC-14 & 1.02 & 6.00 & 7.00 & 783.65 & 178.2 & - & 2.510 \\
\hline SC-15 & 1.01 & 6.00 & 7.00 & 783.34 & 178.5 & - & 2.498 \\
\hline SC-16 & 1.01 & 6.00 & 7.00 & 783.34 & 171.7 & - & 2.501 \\
\hline SC-17 & 1.00 & 6.00 & 7.00 & 783.17 & 187.9 & - & 2.515 \\
\hline SC-18 & 1.00 & 6.00 & 7.00 & 783.17 & 183.7 & - & 2.508 \\
\hline SC-19 & 1.04 & 6.00 & 7.02 & 786.12 & 169.2 & - & 2.507 \\
\hline SC-20 & 1.04 & 6.00 & 7.02 & 786.12 & 189.5 & - & 2.511 \\
\hline SC-21 & 1.04 & 6.00 & 7.02 & 786.09 & 163.5 & - & 2.511 \\
\hline SC-22 & 1.04 & 6.00 & 7.02 & 786.09 & 180.1 & 48,269 & 2.508 \\
\hline SC-23 & 1.02 & 6.00 & 7.02 & 785.55 & 163.7 & 52,235 & 2.511 \\
\hline SC-24 & 1.02 & 6.00 & 7.02 & 785.55 & 173.5 & 48,003 & 2.488 \\
\hline SC-25 & 1.00 & 6.00 & 7.02 & 785.25 & 185.7 & 49,333 & 2.479 \\
\hline SC-26 & 1.00 & 6.00 & 7.02 & 785.25 & 175.2 & 49,705 & 2.529 \\
\hline SC-27 & 0.99 & 6.00 & 7.02 & 785.00 & 190.0 & 48,771 & 2.504 \\
\hline SC-28 & 0.99 & 6.00 & 7.02 & 785.00 & 183.7 & 48,725 & 2.519 \\
\hline SC-29 & 0.98 & 6.00 & 7.02 & 784.65 & 169.7 & 49,527 & 2.504 \\
\hline SC-30 & 0.98 & 6.00 & 7.02 & 784.65 & 184.5 & 50,673 & 2.502 \\
\hline
\end{tabular}


Table A25. Physical property test results - M2.

\begin{tabular}{|c|c|c|c|c|c|c|c|}
\hline Specimen ID & $\begin{array}{c}\text { Time in } \\
\mathrm{CE}_{1} \text { (days) }\end{array}$ & $\begin{array}{c}\text { Time in } \\
\mathrm{CE}_{3} \text { (days) }\end{array}$ & $\begin{array}{c}\text { Time in } \\
\mathrm{CE}_{5} \text { (days) }\end{array}$ & $M\left({ }^{\circ} \mathrm{C}\right.$-days) & $f_{c}(\mathrm{MPa})$ & $E(\mathrm{MPa})$ & $\rho\left(\mathrm{g} / \mathrm{cm}^{3}\right)$ \\
\hline M2-01 & 1.07 & 2.05 & 6.98 & 692.09 & 193.2 & - & - \\
\hline M2-02 & 1.07 & 2.05 & 6.98 & 692.09 & 186.0 & - & - \\
\hline M2-03 & 1.04 & 2.05 & 6.98 & 691.38 & 181.6 & 53,632 & - \\
\hline M2-04 & 1.04 & 2.05 & 6.98 & 691.38 & 184.4 & 52,700 & - \\
\hline M2-05 & 1.00 & 2.00 & 7.00 & 691.01 & 160.6 & - & - \\
\hline M2-06 & 1.00 & 2.00 & 7.00 & 691.01 & 161.2 & - & - \\
\hline M2-07 & 1.00 & 2.00 & 7.00 & 691.01 & 175.7 & 47,673 & - \\
\hline M2-08 & 1.00 & 2.00 & 7.00 & 691.01 & 160.3 & 47,466 & - \\
\hline
\end{tabular}

Table A26. Physical property test results - M13.

\begin{tabular}{|c|c|c|c|c|c|c|c|}
\hline Specimen ID & $\begin{array}{c}\text { Time in } \\
\mathrm{CE}_{1} \text { (days) }\end{array}$ & $\begin{array}{c}\text { Time in } \\
\mathrm{CE}_{3} \text { (days) }\end{array}$ & $\begin{array}{c}\text { Time in } \\
\mathrm{CE}_{5} \text { (days) }\end{array}$ & $\mathbf{M}\left({ }^{\circ} \mathrm{C}\right.$-days) & $\mathbf{f}_{\mathrm{c}}(\mathrm{MPa})$ & $\mathrm{E}(\mathrm{MPa})$ & $\rho\left(\mathrm{g} / \mathrm{cm}^{3}\right)$ \\
\hline $\mathrm{M} 13-01$ & 1.13 & 13.00 & 7.01 & 948.44 & 150.7 & - & - \\
\hline $\mathrm{M} 13-02$ & 1.13 & 13.00 & 7.01 & 948.44 & 143.8 & - & - \\
\hline M13-03 & 1.11 & 13.00 & 7.01 & 947.96 & 150.4 & 46,646 & - \\
\hline M13-04 & 1.11 & 13.00 & 7.01 & 947.96 & 162.9 & 54,445 & - \\
\hline M13-05 & 1.00 & 13.03 & 7.01 & 952.41 & 168.3 & - & - \\
\hline M13-06 & 1.00 & 13.03 & 7.01 & 952.41 & 163.0 & - & - \\
\hline M13-07 & 1.00 & 13.03 & 7.01 & 952.41 & 185.3 & 52,306 & - \\
\hline M13-08 & 1.00 & 13.03 & 7.01 & 952.41 & 171.0 & 52,195 & - \\
\hline
\end{tabular}

Table A27. Physical property test results - M20.

\begin{tabular}{|c|c|c|c|c|c|c|c|}
\hline Specimen ID & $\begin{array}{c}\text { Time in } \\
\mathrm{CE}_{1} \text { (days) }\end{array}$ & $\begin{array}{c}\text { Time in } \\
\mathrm{CE}_{3} \text { (days) }\end{array}$ & $\begin{array}{c}\text { Time in } \\
\mathrm{CE}_{5} \text { (days) }\end{array}$ & $\mathbf{M}\left({ }^{\circ} \mathrm{C}\right.$-days) & $f_{c}$ (MPa) & $E(\mathrm{MPa})$ & $\rho\left(g / \mathrm{cm}^{3}\right)$ \\
\hline $\mathrm{M} 20-01$ & 1.10 & 20.01 & 6.96 & 1104.71 & 145.5 & - & - \\
\hline $\mathrm{M} 20-02$ & 1.10 & 20.01 & 6.96 & 1104.71 & 166.8 & - & - \\
\hline M20-03 & 1.07 & 20.01 & 6.96 & 1104.07 & 154.6 & 48,613 & - \\
\hline M20-04 & 1.07 & 20.01 & 6.96 & 1104.07 & 169.7 & 50,624 & - \\
\hline M20-05 & 0.99 & 20.00 & 7.00 & 1104.44 & 174.5 & - & - \\
\hline M20-06 & 0.99 & 20.00 & 7.00 & 1104.44 & 173.9 & - & - \\
\hline M20-07 & 0.99 & 20.00 & 7.00 & 1104.44 & 185.8 & 50,552 & - \\
\hline M20-08 & 0.99 & 20.00 & 7.00 & 1104.44 & 172.6 & 48,296 & - \\
\hline
\end{tabular}


Table A28. Physical property test results - M27.

\begin{tabular}{|c|c|c|c|c|c|c|c|}
\hline Specimen ID & $\begin{array}{c}\text { Time in } \\
\mathrm{CE}_{1} \text { (days) }\end{array}$ & $\begin{array}{c}\text { Time in } \\
\mathrm{CE}_{3} \text { (days) }\end{array}$ & $\begin{array}{c}\text { Time in } \\
\mathrm{CE}_{5} \text { (days) }\end{array}$ & $\mathbf{M}\left({ }^{\circ} \mathrm{C}\right.$-days) & $f_{c}(\mathrm{MPa})$ & $\mathrm{E}(\mathrm{MPa})$ & $\rho\left(\mathrm{g} / \mathrm{cm}^{3}\right)$ \\
\hline M27-01 & 1.06 & 26.97 & 6.99 & 1267.03 & 158.6 & - & - \\
\hline M27-02 & 1.06 & 26.97 & 6.99 & 1267.03 & 167.8 & - & - \\
\hline M27-03 & 1.04 & 26.97 & 6.99 & 1266.56 & 178.1 & 51,018 & - \\
\hline M27-04 & 1.04 & 26.97 & 6.99 & 1266.56 & 181.2 & 49,526 & - \\
\hline M27-05 & 1.00 & 27.00 & 7.00 & 1265.33 & 158.4 & - & - \\
\hline M27-06 & 1.00 & 27.00 & 7.00 & 1265.33 & 175.3 & - & - \\
\hline M27-07 & 1.00 & 27.00 & 7.00 & 1265.33 & 189.0 & 50,622 & - \\
\hline M27-08 & 1.00 & 27.00 & 7.00 & 1265.33 & 162.5 & 51,885 & - \\
\hline
\end{tabular}




\section{Unit Conversion Factors}

\begin{tabular}{|l|c|l|}
\hline Multiply & By & To Obtain \\
\hline cubic feet & 0.02831685 & cubic meters \\
\hline cubic yards & 0.7645549 & cubic meters \\
\hline degrees Fahrenheit & $(\mathrm{F}-32) / 1.8$ & degrees Celsius \\
\hline feet & 0.3048 & meters \\
\hline inches & 0.0254 & meters \\
\hline microns & $1.0 \mathrm{E}-06$ & meters \\
\hline pounds (force) per square inch & 6.894757 & kilopascals \\
\hline
\end{tabular}




\section{Acronyms, Symbols, and Abbreviations}

AASHTO - American Association of State Highway and Transportation Officials

$A_{c 1}$ - thermal constant found using experimental data

$A_{c 2}$ - thermal constant found using experimental data

ACI - American Concrete Institute

Af - affinity of the reaction

BC - boundary condition

CAVS - Center for Advanced Vehicular Systems

$\mathrm{CE}$ - curing environment

$\mathrm{CE}_{1}-$ lab bench at ambient temperature

$\mathrm{CE}_{2}$ - cold temperature water bath

$\mathrm{CE}_{3}$ - room temperature fog room

$\mathrm{CE}_{4}$ - room temperature water bath

$\mathrm{CE}_{5}$ - hot temperature water bath

$\mathrm{CE}_{6}-$ convection oven

$\mathrm{CE}_{7}-$ modified cold temperature water bath

CMRC - Construction Materials Research Center

CORPS-STIF - Concrete Observations Repository and Predictive Software

- Structural and Thermodynamical Integrated Framework

COV - coefficient of variation 
C-S-H - calcium silicate hydrate

CTE - coefficient of thermal expansion

Cy - cylinder

$\mathrm{D}$ - diameter

DCPM - damaged concrete plasticity model

DEF - delayed ettringite formation

DEM - discrete element model

DP - decision point

DRI - degree of hydration indicies

E - elastic modulus per ASTM C469

$\mathrm{E}_{23}$ - elastic modulus measurement adjusted to equivalent measurement at $23^{\circ} \mathrm{C}$ using Equation 8.

Eac - cement hydration activation energy

EAV - early age variability

Edial - elastic modulus measured with analog dial

$\mathrm{E}_{\text {lim }}$ - limiting elastic modulus achieved after infinite curing time

ELVDT - elastic modulus measured with LVDT

ERDC - Engineer Research and Development Center

$\mathrm{E}_{\mathrm{T}}-\mathrm{E}_{\text {dial }}$ measured at temperature $\mathrm{T}$

ET - set of specimens made to test temperature sensitivity of elastic modulus measurements 
EWD - Engineering Work Directive

FDOT - Florida department of transportation

FE - finite element

FEA - finite element analysis

FHWA - Federal Highway Administration

FRP - fiber reinforced polymer

FT - set of specimens made to test temperature sensitivity of compressive strength measurements

Group A - isothermal data group associated with strength gain comparisons using maturity and numerical modeling

Group B - early age isothermal data group exposed to curing temperature immediately after molding

Group C - coefficient of variation isothermal data group intended for group statistics

GUHPC - general ultra-high performance concrete

$\mathrm{H}$ - height

HPC - high performance computing

I10 - isothermal curing at $10^{\circ} \mathrm{C}$ in a lime bath

I23 - isothermal curing at $23^{\circ} \mathrm{C}$ in a lime bath

I23CR - isothermal curing at $23^{\circ} \mathrm{C}$ in a curing room

I30 - isothermal curing at $30^{\circ} \mathrm{C}$ in a lime bath

I5O - isothermal curing at $50^{\circ} \mathrm{C}$ in a lime bath 
I70 - isothermal curing at $70^{\circ} \mathrm{C}$ in a lime bath

I90 - isothermal curing at $90^{\circ} \mathrm{C}$ in a lime bath

IC - initial condition

$\mathrm{K}$ - thermal constant found through experimental data

LDPM - lattice discrete particle model

LVDT - linearly variable displacement transducer

$\mathrm{M}$ - final adjusted maturity

M\&S - modeling and simulation

$\mathrm{M}_{1074}$ - maturity according to ASTM C1074

M2 - Mixed temperature curing where specimens spent 2 days in $\mathrm{CE}_{3}$

M13 - Mixed temperature curing where specimens spent 13 days in $\mathrm{CE}_{3}$

M2O - Mixed temperature curing where specimens spent 20 days in $\mathrm{CE}_{3}$

M27 - Mixed temperature curing where specimens spent 27 days in $\mathrm{CE}_{3}$

$\mathrm{M}_{\mathrm{adj}, 1}$ - maturity adjustment for heating/cooling of curing environment

$\mathrm{Madj}, 2_{2}$ - maturity adjustment for preparation time of isothermally cured specimens

MAPE - mean absolute percent error

$\mathrm{M}_{\mathrm{B}}$ - baseline maturity considering average temperature of curing environments

$\mathrm{MC}$ - moisture content

MSU - Mississippi State University 
$\mathrm{N}$ - total number of points

$\overline{\mathrm{Nu}_{\mathrm{H}}}-$ Nusselt number correlation for 1:2 ratio in vertical cylinders

$\overline{\mathrm{Nu}_{\mathcal{L}}}$ - Nusselt number correlation for 1:1 ratio in vertical cylinders

OR - observations repository

PCA - Portland Cement Association

POI - product of interest

PP - polypropylene

Pr - Prandtl number

PVC - polyvinyl chloride pipe

$\dot{Q}$ - rate of cement hydration heat generation per unit volume

$\mathrm{Q}_{\mathrm{c}}^{\infty}$ - latent heat of reaction per unit hydration mass

$\mathrm{R}$ - universal gas constant

$\mathrm{R}^{2}-$ coefficient of determination

RaH - Rayleigh number based on height

$\operatorname{Ra} \mathcal{L}$ - Rayleigh number based on $\mathcal{L}$

RMSPE - root mean square percent error

$\mathrm{S}$ - hyperbolic expression to numerically predict strength

SC - standard curing

SCM - supplementary cementitious material

SIF - structural integrated framework 
SimBRS - Simulation Based Reliability and Safety

Slim - limiting mechanical property achieved after infinite curing time

Stdev - standard deviation

$\mathrm{T}$ - temperature

$\mathrm{T}_{0}$ - datum temperature

$\mathrm{T}_{\infty}$ - average ambient temperature

$\mathrm{T}_{\mathrm{b}}$ - specimen temperature at beginning of ramp test

$\mathrm{TC}$ - thermocouple

$\mathrm{T}_{\mathrm{i}}$ - average temperature of $\mathrm{CE}_{\mathrm{i}}$ over duration $\Delta \mathrm{t}_{\mathrm{i}}$

TIF - thermal integrated framework

$T_{\text {ini }}$ - average initial concrete temperature

TPOC - technical point of contact

TR - technical report

$\mathrm{T}_{\text {ref }}$ - reference temperature defined as $-10^{\circ} \mathrm{C}$

$\mathrm{T}_{\mathrm{s}}$ - surface temperature

$\mathrm{T}_{\text {set }}-$ temperature of curing environment

UHPC - ultra-high performance concrete

UMAT - user defined material model

USACE - United States Army Corps of Engineers

USDFLD - user defined field variable 
V/A - volume to area ratio

VHSC - very high strength concrete

WD67 - Work Directive 67

$\mathrm{a}(\mathrm{T})$ - parametric function of temperature that scales the rate with curing temperature

$\mathrm{b}(\mathrm{T})$ - parametric function of temperature that affects decay of development rate with curing temperature

$c_{o}-c_{8}-$ fitting coefficients for $f_{c}$ model

$\mathrm{cm}$ - cementitious content mass

$c_{p}-$ specific heat

$\mathrm{d}_{0}-\mathrm{d}_{8}-$ fitting coefficients for $\mathrm{E}_{23}$ model

$\mathrm{d}_{\text {dial }}$ - displacement of compressometer dial during an elastic modulus test

$\mathrm{f}_{\mathrm{c}}$ - compressive strength per ASTM C39

$\mathrm{f}_{\text {lim }}$ - limiting compressive strength achieved after infinite curing

$\mathrm{h}$ - convection heat transfer coefficient

$\mathrm{k}$ - rate constant described using a descending power function

$m_{p a n}-$ mass of pan

$\mathrm{m}_{\text {spec,dry }}$ - mass of specimen after moisture content testing

$\mathrm{m}_{\text {spec,wet }}-$ mass of specimen before moisture content testing

$\mathrm{n}_{\mathrm{i}}-$ number of points in a curing group

$\dot{\mathrm{q}}$ - heat generation 
$\mathrm{r}$ - radial distance

$\mathrm{s} / \mathrm{c}_{\text {req }}-$ minimum amount of silica fume required to consume all calcium hydroxide

$\mathrm{sm}$ - silica fume mass content

$\mathrm{t}$ - time

$t_{0}-$ offset time to start development of strength

tprep - duration of time corresponding to test preparation, i.e., time between specimen removal from curing and when first test is started

$t_{\text {set }}-$ duration of time (in minutes) required to reach $\mathrm{T}_{\text {cure }}$ during thermal ramp test

$\mathrm{w} / \mathrm{cm}$ - ratio of water to cementitious materials

wm - water mass content

$\mathcal{L}$ - square root of the area of the cylinder

$\alpha$ - hydration degree

$\alpha_{C}^{\infty}$ - asymptotic degree of cement hydration

$\alpha_{S}^{\infty}$ - asymptotic degree of silica fume hydration

$\alpha_{T D}-$ thermal diffusivity

$\gamma$ - apparent specific gravity

$\Delta \mathrm{T}_{\text {longitudinal }}$ - temperature change in the $\mathrm{z}$ direction

$\Delta \mathrm{t}-$ duration of time

$\Delta \mathrm{t}_{\mathrm{i}}-$ duration of time in $\mathrm{CE}_{\mathrm{i}}$

$\varepsilon-$ strain 
Eins - emissivity of insulation

$\kappa-$ thermal conductivity

$\eta$ - thermal constant found through experimental data

$\mu(t)$ - maturity relationship of UHPC

$\rho-$ density

$\sigma-$ Stefan-Boltzmann constant

$10 \mathrm{~cm}-\mathrm{Cu}-10-\mathrm{cm}$-sided cube instrumented with thermocouples used in thermal experiments

$20 \mathrm{~cm}-\mathrm{Cu}-20-\mathrm{cm}$-sided cube instrumented with thermocouples used in thermal experiments

$40 \mathrm{~cm}-\mathrm{Cu}-40-\mathrm{cm}$-sided cube instrumented with thermocouples used in thermal experiments

7.6cm-Cy $-7.6-\mathrm{cm}$ by 15.2-cm (3-in. by 6-in.) Polypropylene cylinder instrumented with thermocouples used in thermal experiments

10.2cm-Cy -10.2 -cm by 20.3-cm (4-in. by 8-in.) Polypropylene cylinder instrumented with thermocouples used in thermal experiments

$15.2 \mathrm{~cm}-\mathrm{Cy}-15.2 \mathrm{~cm}$ by $30.5 \mathrm{~cm}$ (6-in. by 12 -in.) Polypropylene cylinder instrumented with thermocouples used in thermal experiments

15.2x15.2-PP - 15.2-cm by 15.2-cm (6-in. by 6-in.) modified Polypropylene cylinder instrumented with thermocouples used in thermal experiments

15.2x30.5-PP $-15.2 \mathrm{~cm}$ by $30.5 \mathrm{~cm}$ (6-in. by 12-in.) Polypropylene cylinder instrumented with thermocouples used in thermal experiments

15.2X15.2-PVC - 15.2-cm by 15.2-cm (6-in. by 6-in.) PVC cylinder instrumented with thermocouples used in thermal experiments 
15.2x30.5-PVC - 15.2-cm by 30.5-cm (6-in. by 12 in.) PVC cylinder instrumented with thermocouples used in thermal experiments 


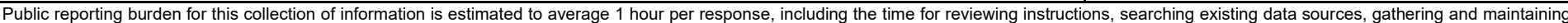

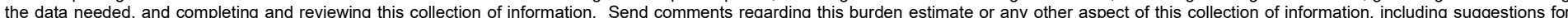

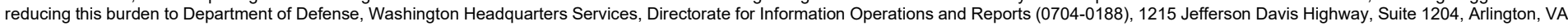

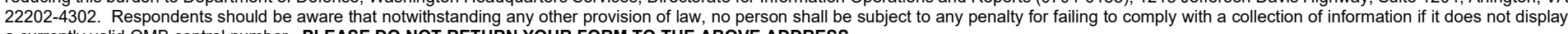
a currently valid OMB control number. PLEASE DO NOT RETURN YOUR FORM TO THE ABOVE ADDRESS.
1. REPORT DATE (DD-MM-YYYY) April 2021

\section{TITLE AND SUBTITLE}

Development of CORPS-STIF 1.0 with Application to Ultra-High Performance Concrete (UHPC)

\section{AUTHOR(S)}

Isaac L. Howard, Thomas Allard, Ashley Carey, Matthew Priddy, Alta Knizley, and Jameson D. Shannon

\section{PERFORMING ORGANIZATION NAME(S) AND ADDRESS(ES)}

Geotechnical and Structures Laboratory

U.S. Army Engineer Research and Development Center

3909 Halls Ferry Road

Vicksburg, MS, 39180

\section{SPONSORING / MONITORING AGENCY NAME(S) AND ADDRESS(ES)}

U.S. Army Corps of Engineers

Washington, DC 20314-1000

\section{DISTRIBUTION / AVAILABILITY STATEMENT}

Approved for public release; distribution is unlimited.

\section{SUPPLEMENTARY NOTES}

Project W56HZV-08-C-0236, "Modeling and Simulation of Multi-Physics Material Response in Geo-Environments"

\section{ABSTRACT}

This report introduces the first release of CORPS-STIF (Concrete Observations Repository and Predictive Software - Structural and Thermodynamical Integrated Framework). CORPS-STIF is envisioned to be used as a tool to optimize material constituents and geometries of mass concrete placements specifically for ultra-high performance concretes (UHPCs). An observations repository (OR) containing results of 649 mechanical property tests and 10 thermodynamical tests were recorded to be used as inputs for current and future releases. A thermodynamical integrated framework (TIF) was developed where the heat transfer coefficient was a function of temperature and determined at each time step. A structural integrated framework (SIF) modeled strength development in cylinders that underwent isothermal curing. CORPS-STIF represents a step toward understanding and predicting strength gain of UHPC for full-scale structures and specifically in mass concrete.

\section{SUBJECT TERMS}

Ultra-High Performance Concrete

\begin{tabular}{|l|l|}
\hline \multicolumn{2}{|l|}{ 16. SECURITY CLASSIFICATION OF: } \\
\hline a. REPORT & b. ABSTRACT \\
Unclassified & Unclassified
\end{tabular}

Mass concrete
Thermal modeling

Thermodynamic testing

Heat Transfer Coefficient

Finite element method

\section{PERFORMING ORGANIZATION REPORT NUMBER}

ERDC/GSL TR-21-14

10. SPONSOR/MONITOR'S ACRONYM(S)

11. SPONSOR/MONITOR'S REPORT NUMBER(S) 
